University of New Hampshire

University of New Hampshire Scholars' Repository

Spring 1977

\title{
THE DESIGN, ANALYSIS AND FIELD TEST OF A DYNAMIC FLOATING BREAKWATER
}

DAVID JAQUITH AGERTON

Follow this and additional works at: https://scholars.unh.edu/dissertation

\section{Recommended Citation}

AGERTON, DAVID JAQUITH, "THE DESIGN, ANALYSIS AND FIELD TEST OF A DYNAMIC FLOATING BREAKWATER" (1977). Doctoral Dissertations. 1150.

https://scholars.unh.edu/dissertation/1150

This Dissertation is brought to you for free and open access by the Student Scholarship at University of New Hampshire Scholars' Repository. It has been accepted for inclusion in Doctoral Dissertations by an authorized administrator of University of New Hampshire Scholars' Repository. For more information, please contact Scholarly.Communication@unh.edu. 


\title{
INFORMATION TO USERS
}

This material was produced from a microfilm copy of the original document. While the most advanced technological means to photograph and reproduce this document have been used, the quality is heavily dependent upon the quality of the original submitted.

The following explanation of techniques is provided to help you understand markings or patterns which may appear on this reproduction.

1. The sign or "target" for pages apparently lacking from the document photographed is "Missing Page(s)". If it was possible to obtain the missing page(s) or section, they are spliced into the film along with adjacent pages. This may have necessitated cutting thru an image and duplicating adjacent pages to insure you complete continuity.

2. When an image on the film is obliterated with a large round black mark, it is an indication that the photographer suspected that the copy may have moved during exposure and thus cause a blurred image. You will find a good image of the page in the adjacent frame.

3. When a map, drawing or chart, etc., was part of the material being photographed the photographer followed a definite method in "sectioning" the material. It is customary to begin photoing at the upper left hand corner of a large sheet and to continue photoing from left to right in equal sections with a small overlap. If necessary, sectioning is continued again - beginning below the first row and continuing on until complete.

4. The majority of usars indicate that the textual content is of greatest value, however, a somewhat higher quality reproduction could be made from "photographs" if essential to the understanding of the dissertation. Silver prints of "photographs" may be ordered at additional charge by writing the Order Department, giving the catalog number, title, author and specific pages you wish reproduced.

5. PLEASE NOTE: Some pages may have indistinct print. Filmed as received.

\author{
University Microfilms International \\ 300 North Zeeb Road \\ Ann Arbor, Michigan 48106 USA \\ St. John's Road. Tyler's Green \\ High Wycombe, Bucks. England HP10 8HR
}




\section{$77-14,229$}

AGERTON, David Jaquith, 1947-

THE DESIGN, ANALYSIS AND FIELD TEST OF A DYNAMIC FLOATING BREAKWATER.

University of New Hampshire, Ph.D., 1977 Engineering, genera ]

Xerox University Microfilms, Ann Arbor, Michigan 48106 
THE DESIGN, ANALYSIS AND FIELD TEST

OF A

DYMAMIC FLOATING BREAKWATER

by

DAVID J. AGERTON

B.A., TRINITY COLLEGE, HARTFORD, 1971

M.S.E.E., RENSSELAER POLYTECHNIC INSTITUTE, 1971

\title{
A DISSERTATION
}

Submitted to the University of New Hampshire

In Partial Fulfillment of

the Requirements for the Degree of

\author{
Doctor of Philosophy \\ in
}

Engineering

May 1977 
This dissertation has been examined and approved.
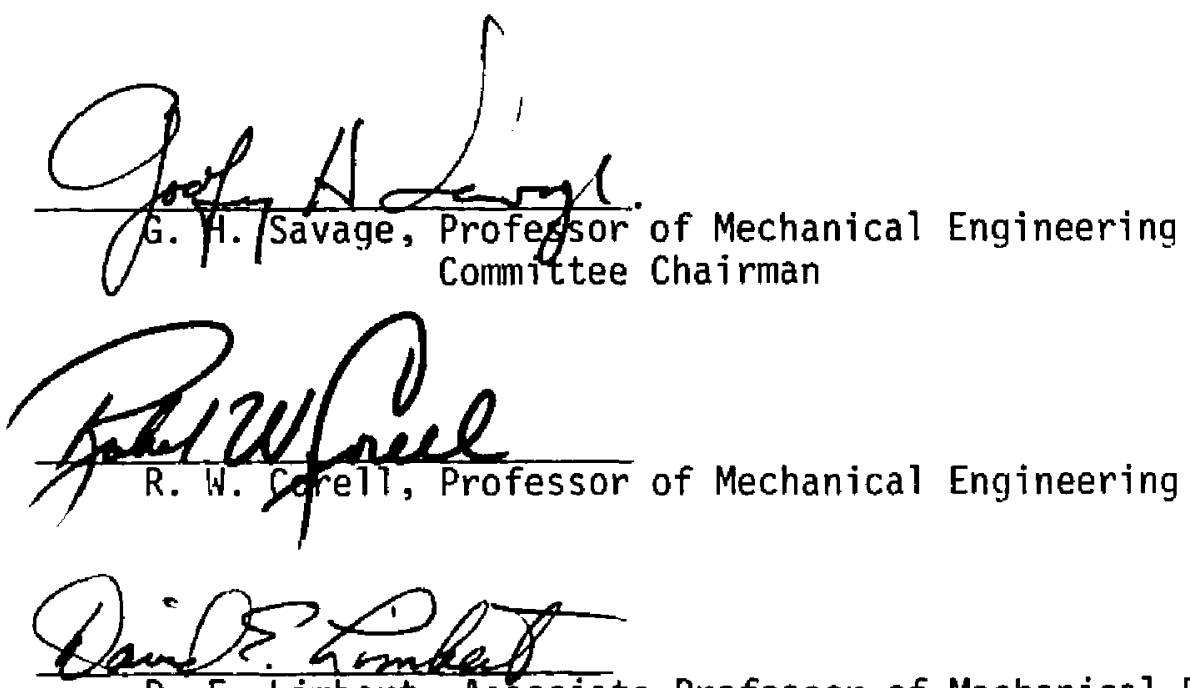

D. E. Limber, Associate Professor of Mechanical Engineering

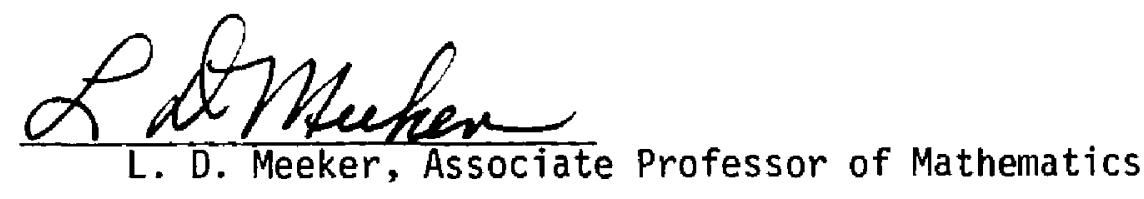

S.GCSprague, Associate Professor of Business Administration

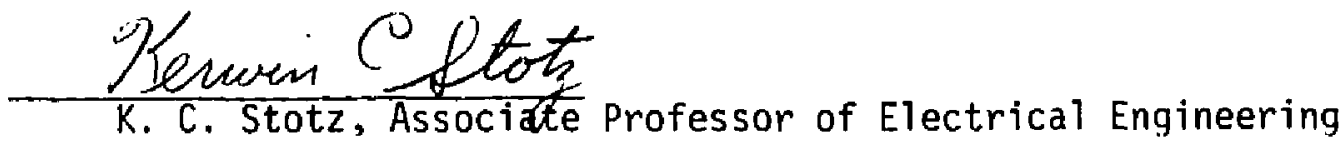

$\frac{\text { Q. W. Win, Professor of Electrical Engineering }}{\text { A. }}$

December 2, 1976

Dated 


\section{ABSTRACT}

The engineering design and analysis of a dynamic floating breakwater consisting of an array of independent buoys moored beneath waves by elastic tethers is presented. It is proposed that a properly tuned system can dissipate substantial wave energy in the turbulent wake of each oscillating buoy through the mechanism of hydrodynamic drag. The evolution and synthesis of a project to investigate this concept is provided as an engineering case history.

A general two degree of freedom mathematical model is forwarded to describe buoy dynamic response and then soived for irregular-wave excitations in the time domain. Design insights from a linear model solved in the frequency domain are discussed as well. A linear model of energy dissipated is advanced so that this phenomenon can be treated as a function of buoy relative-velocity spectra.

Wave tank tests, designed to test the notion that an elastictethered array can dissipate more wave energy than a comparable wiretethered one, are described. The use of a non-contact optical displacement follower to track the orbital motions of a tethered element is noted. 
The field test of an elastic-tethered array in storm waves on a large lake is described, including the design of a multi-legged anchoring system and instrumentation for measuring waves and buoy response, both built by other graduate students. Buoy response and breakwater energy dissipation are compared to that predicted by analytical models. Finally, breakwater design insights from modeling are offered. 


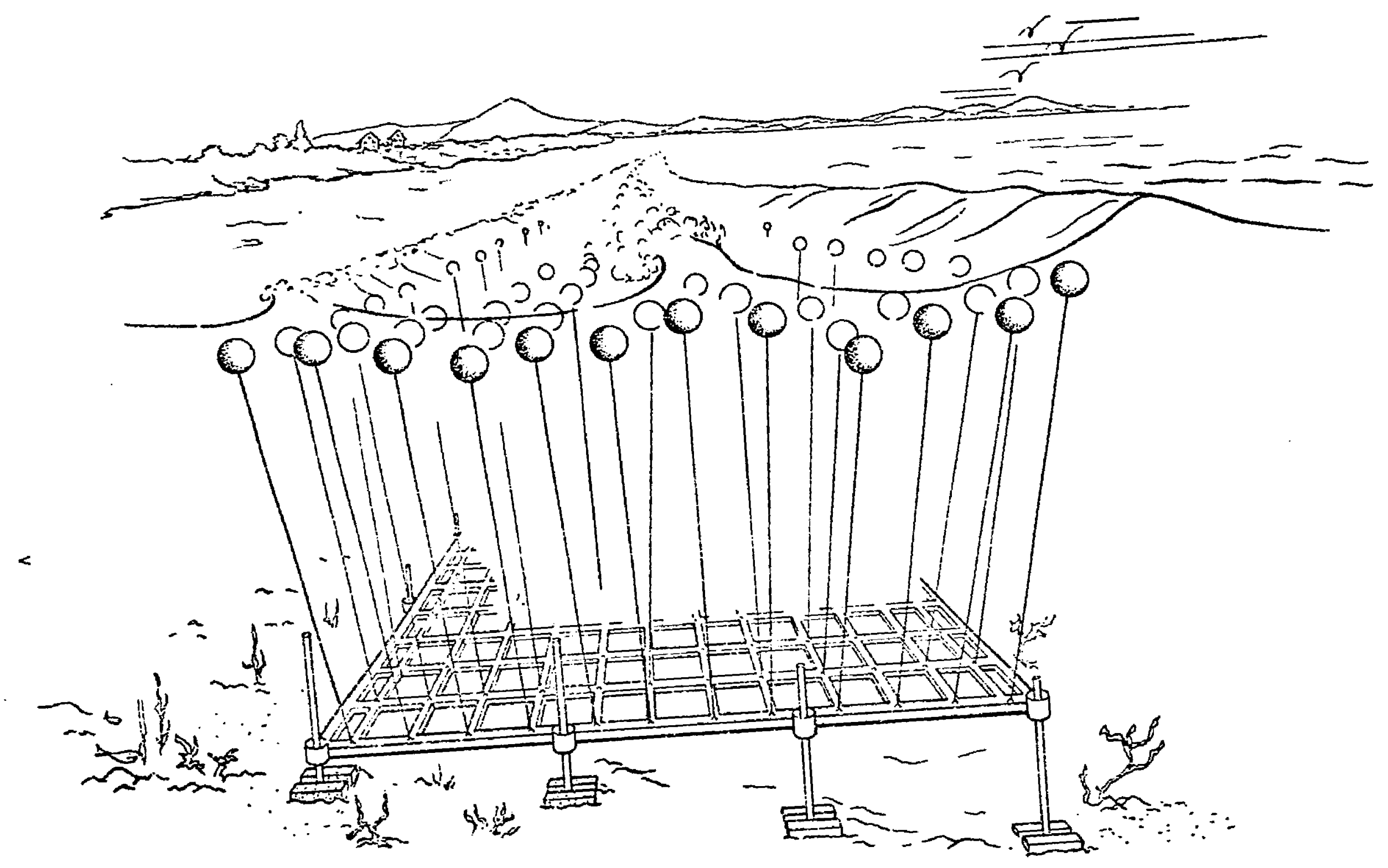

Frontispiece: Elastically tethered dynamic breakwater 
"The scientist studies what is;

The engineer creates what has never been"

Theodore von Karman 
TABLE OF CONTENTS

\section{Page}

ABSTRACT

NOMENCLATURE

viii

FIGURES

PREFACE

xiv

I . INTRODUCTION

A. Background and Objectives

B. Scope and Approach

II. EVOLUTION AND SYNTHESIS OF THE DYNAMIC BREAKWATER PROJECT

III. MODELING A DYNAMIC BREAKWATER

A. Wave Forces on a Tethered Float

1. The Morison Equation

2. Coefficients of Mass and Drag

3. Wave Forces in Two-Dimensional Flow

B. Analysis of Buoy Response and Energy Dissipation

1. Frame of Reference

2. Tether Modeling

3. Equations of Motion

4. Energy Dissipation

C. Solution by Simulation

1. Numerical Methods

2. A Perspective on Simulation

3. Results of the Non-Linear Model

D. Solution by Linear Analys is

1. Equations of Motion

2. Linear Analysis in Irregular Waves 
IV. SCALE MODEL EXPERIMENTS

A. Scaling Laws 66

B. Design of the Scale Model Experiments 69

C. Results of the Scale Model Experiments 75

V. FIELD EXPERIMENTS

A. Design of the Field Experiments 85

1. Selection of Test Site

2. Design of Breakwater Elements

3. Frame Design

4. Instrumentation

5. Problems Encountered During the Field Experiment

B. Results of the Field Experiments

1. Data Analys is

2. Energy Dissipation by the Array

VI. COMPARISON OF MODEL AND FIELD TEST RESULTS

A. Modeling Buoy Response $\quad 123$

B. Modeling Energy Dissipation $\quad 135$

C. Discussion of Dynamic Breakwater Design 140

VII. CONCLUSIONS AND RECOMMENDATIONS 155

$\begin{array}{lll}\text { VIII. REFERENCES } & 158\end{array}$

$\begin{array}{ll}\text { IX. APPENDICES } & 162\end{array}$
A. Kinematics of a Small Amplitude Wave
B. Instrumentation Calibration Curves
C. Computer Programs
D. Frequency Response Data 
NOMENCLATURE

a

A

$A_{t}$

a $r$

B

$C_{M}, C_{D}$

$C_{z, y}(\omega)$

D

$D^{\prime}$

D"

d

$E, E_{D}$

$\mathrm{F}$

f

g

$\mathrm{H}, \mathrm{H}_{\mathrm{S}}$

$H_{x}(\omega), H_{u_{r}}(\omega)$

$j \omega$

$k, k_{x}, k_{y}$

$k$

$k_{t}$

$1_{0}$

$\zeta$ amplitude

area

projected area of tether

amplitude of buoy displacement

relative to water particle displacement

net buoy displacement

coefficients of added mass and drag

Co-spectrum of $z$ and $y$

lumped drag constant of form $\frac{1}{2} P A C_{D}$

lumped drag constants of form $\frac{1}{2} \rho A C_{D} U_{0}$

lumped linearized drag constant including buoy and tether drag

diameter

energy dissipated

force

frequency

acceleration of gravity

wave height (significant)

linearized transfer functions

complex frequency

lumped restoring force constant

wave number

spring constant for tether

tether length for buoy at rest

damping coefficient 


\begin{tabular}{|c|c|}
\hline M & lumped mass constant: $M_{W} C_{M}+M_{S}$ \\
\hline $\mathrm{M}_{\mathrm{S}}$ & mass of sphere \\
\hline$M_{W}$ & mass of displaced water \\
\hline$N\left(\mu, \sigma^{2}\right)$ & normal distribution \\
\hline N & lumped mass constant: $M_{W}\left(I+C_{M}\right)$ \\
\hline$N_{R}$ & Reynolds number \\
\hline$n, n_{r}$ & number of rows \\
\hline $\mathrm{p}$ & percentage energy reduction \\
\hline$P_{D}$ & drag power \\
\hline$P_{W}$ & wave power \\
\hline$Q$ & Tinearization constant \\
\hline$Q_{z, y}(\omega)$ & Quad-spectrum of $z$ and $y$ \\
\hline $\mathrm{R}$ & stretched tether length \\
\hline$\vec{r}$ & vector relative velocity \\
\hline rms & root mean square value \\
\hline$r_{0}$ & unstretched tether length \\
\hline$S_{z}(\omega)$ & spectrum of $z$ \\
\hline$S_{z, y}(\omega)$ & cross spectrum of $z$ and $y$ \\
\hline $\mathbf{s}$ & LaPlace operator \\
\hline $\mathrm{T}$ & tension in tether \\
\hline $\mathrm{t}$ & time \\
\hline$u_{r}, v_{r}$ & $\begin{array}{l}\text { horizontal and vertical relative } \\
\text { velocity respectively' }\end{array}$ \\
\hline $\mathrm{U}_{0}, \mathrm{~V}_{0}$ & $\begin{array}{l}\text { "characteristic" relative velocity } \\
\text { - linearization constants }\end{array}$ \\
\hline$u, v$ & water particle velocity \\
\hline$\dot{u}, \dot{v}$ & water particle acceleration \\
\hline$U_{m}$ & maximum relative velocity \\
\hline
\end{tabular}




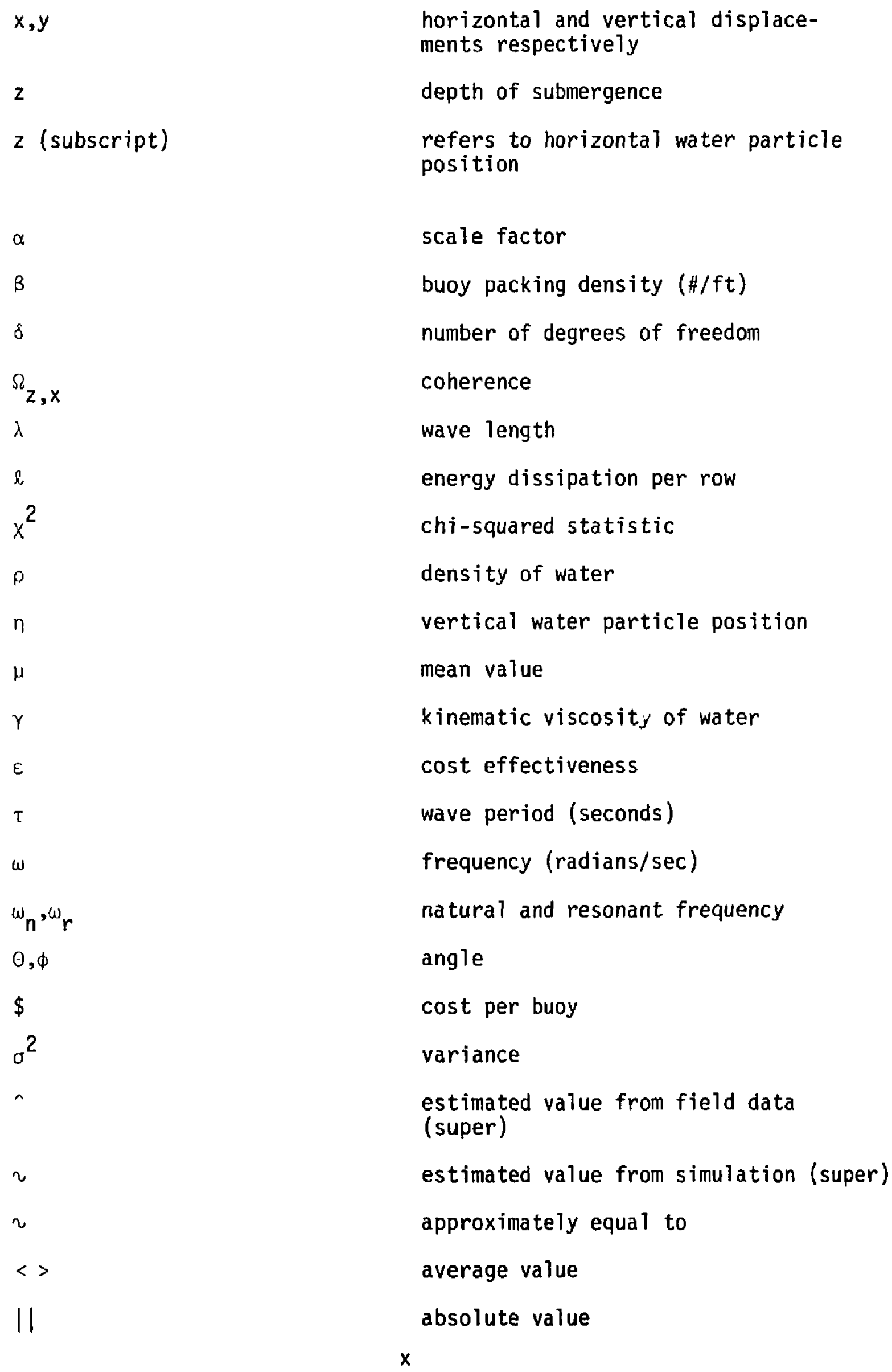

horizontal and vertical displacements respectively

depth of submergence refers to horizontal water particle position

scale factor

buoy packing density (\#/ft)

number of degrees of freedom

coherence

wave length

energy dissipation per row

chi-squared statistic

density of water

vertical water particle position

mean value

kinematic viscosity of water

cost effectiveness

wave period (seconds)

frequency (radians/sec)

natural and resonant frequency

angle

cost per buoy

variance

estimated value from field data (super)

estimated value from simulation (super)

approximately equal to

average value

absolute value 


\section{LIST OF FIGURES}

Figure

1 Frontispiece: Elastically tethered dynamic breakwater.

2 Conceptual drawing of a tethered float breakwater

from Seymour and Isaacs (1974).

3 Elastically tethered sphere in waves.

4 Typical load-elongation curve for solid elastic

filament from Savage (1973).

5 Simulated frequency response for an elastically tethered sphere.

6 Spatial plot of simulated buoy response. 49

$7 \quad$ Spatial plot of simulated buoy response. 50

8 Simulated dissipation by rows of wire and elastically tethered spheres.

9 Simulation of relative dissipation in horizontal and verticle dimensions.

10 Simulated dissipation for different diameter spheres.

11 Effect of mathematical simplifications on model resurts.

12 Layout of wave tank experiments.

13 Horizontal frequency response measured in a wave tank for an elastically tethered sphere.

14 Vertical frequency response measured in a wave tank for an elastically tethered sphere. 
Figure

15 Dissipation calculated from simulation and wave tank experiments for elastically tethered spheres.

16 Dissipation by small scale arrays of wire and elastically tetheres spheres.

17 Map of Lake Winnipesaukee, New Hampshire.

18 Load-elongation curve for working region of synthetic rubber from Winn, Savage and Hickman (1975).

19 Configuration of elastically tethered buoy used in field experiment.

20 Site of the field experiment at Diamond Is 1 and.

21 Three of four sections of structural steel frame and concrete anchor blocks used to support loads of the breakwater array.

22 Wave staff support piling. 104

23 Instrumentation to measure buoy response. 109

24 Layout of test breakwater array in lake. 110

25 Measured incident and attenuated wave spectra.

26 Incident and attenuated wave spectra.

27 Simulated breakwater performance in waves of varying height.

28 Measured energy dissipation per row of breakwater array.

29 Measured and simulated incident wave spectra.

30 Horizontal frequency response. 
31 Spectrum of horizontal relative velocity.

32 Horizontal frequency response.

33 Spectrum of horizontal relative velocity.

34 Measured and modeled breakwater performance.

35 Measured and modeled breakwater performance.

36 Breakwater performance versus tether compliance

$$
\text { (\% elongation). }
$$

37 Horizontal and vertical components of breakwater performance.

38 Drag and mass coefficients for spheres vs, period parameter (Sarpkaya, 1975).

39 Maximum wave force parameter vs. $a / d$ and $N_{r}$ for cylinders (Rance, 1969).

40 Unit cost for a tethered buoy in dollars.

41 Total volume displacement per foot and number of rows of buoys required to dissipate $75 \%$ of incident wave energy vs. $H_{s} / d$ ratio.

42 Cost per foot frontage to dissipate $75 \%$ of incident wave energy vs. $H_{s} / d$ ratio. 


\section{PREFACE}

First and foremost I am indebted to Professor G. H. Savage under whose counseling and tutelage I conducted this research. He was also responsible for the overall project of which this dissertation is a part.

I am most grateful to the other members of my Engineering PhD Committee as well. Professor L. G. Sprague critically reviewed initial drafts and set high writing standards for me without which I would not ask you to endure reading this document. Professor $A$. L. Winn developed the necessary instrumentation for the field test and assumed overall responsibility for the research grant during Professor Savage's sabbatical leave. Professor K. C. Stotz solved troublesome problems with the wave measuring system in addition to reviewing my mathematical models. Without the electrical engineering contributions of Professors Stotz and Winn, I could not have completed this dissertation. Early in my analysis, Professor D. E. Limbert posed penetrating questions about modeling. Later, he critically reviewed my analysis and suggested constructive changes. Professor R. W. Corell contributed his support and suggestions not only to me, but also to D. A. Vidal whose work on anchoring system design was essential to this project. Professor Meeker was a valuable reference regarding the statistical aspects of my analysis.

I am deeply indebted to three graduate students. D. A. Vidal and J. R. Delano built the breakwater frame/anchor system and wave measuring instrumentation, respectively. D. 0 . Libby provided generous 
assistance in computer programming and data-tape deciphering. I am indebted to him also for retrieving me from the frozen shores of Lake Winnipesaukee where I was stranded in the aftermath of a winter storm which provided the long-awaited wave conditions for test data. Undergraduate engineering students G. W. Ruetenik and G. S. Lord gave their enthusiastic, hard labor to this project, mostly underwater. R. A. Blake, technician for the Engineering Design and Analys is Laboratory provided valuable assistance in constructing the experimental array. P. E. Lavoie, UNH Diving Safety Officer and electrical engineer, not only supervised the safety aspects of field construction, but also built critical electronic instrumentation.

Several people outside of UNH deserve mention. R. J. Seymour willingly discussed his own work on floating breakwaters in considerable detail. F. C. Spooner of Lincoln, Mass. and D. H. Clewe11 of Greenwich, Conn. generously permitted installation of test breakwater in waters just off their Lake Winnipesaukee property. W. J. Miskoe, a professional civil engineer and welder brought his creative mind to bear on construction of the structional steel frame and anchoring system. R. C. Scribner (deceased) and his crane-barge crew gingerly maneuvered the multi-legged structural frame and cement anchor blocks into place with exacting precision, guided only by wire-line instructions from divers below.

Finally, although I have acknowledged the principal financial support from the National Sea Grant Program elsewhere in this document, I wish to acknowledge the support of D. B. Duane and A. G. Alexiou of the Sea Grant Office; they made several personal visits to the Lake 
Winnipesaukee test site. Valuable information and contributions were also received from previous related research, notably the office of Naval Research Contract No. N00014-67-A-0158-0004 and the United States Coast Guard Research and Development Contract No. 4-20050-000. 


\section{INTRODUCTION}

\section{A. Background \& Objectives}

The art of building massive rock barriers to reflect the energy of storm waves while surviving their impact is probably as old as the art of building ships. The techniques used in their design have evolved from trial and error to empirical rules arrived at through experience and scale model tests, and finally to predictive mathematical models. Changes in breakwater design have been slow to come; for many years ocean engineers had more incentive to develop new components or methods of construction than to improve the overall design of these structures. Recently, however, several factors have rekindled engineering design interest in wave barriers:

1. Natural harbors and protected shore areas are heavily utilized by the industry and recreation activities concentrated there. This crowding has created a need for man-made wave barriers to open up more coastal area for use as ports and recreational boat harbors, and in some cases, to protect existing shore features from coastline erosion.

2. The cost of heavy marine construction has increased, creating economic incentives for ocean engineers to investigate breakwater designs based on mechanisms other than reflection.

3. Finally, the worldwide seaward advance of offshore construction into greater water depths for oil tanker terminals, oil production and storage facilities and offshore power plants has created a need for wave protection in deep water. However, costs of traditional 
bottom-mounted breakwaters increase exponentially with depth, making them prohibitively expensive in most cases for water depths exceeding fifty feet. Such a limit seems unacceptably shallow if breakwaters are to be used during the development of the world's continental shelf territories. Therefore, it is timely to focus on discovering and testing some new concepts of breakwater design.

At the Sea Grant-sponsored International Floating Breakwater Conference at Newport, Rhode Island in April, 1974, R. J. Seymour and J. D. Isaacs advanced a novel, but untested, design concept for a "tethered float" breakwater. As shown in Figure 2, their concept consists of a rectangular array of spherical floats, each taut-moored beneath the mean free surface of the water by a cable. The motion of each tethered element is analogous to the motion of a damped pendulum driven by sinusoidal wave forces. When the wave frequency matches the resonant frequency of the tethered float, the velocity of the float moving back and forth is amplified over that of the wave-driven water particles and is out of phase with the water particles by about $90^{\circ}$. As a result, energy is dissipated by hydrodynamic form drag in the turbulent wake of the buoy.

Seymour and Isaacs (1974) tested this concept on a small scale in a wave tank. To obtain initial confirmation of the concept on a larger scale, they mathematically modeled the measured response of a single tethered float in ocean waves. From their modeling results, they projected a tethered float breakwater which would have the following general characteristics: buoy diameters equal to $10 \%$ or less of the anticipated wave length; wire tethers at least ten times as long 


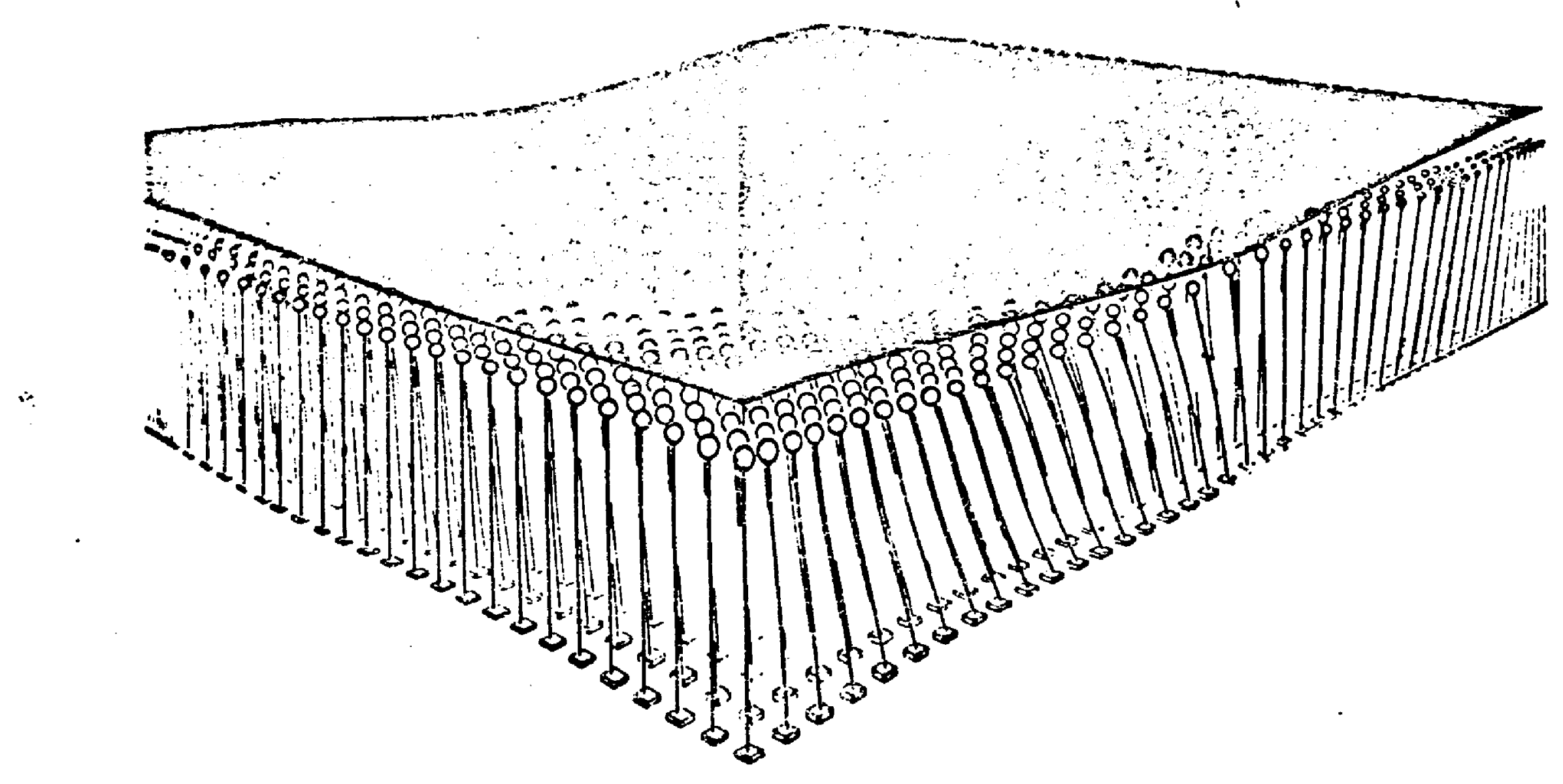

Figure 2. Conceptual drawing of a tethered float breakwater from Seymour and Isaacs(1974). 
as the buoy diameter; clear spaces of at least one diameter separating successive rows and columns of floats. According to their mathematical model, an array to attenuate wave heights by 75 percent would have to be about 35 rows wide and as long as the desired wave shadow.

The economic feasibility of a tethered float breakwater system is strongly related to the required number of rows and sizes of floats. An investigation to design more effective breakwater elements, and consequently a breakwater which requires fewer floats, could advance the concept towards commercial application. One way of increasing dissipation might be to moor each buoy with a highly compliant elastic tether. Not only might these improve the survivability of breakwater elements, but they might also increase the dissipation of energy because they could allow the floats to respond to vertical as well as horizontal wave forces. This idea seemed worthy of investigation.

R. J. Seymour suggested a second research objective. He pointed out that the next logical step in the development of the dynamic breakwater concept would be a lake-scale field test of the concept. Such an experiment might not be subject to the small-scale effects of wave tank experiments. At the same time, it would not entail the high cost of a large-scale ocean test.

These two goals--improving the effectiveness of the proposed breakwater elements and field testing the concept in the context of an analytical model--are the principle research objectives of this engineering dissertation. 


\section{B. Scope \& Approach}

This dissertation is part of a larger project titled "The Design Analysis and Field-Test Verification of a Dynamic Floating Breakwater"*, hereafter referred to as The Breakwater Project. In addition to myself, the main participants were three other graduate students, D. A. Vidal, J. R. Delano, and D. O. Libby, and an equal number of faculty, Professors G. H. Savage, A. L. Winn, and K. C. Stotz, all with distinct but complementary professional interests in ocean engineering. Because this dissertation incorporates their efforts with mine, I will explain the composition of the project and describe its synthesis. That discussion comprises Chapter II.

The scope of this dissertation can be viewed as having five principal parts, all mutually dependent upon one another:

1. A literature search and industry survey to develop the necessary analytical and conceptual background.

2. Development of analytical mathematical models to describe breakwater response and energy dissipation.

3. Scale model experiments in a wave tank to test ideas and provide initial confirmation of mathematical models.

4. Field test experiments of a dynamic breakwater, and their analysis in light of analytical models.

5. Generalization of the results of mathematical modeling, scale model experiments and field tests to the design of dynamic breakwaters; synthesis of the above four steps into this dissertation and a report to industry.

*This project was funded by the National Sea Grant Program of NOAA. Grant \#04-3-158-38. 
Literature Search and Industry Survey: The available literature describing the forces of waves on objects, the statistical analysis of ocean waves and forces, the phenomenon of hydrodynamic drag, and the design of floating breakwaters was reviewed. Technical discussions were held with engineers having firsthand knowledge of, and experience with, floating breakwaters. These included R. J. Seymour, a current, leading analyst of dynamic floating breakwaters and Professor J. D. Isaacs, originator of the concept, both at Scripps Institution of Oceanography.

G. H. Savage and I attended the First International Floating Breakwater Conference where the concept of a dynamic tethered breakwater float was first introduced to a professional gathering of ocean engineers. This conference aiso offered the opportunity to examine several floating breakwater concepts including two prototype installations in Rhode Island: a static type floating breakwater consisting of a mat of rubber tires, and a dynamic type advanced by the Trochoid Corporation of Duxbury, Massachusetts. The latter system appeared likely to literally beat itself apart in large waves; it entailed a complex assembly of mooring lines, counter weights and suspended ballast weights. Further, according to its designer this system was expensive to manufacture. Consequently, I chose not to pursue the concept.

G. H. Savage and I met on two occasions with development and sales engineers from the Marine Products division of Goodrich Rubber Company. They already manufacture a widely-used oil spill containment barrier constructed of rubber, plastic and nyton components. So, they are the sort of company which could manufacture floating breakwater components. Technical discussions about the properties of structural rubber were also held with Delford Industries, Incorporated, the 
manufacturer of solid rubber filaments used to tether buoys in previous mooring research (Savage and Hersey, 1964; Winn and Savage, 1975).

Scale Model Tests: I directed a series of scale model tests in the Massachusetts Institute of Technology wave tank using a variety of breakwater elements and arrays in both regular and irregular waves. The expense of wave tank rental limited the time available to test different arrays. However, rental of an optical tracking instrument enabled Vidal and me to assess the response of a variety of single tethered elements, specifically: a sphere, an egg shape, and a sphere split by a larger-diameter horizontal disk. We also examined spheres moored by tethers of four different elasticities which included a wire. I compared dissipation by arrays of elastic-tethered buoys having different levels of submergence with an array of wire-tethered buoys. The wave tank was not broad enough to test various geometric layouts of buoys, so 1 designed only arrays of uniform density.

Mathematical Modeling: Buoy response and breakwater energy dissipation were modeled in both the time and frequency domains. In the former approach, I used numerical methods to solve non-linear coupled equations of motion for the relative velocity of a single tethered float. Energy dissipation was computed and then compounded for successive rows. Excitations of irregular waves were used in some simulations so results could be related to the expected behavior of tethered floats in real wave fields.

Solution by simulation was somewhat of a "brute force" method and it did not lend analytical understanding to the problem of designing a dynamic breakwater. However, it was a useful tool for confirming 
intuitive analytical judgments about certain design aspects of the breakwater concept, for making comparisons between complex mathematical models and simplifications thereof, and for comparing several different designs.

Alternatively, analysis of the breakwater element as a linear system permitted treatment of the breakwater element as a damped hamonic oscillator in the frequency domain. This latter approach permitted greater analytical insight into the design problem.

Field Tests: I field tested the concept of a dynamic floating breakwater in storm waves on Lake Winnipesaukee. The test array consisted of nine rows of two-foot diameter buoys held on 20-foot long dual elastic tethers each initially one inch in diameter. Electronic instrumentation measured the incident and attenuated waves, the angles of inclination and the mooring line tension of one breakwater element within the array. From this latter data, spectra of buoy response were computed and compared with those predicted by the mathematical models.

In order to assess the added drag resistance introduced by using a thick elastic tether instead of a thin wire one, a buoy held by a wire tether was also tested. The field tests were maintained for four months from early September through late December of 1975. 


\section{EVOLUTION AND SYNTHESIS OF THE DYNAMIC BREAKWATER PROJECT}

Theodore von Karman's quotation, "The scientist studies what is; the engineer creates what has never been", emphasizes that engineering is a process of bringing ideas into reality. As a creative process, it requires careful synthesis of opportunities, resources, new ideas, current technology, and human motivations. This synthesis evolves over the course of the project as problems are continually defined and resolved.

The manner in which the synthesis and evolution of the project is led is a major determinant of the project's outcome. The ensuring discussion gives recognition to this fact. It also allows me to separate my own contributions from the considerable contributions of others which were needed to advance and complete the project.

It may seem unusual in a university setting for a Ph.D. candidate to take part in managing the work of other graduate students, and to incorporate their results with his research. However, such an approach is consistent with preparation for engineering practice. Rarely can an engineer single-handedly undertake a comprehensive project.

Although many of the management aspects of the Dynamic Breakwater Project are transferable to project engineering in general, there are some problems unique to the process in a university setting. Three sets of goals must be coalesced: the students' educational aims, the faculty's research goals, and the project objectives. As a case in 
point, Delano's goal was to write his Master's thesis on wave staffs; Professor Winn's was to develop a new type of wave staff; and the related project objective was to measure waves around the breakwater during the fall of 1975. These goals have common elements, but they are distinct. From my point of view, it would have been preferable had Delano been a staff engineer, hired to provide the required instrumentation. However, the project did not have sufficient funds for that sort of technical support. In Professor Savage's judgment, requesting them would have decreased the likelihood of funding. Thus, organizing the project required careful matching and compromise between project goals and available resources.

Another unique aspect of development engineering in a university is the inordinate degree of risk for the Ph.D. candidate and the associated responsibility incurred by project principal investigators. It may be unrealistic to expect undergraduate and graduate students to follow an unproven Ph.D. candidate who does not have the established authority of a faculty member. Students usually come to a university to work under the direction of professors, not other graduate students. Their primary concern is, rightfully, their degree--not the support of another student's efforts. Sometimes this situation constrained my ability to advance the project and to control my own fate. Had Vidal's frame or Delano's wave staffs failed, I would have failed too; however, failure by me would not have similarly affected them. No such failures occurred on this project, but, I was aware of their possibility. 
Inception of the Project: To initiate the Dynamic Breakwater Project, Professor Savage synthesized three principal elements--the research ideas, the project team, and the funding. Professor J. D. Isaacs and R. J. Seymour had introduced the concept of a tethered float breakwater to him in the fall of 1973. In turn, Professor Savage introduced the concept to me with the suggestion that elastic tethere might improve the breakwater's survivability. Further development of the concept appealed to me as a topic for dissertation research.

It was a timely coincidence that the First International Conference on Floating Breakwaters was held in Newport, Rhode Island in the spring of 1974. The conference provided us with an opportunity to discuss further development of tethered float breakwaters with Seymour. He suggested that a next logical step would be a lake-scale field test, and that we might want to carry it out because he wasn't planning to. We left the conference encouraged in other respects as we11. Attendance by marina operators, manufacturing firms, and oil-industry engineers demonstrated wide-spread interest in floating breakwaters. Arthur Alexiou of the National Sea Grant Program was there and witnessed this statement of commercial interest. He would review the next University of New Hampshire Sea Grant Program proposal so, while at the conference, we advised him of our intentions to submit a research proposal in the fall. During the summer, Professor Savage invited Alexiou to visit the lake site where we intended to install the field test. Thus, the funding agency knew what to expect from us and had an opportunity to comment well in advance.

One of the fortitutious circumstances which increased Professor Savage's willingness to undertake the breakwater project was the avail- 
ability of the Diamond Island Ocean Engineering Laboratory on Lake Winnipesaukee. The Engineering Design and Analysis Laboratory (EDAL) had, under his direction, leased a set of buildings formerly used by the Navy for underwater light transmission experiments on this island. Substantial waves could be anticipated during the fall on the Northwest side of the island. Experiments there would be on a scale commensurate with our physical capability to work at sea, which was in sharp contrast with other recent experience. Professors Savage, Stotz, and Winn had just completed a project in 150 feet of water off the Isles of Shoals, seven miles at sea. The difficulties of working in large waves, the risks of deep diving, corrosion of instrumentation, and inaccessibility had been worrisome and expensive problems. They would be substantially less so at the lake.

In August 1974 I drafted an initial dissertation research proposal on elastically tethered floating breakwaters to discuss with my committee. I incorporated Professor Savage's suggestion for the use of rubber moorings and further proposed that they might improve the efficiency of the system if their elastic modulus could be selected appropriately. Professor Savage's work with elastic moorings dated from 1965. During a recent project in the United States Coast Guard Research and Development Center, I had learned to design elastic moorings and to fabricate slip-free terminations. In addition, earlier in the year W. Griffiths, a fellow graduate student, had written his master's thesis under Professor Limbert on detuning the dynamic response of a two-body elastic-tethered buoy system. Thus, given my exposure to and own work with elastic moorings, it was natural to consider using them in a buoy breakwater array. 
Another circumstance which increased Professor Savage's willingness to undertake the project was the considerable carry-over in experience, equipment, and personnel from the recently-completed Wave Amplitude Measuring (WAM) Buoy Project. For that effort, Professor Winn had designed instrumentation to measure the motions of a tethered buoy and to record the data at a shore station. Under the same contract, one of his graduate students had built a transmission-line wave staff which could measure waves in fresh water. His present graduate student, J.R. Delano, could re-design the system for field use. Professor Stotz had rebuilt the shore station and had processed data from it. He had modeled buoy motions. With graduate student D. 0 . Libby, he had written computer programs to process wave data. Libby, who liked to work in the field as well and had done so for Professor Savage, could be hired for a variety of tasks ranging from trucking scuba tanks to programming a computer.

It was our good fortune that a new graduate student with interest in the project arrived in September 1974. During his preliminary visit the previous May, Ensign D. A. Vidal had said he wanted to work on structural design problems in an ocean engineering field project. Although he could stay for only one year, his goals for his Master's program fit with those of the project. To undertake responsibility for trying to educate a master's level student in only one year, complete with a field experience, was a high-risk and high-responsibility commitment, but we needed him: so, Professor Savage took him on as an advisee. My degree requirements were the principal motivating factor in formation of the project. Through the Engineering Ph.D. Program, I was given a mandate to manage and coordinate parts of a large project in- 
volving other students. I had prepared for this management role during the previous year when, under Professor Savage's tutelage, I had coadvised and coordinated an undergraduate Sea Grant Project--the first time a graduate student had taken such a role in the ten-year history of that project course.

In September, Professor Savage and I drafted the research funding proposal. He asked me to present the body of the proposal and to demonstrate the physical concept behind the breakwater system to the Sea Grant Site review panel--few of whom were engineers. For the demonstration, I proposed that we make a film of different tethered floats in a wave tank. The previous summer, Professor Savage, working with Professor Milgram from MIT, had purchased a high-quality camera to film the dynamic response of mooring cables in deep water off Diamond Island. That camera was available. Vidal agreed to film the buoy motions in a crudely-arranged wave tank. The result--dubbed the "breadwinner"--was the highlight of our proposal presentation; it effectively communicated the physical concept far better than words and drawings could have done.

Preliminary Mathematical Modeling and Wave-Tank Tests: Seymour had advanced a linearized mathematical model for the special case of a wire-tethered sphere in irregular waves. An elastic-tethered system would exhibit coupled two-dimensional response and possibly substantial tether drag, so I formulated a model describing the general case. Such a model did not require the questionable simplifications implicit in a linearized model. In January, Professor Stotz and I visited Seymour in California to ask questions about his statistical linearization technique 
which, at the time, neither of us understood entirely because of the nomenclature used and apparent typographical omissions.

Upon return, I formulated an initial simulation model to provide a reference point for wave tank tests in January and February. Results from these wave tank tests confirmed the initial mathematical model and the notion that elastic tethers could improve breakwater performance. They also demonstrated to our group that the concept of using elastic tethers was worthy of further pursuit.

The tank tests gave Delano an opportunity to test the laboratory wave staff in known excitations. Some operating problems with the instrument and its developer, Delano, were revealed early in the time schedule by these pilot tests and enabled me to plan corrective measures.

To measure the dynamic response of a scale-model buoy, Professor Winn proposed to build a computer-controlled film scanner which would analyze, frame-by-frame, buoy motion filmed against a grid background. Alternatively, I proposed that we lease a biaxial optical displacement follower which could provide voltage outputs proportional to buoy displacement. After a demonstration of the optical instrument, Professor Winn abandoned his proposal in favor of the proven, available system which we then leased after considerable negotiation with the manufacturer. From my point of view, had we pursued the alternative of building the film reader, the breakwater project would have been side-tracked from its primary objectives. Fortunately, there was enough new instrument development associated with the project already that curtailment of additional instrument development was not long missed. 
Vidal built the array of buoys we tested in the MIT wave tank. He also analyzed the results of tests in regular waves. I planned the tests and analyzed the results in irregular waves. This was an advantageous division of responsibilities: al though Vidal's role in the project was not yet clearly defined, the arrangement gave him his own piece of the project, a requirement for any ambitious graduate student.

Planning the Field Experiments: Planning for the field experiments began in the fall of 1974, when Professor Savage arranged for 1ongterm lease and improvement of the buildings at Diamond Island. Then, in January 1975 we surveyed the tentative experiment site NW of the island through the ice. Such an early start, however, did little to reduce the numerous uncertainties I faced. To predict the wave climate, I had to rely on reports of average storm winds in the area and the eye-ball reports of local residents. To estimate the resonant frequency of possible tethered-buoy designs, I had to rely on drag and mass coefficients estimated in Seymour's ocean experiment. The wave-staff instrumentation was critical to our experiment, yet it was unproven in the field. Least controllable of all, of course, was the weather necessary to generate test-wave conditions. To mitigate these uncertainties, I sought early installation of one instrumented buoy and a wave staff. By so doing, I hope to obtain data useful for the final design of the experiment.

We planned a late-May installation. In April, Vidal and I had only sketchy ideas about how we might mount wave staffs in 35 feet of water. Assuming the bottom was of suitable composition, driven and guyed pilings were a possibility; so were triangular, structural towers 
which Vidal considered a possible topic for his Master's project. Together we visited two marine construction contractors on the lake. From those discussions, the idea of driving 4-inch steel well casings emerged as the most feasible alternative--eminently more likely to succeed than pointed telephone poles and far cheaper than trussed towers.

I described requirements for buoy-response data to Professors Stotz and Winn. The latter designed the necessary instrumentation; P. E. Lavoie built it. An electrical engineer and diving safety officer for the University, Lavoie had participated in several previous projects for Professor Savage. To assure his assistance, I offered to "do all the running around", procurring parts and hiring a student machinist. Having coadvised a student project the previous year, I knew of a skilled one. Professor Savage made arrangements for Lavoie's released time with the Dean of Research. Previous experience and a network of established personal contacts made it possible to solve the day-to-day problems of carrying out the field experiments.

It also became apparent that the ability to expand and contract the project work force on an ad hoc basis was essential to project success. In no other way could the necessary diverse services have been procurred for the project when and as needed. In all, over 25 people were employed at one time or another, though only 8 were specificality noted in the project proposal.

Mooring design was another area which required planning. Again, solutions evolved through a interplay of many factors. Although Professor Savage had used elastic moorings on numerous occasions, I was concerned about the limitations of his particular material for the 
breakwater application; its elastic modulus was too high. Professor Savage happened to be testing the mechanical characteristics of various rubber mooring filaments under contract with the United States Coast Guard Research and Development Center. He made the results of these tests available to me. In addition, he arranged for Vidal and me to visit with his former student, Cory Pierson, who had installed many rubber tethered buoys for Normandeau Associates, Inc., an environmental firm conducting offshore surveys. Although Pierson still terminated his moorings with rubber-taped splices around closed bronze thimbals, he suggested a simple knotted termination using a double sheet bend and half-inch nylon line. Spliced terminations cost over fifteen dollars each, an expense our project could not afford. So, I began testing the reliability of the low-cost knotted terminations in the lake. Also, I used the opportunity of these tests to investigate different rubberfilament compounds in actual buoy moorings in the field. These supplemented Professor Savage's laboratory tests.

The attempt to obtain early wave and buoy-response data was not successful; neither the wave staffs nor the weather system operated as hoped. However, these efforts benefited the project in other ways. First we were alerted to wave-staff design problems and to Delano's apparent lack of awareness of his critical role in the project. Delano required pushing, and I constantly tried to enlist Professors Savage, Stotz, and Winn in this task. In the university setting, there was no possibility of taking Delano's contribution off the critical path. There was no replacement available,for him. Also, he was a graduate student who depended upon the project for his thesis and financial support. 
The second result of the early field installation was a beginning of team unification which evolved out of the installation of the shore station, cables, piling, wave staff, and instrumented test buoy by June 1 , 1975. In all, three faculty, two staff, two undergraduates, three graduate students and I had cooperated successfully in the operation. While I had coordinated the operation and managed aspects of it, I was not yet the project leader. Overall project directive resided with Professors Winn and Savage, to whom the several students and staff reported directiy. I had yet to earn an independent leadership role from either my advisors, the other students, or the staff working on the project.

The third result was that, despite the lack of consistent answers to material design questions from either Professor Savage's or my rubber filament testing programs, the low-cost knotted terminations proved reliable. That saved an estimated $\$ 2500$ in materials and labor which the project could not have afforded to spend.

The Field Experiment: During June, Vidal began to design the structural frame and anchoring system for his Master's degree project under Professor Savage's direction. He adapted my simulation model of buoy response and modified it to predict the total load exerted on a frame by nine successive rows of buoys. Like my work, Vidal's design evolved through a synthesis of many ideas and contributions. His fellow graduate students suggested he place anchor weights on foot pads rather than on the lake bottom, an arrangement which could prevent scour around the feet. Professor Zoller of the Civil Engineering Department advised him on the finer points of structural design. Vidal discussed conceptual 
designs late into the night with Professor Savage. Vidal had to leave on September 1, 1975, for his next Navy duty, so the frame had to be installed and the project approved by then. His original design was beyond the limitations of the budget. Revisions were made through review sessions with Professor Savage and myself. I asked Vidal to make a balsa wood mock-up of the design so we could envision the construction and installation procedure which presented considerable physical risk to all. Professor Savage arranged a fixed-price contract with a professional welder and former student, William Miskoe. Miskoe advised and assisted Vidal in constructing the frame. One of the reasons he was willing to work on this unusual design and construction job and to furnish the necessary equipment was that he happened also to be working for Professor Savage on another project.

Vidal, with Miskoe's advice and Professor Savage's counseling, directed construction of the frame in the muddy, lake-side barge yard of the marine contractor. Two undergraduates and the EDAL technician worked with him there. After a dry-run installation on land, the 50 tons of steel frame and concrete blocks were loaded and barged to the experiment site off Diamond Island. This was Vidal's time to direct the action: he had his own project within the Dynamic Breakwater Project, as both Delano and I did.

The two-day installation was the most intense period of the project. Everyone was involved, and everyone had clear responsibility and authority. Vidal had designed and built the frame and was in charge of its installation. The contractor, R. Scribner, controlled all operation associated with his crane and barges. Lavoie controlled all diving 
operations. Professor Savage, principal investigator and director of EDAL, was present to accept overall responsibility for the project.

In general, there was an irregular but gradual transition in my project role from coordinating to managing. The installation of the buoys marked a significant milestone in the process. Several days after the frame installation, I directed the installation of the buoy array from the EDAL barge. Vidal and two undergraduates attached and inflated buoys underwater while Libby assisted topside. Neither Lavoie nor Professor Savage nor any faculty or staff were present, in effect, their absence symbolized the shift in my role.

Once the breakwater was installed, our attention aga in focused on wave staff instrumentation. It was September 1 , and after numerous design alterations, one wave staff still did not function properly. Professor Stotz left for sabbatical at Woods Hold Oceanographic Institute. In a meeting of myself, Professor Savage, Professor Winn, and Delano, the latter two agreed to build an entire new wave-staff unit, incorporating design changes. Much to the relief of all, it worked.

In October we sought and received a second year of funding from Sea Grant. We were able to report that all systems were installed and operating and that we awaited only the weather necessary to generate sufficiently large waves. However, during the fall the electronics in the wave staffs and shore station required continual repair, calibration and circuit replacement. Beyond this, it was a period of impatient waiting.

My persistence had to endure until December 18 when we were blessed with the long-awaited northwest winds of sufficient velocity to 
generate three foot waves. I ferried Delano to Diamond Island to check the operation of the shore station before the weather front arrived. He repaired it. I ferried him back to the shore and returned with my sleeping bag and enough food for overnight. The project had evolved to this; one person, alone, waiting on Diamond Island for an early winter storm to bring test conditions. They came not once, but twice. In the brief interlude, while trying unsuccessfully to start the frozen outboard motor, I heard a plane flying overhead checking on my well-being. It was the only way Professor Savage could make contact with me for the two days I stayed on the island. Indeed, control of the project was totally in my hands at that moment.

Leadership of the project remained mostiy in my hands during the remainder of the project, especialiy because Professor Savage was in Scotland on sabbatical. Professor Winn was appointed the Acting Director of EDAL. With his approval, I extended Libby's contract to provide computer programming services and to work during removal of all wave staffs and supports which penetrated the ice surface at the experiment site.

In the spring, I hired Gus Ruetenik, one of the undergraduates who had worked on the field project all along, to organize the dissembly of the field array, instrumentation, and shore station and their proper disposal. We agreed on a work plan and team of divers, but I wanted him to lead the operation without my presence. He reported directly to me, although I always advised Professor Winn of our plans. Ruetenik's responsibilities were unusual for an undergraduate, but he had more skill and experience than the other students. However, the University pay scale for part-time undergraduate labor made no allowances for such cases. 
In order to pay Ruetenik appropriately, I had to go around the system. Otherwise, I could not have expected him to accept the job.

During the spring, I drafted this dissertation and sent copies for review to Professor Stotz in Woods Hole and to Professor Savage in Edinburgh. Here on campus, I submitted drafts to Professor Sprague, a member of my committee. At the same time I drafted a paper for presentation to the American Society of Civil Engineers Fifteenth Conference on Coastal Engineering and reviewed it in May with Professor Stotz, a coauthor. In June, Professor Savage and 1 revised the presentation considerably during my visit to Edinburgh. Finally, I presented it at the conference in Ju1y 1976.

With the removal of the breakwater floats and instrumentation, and with the presentation of the technical paper which is the project final report, my role in the dynamic breakwater project terminated. I am again a full-time graduate student concentrating on writing and submitting this engineering dissertation. Parts of the project continue. Professors Winn and Savage have built a second-generation wave staff, correcting the instabilities and non-linearities which had limited its use. Delano is putting the finishing touches on his Master's project. Professor Savage is considering a new phase of work and the possibilities of staffing and funding.

My principal contributions to the project were the development of the analytical models, the design and analysis of the scale model and field experiments of the tethered float breakwater, and those aspects of the project management identified herein. 


\section{MODELING A DYNAMIC BREAKWATER}

Effective engineering design of a dynamic floating breakwater for a specified wave condition requires a scalable mathematical or physical model to guide the process. In either case, though, predictions of buoy motion and breakwater energy dissipation are not likely to be exact. Physical wave tank models may suffer from scale effects while mathematical models depend upon experimental estimates of drag and mass coefficients which often show large variance. In addition, mathematical models may suffer from simplifying assumptions which are necessary to formulate a tractable model.

My objective in modeling is to describe the response of an individual breakwater element and the average rate of energy dissipation by an array of elements. There are advantages to analyzing these phenomena in the frequency domain. However, such analys is requires more simplifying assumptions than analysis in the time domain. Therefore, in verifying a model of breakwater performance I will compare experimental results from a field test to the results of mathematical models in both the time domain and the frequency domain.

Mathematical modeling of a dynamic breakwater can be accomplished in three steps:

1. Writing equations to describe the motion of one tethered breakwater element in the wave field.

2. Calculating the wave energy dissipated by the motion of the float relative to the surrounding water and expressing this in terms of dissipation per foot of frontage. 
3. Compounding this dissipation through successive rows of breakwater elements.

Small amplitude Airy Wave Theory will be used throughout this analysis to describe the water particle kinematics. Although there is some question about the accuracy of this mathematical description when applied to rea] waves of finite height, it has proven to be broadly applicable and often as accurate as other theories of higher order. Agerschou \& Edens (1966) analyzed the published data of Wiegel, Beebe and Moon (1957) and unpublished data of Bretschnieder describing wave forces on piles. They compared the force predictions from linear, first order theory with those from Stokes fifth order theory and concluded that the latter was not superior for that application. Furthermore, the use of linear wave theory is necessary in the spectral analys is techniques used to describe real wave fields. (The equations describing water particle velocities and accelerations in a linear first order wave are provided in Appendix A.)

\section{A. Wave Forces on a Tethered Float}

1. The Morison Equation

Wave forces on a bluff object such as a submerged buoy can be described by the Morison equation when the dimensions of the object are small with respect to the crest-to-crest length of the incident wave (Morison, O'Brien, Johnson, and Schaaf, 1950; O'Brien and Morison, 1952).

This approach treats the wave force as the sum of inertial and drag components, each of which depends on the flow acceleration and velocity respectively. The approach of representing the wave force as the sum 
of inertial and drag components was first formulated by Stokes in 1851; one hundred years later Morison and co-investigators showed it led to acceptable predictions of wave forces.

The Morison equation most often describes one dimensional wave forces on a fixed object. It is formulated as the sum of drag and inertial components respectively:

$$
\begin{aligned}
& F=F_{D}+F_{I} \\
& F=\frac{1}{2} \rho A C_{D}|u| u+M_{W}\left(1+C_{M}\right) \dot{u}
\end{aligned}
$$

$A$ is the area of the object projected normal to the flow, $M_{w}$ is the mass of water displaced by the object, and $\rho$ is the fluid density. The velocity and acceleration of the surrounding water are $u$ and $\dot{u}$, respectively. $C_{D}$ and $C_{M}$ are experimentally determined constant coefficients of drag and mass; their values depend upon the shape and size of the object as well as the characteristics of the flow relative to it. In this paper, $C_{M}$ will be taken as the coefficient of added mass. The virtual mass is then written as $M_{W}\left(1+C_{M}\right)$.

One part of the inertial force is due to the pressure gradient in the accelerating flow. For an inviscid, incompressible fluid, this pressure gradient is expressed by the Eulerian equation for fluid motion in the horizontal direction (Lamb, 1945, p. 4):

$$
\frac{d P}{d x}=-\rho \frac{d u}{d t}
$$

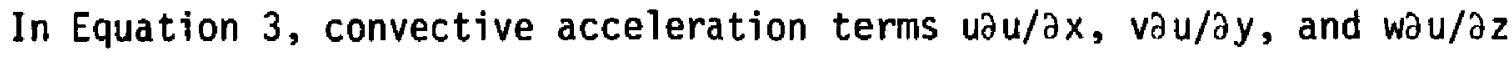
are small relative to $\partial \mathrm{u} / \partial \mathrm{t}$ except in steep waves $\left(0^{\prime} \mathrm{Brien}\right.$ and Morison, 
1952). Body force gravity appears in the equation describing vertical forces. Integrating over the volume of the object, yields:

$$
F_{x} \text { (pres. grad) }=M_{w} d u / d t
$$

where $M_{W}$ is the mass of fluid displaced by the object. The object is assumed small enough that fluid acceleration caused by the wave is that which would occur in the space occupied by the object if the object were not there.

The second part of the inertial force is due to the added mass which exists whenever there is a relative acceleration of an object in fluid because work must be done on the surrounding flow field. This relationship is expressed as:

$$
F_{x} \text { (virtual mass) }=C_{M} M_{w} d u / d t
$$

For a sphere in potential (inertial) flow conditions, $C_{M}$ is 0.5 . This can be calculated (Lamb, 1945, p. 124) by considering the kinetic energy imparted to initially still fluid by a sphere moving with velocity $u(t)$. The fluid velocity potential can be represented by the equation for a three dimensional doublet. The fluid's kinetic energy is equivalent to that of half the mass of water displaced by the sphere moving at velocity $u(t)$. In formulating forces, the effect of the fluid presence is usualiy accounted for by increasing the inertia of the object--the increment being called "added mass".

The remaining term in Equation 2 accounts for the form drag of the object. In turbulent flow the magnitude of the drag force is proportional to the square of flow velocity relative to the object--an empirically formulated relationship. In turbulent flow, the values 
of both $C_{D}$ and $C_{M}$ must be determined by experiment.

2. Coefficients of Mass and Drag

In steady flow, the coefficients of mass and drag are well

defined functions of Reynolds number for a given shape such as a sphere or cylinder. In horizontal oscillatory flow, these coefficients have been successfully correlated with period parameter, a dimensionless number defined by Keulegan and Carpenter (1958). Like the Reynolds number, period parameter is a measure of the ratio of drag forces to inertial forces. However, Reynolds number is the ratio of inertial forces to viscous shear forces in the boundary layer while period parameter is a ratio of water particle acceleration (inertial) forces to form drag forces over the total object. For an object in simple oscillatory flow, period parameter is written:

$$
\frac{U_{m}^{\tau}}{d}=\frac{2 \pi a}{d}
$$

where $U_{m}$ is the maximum flow velocity relative to the object, $\tau$ is the flow period, $d$ is the critical dimension (diameter) of the object normal to the flow, and a is the flow amplitude relative to the object.

The period parameter lends itself to physical interpretation. According to Keulegan and Carpenter (1958), at low period parameters inertial forces dominate. Fluid particles travel only a small fraction of the object diameter during a half cycle of the wave, and vortices are not shed. In such cases, the theoretical potential flow value of $C_{M}$ can be assumed and the drag forces can be neglected or assumed proportional to the first power of fluid velocity. At high period parameters, drag forces are predominant and steady flow values of drag co- 
efficient can be assumed. During each half-cycle of the wave, fluid particles travel a distance many times the object diameter. The coefficient of mass must be determined empirically.

At medium period parameters, the drag and inertial forces are of the same order of magnitude. In this case, both mass and drag coefficients are determined empirically.

Data upon which to base estimates of drag and mass coefficients for a tethered sphere in irregular waves are not plentiful. Harleman and Shapiro (1958) investigated the response of wire tethered spheres in a mode 1 tank. Their experiments were carried out on $1 y$ in regular waves and at low period parameters; the latter ranged from 0.2 to $3.0 \mathrm{la} / \mathrm{d}$ from .04 to .50). They estimated $C_{M}$ and $C_{D}$ as .50 and .42, respectively. Grace and Casjano (1964) measured the forces on an 8-inch diameter sphere mounted near the sea floor in shallow water off Hawai $i$. They treated the 12 to 14 second ocean swell as regular waves and calculated $C_{M}$ and $C_{D}$ at the quarter points of the wave cycle where either drag or inertial forces were theoretically zero. Their results show wide scatter and are inconclusive.

Seymour (1974) was first to calculate coefficients for spheres in irregular waves in both the laboratory and the ocean. In laboratory experiments using irregular excitations, he oscillated a rigidly restrained sphere in initially still water and concluded that at period parameters greater than 5 ( $r m s$ a/D $>0.8$ ) the average coefficient of drag was constant. He took this result as an indication that the flow was fully turbulent. He further observed that the coefficient of mass decreased in a linear fashion with increasing period parameter. However, the rate of decrease was gradual so that assuming a single value over a 
particular excitation spectrum would be an acceptable approximation. Seymour also observed that the drag coefficient increased almost two fold when the sphere was not rigidly restrained but instead allowed to vibrate transversely in response to vortex shedding. He reasoned that this lateral vibration increased the width of the wake, an increase which was reflected in the values of the coefficients. Laird (1962) made similar observations for cylinders.

In an ocean experiment, Seymour calculated values of 0.35 for $C_{M}$ and 0.25 for $C_{D}$. The damping of his tethered float was small because the mass of the steel buoy he used was a large proportion of the water mass displaced. So, he equated the natural frequency of the system to the resonant frequency inferred from measured response. He calculated $C_{M}$ as a function of natural frequency according to a linear mathematical model. Then, he estimated $C_{D}$ by fitting the response of the model to that measured for the system in real waves. His values of $C_{M}$ and $C_{D}$ were about $70 \%$ higher than those calculated in laboratory experiments; he suggested the difference may be attributable to transverse vibrations. I adopted Seymour's estimated values of $C_{M}$ and $C_{D}$ in order to carry out the initial design of my own experiments.

One of the requirements of the Morison equation is that the object be relatively small with respect to the wave length. As the object under consideration increases in size, it begins to act like a wall, reflecting or scattering a portion of wave energy. Unfortunately, the term "relatively small" has suffered from lack of definition; few investigators have ventured a quantitative estimate of this criteria. Faltinsen (1975) describes "small" as less than 1/5 of the wave length. 
When object dimensions exceed this criteria, diffraction theory--based on assumptions of potential flow--can be used to compute the wave forces and to account for deformation of the wave pressure field. (McCamy and Fuchs, 1954).

Other assumptions implicit in the Morison equation should be put into perspective before a model of tethered buoy response is presented. Drag coefficient is assumed to be a constant. Strictly speaking, this is true only for steady flow conditions. However, Keulegan and Carpenter (1958) demonstrated that in unsteady, oscillatory flow, errors introduced by treating the coefficients as constants can be small. During phases of the wave cycle when $C_{D}$ changes the most, the flow velocity and thus drag force, approaches its minimum. Similarly, when changes in $C_{M}$ are greatest, flow acceleration--and thus, intertial force--approaches its minimum. It has also been assumed in the Morison equation that the area and shape of the object normal to the direction of flow do not change during the wave cycle. This restriction has important implications in the formulation of wave forces in two-dimensional flow around objects other than spheres or vertical cylinders.

Weigel (1964, p. 250) acknowledged that the assumption by Morison, O'Brien, Johnson, and Schaaf (1950) that inertial and drag forces should be added linearly to obtain total wave force is open to question from a theoretical standpoint. For instance, formulation of the inertial term was based on assumptions of inviscid flow. To this term, a viscous force was added. However, Wiegel also pointed out 
that despite such incongruities, the Morison equation has proven to be an acceptable approach for predicting wave forces on some objects and thus, he justified its use for design decisions.

\section{Wave Forces in Two-Dimensional Flow}

Morjson and co-investigators (1950) formulated their wave force equation to describe the forces on two sorts of objects--slender vertical piles and small spheres representing sand pebbles on the ocean floor. Both of these are one-dimensional problems: the principal wave force on a vertical pile is due to the horizontal component of flow because of object geometry; around a sphere on the sea floor flow is horizontal because of boundary conditions. Keulegan and Carpenter (1958) placed fixed cylinders in the node of a standing wave. Morison and $0^{\prime} B r i e n$ (1952) mounted spheres close to the bottom boundary of a wave tank. Seymour (1974) oscillated a sphere horizontally in initially still water. None of these investigators dealt with a two-dimensional flow problem. They did not have to if their interest was in maximum wave forces. However, predicting the wave force history on horizontal pipelines and subsurface tethered buoys are two-dimensional flow problems and should be formulated as such or justified as two onedimensional formulations.

Consider a sphere rigidly mounted in the wave field. (A cylinder whose longitudinal axis is oriented horizontally and in line with the wave crest would do as well for this example). According to a two-dimensional formulation of the Morison equation, the wave force acting on the sphere is written: 


$$
\begin{gathered}
\vec{F}=\vec{F}_{D}+\vec{F}_{I} \\
\vec{F}=\frac{1}{2} \rho A C_{D}|\vec{r}| \vec{r}+M_{W}\left(1+C_{M}\right) \vec{r}
\end{gathered}
$$

where $r$ is the relative velocity of the fluid and $\dot{r}$ its relative acceleration. Substituting,

$$
\text { and } \quad \begin{aligned}
& \vec{r}=\overrightarrow{i u}+\overrightarrow{j v} \\
& \quad \vec{r}=\vec{i} \dot{u}+\vec{j} \dot{v}
\end{aligned}
$$

into Equation 8 will resolve the formulation into horizontal ( $x$ ) and vertical $(y)$ components in the direction of unit vectors $\vec{i}$ and $\vec{j}$ respectively. In regular waves, the horizontal and vertical water

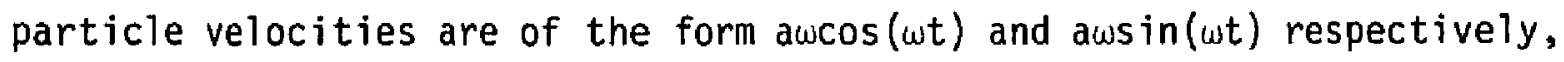
where $a$ is the flow amplitude and $\omega$ is the radian frequency.

The two-dimensional vector formulation results in a coupled drag term. Both one and two-dimensional formulations are presented below for comparison. The two-dimensional formulation requires that parameters $A$, $C_{D}$, and $C_{M}$ be the same from any direction in the $x-y$ plane, while the one-dimensional formulation does not. $C_{1}$ and $C_{2}$ have been substituted for the products $\frac{1}{2} \rho A C_{D}$ and $M_{W}\left(1+C_{M}\right)$ respectively.

Two-dimensional formulation

One-dimensional formulation

$$
\begin{array}{ll}
F_{x^{\prime \prime}}=c_{1} u \sqrt{u^{2}+v^{2}+c_{2} \dot{u}} & F_{x^{\prime}}=c_{1} u|u|+c_{2} \dot{u} \\
F_{y^{\prime \prime}}=c_{1} v \sqrt{u^{2}+v^{2}}+c_{2} \dot{v} & F_{y^{\prime}}=c_{1} v|v|+c_{2} \dot{v}
\end{array}
$$


There are no differences between the inertial terms of the two formulations. There are differences only in the non-linear drag terms. Although the maximum drag forces are the same, the average drag force in the two-dimensional formulation is larger. The magnitude of the difference between the formulations can be estimated by calculating the average rate of wave energy dissipation or drag power. Drag power, $P_{D}$, is the dot product of drag force and relative velocity:

$$
P_{D}=\vec{F}_{D} \cdot \vec{r}
$$

By either formulation, drag power can be resolved into horizontal and vertical components:

$$
P_{D}=F_{D x} u+F_{D y} v
$$

Considering only horizontal drag power for this example, the ratio of drag power according to the two different formulations compares as

$$
\frac{P_{D}^{\prime}}{P_{D}^{\prime \prime}}=\frac{|\operatorname{Cos} \omega t| \operatorname{Cos}^{2} \omega t}{\operatorname{Cos}^{2} \omega t}
$$

Integrating both expressions over a wave cycle yields the ratio of energy dissipated according to the two formulations:

$$
\frac{E_{D}^{\prime}}{E_{D}^{\prime \prime}} \sim 0.85
$$

Thus, 15\% less energy is dissipated by the one-dimensional formulation than by the two-dimensional formulation. 
A similar comparison of the two formulations applied to a tethered sphere (rather than to a fixed sphere) is not as simply accomplished because the tethered sphere is free to move in the wave field. Furthermore, if the tether is elastic, the object can oscillate vertically as well as horizontally. If the dynamic response of the system were the same in each dimension, then the horizontal and vertical relative velocities would have the same magnitudes and would be phased by $\pi / 2$ radians. For this particular case, the magnitude of vector relative velocity would again be a constant. Therefore, the difference in performance of $15 \%$ cited above represents the maximum feasible case. However, for the case of a stiff elastic or wire tethered system, the magnitude of the vector relative velocity is not a constant because horizontal and vertical responses are not the same. Although the formulation does not simplify as before, it can be said that the drag term formulated by the two-dimensional approach will have a larger average magnitude than that formulated by the one-dimensional approach.

If the component of relative velocity in one dimension is greater than that in the other dimension, or if the object is not a sphere, consideration must be given to the possibility that flow coefficients could be unique to a particular dimension. To elaborate, consider the case of an ellipsoid in two-dimensional oscillatory flow: not only would the coefficients of mass vary in time according to the direction of flow, but the area normal to the flow would change in time as well. Obviously, the requirement of the two-dimensional formulation that the parameters $A, C_{M}$, and $C_{D}$ be constant cannot be met for certain shapes and dynamic responses. In the section of this 
chapter which deals with simulation, I will compare our results of tethered buoy models identical in all respects except for formulation of drag forces. In this way, the one and two-dimensional formulations will be compared quantatively for a tethered sphere.

\section{B. Analysis of Buoy Response and Breakwater Energy Dissipation}

1. Frame of Reference

Figure 3 depicts an elastically tethered sphere in waves. The angle of inclination measured from the vertical is $\theta$. The stretched length of the tether measured to the center of the sphere is R. Demos, Stewart, and Core 11 (1970), and Stotz, Libby, and Savage (1975), found catenary in the tether and articulation between buoy and tether insignificant for highly tensioned elastic moorings. Seymour observed no tether catenary or articulation in wave tank experiments; neither did I. Therefore, the tether was assumed to form a straight 1 ine. The unstretched length of the tether is $r_{0}$, and the statically stretched length is $1_{0}$. $R$ and $\theta$ can be expressed by geometric relations in terms of $x, y$, and $1_{0}$.

\section{Tether Modeling}

The tension exerted by an elastic tether can be expressed in terms of its stretched length if the mechanical characteristics of the material are known. Figure 4 shows a typical load-elongation curve for the type of structural rubber used in buoy moorings. The working range of the loaded tether is approximately linear so that tension is described by an equation of the form 


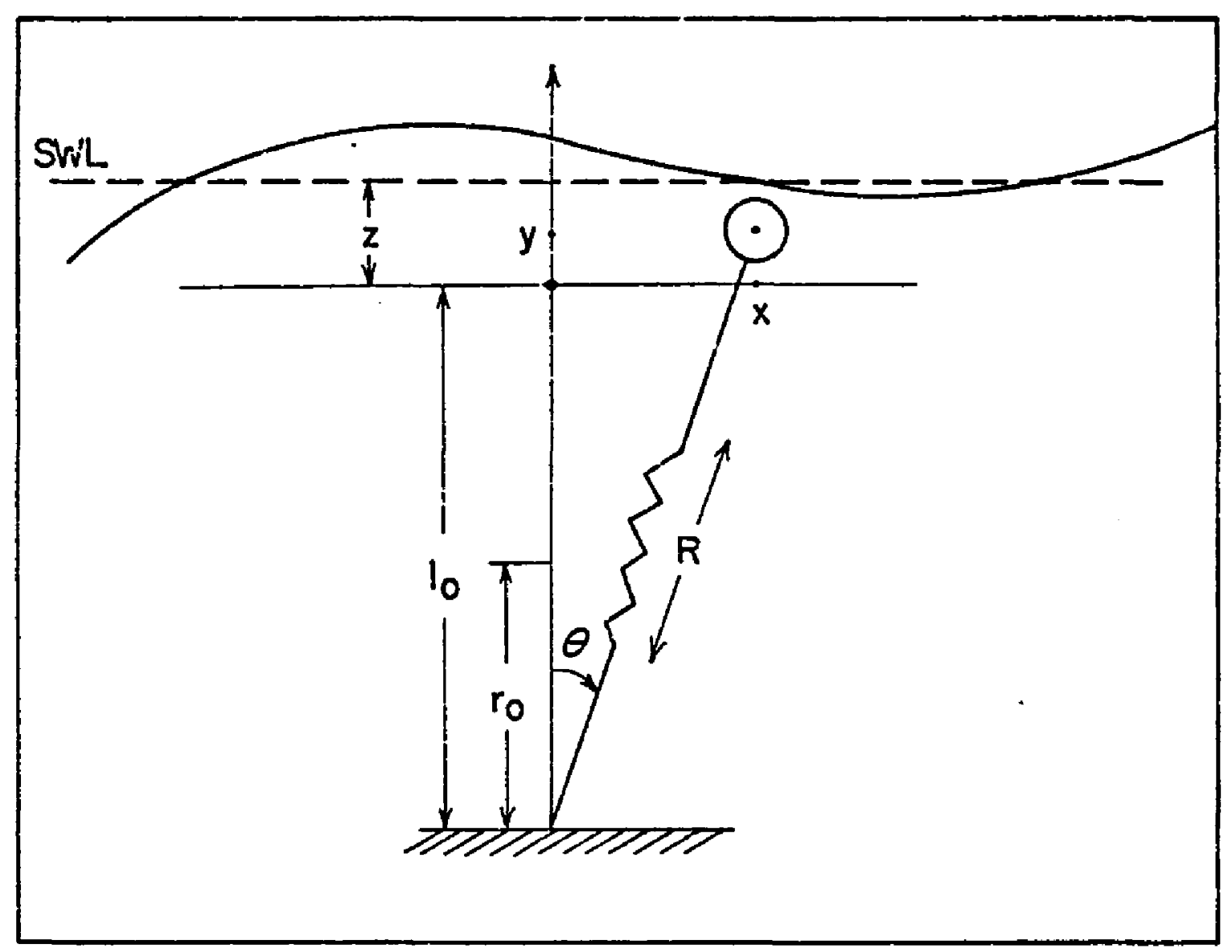

Figure 3. Elastically tethered sphere in waves. 


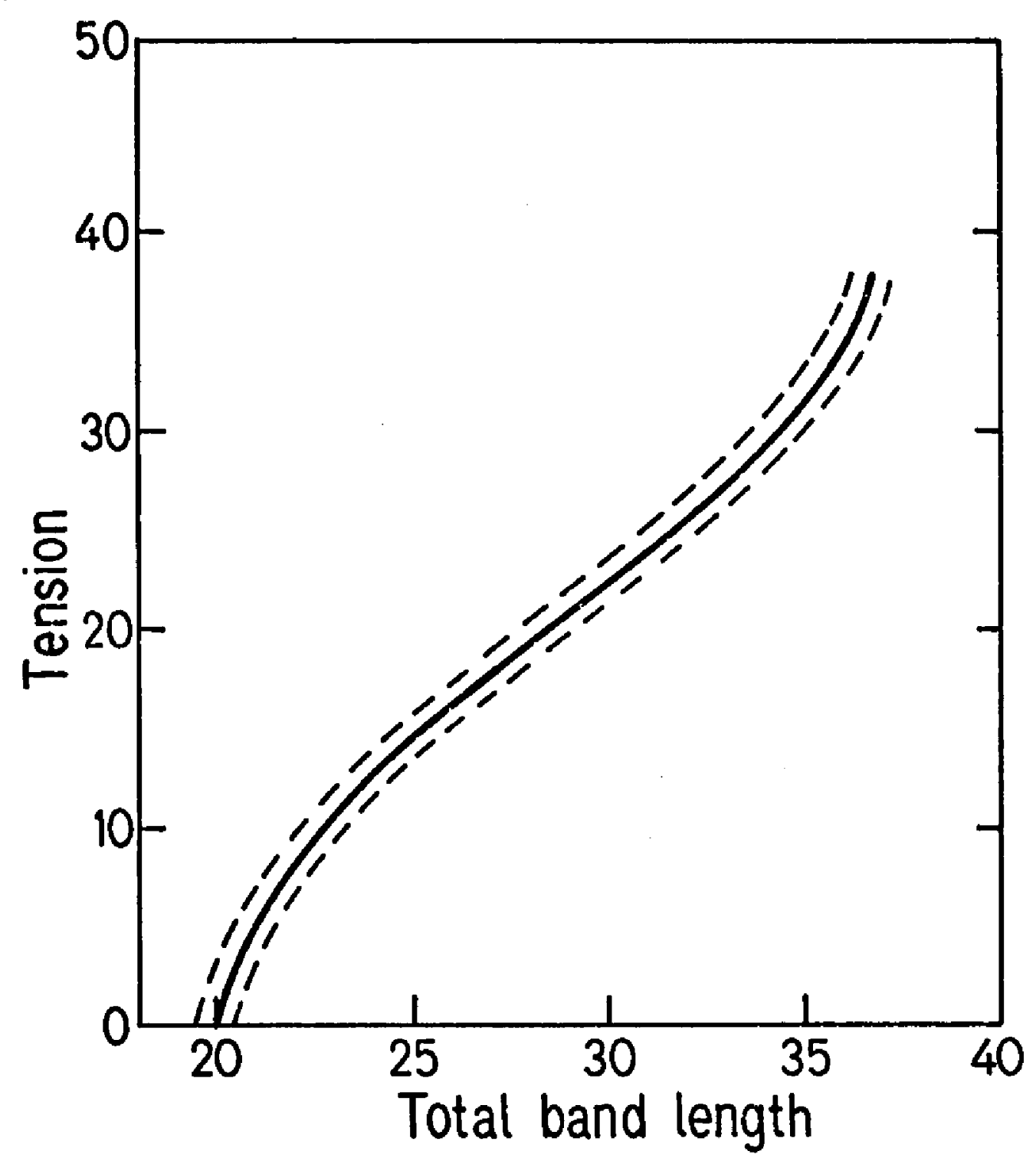

Figure 4. Typical load-elongation curve for solid elastic filament from Savage (1973). 


$$
T=k_{t}\left(R-r_{0}\right)+B
$$

where $k_{t}$ is the linear spring constant for the elastic tether in its working range; $\mathrm{B}$ is a constant. Inertial forces on the tether are neglected because they are much smaller than the inertial force on the buoy. Drag force on the tether, however, may be substantial relative to that on the buoy so it is accounted for in the equation of motion. To simplify formulation, wave-induced water motion is ignored and tether drag is treated as being dependent upon the velocity of the tether moving back and forth. Drag force is formulated for a differential section of tether whose free end moves with the velocity of the buoy, $\dot{x}$. Integrating over the length of the tether yields:

$$
F_{D t}=\frac{1}{6} \rho A_{t} C_{D_{t}}|\dot{x}| \dot{x}
$$

\section{Equations of Motion}

The buoyancy, acceleration, wave and tether forces on the buoy can be resolved into vertical and horizontal components, summed, and algebraically rearranged. The resulting equations of motion are:

$$
\begin{aligned}
& M_{x} \ddot{x}+D_{x}|\vec{r}|(\dot{x}-u)+D_{t}|\dot{x}| \dot{x}+T \sin (\theta)=N_{x} \dot{u} \\
& M_{y} \ddot{y}+D_{y}|\vec{r}|(\dot{y}-v)+T \cos (\theta)-\left(M_{w}-M_{s}\right) g=N_{y} \dot{v}
\end{aligned}
$$

where

$$
\begin{array}{ll}
M=M_{s}+M_{w} C_{M} & D=\frac{1}{2} \rho A C_{D} \\
N=M_{w}\left(1+C_{M}\right) & D_{t}=\frac{1}{6} \rho A_{t} C_{D_{t}}
\end{array}
$$


$M$ accounts for the mass of the buoy plus the entrained mass of water. The coupled mooring line tension is expressed as:

$$
T=k_{t}\left[\begin{array}{ll}
\sqrt{x^{2}+\left(y+1_{0}\right)^{2}} & -r_{0}
\end{array}\right]+B
$$

The water particle velocities are expressed:

$$
\begin{aligned}
& u=\frac{\cosh [k(z+h)]}{\cosh (k h)} \cos (\omega t-k x) \\
& v=\frac{\sinh [k(z+h)]}{\cosh (k h)} \sin (\omega t-k x)
\end{aligned}
$$

where $a$ is the wave amplitude, $\omega$ is the radian wave frequency, $k$ is the wave number and $z$ is the depth of submergence of the center of the buoy. In deep water, where depth $h$ exceeds one-half wavelength, the hyperbolic sine and cosine terms expressing orbital attenuation with submergence $z$ simplify to $e^{-k z}$. The water particle acceleration is, of course, the time derivative of velocity. Wave number is calculated as $k=$ $2 \pi / \lambda$ where $\lambda$ is wave length.

\section{Energy Dissipation}

The rate of drag energy dissipation by a buoy--drag power--is the dot product of dissipative force and relative velocity. Adjusted for buoy density $B$, the number of buoys per foot, the drag power per foot in the vertical and horizontal dimensions is written as:

$$
P_{D_{x}}=\frac{1}{2} B \rho A C_{d}|\vec{r}| u_{r}^{2} \quad P_{D_{y}}=\frac{1}{2} B \rho A C_{D}|\vec{r}| v_{r}{ }^{2}
$$


where

$$
u_{r}(t)=\dot{x}(t)-u(t)
$$

and

$$
v_{r}(t)=\dot{y}(t)-v(t)
$$

The total drag power is then

$$
P_{D}=P_{D_{x}}+P_{D_{y}}
$$

The average incident wave power per foot of wave crest is written:

$$
P_{w}=\frac{1}{2} \quad \rho g a^{2}\left(\frac{\lambda}{2 \tau}\right)
$$

where $\lambda$ is wave length and $\tau$ is the wave period (Wiegel, 1964, p. 21).

Consider a row of breakwater elements each spaced $1 / \beta$ apart on a line parallel with the incident wave crests. Elements are separated by at least one buoy diameter, a distance which appears sufficiently large that the buoys will not collide or significantly interfere with one another. In a wave tank, Seymour (1974) observed that at a buoyseparation distance greater than one diameter, lateral interaction between buoys was unnoticable. Turbulence generated by one row of oscillating buoys may affect that row or adjacent rows. Petryk (1969) found that turbulence generated in the wake of objects in oscillatory flow can lower the critical Reynolds number.

Integrated over a wave period, the drag power and wave power are compared to yield the percentage of wave energy dissipated by a single row of buoys.

$$
\ell_{1}\left(\omega, a_{1}\right)=\frac{\int_{0}^{\tau} P_{D} d t}{\int_{0}^{\tau} P_{w} d t}
$$


Because wave energy is proportional to the square of wave amplitude, the amplitude of the wave after it has been attenuated by the first row of buoys is written:

$$
a_{2}=a_{1} \sqrt{1-l_{1}\left(\omega, a_{1}\right)}
$$

It is assumed that this amplitude reduction is complete within a very short time after the water and buoy have interacted. Therefore, the attenuated amplitude $a_{2}$ is the input wave amplitude for the second row of buoys. The equations of motion are solved again, drag and wave power calculations made, and an attenuation factor, $\ell_{2}\left(\omega, a_{2}\right)$ calculated for the second row. The procedure is then repeated for all $n$ rows of the array. So, the model for dissipation by the array is one of discrete, step-like amplitude reductions in the wave for each row of breakwater array. It is assumed that the array is long enough that end diffraction effects can be ignored for calculating the attenuated wave height in the desired area of breakwater shadow.

Initial estimates by Seymour and Isaacs (1974) of the wave energy reduction by one row of floats is on the order of $5 \%$. Even at a rate of energy dissipation of $10 \%$, the attenuated wave amplitude after the first row of buoys would be about $95 \%$ of the initial wave amplitude. Because the dissipation by each row is small, large error is not incurred by lumping the effects of several rows together to reduce the computation. Seymour (1974) went a step further and assumed a constant energy reduction factor for all rows. This estimate was a conservative one because, as will be shown presently, the effectiveness of the system increases as wave heights decrease--a 
result of non-linear system response. Using the conservative model, the energy attenuation of the array is estimated as

$$
\frac{a_{n}^{2}}{a_{1}{ }^{2}}=(1-l)^{n}
$$

where $\ell$ is the percentage dissipation per row.

A first estimate of the number of rows of buoys required to dissipate a chosen percentage of the incident wave energy is:

$$
n=\frac{\log \left(a_{n}{ }^{2} / a_{1}{ }^{2}\right)}{\log (1-l)}
$$

For example, assuming $8 \%$ reduction per row the number of rows of floats required to reduce the wave energy by $50 \%$ would be $\log (.5) / \log (.92) \sim 8$. However, making such estimates of dynamic breakwater performance requires solutions to the equations of motions.

\section{Solution by Simulation}

1. Numerical Methods

To solve the pair of non-linear coupled equations of motion for an elastically tethered buoy without making further simplifying assumptions, I turned to numerical integration techniques on a digital computer. Specifically, I used the IBM Continuous Systems Modeling Program (CSMP) to simulate the response of an elastically tethered buoy in both regular and irregular waves.

The integration technique selected was fourth order RungeKutta with a variable integration step. Prior to utilizing the CSMP package, several numerical integration techniques were tested on a 
simple pendulum problem. The results of using Runge-Kutta integration with Runge's coefficients (Kuo, 1971), CSMP's fourth order variablestep Runge-Kutta integration, and an approximated closed-form solution showed no discernable differences in modeling the motions of a pendulum released from an initial displacement of ten degrees. There was probably less uncertainty in the accuracy of the numerical integration than there was in estimates of coefficients $C_{M}$ and $C_{D}$. Fourth order Runge-Kutta and fifth order (Milne) integration techniques were compared through simulations of tethered spheres: results were within one percent of one another.

The CSMP package provided the option of varying a model parameter successive simulations. Thus, the frequency response of the elastically tethered buoy could be calculated from a series of simulations over a range of wave heights and frequencies. A routine--XNXT-devised by K. C. Stotz on a previous project (Stotz, Libby and Savage, 1975) was added to the DYNAMIC section of the CSMP program, enabling variables such as buoy position and water particle position to be written on a disk device at a specified time interval. This data was then available for subsequent plotting and analysis programs of my own design. These included a two dimensional spatial plot tracing the buoy orbit in time, a four variable time plot, and a frequency response calculation routine.

During simulation, the drag power of the buoy was calculated and integrated over several wave periods after the response reached steady state. This energy dissipation was scaled by the density of a row of equally spaced buoys and then compared with the wave energy incident during the same period of time. 
In a real wave field, where a spectrum of wave frequencies is present, the energy in each frequency band is proportional to the square of the amplitude of $i$ ts Fourier component. However, the energy dissipation by a breakwater element in irregular waves cannot be estimated directly as the sum of the dissipation in regular wave components: drag power is proportional to the cube of relative velocity, not its square. Therefore, I depended upon estimates of energy dissipation in regular waves only for the purpose of comparing different element designs rather than for estimating the actual performance of a row of breakwater elements in real waves.

To simulate the response of the tethered element in irregular waves, the sum of thirteen randomly phased Fourier sine waves was used as the excitation function. Data was written to a disk file and then spectrally analyzed. By linearization, drag power over each frequency band was estimated from the spectrum of relative velocity. This approach will be detailed presently and results discussed later with the field experiment.

2. A Perspective on Simulation

Before discussing the results of the simulations, I will put the approach into perspective and identify what was sought in its use. In some respects, numerical integration was a "brute force" solution to the equations of motion; it did not lend physical and analytical insight into the nature of the problem in the way that linear analysis could. Analys is of breakwater design based solely on the results of simulation would have been a process guided by trial and error. Alternatively, a 
more elegant linear analysis required questionable simplifications of the coupled non-linear equations of motion. Simulation provided a means for assessing the effects of such simplifications. In addition, such complexities as those created if the float broached the water surface during its orbit, could be treated, and the performance of different breakwater element designs could be compared. Finally, results of a field test in real waves could be modeled by simulation using irregular wave excitations. Simulation was a valuable tool in this analysis-necessary, though not sufficient, to an understanding of the behavior of the tethered float breakwater.

3. Results of the Non-Linear Model in Regular Waves

Frequency Response: In order to calculate the frequency response of an elastically tethered sphere, the attenuation of wave pressure and water particle velocity with depth was ignored. Thus, the amplitude of exciation was the same across all frequencies for this particular series of simulations.

Figure 5 shows the horizontal and vertical frequency response for an elastically tethered system. Results are plotted against frequency normalized according to the natural frequency of the system in the horizontal direction. Wave heights $H$ in the simulation were normalized to the buoy diameter $d$. Response was greatest for the lowest waves $(H / d=0.5)$, as might be expected due to the non-linear damping. When the frequency of excitation was about 1.6 times higher than the estimated natural frequency of the system in the horizontal mode, the simulation model began to predict response at frequencies 

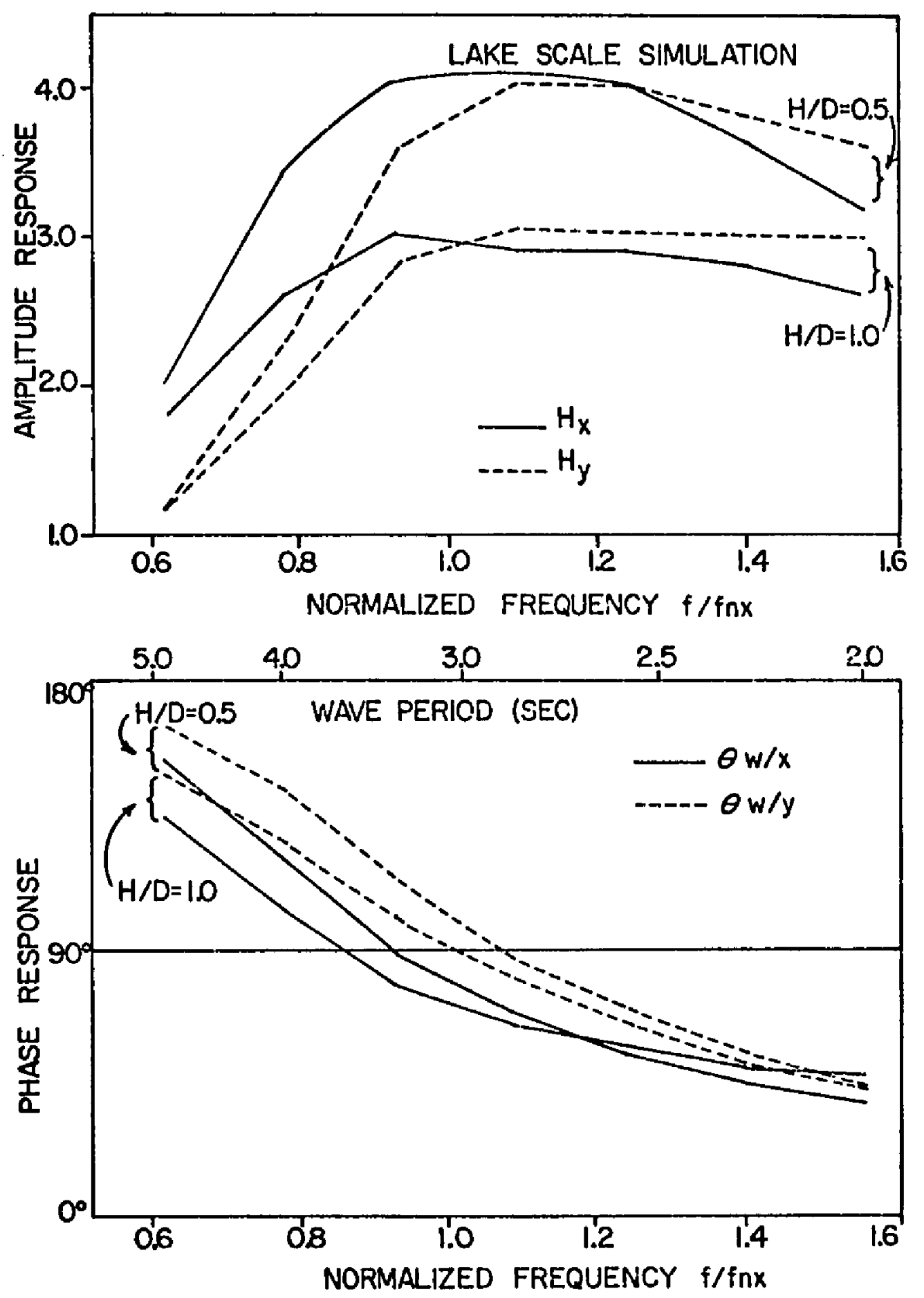

Figure 5. Simulated frequency response for an elastically tethered sphere. 
twice the frequency of excitation. However, these high frequency phenomenon were not of interest because they occurred near the extreme of the anticipated operating range of the system.

Spatial Plot of Buoy Orbit: The orbit of a buoy and the water particle located at the origin of the coordinate system are presented in Figures 6 and 7 . Such plots provided a visual impression of the response of the system in each dimension. The center of the orbit was offset from the center of the coordinate system possibly because when the buoy moved upwards during its orbit it entered a higher wave pressure regime and when it moved downwards it entered a lower wave pressure regime. These plots were also helpful in visualizing the effect of the buoy broaching the surface during its orbit.

Energy Dissipation: As discussed earlier, energy dissipation by the breakwater element in regular waves was considered only a means of comparing the results of different designs and model formations and not an absolute measure of performance. The performance of wire and elastic tethered systems is compared by simulation in Figure 8 . Even though the elements moored by an elastic tether were submerged further beneath the still water level to prevent their broaching the surface during their motion, the design dissipated more energy than the same system tethered by a wire. This was especialiy so at higher frequencies when the wave frequency began to approach the natural frequency of the system in the vertical dimension.

It was revealing to compare the relative contributions of performance in the horizontal and vertical modes as shown in Figure 9 . Seymour (1974) assumed that the dissipation of energy in the vertica] 


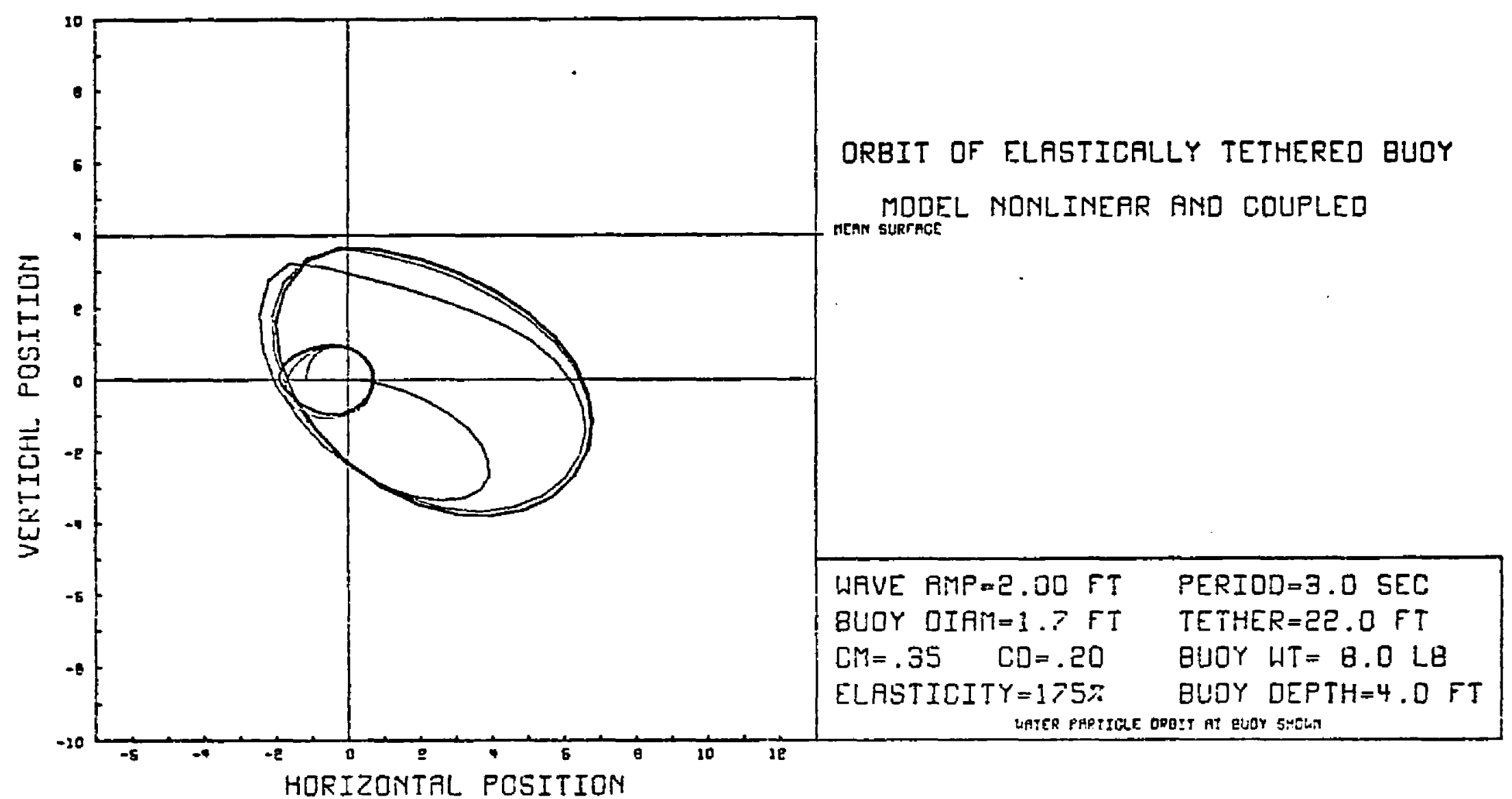

Figure 6. Spatial plot of simulated buoy response 


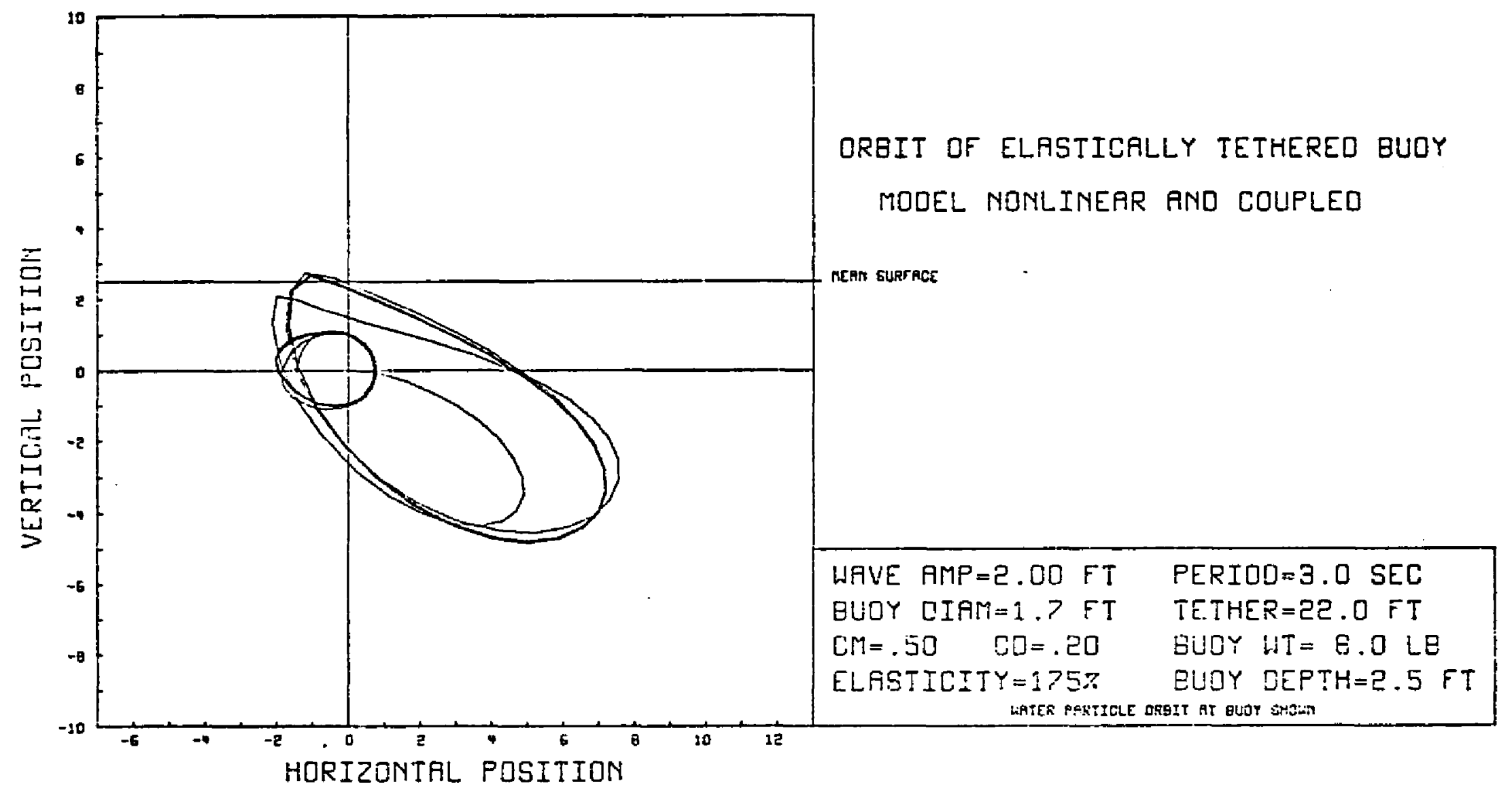

Figure 7. Spatial plot of simulated buoy response. 


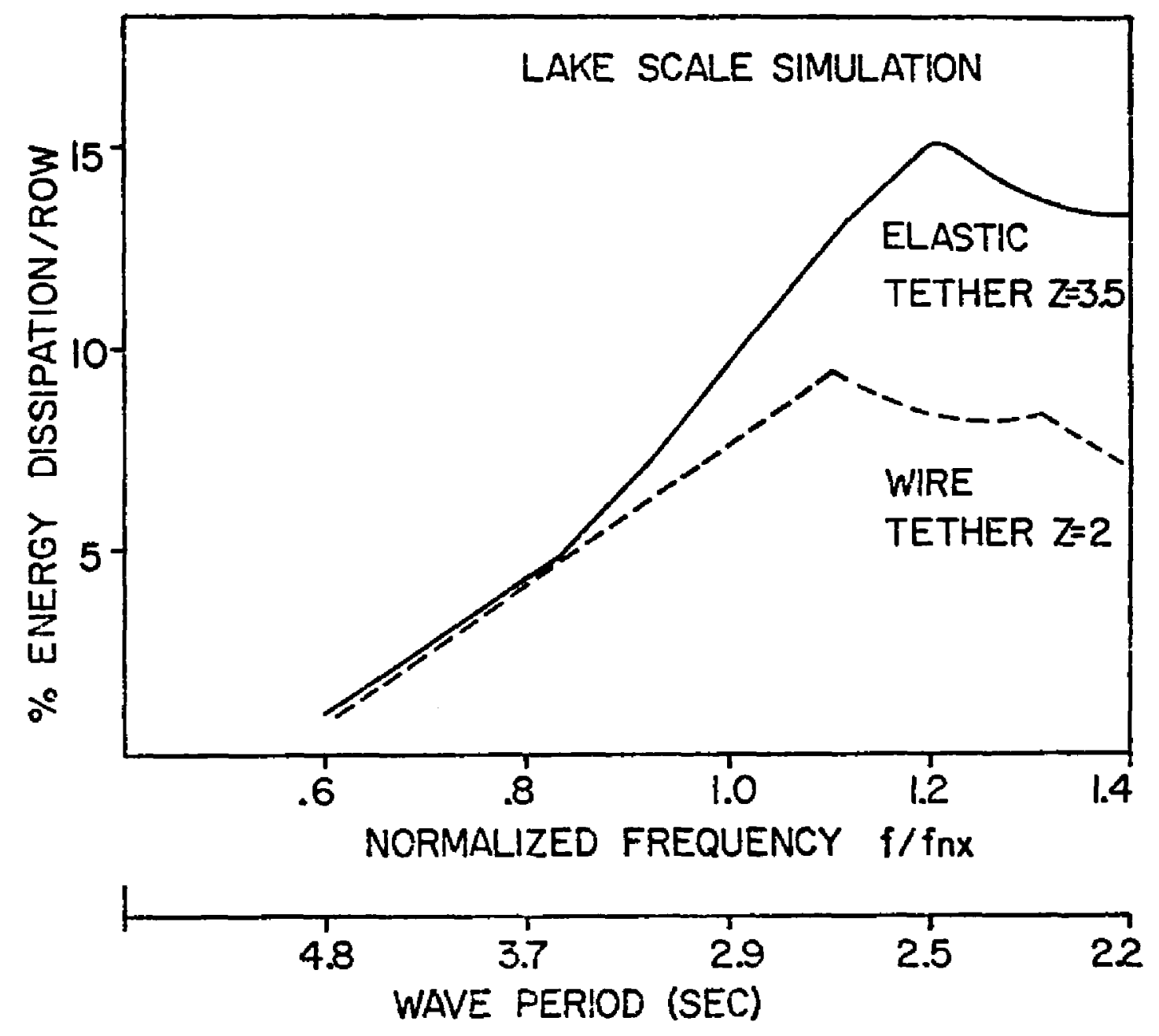

Figure 8. Simulated dissipation by rows of wire and elastically tethered spheres. 


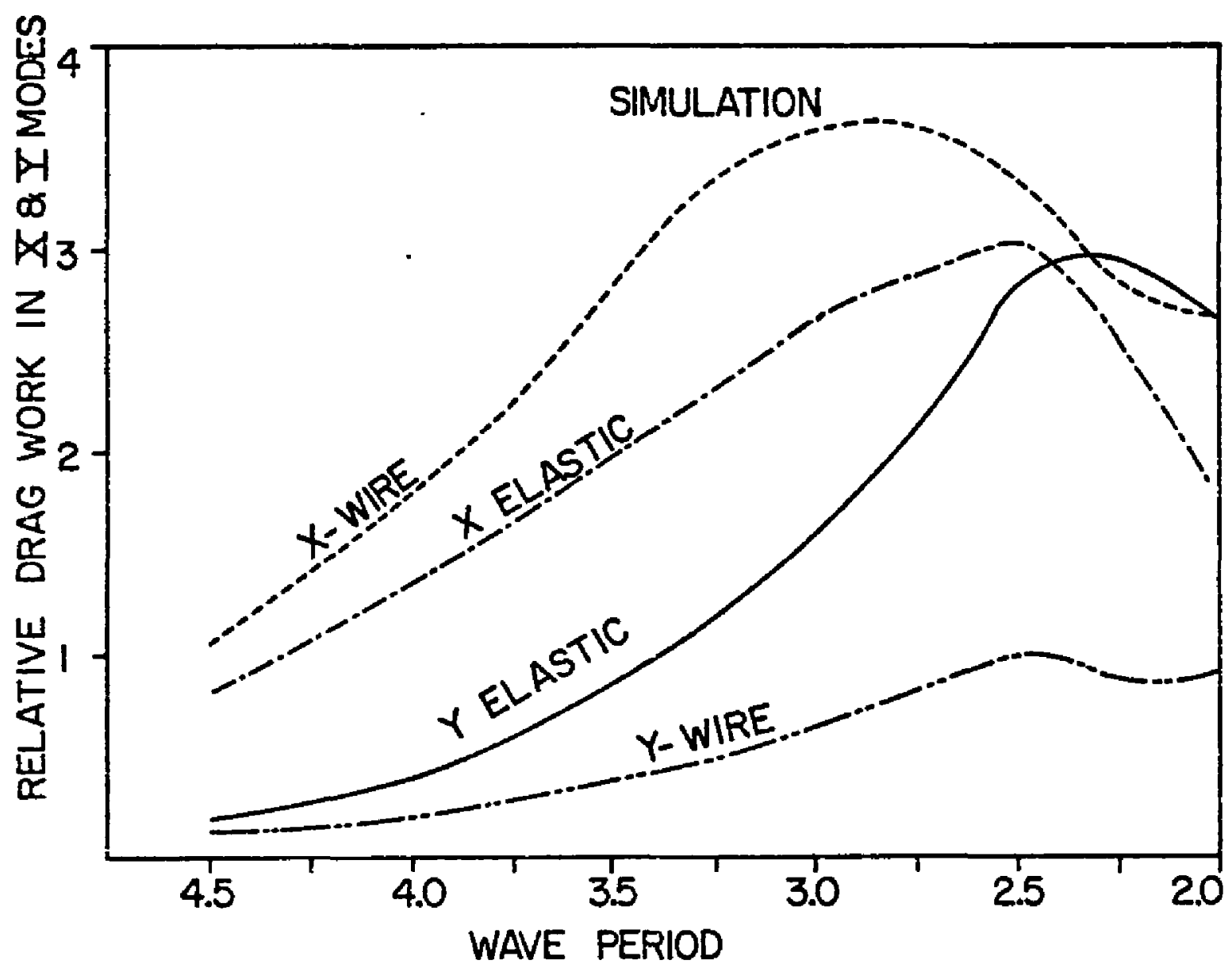

Figure 9. Simulation of relative dissipation in horizontal and vertical dimensions. 
mode was negligible with respect to that in the horizontal mode for a wire tethered system. When a highly compliant tether was used, reduction of dissipation in the horizontal mode was more than compensated for by increased dissipation in the vertical mode.

Figure 10 compares dissipation by buoys of different size, assuming in this case that the same coefficient of drag applies to both buoys. Even when results were adjusted for buoy-packing density, the larger size was still the more effective. However, using the largest float practical will not insure the greatest drag dissipation because at some point, as diameter increases, flow coefficients will change and model assumptions will break down. As previously indicated, neither the buoy diameter to wave length ratio at which model assumptions are no longer valid nor the rate at which the coefficients of drag and mass change with diameter has been well established in the literature.

Drag Force Formulation: Earlier I described one and twodimensional formulations of drag force. Equations of motion identical in al1 respects except for drag formulation were solved over a range of drag and mass coefficients for elastic and wire-tether systems in regular and irregular waves. Drag and mass coefficients did not vary with direction. Maximum static elongation of the elastic tether was 200 percent. In all cases tested, the response and energy dissipation calculated by one model was within ten percent of that calculated by the other and, in most cases, within five percent. The results indicated that decoupling the drag forces would be acceptable for this application. Thus, it is reasonable to refer to a spectrum of horizontal relative velocity and a spectrum of vertical relative velocity. 


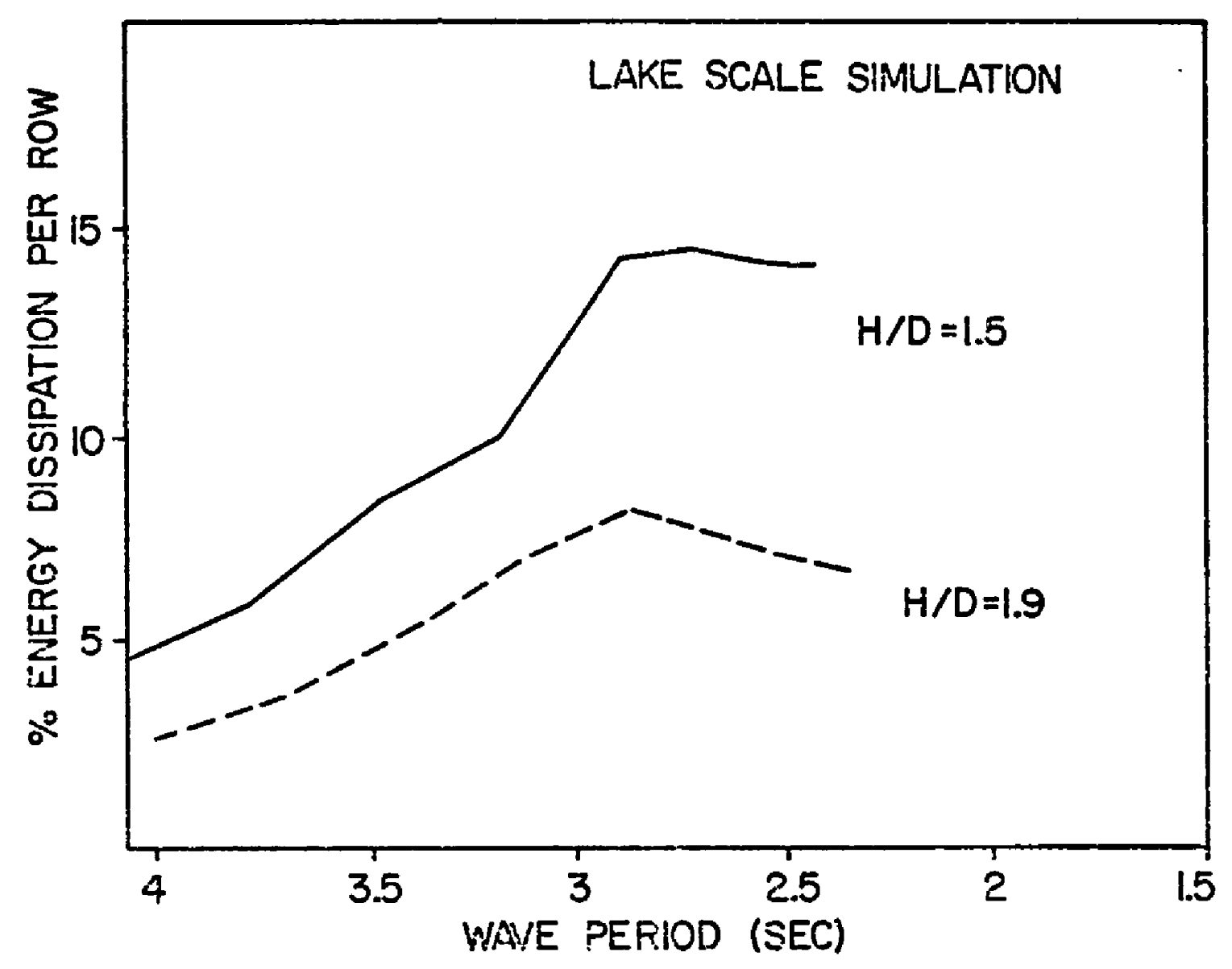

Figure 10. Simulated dissipation for different diameter spieres. 
To relate these to energy dissipation, however, requires a linearized model of drag work.

\section{Linear Analysis}

Linear analysis of tethered float response and breakwater energy dissipation requires simplification of the coupled non-linear equations of motion formulated according to the one-dimensional drag-force model. Recalling the geometry of the tethered element and the equations of motion, the restoring force in each dimension is written:

$$
\begin{gathered}
F_{r x}=T \sin (\theta) \\
F_{r y}=T \cos (\theta)-\left(M_{w}-M_{s}\right) g
\end{gathered}
$$

where

$$
\begin{array}{r}
T=k_{t}\left(R-r_{0}\right)+B \\
\theta=\tan ^{-1}\left[x /\left(y+1_{0}\right)\right]
\end{array}
$$

Tether length is assumed long enough that its angle of inclination is small. Therefore, second and third order terms in Taylor series expansions of cosine and sine terms are neglected.

$$
\begin{aligned}
& \sin \theta \simeq \theta \simeq x /\left(y+1_{0}\right) \\
& \cos \theta \simeq 1.0
\end{aligned}
$$

Equation 38 is simplified by the substitution: $R \simeq y+1_{0}$

Vertical dynamic displacement $y$ is small with respect to the static tether length, so the horizontal restoring force can be modeled as though the tether were a constant length $1_{0}$. 
Recognizing that the tethered buoy is constrained at rest by the relationship

$$
\left(M_{w}-M_{s}\right) g=k_{t}\left(1_{0}-r_{0}\right)+B
$$

the linearized restoring forces are written:

$$
\begin{aligned}
& \left.F_{r x}=\left[M_{w}-M_{s}\right) g / 1_{0}\right] x \\
& F_{r y}=k_{t} y
\end{aligned}
$$

At the end of this chapter in a section titled, "Remarks On Linearization", I will discuss how a uniform linearization method can be applied to each term in the equations of motion to arrive at the same result.

Expressions for water particle excitations were also simplified for the linear model. The water particle acceleration and velocity at the buoy change slightly as the buoy changes its position in the wave. Buoy excursion is assumed small enough with respect to the wave length that the term $k x$ can be neglected. Similarly, vertical excursion is assumed small enough that the average depth of submergence can be used to calculate depth-related wave orbit decay.

It now remains to linearize the drag terms of the equations of motion. Jacobsen (1930) developed an approximate solution to equations of the form

$$
\ddot{M x}+D|\dot{x}| \dot{x}+K x=A \cos (\omega t)
$$

He substituted $\mathrm{DQ} \dot{x}$ for the drag term, where $Q$ is a constant. He then evaluated this constant according to the criterion that the dissipative 
work during one cycle in the linearized model must be equivalent to that in the non-linear model. He found that

$$
Q=\frac{8}{3 \pi} a \omega
$$

where $a$ is the amplitude of excitation. Drag terms due to buoy and water particle velocity can now be separated. This procedure applies equally well to linearizing the drag of the tether. The resulting equations of motion of the elastically tethered sphere are now written:

$$
\begin{aligned}
& M \ddot{x}+\left[D Q+D_{t} Q_{t}\right] \dot{x}+K_{x} x=N \dot{u}+D Q u \\
& M \ddot{y}+D Q \dot{y}+K_{y} y=N \dot{v}+D Q v
\end{aligned}
$$

where

$$
Q=\frac{8}{3 \pi}{ }^{a} r^{\omega}
$$

( $a_{r} w$ is the amplitude of the relative velocity in the $X$ or $Y$ direction)

$$
\begin{array}{ll}
K_{x}=\frac{\left(M_{w}-M_{s}\right) g}{1_{0}} & k_{y}=k_{t} \\
D_{t}=\frac{l}{6} \rho A_{t} C_{D_{t}} & a_{t}=\frac{8}{3 \pi} a_{x} w
\end{array}
$$

As noted, $M, N$, and $D$ each contain drag or mass coefficients appropriate to the particular dimension being modeled.

An estimate of the natural frequency of the system in each dimension is readily calculated from these equations if the mass of water displaced by the buoy is much greater than the mass of the buoy alone. 


$$
\begin{aligned}
& \omega_{n x}^{2}=\frac{g}{C_{M} 1_{0}} \\
& \omega_{n y}^{2}=\frac{k t}{M}
\end{aligned}
$$

$\omega_{n y}$ will always be greater than $\omega_{n x}$ if the coefficients of mass are nearty the same in each dimension and if the tether is a real spring. If the tether were an ideal linear spring, then

$$
\begin{gathered}
\omega_{n y}^{2}=\frac{g}{c_{m}\left(1 c_{0}-r_{0}\right)} \\
{\left[\frac{\omega_{n y}}{\omega_{n_{x}}}\right]^{2}=\frac{1_{0}}{10 r_{0}}}
\end{gathered}
$$

Recalling that $1_{0}$ is the stretched tether and that $r_{0}$ is its unstretched length, the implications of the above relations to the breakwater design are apparent: in order for the natural frequency of oscillation in the vertical dimension to be close to that in the horizontal dimension, the percentage elongation of the tether must be large. This may be difficult to achieve because most elastic tethers stiffen when loaded, thus increasing their modulus.

In order to assess the effect of the simplifying assumptions made in decoupling and linearizing the equations, the results of simulations incorporating such assumptions were compared with previous results. This comparison is presented in Figure 11 . The predictions by a model in which the restoring force terms have been decoupled and the drag term linearized were close to those of the non-linear coupled 


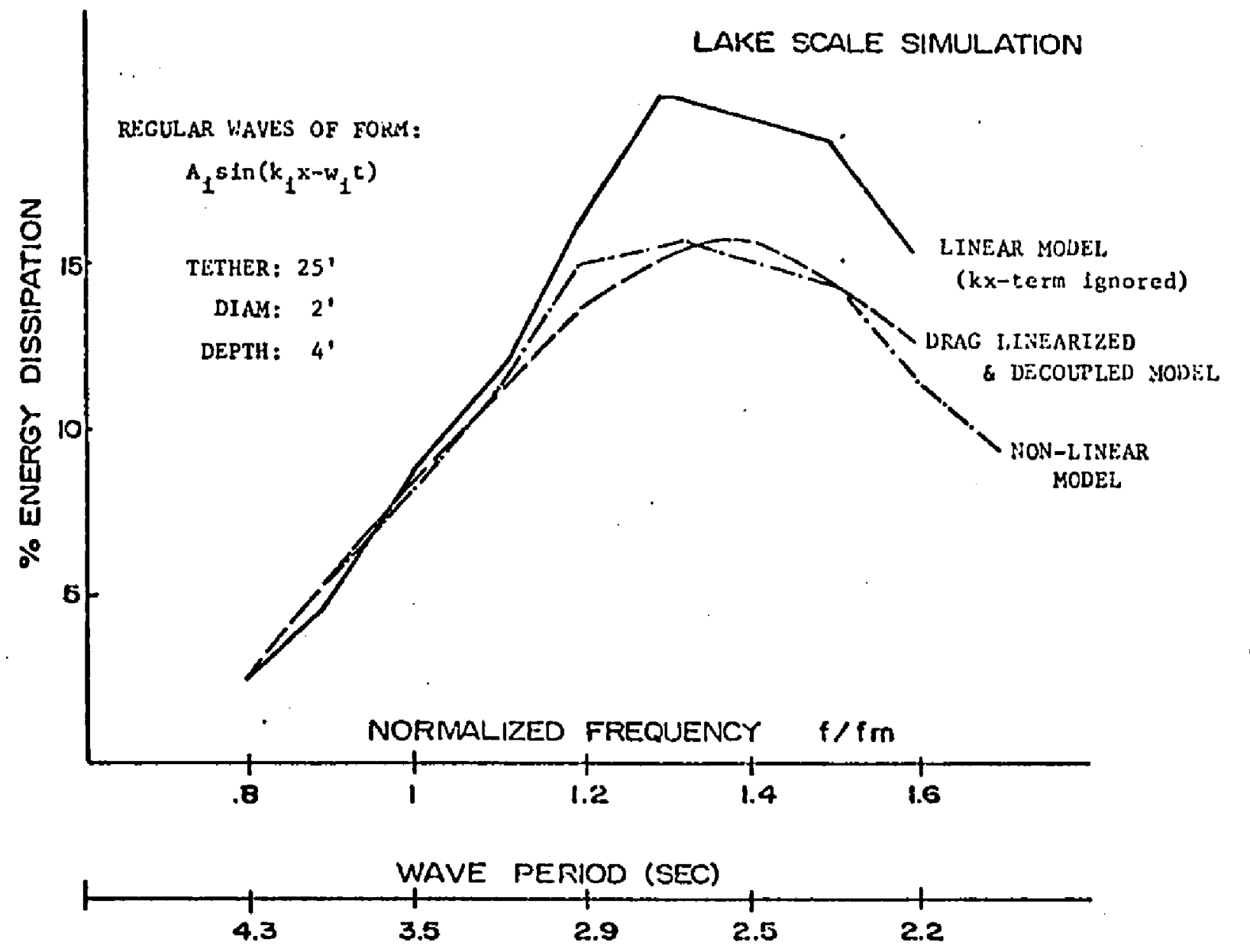

Figure 11. Effect of mathematical simplifications on model results. 
model. However, when the spatial excursions of the buoy in the wave field were ignored, predictions of performance were increased by as much as $30 \%$ at a normalized frequency of 1.3 . Thus, a model on which the $k x$ term has been ignored is expected to overpredict results at relatively high frequencies.

Linear Analysis in Irregular Waves: Irregular waves and linear system response to irregular waves can be modeled by Fourier analysis as a complex periodic process; both are treated as the sum of many harmonic components whose phases are random. It is assumed that the random excitation is stationary and ergodic and its probability density function has a Gaussian distribution. Finally, the mechanical system must be linear. In order to meet the last requirement, Seymour (1974) extended Jacobsen's "work equivalance" technique for irregular flows.

If the relative horizontal flow velocity $u_{r}(t)$ is modeled as a complex periodic process, then each component is of the form

$$
\begin{aligned}
& u_{r}(t)=a \omega \cos (\omega t)+b \omega \sin (\omega t) \\
& u_{r}(t)=A \omega \cos (\omega t-\phi)
\end{aligned}
$$

where

$$
\begin{aligned}
& A^{2}=a^{2}+b^{2} \\
& \phi=\tan ^{-1}(b / a)
\end{aligned}
$$

If the system is 1 inear, then its response (relative velocity) will have a Gaussian distribution if the excitation has a Gaussian distribution. Wind-driven water particle motions will be assumed to have a 
Gaussian distribution.

The horizontal drag power formulated according to the nonlinear drag force model is written:

$$
P_{D}=D\left|u_{r}^{3}\right|
$$

Formulated according to a linear model it is written:

$$
\bar{P}_{D}=D_{0} u_{r}^{2}
$$

where the overhead bar denotes the linearized formulation. The mean squared difference between these two models is written:

$$
\begin{aligned}
\left\langle e^{2}\right\rangle & =\left\langle\left[P_{D}-\bar{P}_{0}\right]^{2}\right\rangle \\
& =D^{2}\left\langle\left[u_{r}{ }^{6}-2 u_{0}\left|u_{r}^{5}\right|+u_{0}{ }^{2} u_{r}^{4}\right]\right\rangle \\
& =D^{2}\left[\left\langle u_{r}{ }^{6}\right\rangle-2 u_{0}\left\langle\left|u_{r}{ }^{5}\right|\right\rangle+u_{0}{ }^{2}\left\langle u_{r}{ }^{4}\right\rangle\right]
\end{aligned}
$$

Because $U_{r}$ is $N\left(\mu, \sigma^{2}\right)$, the average of some function $G\left(U_{r}\right)$ is:

$$
E\left[G\left(U_{r}\right)\right]=\int_{-\infty}^{\infty} G\left(U_{r}\right) f\left(U_{r}\right) d U_{r}
$$

where $E[]$ designates expected value, the probability density function of $U_{r}$ is

$$
f\left(u_{r}\right)=\frac{1}{\sigma^{\sqrt{2 \pi}}} \exp \frac{-\left(u_{r}-\mu\right)^{2}}{2 \sigma^{2}}
$$

For a process with zero mean $(\mu=0)$, 


$$
\begin{aligned}
& \left\langle u_{r}{ }^{6}\right\rangle=15 \sigma^{6} \\
& \left\langle\left|u_{r}{ }^{5}\right|>=160^{5} / \sqrt{2 \pi}\right. \\
& \left\langle u_{r}{ }^{4}\right\rangle=3 \sigma^{4}
\end{aligned}
$$

Substituting these into Equation 65 ,

$$
\left\langle e^{2}>=D^{2}\left[15 \sigma^{6}-32 U_{0} \sigma^{5} / \sqrt{2 \pi}+3 U_{0}^{2} \sigma^{4}\right]\right.
$$

If the mean square difference between the two models is minimized with respect to the 1 inearization constant--a "characteristic" relative velocity--then,

$$
U_{0}=16 \sigma / 3 \sqrt{2 \pi} \simeq 2.1 \sigma
$$

The same procedure applies as well to linearizing the tether drag in irregular waves. Thus, the equations of motion can be linearized for a particular excitation spectrum. * The equations are transcendental; their iterative solution poses no great problem though. The linearized equations of motion are written:

$$
\begin{aligned}
& M \dot{x}+\left[D^{\prime}+D_{t}^{\prime}\right] \dot{x}+K_{x} x=D^{\prime} u+N \dot{u} \\
& M \ddot{y}+D^{\prime} \dot{y}+K_{y} y=D^{\prime} v+N \dot{v}
\end{aligned}
$$

where $D^{\prime}=D_{0}$ or $D V_{0}$, and $D_{t}{ }^{\prime}=D_{t} U_{x}$. Equations 73 and 74 are analogous, only operations on the first will be discussed. $U_{0}$ is the *The results of Seymour (1974) were $U_{0}=\frac{8 \sigma}{3 \sqrt{\pi}}$ which differs from mine by a factor of $\sqrt{2}$; this probably results from the manner in which variance is calculated. 
characteristic relative velocity in the horizontal direction, $V_{0}$ is the characteristic relative velocity in the vertical direction, and $U_{x}$ is the characteristic velocity of the buoy--all linearization constants.

Taking the Laplace transform of each side of the equation and recognizing that position and velocity are related by $s,[S P(s)=$ $U(s)$ where $P(s)$ is buoy position in the frequency domain] the transfer function of the buoy in the horizontal direction is written:

$$
H_{X}(s)=\frac{X(s)}{P(s)}=\frac{D^{\prime} s+N s^{2}}{M s^{2}+D^{\prime \prime} s+K_{X}}
$$

where

$$
D^{\prime \prime}=D^{\prime}+D_{t}^{\prime}
$$

The transfer function of relative velocity is written:

$$
\begin{array}{r}
H_{u_{r}}(s)=\frac{\dot{X}(s)-U(s)}{U(s)} \\
H_{u_{r}}(s)=\frac{(N-M) s^{2}-D_{t}{ }^{\prime} s-K_{x}}{M s^{2}+D^{\prime \prime} s+K_{x}}
\end{array}
$$

Changing from the Laplace transform to a Fourier transform, the predicted spectrum of horizontal relative velocity is

$$
S_{u_{r}}(\omega)=S_{u}(\omega)\left|H_{u_{r}}(\omega)\right|
$$

where

$$
S_{u}(\omega)=\omega^{2} S_{z}(\omega)
$$

$S_{z}(\omega)$ is the spectrum of horizontal water particle displacement from the 
point $(0,0)$ and $S_{u}(w)$ is the spectrum of horizontal water particle velocity. Now,

$$
\sigma_{u_{r}}^{2}=\int_{-\infty}^{\infty} S_{u_{r}}(\omega) d \omega
$$

Equations 78,79 and 81 are solved iteratively using estimates of $\sigma_{u_{r}}$ and $\sigma_{x}$ to initiate the iterative solution.

The spectrum of relative velocity predicted by the model can be used to predict the drag power in one dimension. According to the linear drag model, the average horizontal drag power of the buoy over an averaged frequency band is

$$
\bar{P}_{D_{x}}(\omega)=\left\langle{\overline{F_{D_{x}} U_{r}}}\right\rangle=\frac{1}{2} D^{\prime}\left\langle U_{r}^{2}\right\rangle
$$

Therefore,

$$
\bar{P}_{D_{x}}(\omega)=\frac{T}{2} D^{\prime} S_{u_{r}}(\omega)
$$

Drag dissipation due to the tether is relatively small and, therefore, neglected. Energy dissipation by a row of buoys is modeled over each averaged frequency band as the sum of the dissipation in each dimension.

$$
\ell(\omega)=\frac{\frac{1}{2} \beta\left[D^{\prime} S_{u_{r}}(\omega)+D^{\prime} S_{v_{r}}(\omega)\right]}{P_{w}(\omega)}
$$

From the spectra of buoy relative velocity, the percentage of wave energy dissipated by a row of floats can be computed for each frequency band in the spectrum. Such a model assumes that there is 
no significant transfer of energy between frequency bands and that the process of energy dissipation can be treated as one which can be superimposed. How I used aspects of the linear analysis of the tethered float to design a breakwater for specific wave conditions on Lake Winnepesaukee will be considered in Chapter V, Field Experiments.

As Seymour (1974) showed, the linear model also provides a basis for projecting the average performance of a tethered float system at each frequency band from measured response and excitation spectra. Buoy velocity at any frequency can be written:

$$
\dot{x}(t)=a_{1} \omega \sin \omega t+a_{2} \omega \cos \omega t
$$

Fluid velocity is written:

$$
u(t)=a_{3} \omega s \text { in } \omega t
$$

Rearranging terms of the expression for $\dot{x}(t)-u(t)$ and transforming to the frequency domain will yield:

$$
u_{r}(\omega)=\omega^{2}\left[\left(a_{1}{ }^{2}+a_{2}{ }^{2}\right)+a_{3}{ }^{2}-2 a_{1} a_{3}\right]
$$

The value of the spectrum of relative velocity at each frequency band can be computed from the measured displacement spectra as

$$
S_{u_{r}}(\omega)=\omega^{2}\left[S_{x}(\omega)+S_{z}(\omega)-2 C_{x, z}(\omega)\right]
$$


Remarks on Linearization: Treatment of tethered buoy response and energy dissipation by spectral analysis techniques requires a linear model. The linearization approaches applied earlier in this chapter were not the same for every term in the equations of motion. In addition, they may have suppressed any coupled terms in the linear model. Therefore, I wrote a describing function for each nontinear term. Then I minimized the average of the squared difference between the nonlinear and linear force models with respect to the constant coefficients of the linear terms and solved for those coefficients.

$$
\begin{aligned}
& \left\langle d^{2}\right\rangle=\frac{1}{\tau} \int_{0}^{\tau}\left[F_{n 1}-F_{1}(x, y, t)\right]^{2} d t \\
& \frac{\left.d<d^{2}\right\rangle}{d U_{0}}=0
\end{aligned}
$$

To integrate the expression for restoring force terms, I had to make several simplifying assumptions. That the anqle of inclination was always small was one. The other was that integrals of the form

$$
\int_{0}^{\tau} \frac{f(x, y, t)}{1_{0}+y} d t
$$

[where $x=A_{0} \cos \omega t, y=B_{0}$ sinut and $f(x, y, t)=x^{2}$ or $x y$ or $x y^{2}$ or $x^{2} y$ ] could be approximated by integrals of the form $\int_{0}^{\tau} \frac{f(x, y, t)}{1_{0}} d t$ because $1_{0} \gg y$. The results of this linearization procedure produced the same results presented earlier in this chapter. No coupled terms appeared in the linearized equations of motion. 
To integrate the expression of drag force terms, I had to resort to the uncoupled "one-dimensional" drag-force model because I could not integrate expressions of the form

$$
\int_{0}^{\tau} u_{r}^{2} \sqrt{u_{r^{2}}+v_{r^{2}}} d t
$$

but I could integrate expressions of the form

$$
\int_{0}^{\tau} u_{r}{ }^{2}\left|u_{r}\right| d t
$$

Again, linearization results were the same as those presented earlier in this chapter. Through simulation, I found negligible differences between performance prediction by the one-dimensional and the twodimensional (coupled) drag-force formulations, and thus justified use of the former formulation. In practice, increase in rms drag force due to coupling--if such an effect is present--is accounted for by a larger drag coefficient inferred from measured frequency response in each dimension of motion--horizontal and vertical. 


\section{SCALE MODEL EXPERIMENTS}

Scale model experiments in the ship model tank at the Massachusetts Institute of Technology (MIT), Department of Ocean Engineering, had four objectives: First, to verify the non-linear response of an elastic-tethered float in actual waves; second, to test and compare different breakwater element designs; third, to examine the process of energy dissipation by an array of tethered floats; and fourth, to compare a preliminary mathematical model with measured results. In contrast to many model studies, the scaling of design was not sought in these investigations because the scaling laws which govern model experiments could not be satisfied for all dimensionless parameters of interest.

\section{A. Scaling Laws}

The problem of scaling drag forces is a shortcoming of model testing ocean structures in a wave tank. For the naval architect, it is standard practice to neglect the scaling of viscous forces (Weigel, 1964, p. 491). This is general1y acceptable because, for most structures of interest to him, drag forces play a minor role compared to inertial and gravity forces. However, viscous forces are, by design, the principal wave energy dissipation mechanism in a tethered float breakwater, and thus their scaling cannot be ignored. 


\begin{tabular}{llc} 
Parameter & Model & Prototype \\
amplitude & $\mathrm{a}$ & $\alpha \mathrm{a}$ \\
frequency & $\omega$ & $\omega / \sqrt{\alpha}$ \\
period & $\tau$ & $\tau \sqrt{\alpha}$ \\
wavelength & $\lambda$ & $\alpha \lambda$ \\
wave number & $k$ & $k / \alpha$ \\
buoy submergence & $z$ & $\alpha z$ \\
depth attenuation & $\mathrm{e}^{-k z}$ & $\mathrm{e}^{-k z}$ \\
wave power & $\mathrm{P}_{\mathrm{w}}$ & $\alpha^{2.5} \mathrm{P}$ \\
\hline
\end{tabular}

Wave Forces: Forces on a small fixed object in waves are scaled if values of the dimensionaless parameters $\lambda / H, H / d, C_{M}$ and $C_{D}$ are maintained. For geometricaliy scaled systems, $\lambda / H$ and $H / d$ are maintained. The ratio $\mathrm{H} / \mathrm{d}$ is proportional to period parameter by the constant $\pi$. In the Bass Straits Test, Kim and Hibbard (1974) measured fluid velocity and wave forces on a vertical pile in ocean waves and demonstrated that the drag and mass coefficients could be considered constant at Reynolds numbers above $1.5 \times 10^{5}$. They concluded that there was a minimum size for their model pile structure--and therefore a minimum Reynolds number--at which scalable model tests could be conducted. For smooth cylinders in steady flow, the minimum $N_{R}$ necessary for this "fully turbulent" flow condition is usually noted as $2.5 \times 10^{5}$ : here, the boundary layer becomes turbulent. The points of flow separation shift toward the downstream side of the object, thereby reducing the width of the wake and its associated drag. The lower critical value of $N_{R}$ noted by $\mathrm{Kim}$ and Hibbard $\left(1.5 \times 10^{5}\right.$ instead of $\left.2.5 \times 10^{5}\right)$ may be due 
to the effects of previous flow oscillations past the object or from turbulence generated by neighboring objects.

The commonly noted critical Reynolds number at which steady onedimensional flow past a smooth sphere becomes fully turbulent is also $2.5 \times 10^{5}$. However, for a tethered sphere, which is free to vibrate in the transverse direction, the critical Reynolds number for fully turbulent conditions may be different. In view of such uncertainty, $2.5 \times 10^{5}$ was chosen as the minimum Reynolds number desired for experiments.

As previously discussed (Chapter III, Section 2), the minimum ratio rms $a_{r} / d$ necessary for fully turbulent flows appears to be about 0.80. This does not appear difficult to achieve for a tethered sphere in either the wave tank, lake, or ocean scale system. However, achieving the necessary Reynolds number is a problem on smaller scales. The motion of a tethered sphere was simulated on the scale of the wave tank using a buoy diameter of 0.17 feet, a wave height of 0.25 feet, and a wave period of 1.0 seconds. The Reynolds number based on the rms of peak relative velocity was about $1.5 \times 10^{4}$, more than an order of magnitude smaller than desired. For a lake test installation ten times larger, the estimated Reynolds number would border on the minimum desired value of $2.5 \times 10^{5}$.

Elastic Tether: Scaling the mechanical characteristics of an elastic tether presents a problem for breakwater testing. If model and prototype tethers are to operate in the same region of the stress-strain curve for the same elastic material, then stress in the material must be maintained from model to prototype. However, by geometric scaling, the cross sectional area of the tether increases as $\alpha^{2}$ while the tension 
increases as $\alpha^{3}$. Therefore, to preserve stress, the diameter must be scaled by $\alpha^{3 / 2}$ instead of the desired $\alpha$. The additional damping incurred by the larger diameter tether will slow down the buoy and is undesirable from the standpoint of performance.

Energy Dissipation: If the coefficient of drag is not preserved from model to prototype, energy dissipation cannot necessarily be scaled. But, if $C_{D}$ is preserved between model and prototype, the models will be dynamically similar and dissipation can be scaled. For geometrically scaled systems, the drag power of a buoy scales as $\alpha^{3.5}$. Adjusted for the buoy packing density of a row--which scales as $1 / \alpha-$-the drag power for a row of buoys scales as wave power by $\alpha^{2.5}$.

\section{B. Design of Scale Model Experiments}

Model Size: The practical limit on wave heights in the MIT wave flume was three inches for a regular wave. Styrofoam spheres two inches in diameter were selected because they were readily available, they could be easily tethered, and $H / d$ ratios for the experiment could range from 0.5 to 1.5 . Tether lengths of 20 and 28 inches were tested.

Several elastic bands were evaluated for use through static tests. The material selected was a \#19 Plymouth, Inc. gum rubber band. Its average working moduius was the lowest of three bands tested $(0.33$ $1 \mathrm{bs} / \mathrm{ft}$ ). For comparison, wire tethers 0.0075 inces in diameter were also tested.

Each tether was attached to a thin wire hook whose shank was run through the float and bent over so as not to be pulled back through the styrofoam by tether tension. The other end of each band was stapled 
onto a wooden slat $3 / 4 "$ wide. The use of stapled attachments facilitated the adjustment of individual tethers, necessary once the row was installed because of slight variations between rubber bands. Tethers were stapled on at 4" intervals so that each buoy was separated from its neighbor by one diameter of clear space.

The dozen slats, each holding a dozen buoys, were fitted onto pins at 4 " intervals on the underside edges of a rectangular frame. In turn, the frame was anchored to clump weights. This arrangement allowed the frame to swing slightly on its moorings when the buoys were excited by waves, as might be expected in a practical full scale installation. The elastic-tethered buoys were held 5 " beneath the still water level (SWL) as measured to the buoy midline. This distance was large enough that the buoys did not broach the water surface during the tests.

An array of 6 rows by 24 columns across the tank, was initially tested. In regular waves, too little dissipation was observed for purposes of comparing experiments. Therefore, the wave flume was divided by a thin, sheet-metal wall 4 feet high by 12 feet long, and one half of the array was moved behind the other, increasing the rows from 6 to 12 . The layout of the wave tank test is shown in Figure 12.

Instrumentation: Incident and attenuated waves were measured by platinum wire resistance probes, part of the testing facility's operating equipment. These are calibrated by the facility's standard procedure. The output probe was located 0.5 feet behind the array; several experiments were repeated with the probe 4.0 feet away to test whether results were affected by probe location. They were not. The input probe was located 1.0 feet in front of the array. Viewed from the side, the input wave probe was aligned with a single tethered float identical to 

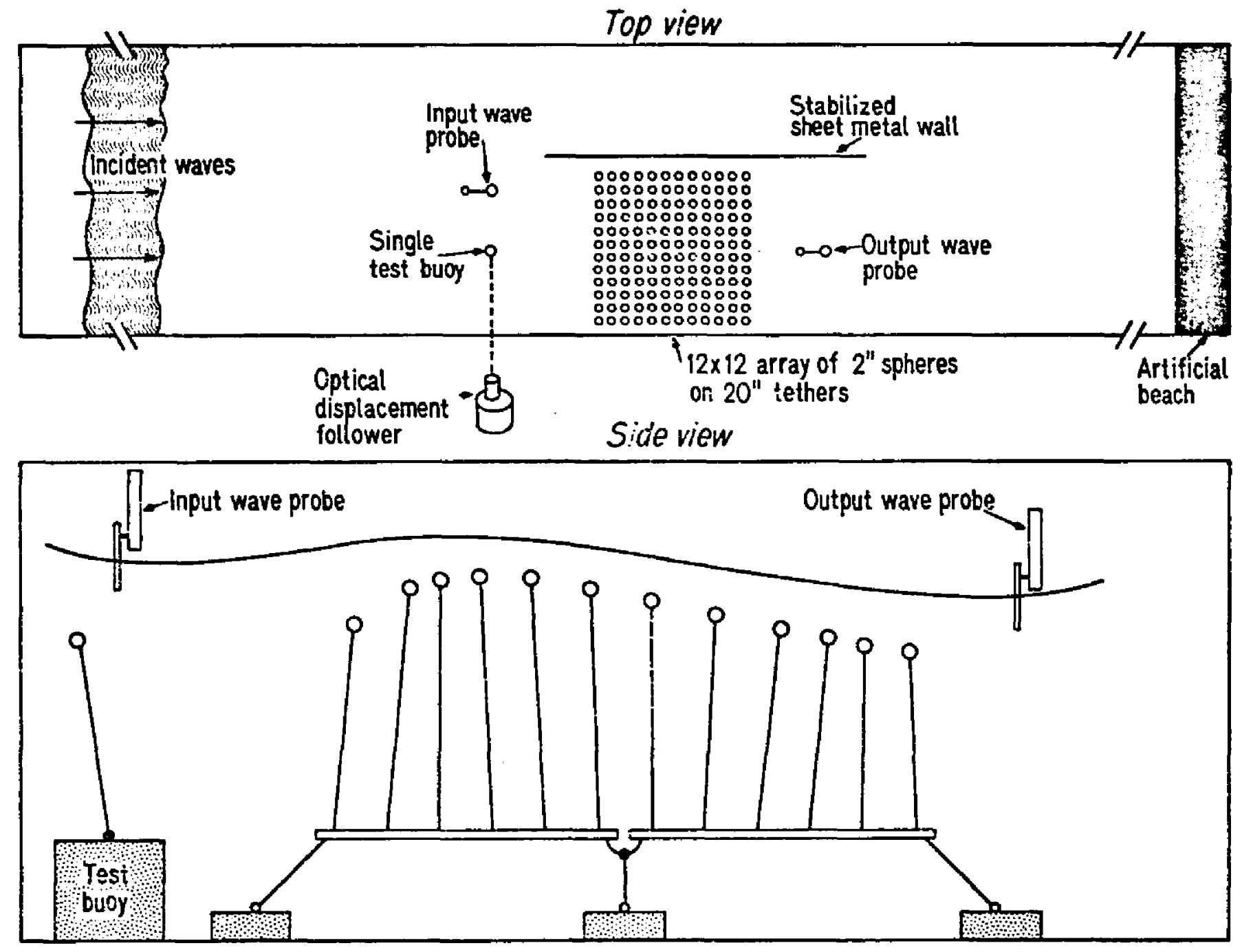

Test array

Figure 12. Layout of wave tank experiments. 
those in the array. The response motion of this single float was tracked by an Optron, Inc., Model 561 Non-Contact Bi-Axia] Displacement Follower. This instrument provided voltage outputs proportional to the horizontal and vertical displacement of the buoy from its at-rest position. The optical discontinuity of the single, white target buoy was enhanced by hanging a dark cotton drop cloth on the far side of the wave flume and illuminating the lower left and bottom edges of the target with an underwater lamp. A calibration jig was arranged whereby the target buoy was temporarily moved out of the field of view and replaced by an identical target mounted on a dark, solid rod which fit into a base drilled at two-inch intervals. Vertical calibration was accomplished by sliding the calibration target a fixed distance between stops on the rod. Horizontal calibration was accomplished by moving the target and rod right and then left from its center position by fixed increments of two inches.

Wave Generation: Waves were generated by a hydraulically actuated, bottom-hinged flap. The frequencies selected ranged from 0.5 to $1.4 \mathrm{hz}$ and wave heights ranged from 1.0 to 3.0 inches for the tests in regular waves. As shown in Table 1, four irregular scale seas were generated. The sea spectra which the wave actuator could be programmed to generate were 1/100-scale fully developed Pierson-Moskowitz seas. Relative to the size of waves anticipated in a lake, they were about $1 / 10$ scale. To simulate fetch-limited seas, the $27-\mathrm{ft}$ fully developed Pierson-Moskowitz sea states was "peaked" by increasing the actuator gain.

Sea-state generating signals were created on analog magnetic tape in series of five 500-foot records. The desired experiment record 
TABLE 1

Scale Sea States for Wave Tank Tests

\begin{tabular}{lccc} 
Sea State & $\mathrm{H}_{\mathrm{S}}$ & $\mathrm{H}_{\mathrm{s}} / \mathrm{d}$ & ${ }^{\tau} \mathrm{pk}$ \\
\hline 18-kt Pierson-Moskowitz & .9 & 0.5 & .7 \\
27-kt Pierson-Moskowitz & 1.8 & 0.9 & 1.0 \\
27-kt Peaked Pierson-Moskowitz & 2.2 & 1.1 & 1.0 \\
37-kt Pierson Moskowitz & 3.1 & 1.6 & 1.4 \\
\hline
\end{tabular}


length in time was determined by the number of sample points required and the highest wave frequency of interest. For a sampling interval of 0.2 seconds and a desired record of 1500 points, a 100-foot magnetic tape record was sufficient. Therefore, it was possible to carry out five sets of five comparative experiments with identical wave-generating series within each set.

Al though a wave-absorbing beach was located at the far end of the wave flume, each 100 -foot record was recorded in 10-foot increments; during the interval between each, the water surface was allowed to reach a calm, thus minimizing reflected wave effects from the tank.

Data Processing: There were no facilities at the University of New Hampshire available to process the irregular input and output wave data and the irregular two-dimensional buoy response data was recorded on 1/2-inch analog tape. Test data were processed at MIT with their digitizing equipment and Fourier transform programs. Input and output wave spectra and the spectra of horizontal and vertical buoy motions were computed for each experiment in irregular waves.

The amplitude response was calculated without correcting for the attenuation with depth of submergence because this could be accounted for theoretically, if desired, by multiplying the amplitude response operator by the function $e^{-k z}(\omega)$. Phase response in irregular waves was not calculated because the MIT spectral analysis programs were not available for modification.

Experiments in regular waves were analyzed by $D$. A. Vidal from simultaneous strip chart recordings for the four parameters of interest. In addition, output from the optical displacement follower was fed into 
an $X-Y$ recorder during the experiment to obtain a visual trace of the buoy motion.

C. Results of Scale Model Experiments

Frequency Response: The horizontal and vertical frequency responses of the scale model element were calculated in regular waves. As shown in Figures 13 and 14 , at frequencies near the system natural frequency, system response is different for differing wave heights. This confirms the conclusion reached through simulation that the system is non-linear. The frequency response of the tethered float was also calculated from the mathematical model using regular-wave excitations and simulation techniques described earlier. Measured values of tether spring constant and buoy mass were substituted into the model. Mass and drag coefficients of 0.50 and 0.42 were assumed, values Harleman and Shapiro had measured (1958).

Energy Dissipation: The total percentage of energy dissipated from the incident regular waves by the 12 row array was calculated as

$$
E_{D}=1-\left[H_{a} / H_{i}\right]^{2}
$$

where the subscripts $a$ and $i$ denote attenuated and incident, respectively. $H$ is wave height. For irregular waves, the significant wave height-which is proportional to the square root of the variance of the spectrum-was used in this calculation.

Reduction in energy over each averaged frequency band in the spectrum was calculated as

$$
E_{D}(\omega)=1-S_{n a}(\omega) / S_{n i}(\omega)
$$



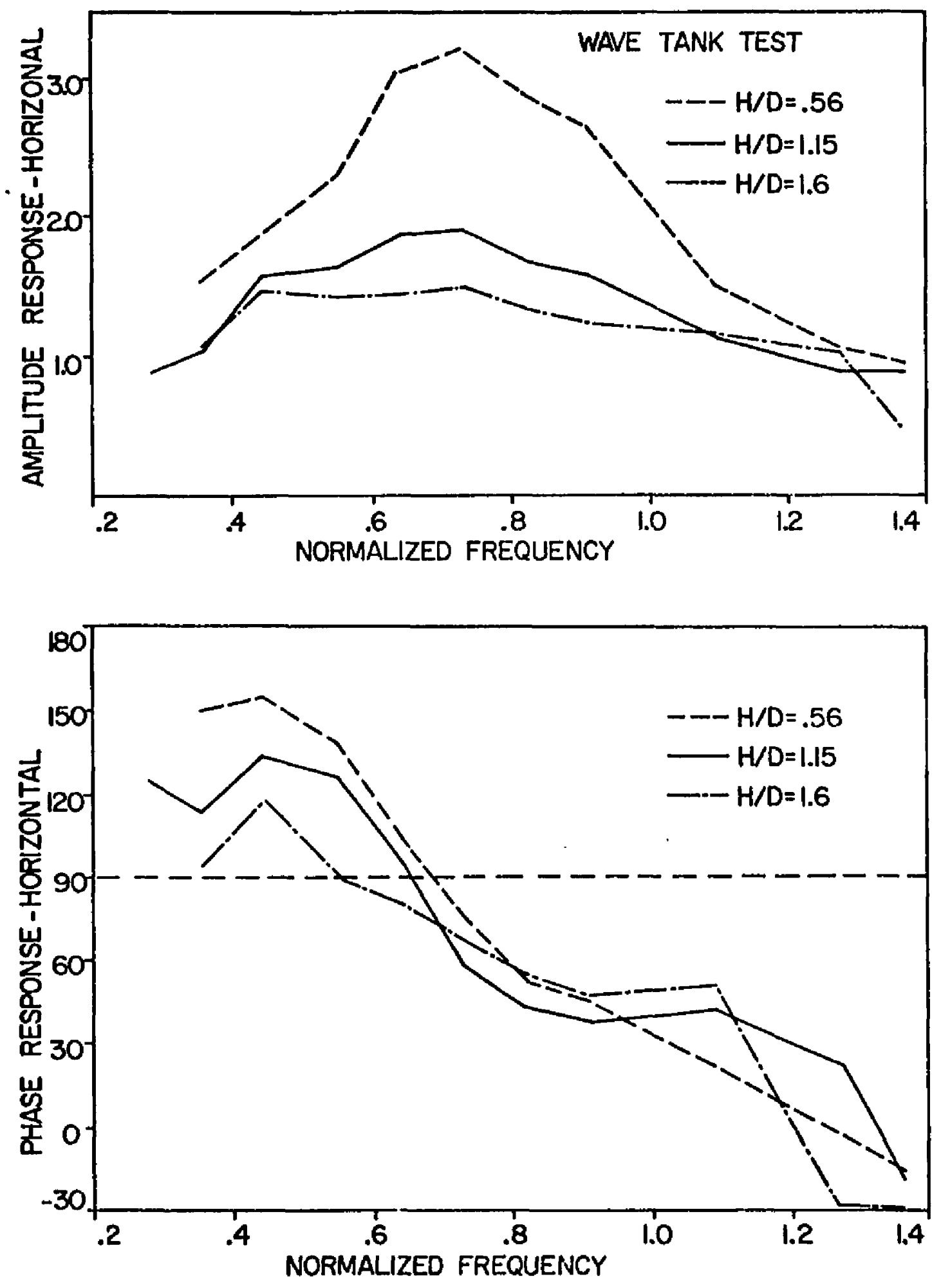

Figure 13. Horizontal frequency response measured in a wave tank for an elastically tethered sphere. 

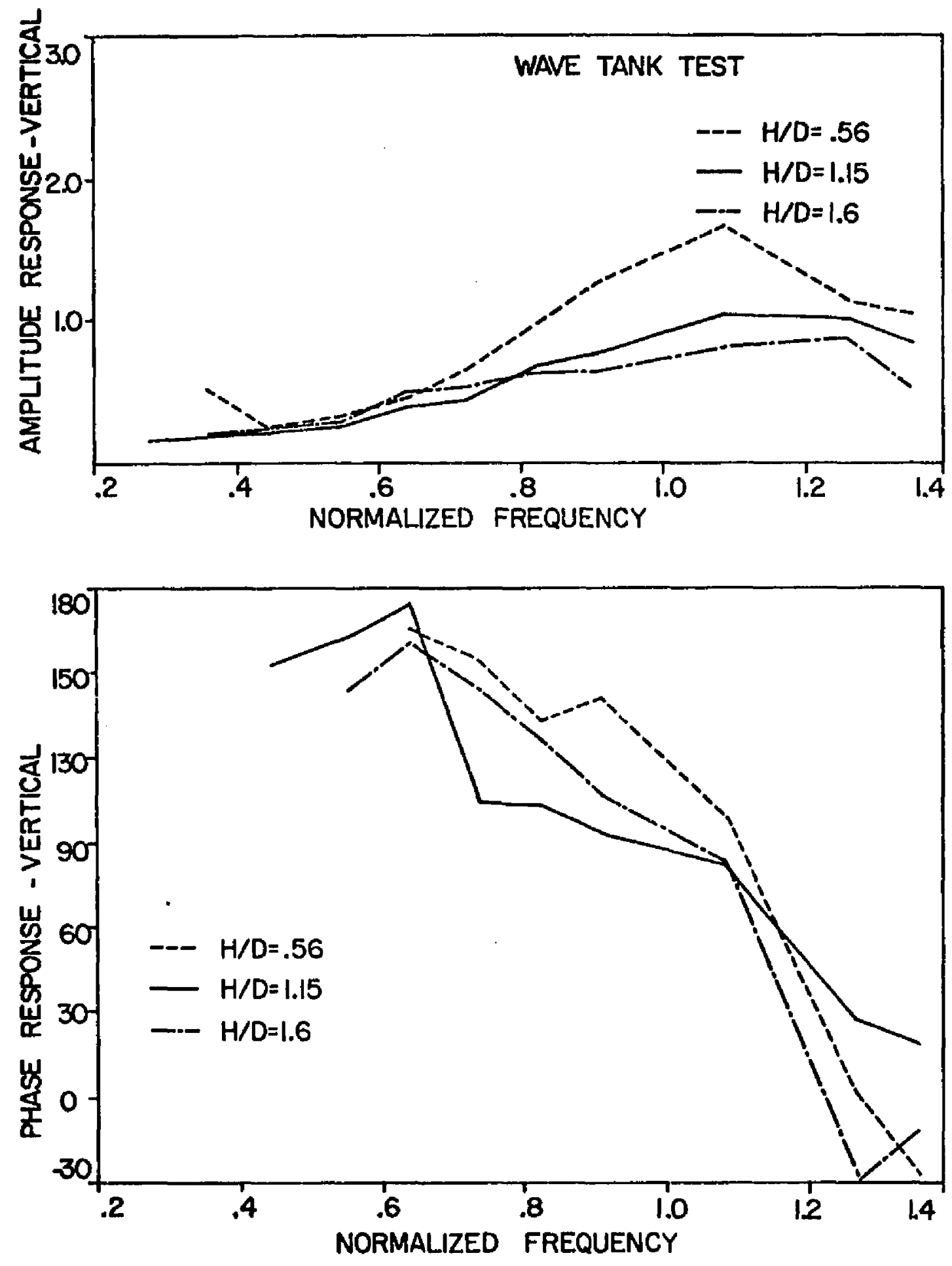

Figure 14. Vertical frequency response measured in a wave tanic for an elastically teti:ered sphere. 
where $S_{\eta a}(\omega)$ and $S_{\eta i}(\omega)$ are the values of the attenuated and incident wave spectra over the frequency bands of interest. Using the simplifying assumption that the dissipation by each row of floats is constant for a particular band, the percentage of energy dissipated by each row was estimated as

$$
\ell(\omega)=1-E_{T}(\omega)^{1 / 12}
$$

where $E_{T}(w)$ is the energy transmitted by the 12-row array. The energy dissipation of buoys was plotted as a function of frequency for the physical and mathematical models. Wave energy dissipation was frequency dependent, a result which conflicts with the findings of Seymour and Isaacs. They noted that dissipation was approximately constant across a broad range of frequencies. The conclusion that energy is dissipated differentially across the frequency bands was not regarded as being a firm one at this point because it required verification in the field. In addition, it required the assumption that energy dissipation in one frequency band is independent of that in another.

The energy dissipation by a row of scale model buoys in regular and irregular waves, and the dissipation calculated in the simulation model are compared in Figure 15. A reasonable correspondence in these curves is noted.

Because of the non-linearity in response, it was expected that the performance of the system would decrease with increasing $H / d$ ratio. This was indeed the case as summarized in Table 2, which presents results of experiments using an array of elastic-tethered elements. 


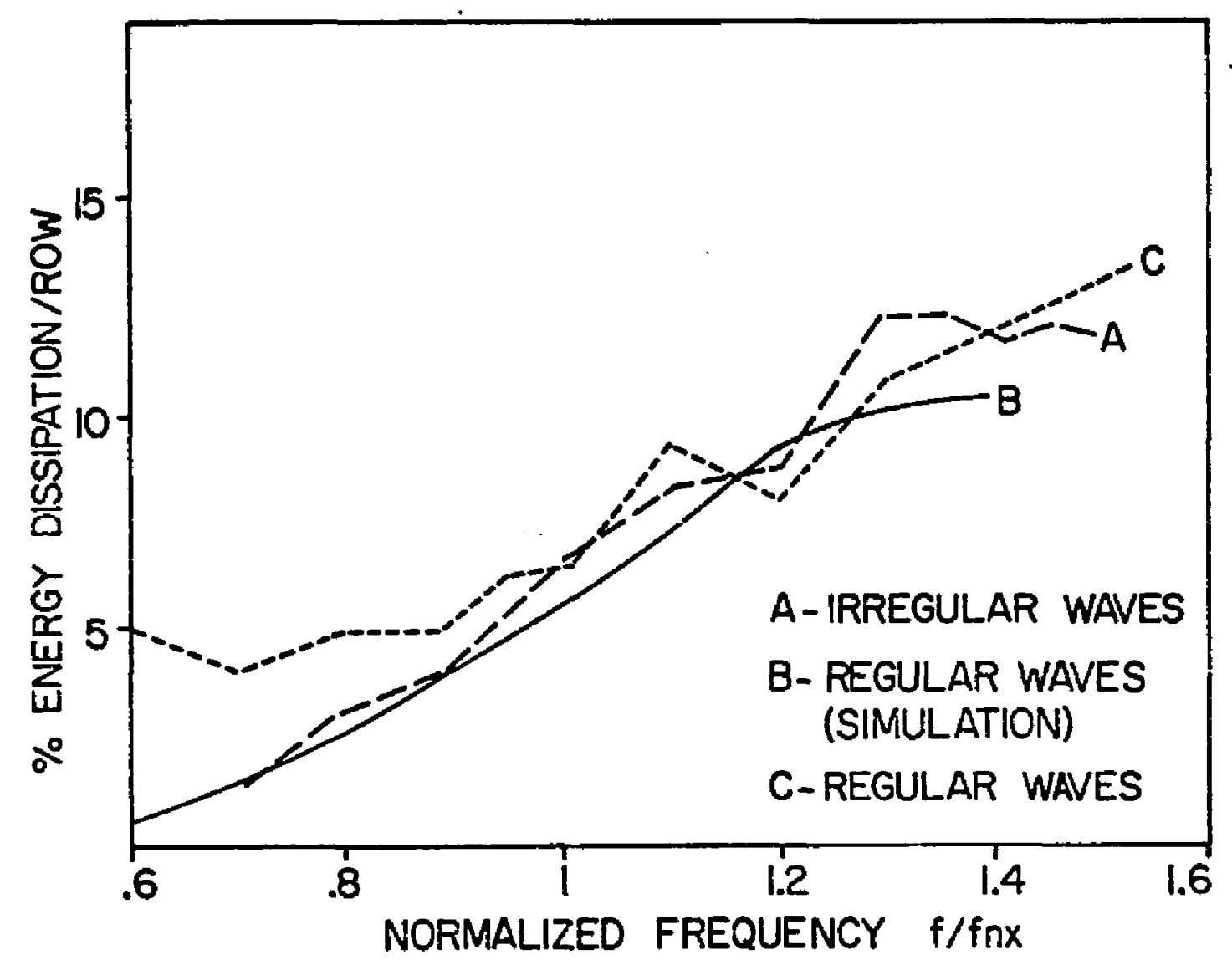

Figure 15. Dissipation calculated from sifiulation and wave tank experiments for elastically tethered spheres 
TABLE 2

\section{Comparison of $\mathrm{H} / \mathrm{d}$ Ratio and Performance}

Sea

Percent

State

$\mathrm{H}_{\mathrm{s}} / \mathrm{d}$

Energy Reduction

$18-k t$

0.7

60

$27-k t$

0.9

55

27-kt peaked

1.7

50

37-kt

1.6

40 
Wire vs. Elastic Tether: The elastic tethers were replaced with thin wire tethers and array performance compared with that measured previously. Each wire tethered sphere was submerged 3 inches beneath the still water level as measured to the mid-line of the buoy. Each elastictethered sphere was submerged 5 inches. Figure 16 shows the energy dissipation for two series of tests in irregular waves: in both, the performance of the elastic-tethered system was about 10\% greater for the entire array.

Diffraction Effects: If one side of the test array were open rather than bordered by a sheet-metal wall, then unattenuated waves to the side of the array might diffract into the region of attenuated waves behind and within the array. To test this diffraction hypothesis, I measured the energy dissipation by the array first with the barrier bordering one side and then without the barrier. The other side of the array was bordered by the glass wall of the wave tank. Dissipation in these tests was $57 \%$ and $55 \%$ respectively, an inconsequential difference. No general conclusions were drawn from these results, but it was hypothesized that diffraction effects were countered by reflection and interference along the side of the array.

Depth of Submergence: An obvious design problem is the depth of buoy submergence for maximum performance. When an object in potential flow approaches within a diameter of the free surface, the coefficient of mass can decrease (Nath and Yamamoto, 1973). If the element broaches the surface, there is an obvious loss of submerged buoyancy. Surface effects should be considered as well. Exactly how these changes affect the performance of tethered buoys in turbulent flow is not clear, but 

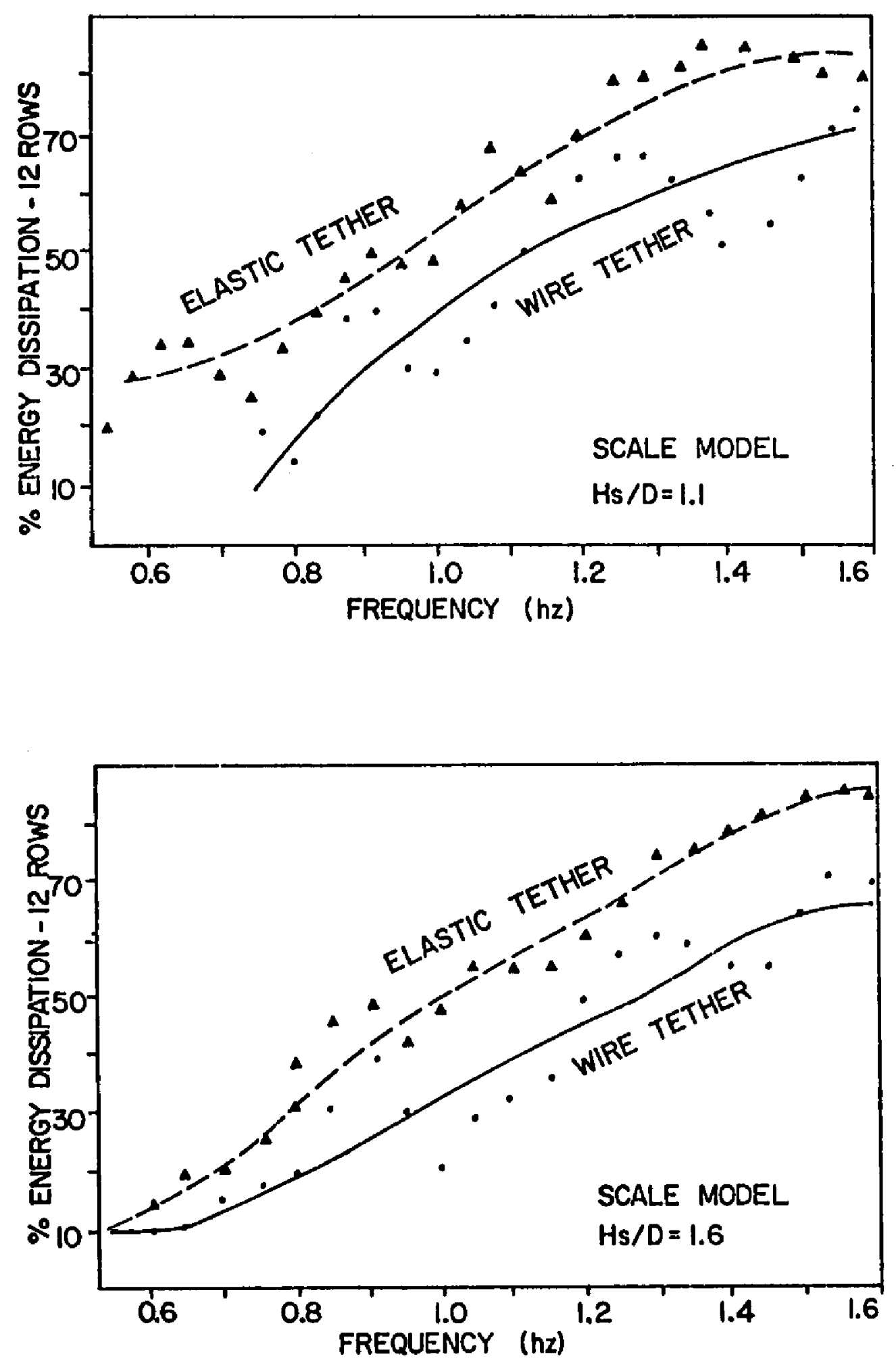

Figure 16. Dissipation by small scale arrays of wire and elastically tethered spheres. 
if it is assumed that drag is the principle mechanism of wave attenuation, then it seems reasonable to assume that complete submergence during the entire wave cycle is desirable. The problem might be investigated in large-scale model testing.

Scale model tests in waves 2.1 inches in significant height were carried out for buoys at 5 inches and 0.8 inches below SWL as measured to the buoy mid-Tine (i.e., the top of the buoy broke the SWL slightly in the latter case). There was no significant difference between the performance of the arrays. However, it is not clear whether the surface-penetrating buoys attenuated the waves in the same manner as the submerged buoys. It is conceivable that a Tower drag dissipation by the surface-penetrating buoys could have been compensated by increased reflection and scattering of the incident waves.

Conclusions: Results of the wave tank tests led to the following conclusions:

1. Dynamic response of the tethered float is measurably nonlinear.

2. The potential for higher performance of an elastically tethered system can be demonstrated.

3. The process of energy dissipation is frequency dependent; decompounding energy dissipation by assuming a constant percentage energy decrease per row over the selected frequency band is a reasonable first approximation of the process. 
4. The buoy response and breakwater energy dissipation can be modeled mathematically using coupled non-linear differential equations.

5. The absolute performance of the physical scale model cannot necessarily be translated to a larger scale. Elastic properties of the tether cannot be scaled if the diameter of the tether is to be scaled geometrically. Therefore, the effect of tether drag and the availability of strong, high compliant elastic materials should be investigated for use in larger scale installations. 


\section{FIELD EXPERIMENTS}

The field experiments had three principal objectives. The first was to test the concept of the tethered float breakwater under actual operating conditions and on a sufficiently large scale that results could be related to ocean installations. The second was to field test the use of elastic tethers for improving breakwater performance and survivability. The third was to verify, or modify as required, a mathematical model of both buoy response and breakwater energy dissipation.

A. Design of the Field Experiments

1. Selection of Test Site

Selection of the test site was based upon three principal criteria. In order to meet the first objective above, Reynolds numbers associated with the experiment were to be at least $2.5 \times 10^{5}$. (Reasons for this were discussed in the preceeding chapter.) Second, the ratio rms $a_{r} / d$, a period parameter, should exceed 0.80. Although Seymour (1974) based this criterion on scale model experiments in which he oscillated a sphere back and forth in initially still water, it is the only experimentally established guideline available relating the concept of a period parameter to spheres in oscillatory flow. Third, in order to minimize costs, the scale of the experiment was to be as small as acceptable.

Exposure over open water to the most frequent storm winds and accessibility to servicing the instrumentation also had to be considered 
in choosing the experiment site. Accessibility was important because wave staffs were still under development and would require frequent field calibration. A bottom-mounted anchoring system was desired so that analysis of the breakwater would not have to account for a moving frame of reference.

The Diamond Island Ocean Engineering Field Station on Lake Winnipesaukee, a facility maintained by the University of New Hampshire Engineering Design and Analysis Laboratory, provided an operating base in a large nearby body of water. The principal resident on the island, F. C. Spooner, reported predominant NW storm-winds during the fall which commoniy generated 3.5 foot waves. He also reported that larger waves-up to 4.5 feet--could be expected from the NW, but that these might occur only once during a typical fall season. Figure 17 is a map of the lake.

The New England Weather Service, Inc. of Center Harbor, New Hampshire, provided a fall wind forecast for the lake region. Although statistical meterological observations for the lake were not available, they reported that the predominant storm-wind pattern occurred in the aftermath of low pressure systems over New England when dry polar air moved into the region from a high pressure system over Canada and the Great Lakes. Under these conditions, NW winds, generally ranging from 15 to 30 knots, could be expected; sustained winds of 30 knots had occurred only once in the past three fall seasons. Therefore, a maximum sustained wind speed of 25 knots was assumed for the purposes of forecasting the wave climate. 


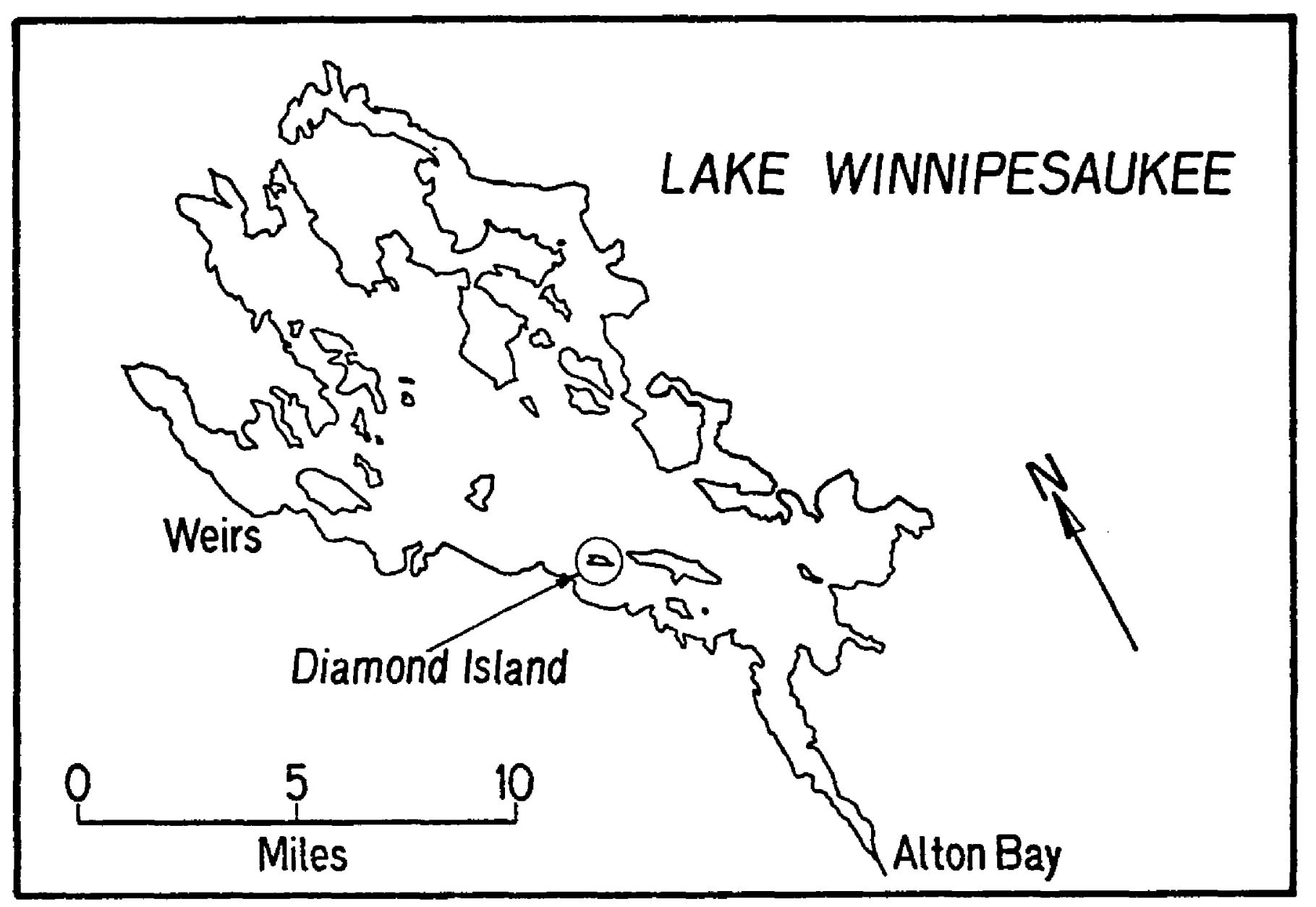

Figure 17. Map of Lake Hinnipesaukee, ilew Hampshire. 
The NW side of Diamond Island was exposed to a fetch of 4.5 nautical miles. Because this fetch is restricted in width, an effective fetch of $3.0 \mathrm{nmi}$ was estimated according to a procedure described by Wiegel (1964, p. 230). Referring to the wave forecasting curves of C. L. Bretschneider (1958), I estimated that waves 2.5 to 3.0 feet in significant height $\left(H_{s}\right)$ and 3.0 seconds in peak period $T_{p k}$ could be expected.

It now remained to estimate the Reynolds numbers and period parameters which might be expected for a range of design conditions. Lake water temperature in the late fall was estimated at $45^{\circ} \mathrm{F}$ so kinematic viscosity was assumed to be $1.5 \times 10^{5}$. For the parameter estimates, a range of buoy diameters from 1.0 to 2.0 feet was considered because preliminary modeling showed that buoys of this size would be effective as well as practical. The velocity used to estimate Reynolds number was the rms of the horizontal relative velocity of the buoy. The wave excitations were those of the forecast significant wave at the forecast peak frequency. From simulation, it appeared that the Reynolds number requirements would be met for buoys 1.5 feet or greater in diameter and that the period parameter requirements would be met for buoys two feet or less in diameter.

\section{Design of Breakwater Elements}

Buoy Size and Composition: With the range of buoy diameters narrowed, two criteria remained for choosing buoy size: diameter to wave length ratio below $1 / 10$ and maximum cost effectiveness. 
The highest frequency waves of interest anticipated at the site were on the order of $0.5 \mathrm{hz}$; by linear wave theory, their length would be on the order of 20 feet. Therefore, in order to be within the $d / \lambda^{\circ}$ criterion, 2.0 feet was chosen as the maximum acceptable buoy diameter. This "maximum acceptable size" does not imply that a larger buoy would not be more effective. As buoy diameter increases, the object will begin to act as a wall, reflecting and scattering a substantial portion of the wave energy. However, large buoys create large mooring and anchoring loads. This would be inconsistent with one of the design virtues of the tethered float breakwater concept--namely, small and light-weight components.

It remained to consider the cost effectiveness of different buoy sizes. The performance of commercially-available buoys 1.7 and 2.0 feet in diameter was simulated in regular waves over a range of wave periods and tether lengths. Averaged over wave frequencies from 0.33 to $0.40 \mathrm{hz}$, the wave energy dissipated per flow of floats \& was on the order of $10 \%$ for 2-foot diameter buoys versus $7 \%$ for 1.7 -foot diameter buoys. Cost effectiveness $\xi$ was calculated as

$$
\xi=\frac{1}{n_{r} \$ B}
$$

when $n_{r}$ was the number of rows required to achieve a total dissipation of $50 \%, \$$ was the unit cost of a tethered buoy, $\beta$ was the spacing $\frac{1}{2 d}$, and $n_{r}=\log (.5) / \log (1-l)$. The cost ratio for buoys 1.7 and 2.0 feet in diameter was on the order of $2 / 3$, respectively. The cost effectiveness of these two buoys compared as 


$$
\frac{\xi_{2.0}}{\xi_{1.7}} \simeq 1.5
$$

indicating that the two-foot diameter buoy would be the more cost effective.

Four types of buoys were considered for use as tethered elements: styrofoam, spun fiberglass, synthetic foam and inflatable fishing floats. Inflatable Norwegian fishing floats were chosen; these were manufactured with a molded eye which created a slightly tear-dropped shape. The exact impact of this shape on performance was not clear. However, displacement and area of the float could be estimated for the model, so this non-spherical shape was accepted. The $45^{\circ} \mathrm{F}$ change anticipated in the water temperature during the possible course of the experiment would change the displacement by about $7 \%$; this too could be accounted for in modeling, so it was accepted. The inflatability of the buoys was advantageous from the standpoint of ease of installation. Finally, these buoys were available at attractive bulk discounts. The model selected was \#6605 SCANFLOAT, 75 inches in circumference and rated at 240 lbs net buoyancy.

Design of the Array: The criterion for choosing the array length was that the unit be long enough that diffraction effects would be negligibly small behind the array where attenuated waves would be measured. In the absence of any field data on which to judge the minimum array length required, I estimated diffraction effects from the results of my own wave tank investigations and from diffraction theory for solid breakwaters. 
Diffraction of regular waves around a thin, vertical, rigid, impermeable, semi-infinite breakwater is analogous to diffraction of light polarized in a plane parallel to the edge of a semi-infinite screen (Weigel, 1964, p. 180). The amplitude of regular waves behind such a breakwater was described graphically by Penny and Pierce (1952). The diffraction coefficient $K^{\prime}$, defined as the ratio of the wave height in the area affected by diffraction to the incident wave height, was plotted according to the ratio of the length of the wave to the distance from the end of the breakwater.

I first assumed that the array was impermeable, and then postulated that diffraction would occur after the last row, though not as intensely as in the case of an infinitely thin barrier because some wave energy should be reflected from the side edge. Therefore, estimates of diffraction by the thin-wall model would be conservative. For this case, the coefficient of diffraction a distance $1 / \beta$ behind the structure and a wave length in along the edge was 0.25 . Diffracted waves coming around behind the breakwater from each side interfere; again assuming the worst case, $K^{\prime}$ would double.

Next, I dropped the assumption of frontwise impermeability and assumed that the crestwise propagation of wave energy (diffraction) depended upon the difference in height between the unaffected waves to the side of the breakwater and the attenuated waves behind the breakwater. Then I hypothesized that the diffraction coefficient would be reduced according to the complement of the percentage wave height reduction $P\left(\right.$ i.e., $1-P^{1 / 2}$ ). For the case of $P=50 \%-$ half of the wave energy dissipated by the array--the diffraction coefficient would be 
$.3 \times 2 K^{\prime}$ or 0.15 . Diffracted energy at the midpoint behind an array two wave lengths long would be on the order of $5 \%$ of the transmitted wave energy. If I had hypothesized instead that the crestwide propagation depended upon the difference in energy rather than wave height between the two regions, then the diffracted energy would have been on the order of $12 \%$ of the transmitted energy. In view of this analysis, the desired minimum array length was two wavelengths.

If incident waves strike the array at zero angle of incidence, the assumption that there is negligible transmission through the sides of the array may be acceptable. Diffraction effects were not observed in the wave tank experiments, perhaps because the small amount of diffraction occurring at the edges of each row was canceled by reflection from the oscillating buoys.

As planning for the design and construction of the frame proceeded, it became apparent that four frame sections were all that could be afforded within the project budget and within the contracts which were negotiated with the marine construction and welding firms. Therefore, a compromise was made on the size of the frame; its length was limited to 40 feet facing the direction of anticipated wave fronts.

At the Offshore Technology Conference (OTC) in Houston, Texas, in May 1976, two investigators working on different breakwater projects each reported a lack of visible diffraction effects behind their respective test installations. H. M. Noble (1976) described the "Wave Maze" scrap-tire type of breakwater as it performed in wind-driven seas. One end of the barrier bordered on the shore, the other end was open; the width (beam) of the wave maze breakwater was about $1 / 2$ wavelength. 
A. J. Harris, who had delivered a paper entitled "The Harris Floating Breakwater" at the Floating Breakwater Conference in 1974, made a brief unscheduled presentation on his breakwater at the OTC; he too noted that wave diffraction behind the barrier was not evident. In view of these experimental observations and the analytical considerations discussed above, diffracted waves were considered negligible at the location of the wave staff directly behind the experimental array in my experiment.

The number of rows of floats was chosen to provide $50 \%$ dissipation of wave energy based on the average simulated performance of the system. Floats were spaced 2.25 diameters apart on centers so that they would not significantly interfere with one another. (This criteria was based on observation during the scale model tests.) The implicit assumption in this case was that the distortion of the pressure field by the object (a distortion which had already been assumed small by the Froude-Krylov hypothesis) would not affect the wave pressure field around its neighbor.

Design of Elastic Tethers: There were three principal criteria for designing the elastic tether--performance, mechanical integrity, and cost. Tether length was selected so that the resonant frequency of the system in the horizontal mode of response matched the predominant wave frequency as closely as possible. Similarly, the elastic modulus of the tether was selected so that the resonant frequency in the vertical mode of response matched the predominant wave frequency as nearly as possible. The minimum band diameter was sought in order to keep the drag of the tether as small as possible.

The optimum tether length for dissipation in the horizontal mode was chosen by maximizing the squared magnitude of the linearized 
transfer function of relative velocity in the horizontal dimension. The drag of the tether was ignored.

$$
\left|H_{u_{r}}\right|^{2}=\frac{\left[(N-M) \omega^{2}-K\right]^{2}}{\left[K-M \omega^{2}\right]^{2}-[D Q \omega]^{2}}
$$

Differentiating with respect to $K$ and setting the result to zero yielded the solution

$$
K=\frac{[D Q]^{2}+M N \omega^{2}}{N}
$$

An estimate of the relative velocity was calculated from simulation in regular waves and then used to solve Equation 96 at the forecast predominant wave frequency of $0.33 \mathrm{hz}$. The optimum tether length was calculated to be 15.0 feet for dissipation in the horizontal direction.

Assuming that flow coefficients were unchanged from one dimension to another, the application of the above approach to maximizing the magnitude of the vertical relative velocity led to the conclusion that, for the resonant frequency in the vertical mode to match that in the horizontal, the net elongation of the tether must equal the total band length desired in the horizontal mode. Obviously, both conditions could not be satisfied simultaneously. Therefore, the band configuration with the lowest working modulus was chosen.

Materials Consideration: The use of calibrated elastic filaments to moor a wave measuring buoy was demonstrated by Winn, Savage and Hickman (1975). As shown in Figure 18, six rubber bands, each initially 60' long and $1 "$ diameter, held 490 lbs at $125 \%$ elongation. Beyond $150 \%$ static elongation, the load-elongation relationship became 


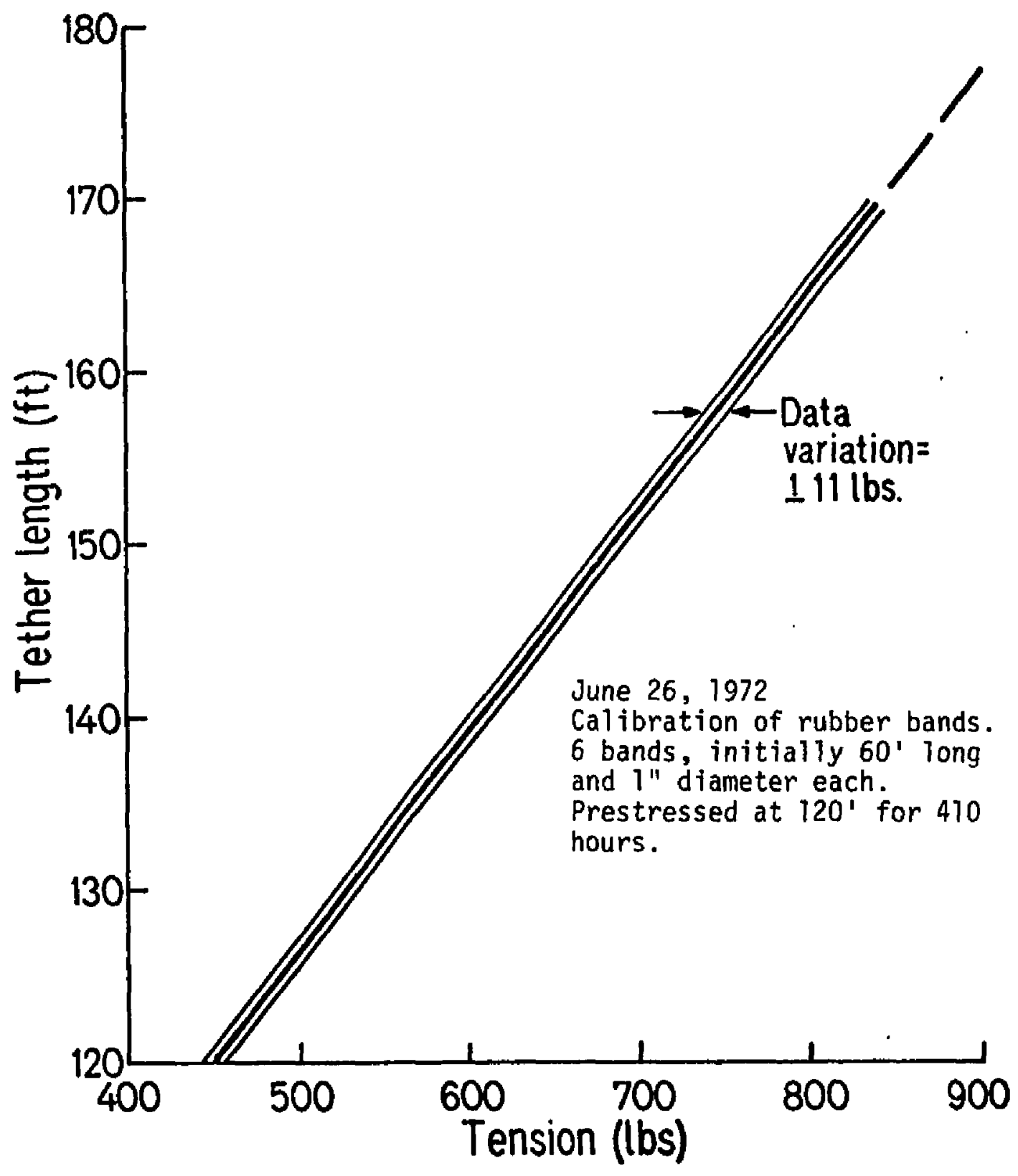

Figure 18. Load-elongation curve for working region of synthetic rubber from Winn, Savage and Hickman (1975). 
non-linear and the working modulus increased. Either two or three 1-inch diameter bands were suitable for tethering the 2-foot diameter buoy.

Only tethers one inch or less in diameter were considered for use because larger diameter bands would be difficult to terminate: they would require a larger bending radius and thimbals were not commoniy available in sizes greater than 1-inch. The use of triple bands was undesirable because these would add damping to the system, decreasing performance. Therefore, I accepted the non-linear character of dual bands statically loaded beyond $150 \%$ elongation and the increased modulus associated with operation in this load regime.

Finally, the termination had to be designed. Fabrication of slip-free terminations around a closed bronze thimbal would have been expensive: cost in labor and materials for such terminations for the entire array was estimated at $\$ 2500$. A less expensive, knotted termination was devised and tested for two months on buoys in the lake. A zero fai]ure rate of eight terminations and no evidence of band deterioration or tearing resulted in acceptance of the knotting technique.

Buoy response and energy dissipation were simulated using an estimated load elongation modulus over a range of tether lengths. Maximum performance was for a tether length of 20 feet. The final buoy/tether design configuration is shown in Figure 19. A section of chain was added to permit compensation of tether length for seasonal changes in lake water level or for variance among the elongation of the bands. 


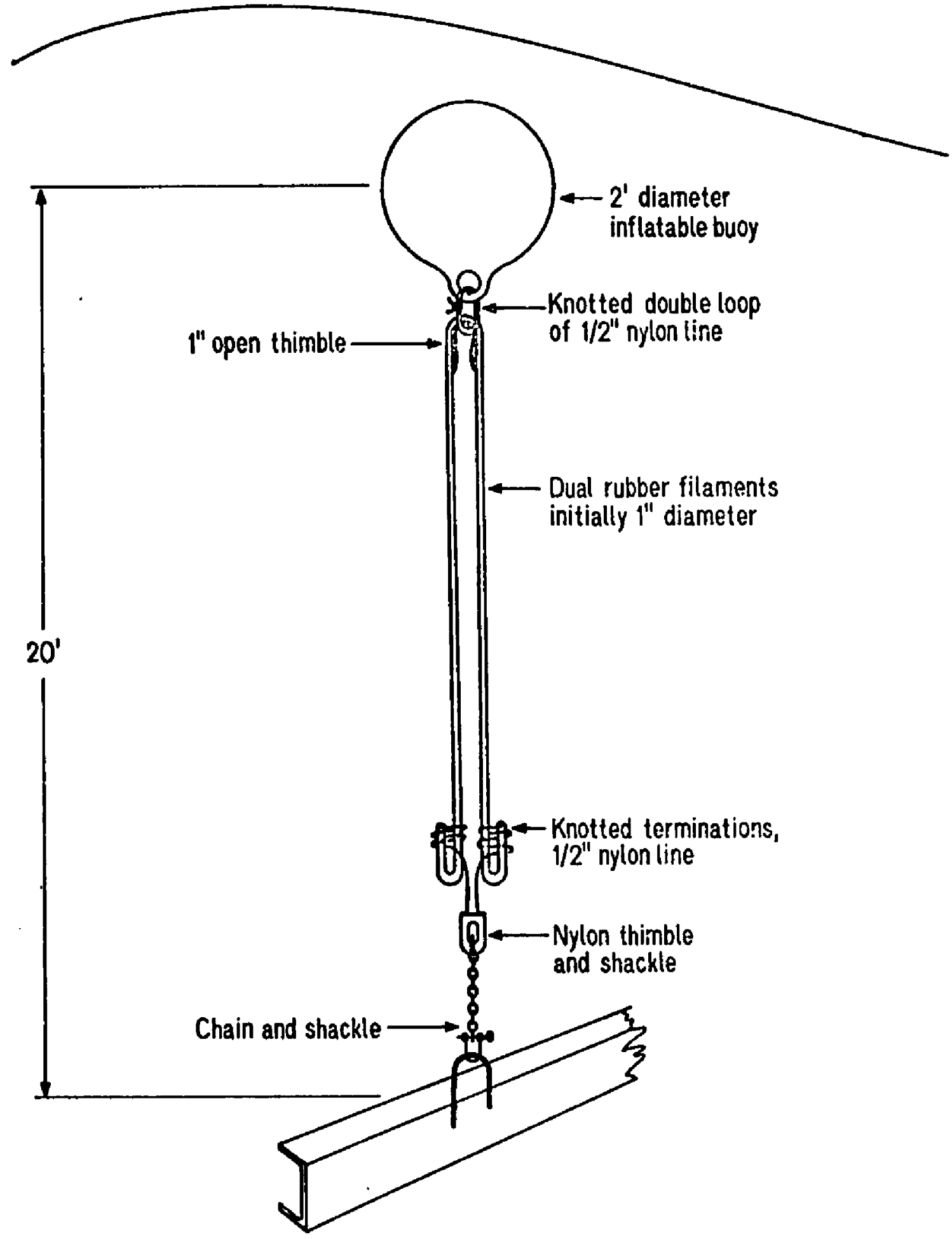

Figure 19. Configuration of elastically tetrered buoy used in field experinent. 


\section{Frame Design}

There were three principal criteria for choosing the design of the array anchoring system: the point of tether attachment to be motionless under dynamic loading conditions; a two year minimum system lifetime; and system cost within budget capabilities of the project. The technique of installation was carefully considered to insure the safety of student divers involved. Because of all these constraints, the frame design was not intended to be a prototype for a commercial system. It was intended to meet the needs of the experiment. D. A. Vidal undertook the design and construction of the array frame and anchor system for his Master's Thesis Project; his results are summarized here. Full details of his design and analysis procedures are available in his report (Vidal, 1975).

The site, surveyed through the ice during the winter, is shown in Figure 20. The sandy lake bottom off the NW shore of Diamond Island sloped at $10^{\circ}$ to a water depth of 40 feet. Vidal wanted to use a sinkable barge with pre-attached buoys and adjustable legs to anchor the array. However, he could not pursue that approach because such a barge was not available on the lake, and it would have cost too much to build. He eliminated the use of wood because of the uncertain strength of waterlogged wood-frame connections over two years. Instead he chose a welded structural steel frame mounted on adjustable legs to accommodate the irregular bottom. To facilitate construction and installation, he built the structure in four sections which could be lifted into position by a barge-mounted crane and held suspended in place while divers jacked and bolted the sections together one at a time. 


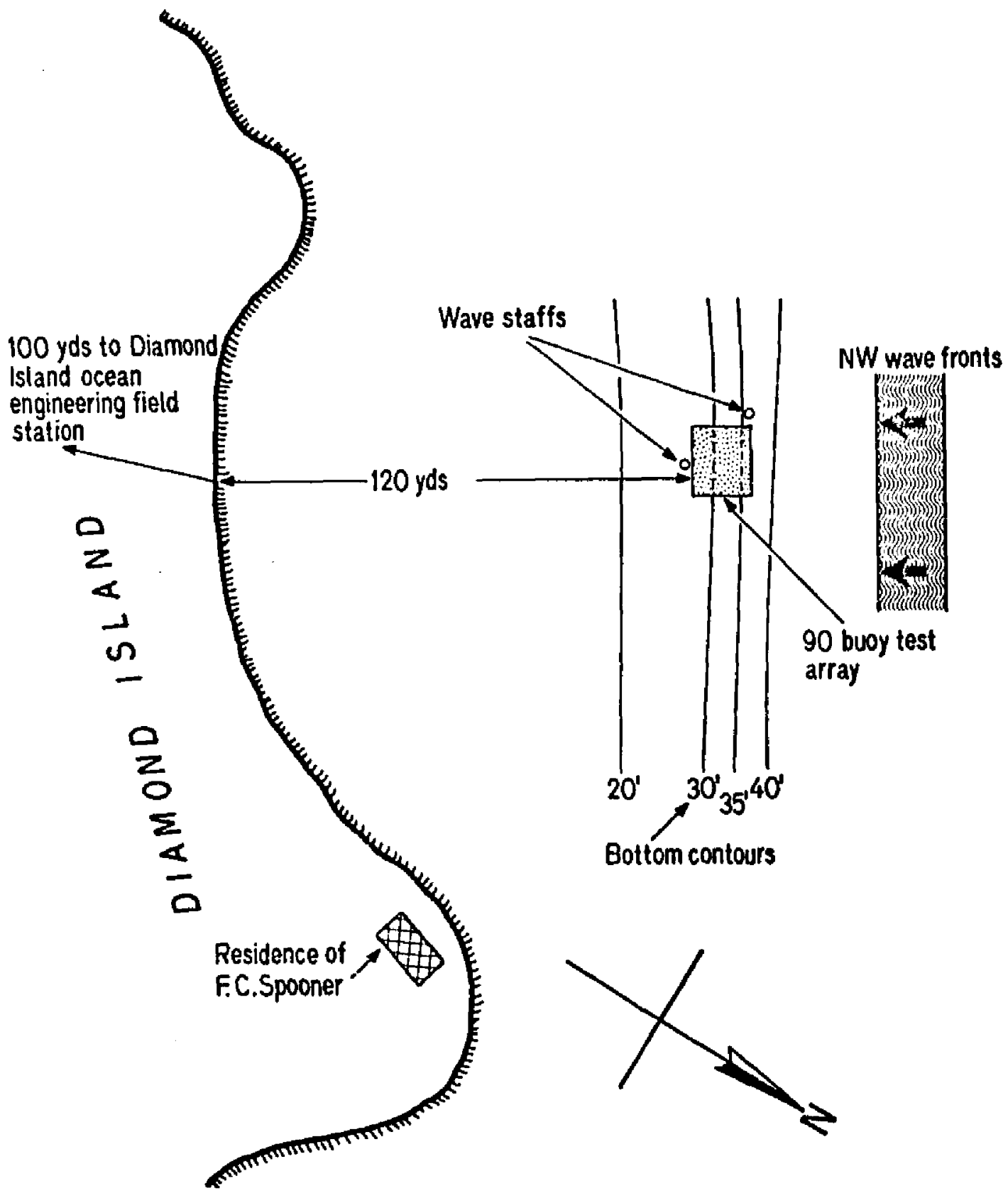

Figure 20. Site of the field experiment at Diamond Islard. 
Chains attaching the frame to the top and bottom of the legs were adjusted to achieve final leveling. The adjustable legs were made of 4inch steel pipe, held in 5-inch pipe collars welded into the frame. The frame design is shown in Figure 21. Only three of the four sections are depicted.

On each leg was a pinned footpad with spades welded to the bottom; these spades penetrated the sand and provided resistance to lateral movement on the $10^{\circ}$ slope. Concrete anchor blocks were set onto the pads to provide the necessary anchoring weight; placement here insured that vibratory motions of the frame would not cause soil fluidization and loss of mechanical soil support. Pad eyes on the legs provided attachment points for cross guys between legs; these eliminated any horizontal motion of the frame, thereby decreasing the likelihood of fatigue failure in connections or buckling at the frame/leg connections. Simple welded loops provided attachment points for buoys at 4.5 foot intervals on the frame.

Breakwater Installation: The frame was assembled by Vidal, two undergraduates, a technician and a professional welder in the docking yard of the Winnepesaukee Marine Construction Company located on the lake. The installation was simulated on land so that the divers, barge operator, and crane operator could be certain that all understood the procedure of maneuvering and emplacing frame sections and anchor blocks. The entire installation of the anchoring system required two days, including driving the second pile into the lake bottom to support wave staff instrumentation behind the array.

A wave staff support structure, representative of both used, is shown in Figure 22 . The pile, a 4-inch steel pipe, was driven into the 


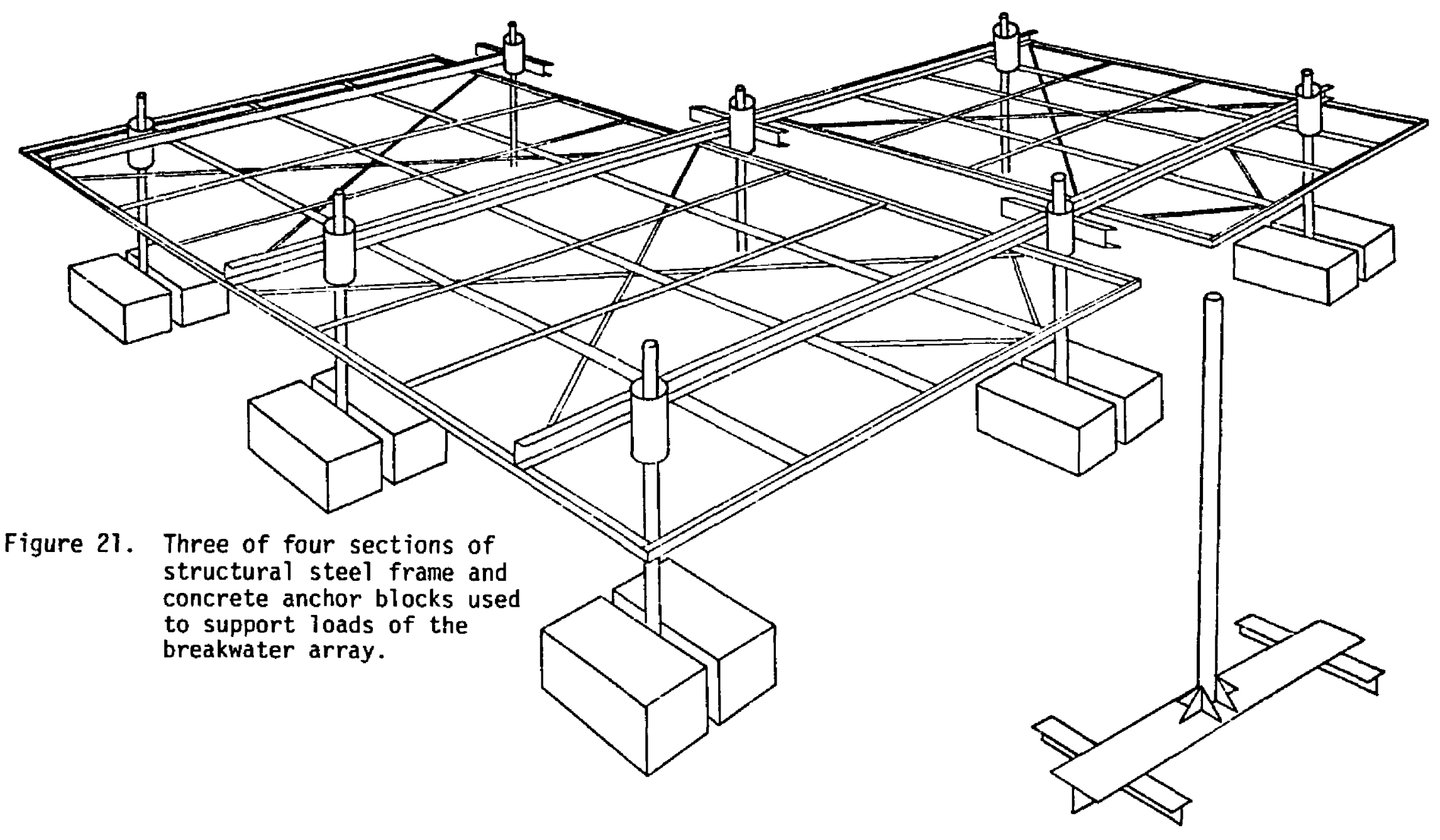




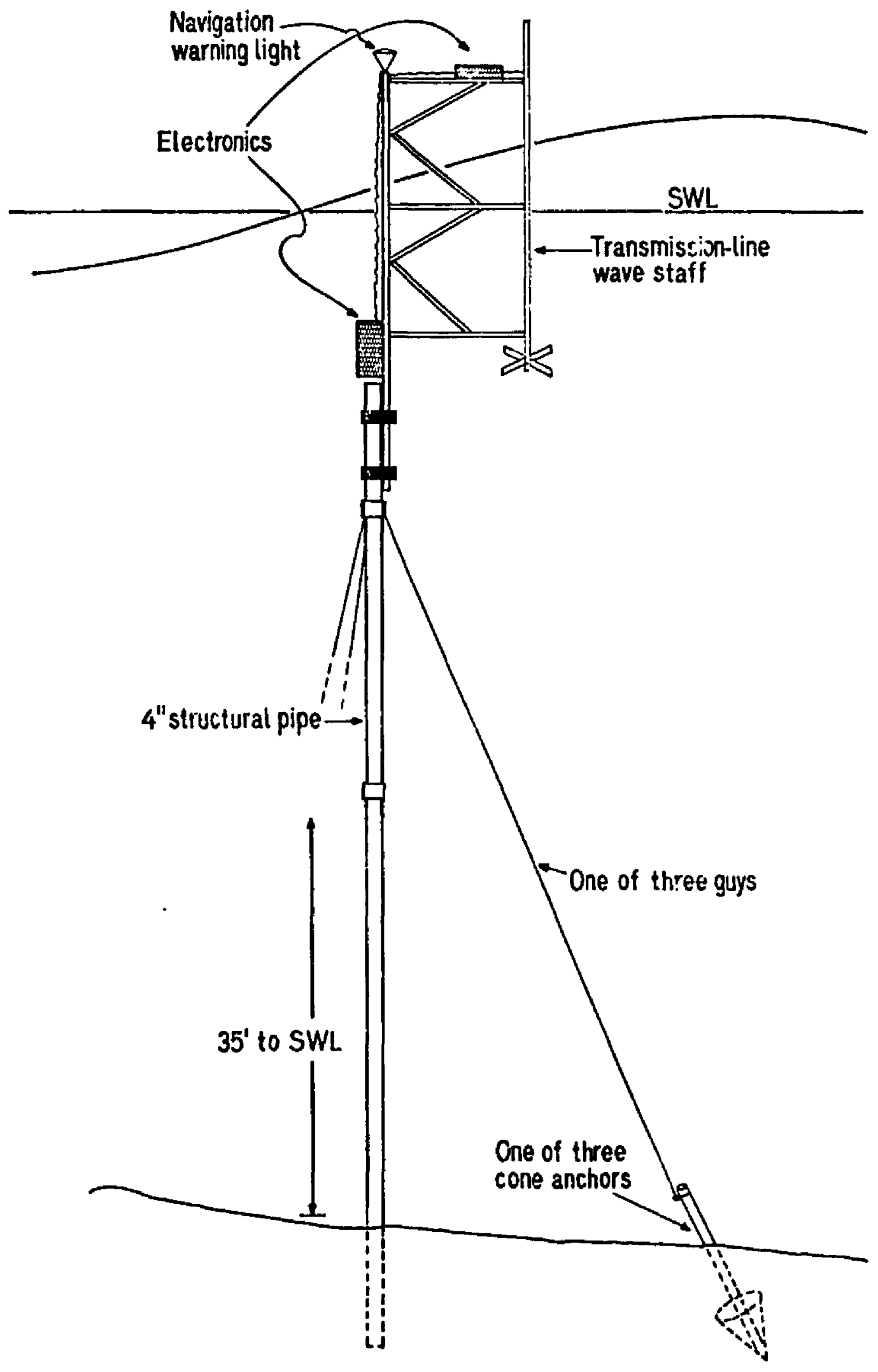

Figure 22. Wave staff support piling. 
sediment approximately 7 feet. Guy wires attached to cone anchors reinforced lateral support. Each anchor consisted of a 16-inch diameter galvanized sheet metal cone brazed onto the end of a 7-foot length of 1.25-inch black-iron pipe. The opposite end of the pipe was threaded to accept a standard fire hose coupling. Water, pumped through the pipe, fluidized the soil bottom in front of the cone so divers could push the anchors into the lake bottom. Early field tests showed these anchors would each support at least 500 pound static vertical loads. Because they might fail under vibratory loads, they were used only to stabilize the wave staff piles and not the buoy array.

Buoy Installation: Buoys were attached to the frame after it was installed because the weight of the structural steel frame was less than the net buoyancy of the buoys and the anchoring system was bottom fixed. Divers shackled tethers to attachment points on the frame and then tied each buoy to the frame by a short, slip-knotted nyton rope threaded through each buoy eye. They inflated each buoy with surfacesupplied compressed air until it filled a pre-measured circular "hat". When they had inflated a buoy sufficiently, they removed the hat and released the slip knot. As each buoy rose toward the surface, it tensioned its elastic tether and expanded to its design circumference, 75 inches. Buoy installation required two days using two divers and two topside personnel.

\section{Instrumentation}

Five measured parameters were needed to calculate buoy response and breakwater performance: 
a) Water surface statistics in front of the breakwater array.

b) Water surface statistics directly behind the breakwater array.

c) Motion statistics for one breakwater element in three directions--north, east, and vertical.

Requirements placed on the instrumentation system included:

a) Highest frequency of interest was $1.0 \mathrm{hz}$.

b) Format of data compatible with available field recording system.

c) Instrumentation capable of sustained, unattended operation for five days.

The design of instrumentation to provide this information is discussed in detail in a report by Winn and Stotz (1976).

Measurement of Water Motion: Prior to the conception of the Dynamic Breakwater Project, Hickman (1973)--under the direction of Winn--designed and tested a transmission line wave staff in the laboratory. Based on initial results, Winn had projected the application of this wave measuring technique for field use.

The redesign and construction of the wave staffs was undertaken by J. R. Delano for a Master's Thesis Project; the detailed design and analysis procedures he used are available in his report (Delano, 1976). Each wave measuring staff shown considered of a ferrous rod sheathed in a polyethylene tube; a fine lacquered wire was would around this sheath. This assembly was in turn encased in a larger polyethylene sheath. The staff was installed vertically in the air-water interface. It operated on the transmission line 
principle that part of a single electronic pulse sent down the winding is reflected at the fluid interface. The reflected pulse triggered a second pulse, and the entire procedure repeated itself over and over; the period (or frequency) of these pulses was calibrated to the distance traveled from the top of the instrument electronics package to the airwater interface (i.e., the height of the water relative to the staff).

In order to avoid measuring any possible reflected waves in front of the array, the forward or "input" wave staff was positioned in line with and 6 feet to the side of the first row of the array. The output wave staff was positioned six feet behind the midpoint of the last row of the array.

Measurement of Buoy Motion: Previous engineering research on an elastic-tethered Wave Amplitude Measuring Buoy (the WAM Buoy) by Winn, Savage, and Hickman (1975) showed that the position of the buoy could be uniquely calculated from two orthogonal angles of declination and tension in the rubber mooring. The length of the mooring was calibrated to the measured band tension.

Instrumentation similar to that used in the WAM Buoy Project was designed to measure the motions of a single breakwater element. Two pendulum inclinometers (Edcliff, Inc. Model 5-510) were mounted orthogonally in an aluminum block and encased in an Ikelite, Inc., Lexan underwater housing, \#5210. This housing was bolted to a short steel shank at the base of a tethered breakwater element. The steel shank was mounted on a universal joint which was in turn mounted on the breakwater frame. A custom-made Brewer Engineering, Inc., Sonar Buoy Towing Transducer was connected to the other end of the shaft. 
Finally, the tether was attached to the force transducer (see Figure 23). The voltage outputs of the load cell and inclinometers were converted by digital logic circuitry to frequency outputs and sent to the shore station on the 7-wire underwater cable. Separate underwater cable provided 24-volt DC power to all instrumentation. A tethered buoy in the first row in line with and near to the forward wave staff was selected for instrumentation in order that its phase response could be determined. Positioning of the instrumentation is shown schematically in Figure 24.

It would be impossible to separate the effect of tether drag from buoy drag in the measured response of a breakwater element. Therefore, I planned to replace the dual-strand elastic tether on the instrumented buoy with a $3 / 16$-inch wire cable after sufficient data for the elastic-tethered element had been obtained. The wire cable could be assumed to have negligible drag resistance: its area exposed to the flow was only $1 / 16$ that of the elastic tether.

I also planned to subsequently replace the smooth buoy on this cable with one with its surface roughened by eighth-inch fiberglass ribs running from top to bottom over its spherical body. I hypothesized that this roughness would help to create a fully turbulent boundry layer and consequently enhance wake development. The ribs were formed as part of a fiberglass shell laid onto an inflated buoy. In addition to providing a roughened surface, they added slightly to the area normal to the flow. Also, some water would become entrained between the fiberglass shell and the buoy during the test. Both of these unplanned effects could be accounted for in modeling. 
Figure 23.

Instrumentation to measure buoy response.

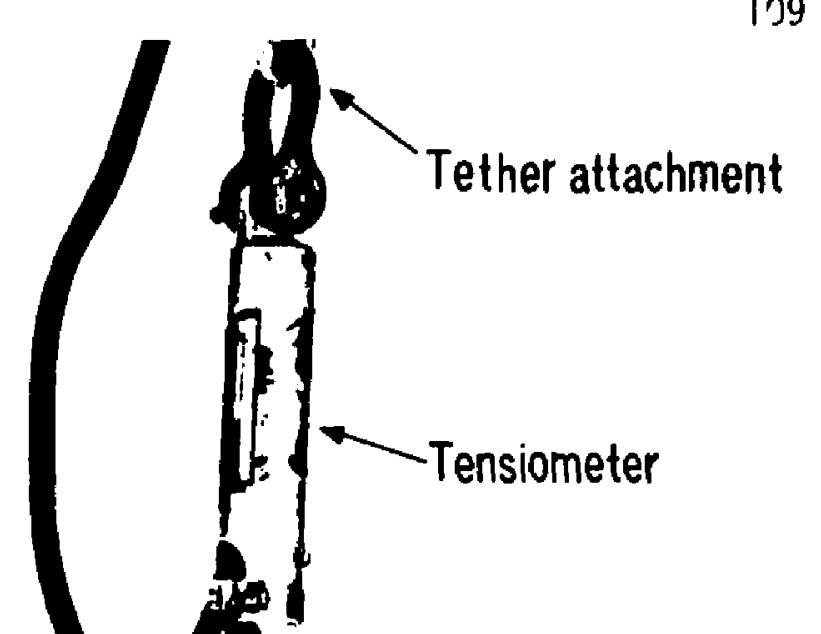

Two inclinometers

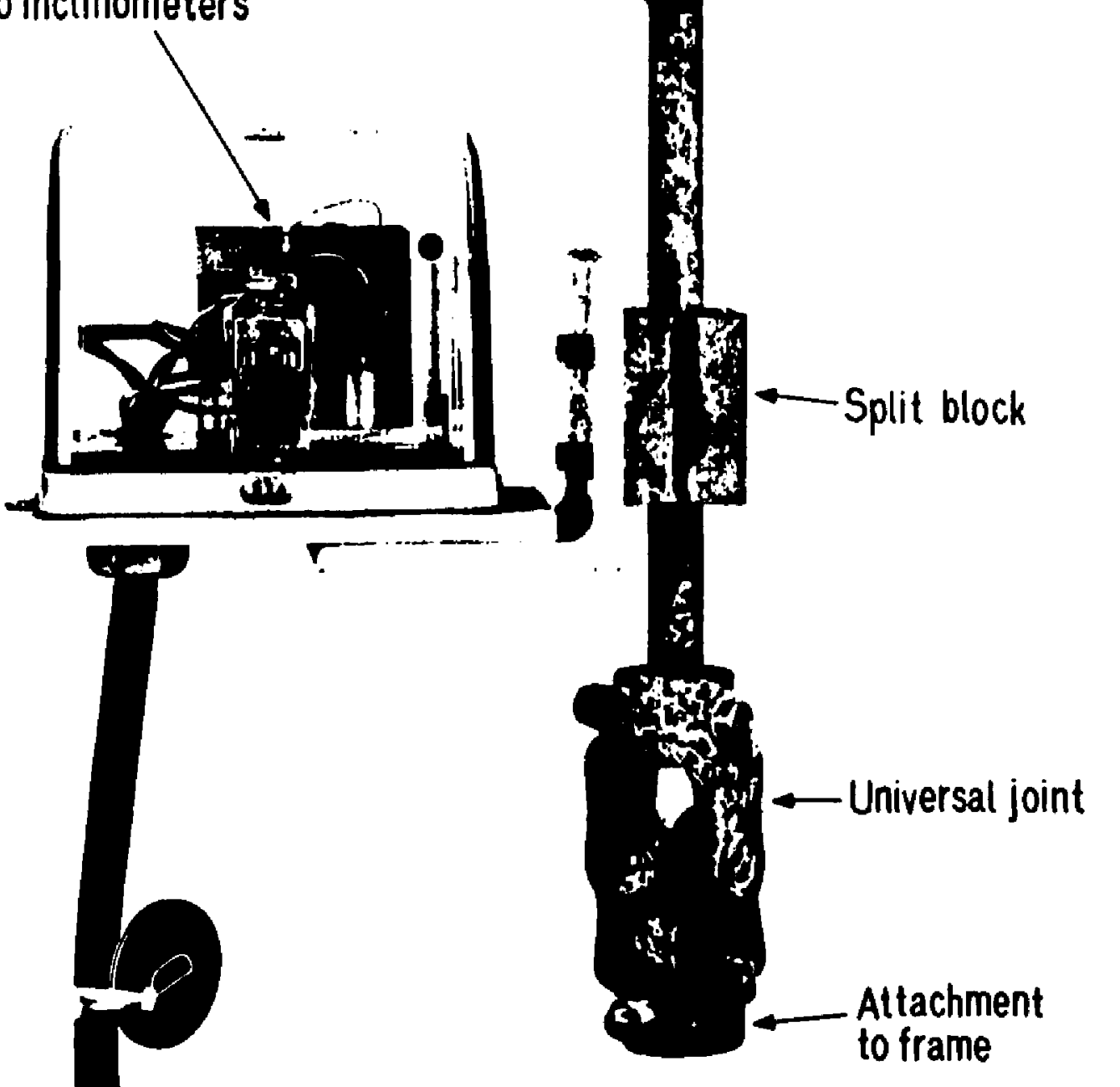




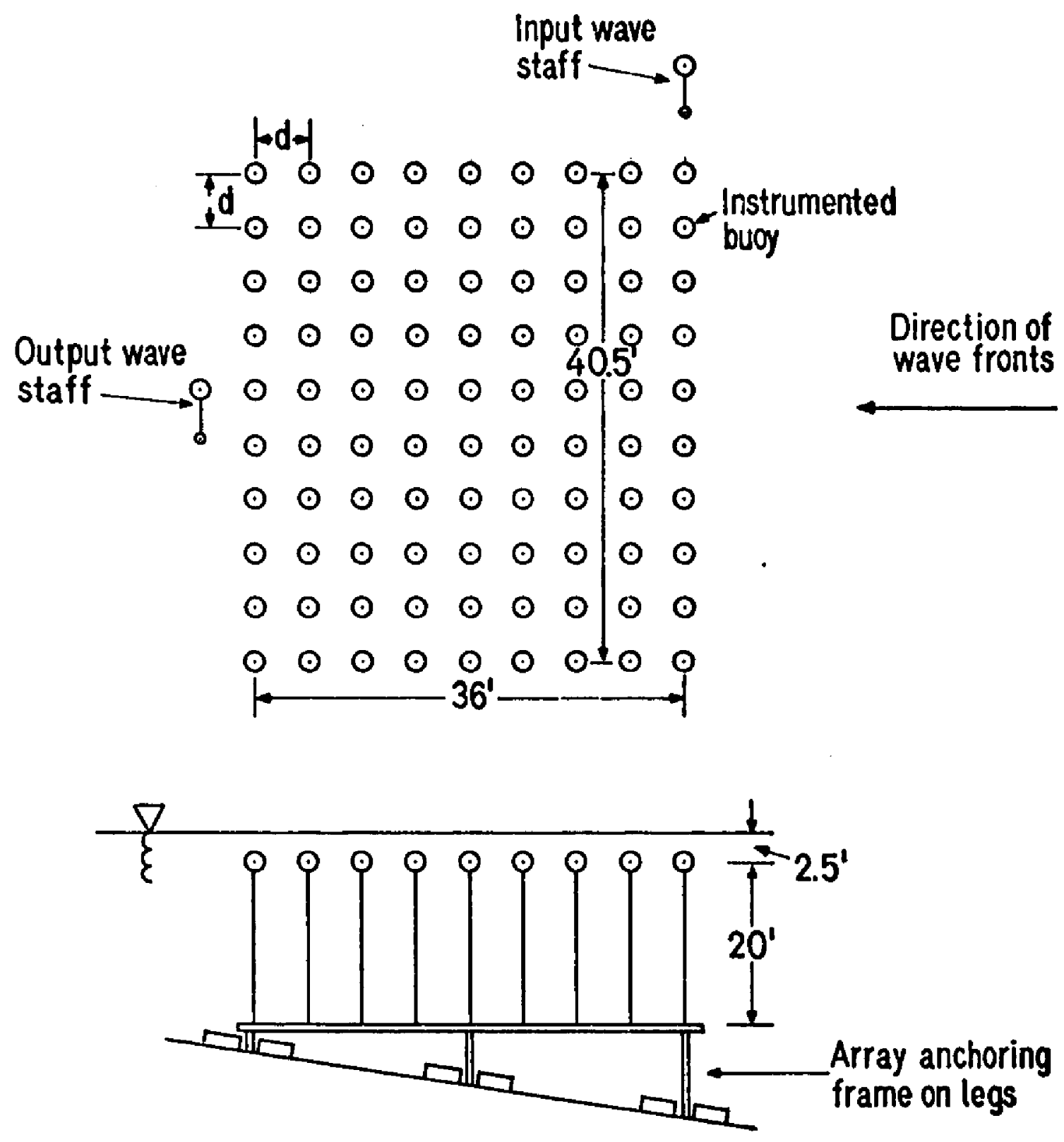

Breakwater array:

Number of rows: 9

Number of columns: 10

Buoy diameter: $\quad \mathbf{2}^{\prime}$

Spacing (d): $\quad 4.5^{\prime}$

Figure 24. Layout of test breakwater array in lake. 
Data Acquisition: Power and signal cables were laid 200 yards underwater and over land to a shore station housed in the machine shop at the Diamond Island Ocean Engineering Field Station. Here, signals were conditioned, multiplexed, and then relayed to a DIGI-DATA Model 1401-LP Incremental Digital Tape Recorder. The unit had seven recording tracks, one for an internally-generated parity bit and six for data. Each frequency count was recorded as a data word consisting of two 6-bit stacked bytes.

Only four channels of information could be recorded on the DigiData unit at the desired sampling frequency. Therefore, two of the five channels of information were connected to a single channel and a switch provided for selecting one. In conjunction with this arrangement, the inclinometer package was oriented so that one inclinometer axis was aligned with the NW (i.e., $N 45^{\circ} \mathrm{W}$ ), the direction from which the predominant waves were anticipated. Then the other inclinometer would measure only transverse oscillations. These would be of secondary interest if waves approached the breakwater from the NW. Normally, the NE angle was switched out of the recording circuit. Data records were five minutes in length; at a sampling interval of 0.22 seconds, approximately 1350 data points were recorded on each channel during a record.

A bank of 12-volt DIE HARD batteries powered the instrumentation and shore station for periods up to 6 days. A trickle charger powered by a gasoline generator recharged the batteries as necessary.

Instrumentation Calibration: The transmission line wave staffs were calibrated statically by adjusting the staff upwards and downwards on its mount in six-inch increments. Calibration holes were drilled for 
this purpose on the ferrous core rod which extended above the polyethylene sheathing. At each position, the frequency count was recorded for a two minute interval. Calibration was carried out only during substantially windless conditions. Data was processed by computer and plotted for the 4.5-foot working region of the staff.

Similarly, tether inclination was calibrated by pulling the instrumented breakwater element over a fixed angle and securing it in this position by a line tied to the frame. A small buoy was then tethered at the apex of the instrumented buoy. The angle of inclination was calculated from the measured length of the three sides of the triangle formed by the inclined tether, the tether of the small buoy rising vertically from the apex, and a line held between the 10-foot points on the first two legs of the triangle. This calibration confirmed previous laboratory calibration of the inctinometers.

The tether length was calibrated statically to the frequency output of the tensiometer by successively hanging lead weights below the buoy and measuring the tether length. The process was repeated for successive additions of small buoys and their subsequent removal. The tether displayed a small hysteresis which was averaged in the final calibration curve. The load-elongation curve was non-linear, but this was accounted for in the computerized field data conversion. Calibration curves for the wave staff, the inclinometers and the tensiometer are presented in Appendix B.

5. Problems Encountered in the Field Experiment

Two of the problems which arose during the field experiment are worthy of mention here. 
Wave Staffs: Upon installation of the first wave staff in May, Delano discovered that the laboratory model could not be scaled up without further development work. Fulses had to travel a longer distance in the field staff than in the laboratory model, and in doing so, were attenuated to the level of the ambient noise in the electronics. (This problem is fuliy documented in a thesis by Delano (1976)). Solution of this problem caused the wave staff response to be nonlinear and temperature sensitive. The non-linearity was accounted for in the piece-wise curve fitting of the calibration data. The temperature sensitivity was dealt with through repeated calibrations; temperature sensitive elements were housed in an instrument package beneath the water where temperature changed gradually during the fall. Later in the fall we discovered that the shore station and recorder were sensitive to temperatures below $35^{\circ} \mathrm{F}$. Provisions were made to heat the system during cold-weather operations.

Lightning protection also became a design consideration after ground strokes twice surged through the instrumentation destroying $D C$ to-DC voltage converters and integrated circuits. Each time the instrumentation had to be removed, burnt-out components replaced, and circuit protection reprovided.

Elastic Tethers: Initial material selection for elastic moorings based on the data of Winn, Savage and Hickman (1975). Sample synthetic rubber filaments as used in previous mooring applications were obtained from the same manufacturer and tested. During a threeweek test installation of a prototype buoy in the lake, the working modulus for a dual filament was measured as $33 \mathrm{lbs} / \mathrm{ft}$. This 
material was selected for use and an order for it placed with the manufacturer. However, the mechanical properties of the final material received from the manufacturer were considerably different from that tested; the material behaved more like an experimental "low modulus" band formulation considered for use but rejected because of unfavorable creep characteristics and concommitant stiffening. The filaments received elongated to $200 \%$ of initial length under $240 \mathrm{lbs}$. load; their average working moduius was $65 \mathrm{lbs} / \mathrm{ft}$. At this time, August 1975, the rubber manufacturer was on vacation for one month. If the experiment was to proceed, it would have to proceed with the tethers as received. Further, with the fall University semester approaching, student divers would not be readily available to carry out installation of the buoys at a later date, much less to return for final adjustment. Failure to proceed with the installation would have incurred a significant risk of later delay and possibly foregone storm wind conditions. Because of the seasonal nature of the experiment, if fall storm conditions were missed, the experiment could have been delayed a full year--an expense which could not be tolerated in the project budget. Therefore, I accepted a less-than-desired vertical buoy response. Some compromises illustrate the constraints which are, to some extent, inherent in conducting engineering design research in an academic institution.

Subsequent investigation of solid rubber filaments by G. H. Savage revealed that serious batch-to-batch variation and quality control problems were inherent in the present state of the art of manufacturing synthetic rubber cord for structural use. 


\section{B. Results of the Field Experiment}

1. Data Analysis

The test section of breakwater and its instrumentation system was fully operational by mid-September 1975. By contract, the New England Weather Service, Inc., informed me whenever they predicted northwest winds greater than 15 knots. Data was recorded on 15 such days, and records of waves containing sufficient energy to be of interest were obtained on four of these. The maximum significant height recorded over a five-minute interval during these days was:

\begin{tabular}{lc} 
Date & Max $\mathrm{H}_{\mathrm{s}}$ \\
\hline & \\
October 6 & $1.8^{\prime}$ \\
November 5 & $2.0^{\prime}$ \\
December 18 & $2.6^{\prime}$ \\
December 19 & $2.6^{\prime}$
\end{tabular}

The experiment remained operational through December 18 and 19 while a series of two low pressure systems passed through New England, each followed by sustained northwest winds of about 30 knots.

The following parameters were sampled at intervals of 0.22 seconds for five continuous minutes per record.
a) Incident waves
b) Attenuated waves
c) NW-SE angle of inclination
d) NE-SW angle of inclination
e) Tether tension

For each sample record, the following were calculated in order to check for spurious values: 

a) Frequency distribution of sample points (histogram)
b) Mean and standard deviation
c) Minimum and maximum

Records were analyzed with the computer programs presented in Appendix C. The following were computed and plotted for the aforementioned four days.
a) Spectrum of incident waves
b) Spectrum of attenuated waves
c) Spectrum of depth-attenuated water particle motion at average depth of buoy
d) Analysis of buoy response in each dimension--NW-SE, NE-SW, and vertical:
1. Spectrum of buoy position
2. Amplitude and phase response
3. Coherence of response and excitation
4. Spectrum of relative velocity

The number of data points analyzed per record for each parameter was 1280. Averaging resulted in 128 frequency bands at 20 degrees of freedom or 64 bands at 40 degrees of freedom in cases where more statistical confidence was sought. Degrees of freedom $\delta$ were calculated as $\delta=2 \mathrm{ND} / \mathrm{FB}$ where $\mathrm{ND}=$ number of data points and $\mathrm{FB}=$ number of frequency bands. To increase confidence, adjacent records recorded within the same ten minute period were sometimes combined. Confidence intervals are presented in Table 3 in percentages above $(U)$ and below $(L)$ the calculated value of the spectrum at any frequency. The percentage interval was calculated as

$$
\left(\frac{\delta}{x_{L}^{2}, \alpha / 2}, \frac{\delta}{x_{U}^{2}, \alpha / 2}\right) \quad \text { where } \alpha=.20
$$

Amplitude and phase response were calculated as 


$$
\begin{gathered}
\left|H_{x}(\omega)\right|=\frac{S_{x}(\omega)^{1 / 2}}{S_{z}(\omega)^{1 / 2}} \\
\theta(\omega)=\arctan \left(Q_{z x}(\omega) / C_{z x}(\omega)\right)
\end{gathered}
$$

where $S_{z}(w)$ is the excitation spectrum;

$S_{x}(\omega)$ is the buoy response spectrum;

$Q_{z x}(w)$ is the quad-spectrum of response and excitation;

$c_{z x}(\omega)$ is the co-spectrum of response and excitation.

Frequency response data was utilized if its coherence exceeded 0.80 . Coherence $\Omega$ was computed as

$$
\Omega_{z x}^{2}(\omega)=\frac{\left|S_{z x}(\omega)\right|^{2}}{S_{z}(\omega) S_{x}(\omega)}
$$

where $S_{z x}(\omega)$ is the cross spectrum. When $\Omega_{z x}^{2}(\omega)=0$ at a particular frequency, the two time processes, $x(t)$ and $z(t)$ are incoherent (uncorrelated). When $\Omega_{z x}^{2}(\omega)=1$ for all $\omega$, then $x(t)$ and $z(t)$ are fully coherent.

Electrical problems arose in the tension-meter and NE-SW inclinometer sometime between December 3 and December 18. Consequentiy, measurement of the vertical and transverse buoy motions was curtailed after December 3. Fortunately that data was not critical to the remainder of the analysis.

Other electrical problems hampered, but fortunately did not prevent, measurement of the response of a wire-tethered buoy. As explained in Section 4 of Chapter V, I replaced the instrumented dual elastic tether with a wire cable during storm winds on December 19. 
Later on the same day, I replaced the smooth buoy attached to this cable with a roughened one. Data for the smooth-surface wire-tethered buoy was unusabie because shore station warm-up problems caused the recording of extraneous data. Fortunately, data for the ribbed wiretethered buoy was not affected. The measured response of the instrumented buoys will be discussed in the succeeding chapter in conjunction with mathematical modeling. Energy dissipation is presented in the section which follows.

TABLE 3

80\% Confidence Interval for Spectra

as a Percentage of Statistical Estimate

$\quad L \quad U$

$\begin{array}{lll}20 & 0.70 & 1.60 \\ 40 & 0.78 & 1.38 \\ 80 & 0.83 & 1.24\end{array}$

2. Energy Dissipation by the Array

The average wave energy dissipation by the test section of breakwater for nine records on December 18 was $53 \%$; for five records on November 5 , it was $51 \%$. Several records were selected for detailed review and modeling. Spectra for records \#9 and 10 of December 18 were averaged together, as were spectra for records $\# 1,2$, and 3 of November 5. The records within each set had been recorded immediately after one another. Record \#11 of December 18 was not included in the averaged 
set for December because attenuated waves were not sampled during that record. The averaged incident and attenuated wave spectra for these records are compared in Figures 25 and 26 . Statistical results are summarized in Table 4. The average total energy dissipation $\hat{\vec{E}}_{D}$ was about $55 \%$ in each case. The average energy dissipation per row over all frequencies in the spectrum was about $8.5 \%$.

\section{TABLE 4}

Statistics of Incident and Attenuated Waves

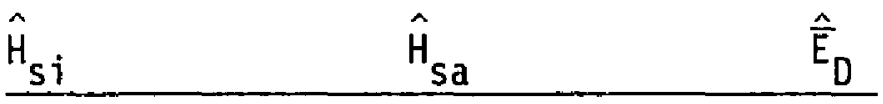

Dec. 18: $\overline{9,10}$

$2.2^{\prime}$

$1.5^{\prime}$

$54 \%$

Nov. 5: $\overline{1,2,3}$

$1.8^{\prime}$

$1.2^{\prime}$

$56 \%$

Until now, the energy dissipation per row was considered a function of both frequency and amplitude. To examine how sensitive energy dissipation was to wave amplitude, the dissipation for regular waves of heights $3.0,2.4$, and 2.1 feet was compared using simulation. Waves of the latter two heights have, respectively, $64 \%$ and $50 \%$ as much energy as the first. In Figure 27 performance of the breakwater in these latter waves is compared with performance in the larger wave. This provides a performance comparison between front and back rows of an array of a row of buoys after $50 \%$ of the energy has been dissipated. At $0.33 \mathrm{hz}$, the difference in performance is about 1.3 percentage points. From the standpoint of mathematical modeling, this increasing efficiency as the waves progress through successive rows could have been accounted 


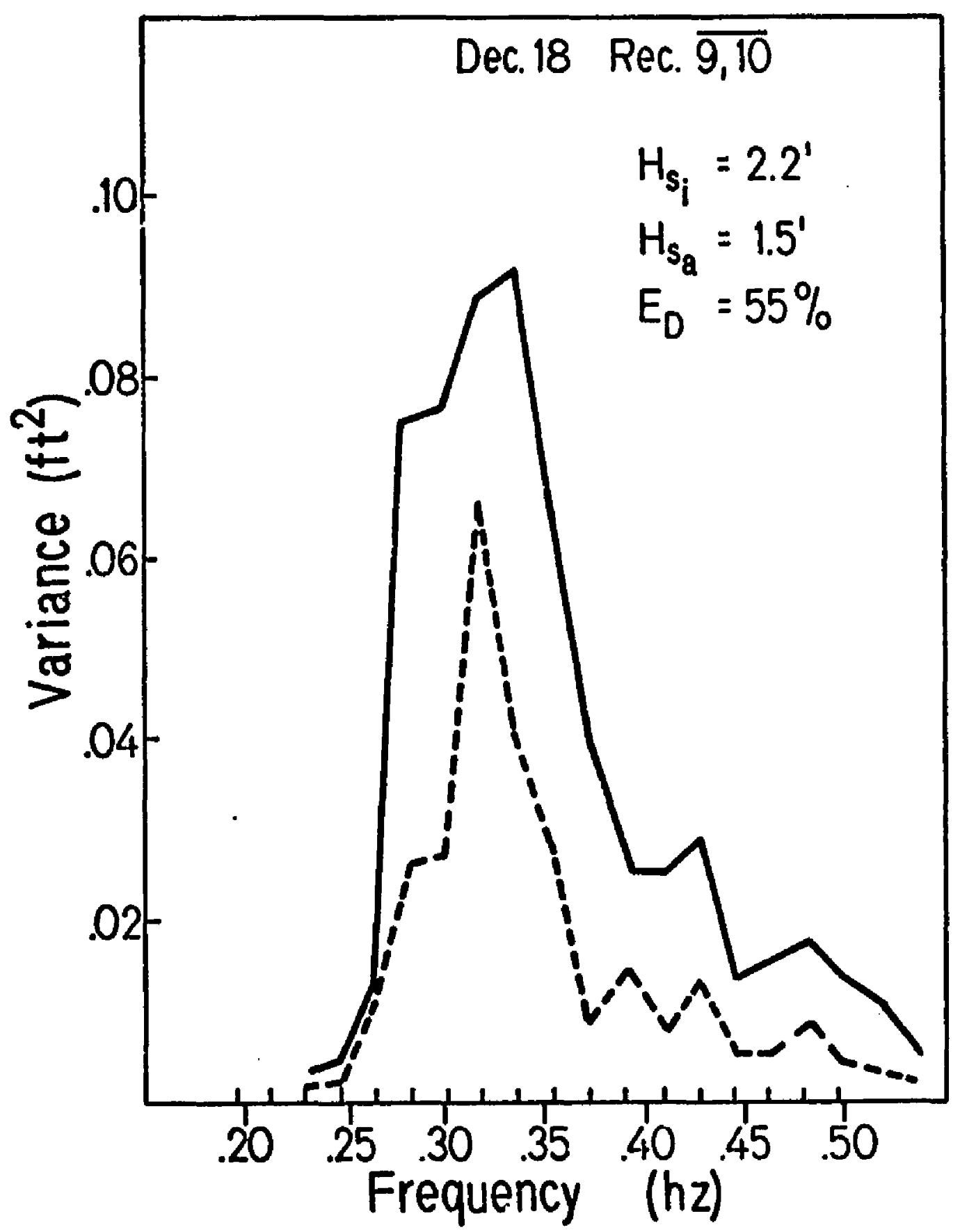

Figure 25. Measured incident and attenuated wave spectra 


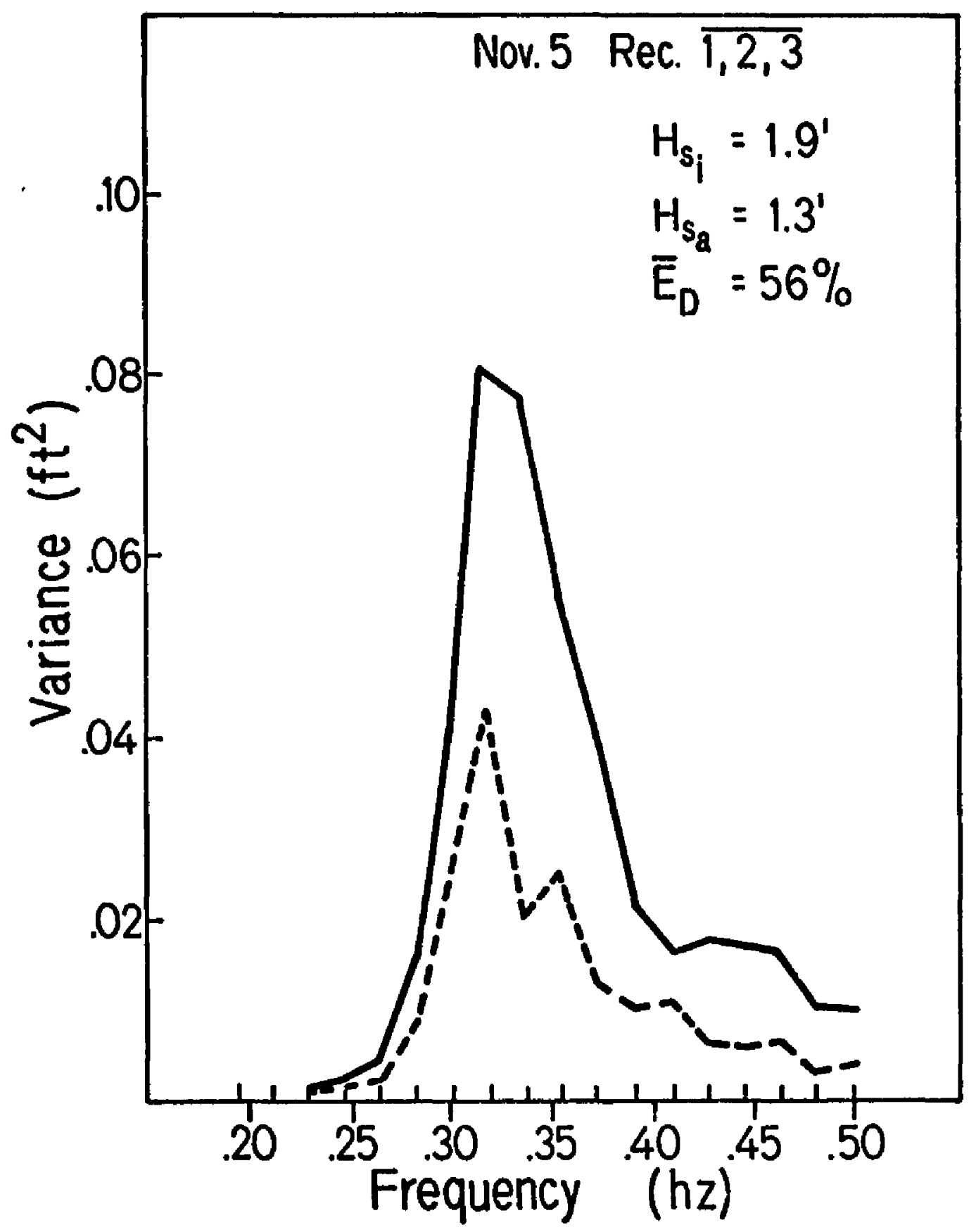

Figure 26. Incident and attenuated wave spectra. 


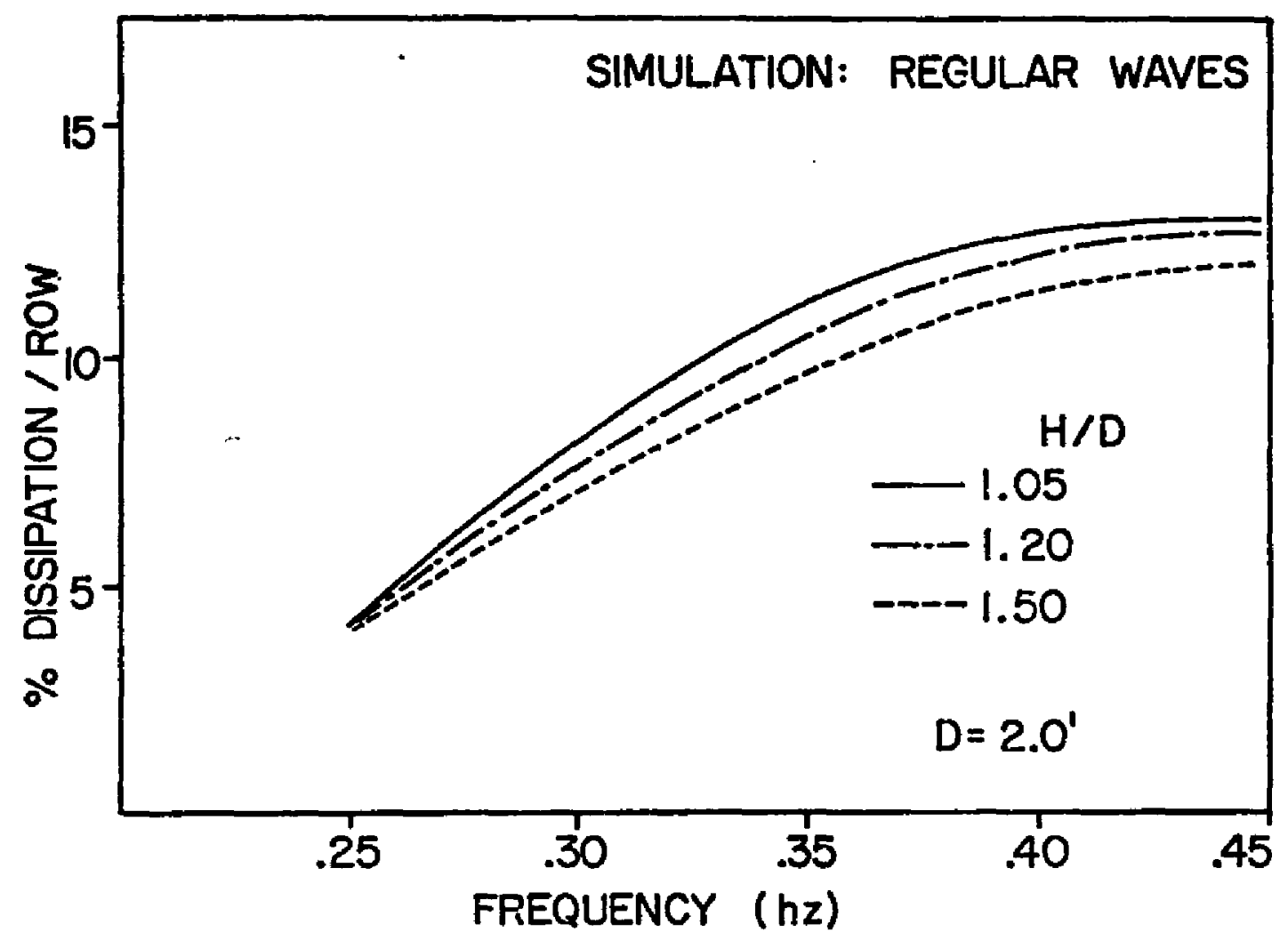

Figure 27. Simulated breakwater performance in waves of varying height. 
for by successive simulations. Instead, I accepted the error inherent in approximating performance over a particular frequency band as being constant for all rows because it greatly simplified the task of decompounding or compounding energy transmission throughout the array.

The resulting error for estimating performance from the mathematical model of buoy response is a conservative one because the dissipation is under estimated. From the field data, the energy dissipated per row over each frequency band was calculated by Equation 92 . Results at frequencies higher than $0.42 \mathrm{hz}$ were discounted because there was relatively little energy in this regime. A linear least square fit was made to the data which is presented in Figure 28 for averaged records from November 5 and December 18. Comparison between the measured performance and that predicted by the linear and non-linear mathematical models will be presented in the succeeding chapter. 


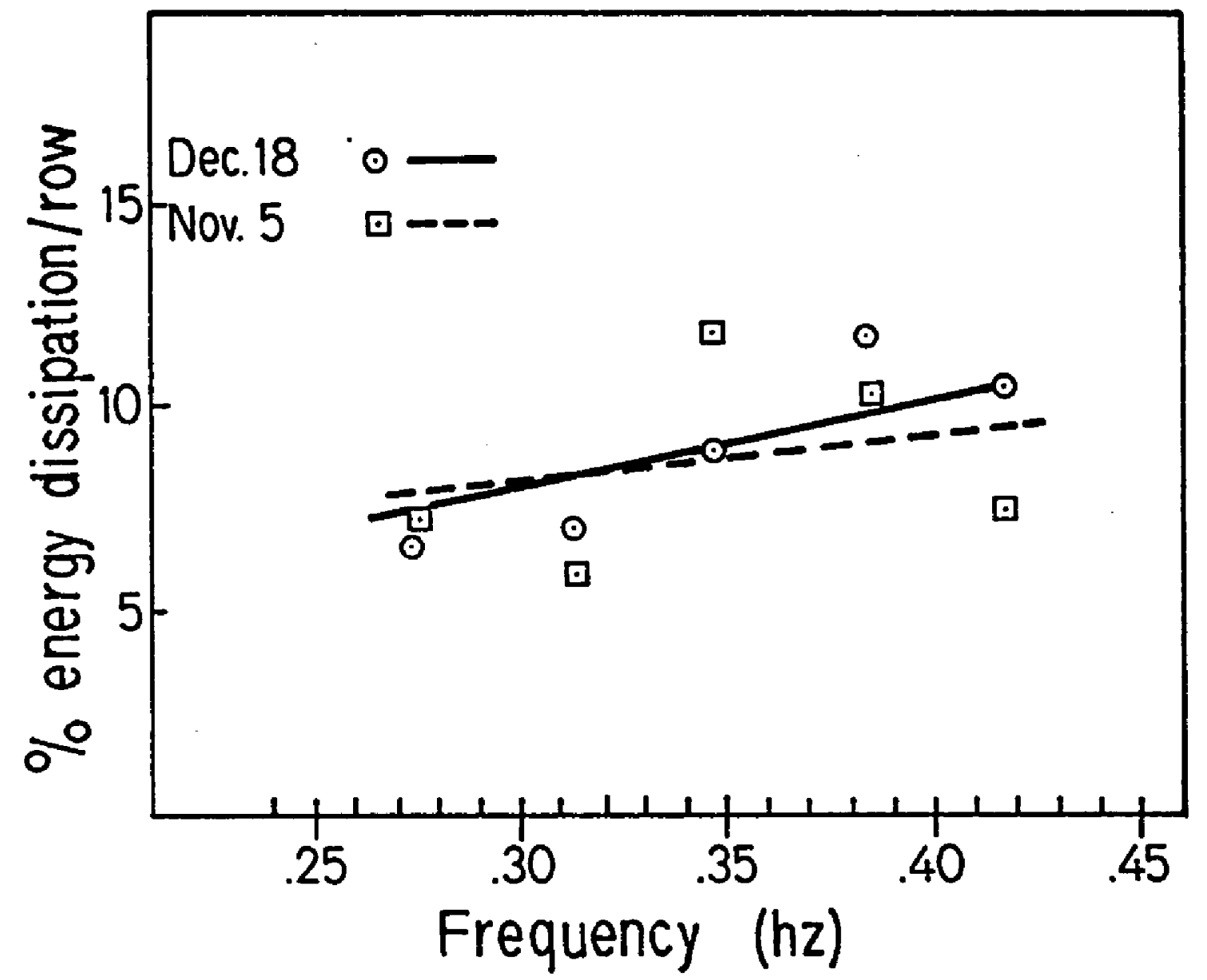

Figure 28. Measured energy dissipation per row of breakwater array. 
VI COMPARISON OF MODEL AND FIELD-TEST RESULTS

\section{A. Modeling Buoy Response}

The response of tethered buoys was modeled first using the simulation approach described in Chapter III. Wave excitation was the sum of 13 randomly phased Fourier components averaged from measured incident wave spectra. The resulting time series of water and buoy displacements were spectrally analyzed just as field data had been. Correspondence between the measured and simulated incident wave spectra of December 18 is demonstrated in Figure 29.

To facilitate relating buoy response to wave excitation, I invented the term "significant buoy excursion". Like significant wave height, significant buoy excursion was calculated as four times the square root of the variance of the spectrum of displacements $--x_{s}=4 \sigma_{x}$. The inverted tear-drop shape of the buoy was accounted for by approximating the area of the buoy eye as that of a $10 \times 6$-inch triangle. Buoy volume was that of a 230-pound displacement sphere. Cable drag coefficient $C_{D_{t}}$ was assumed to be 1.0 . Possible errors in this estimate were unimportant in the case of a wire cable because its drag was negligible with respect to that of the buoy.

The response of the instrumented tethered float was also investigated using the linear model which treated the system as a damped harmonic oscillator. Characteristic parameters of the 


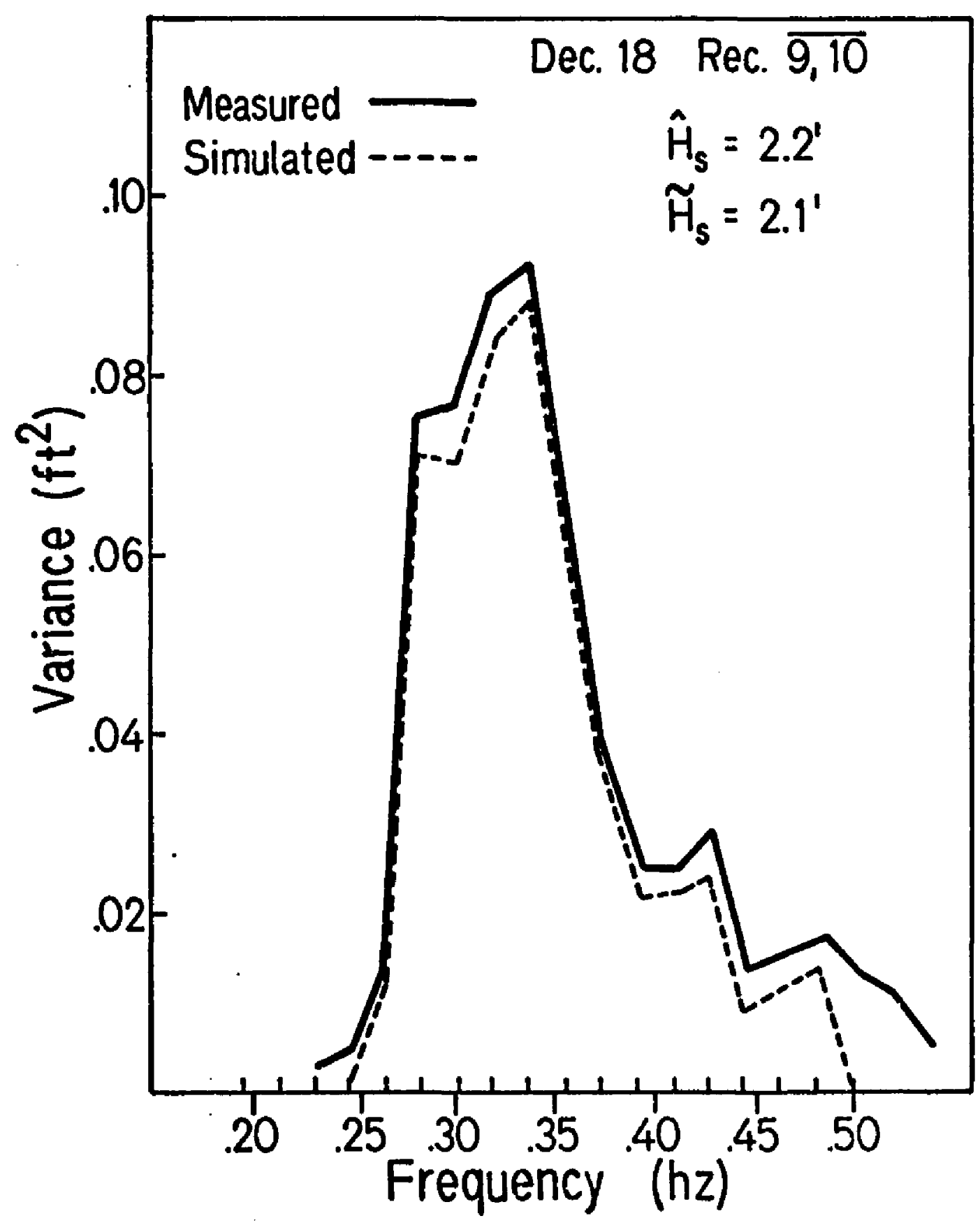

Figure 29. Measured and simulated incident wave spectra. 
system were calculated as follows:

$$
\begin{aligned}
\text { Natura] Frequency: } \omega_{n} & =\sqrt{K / M} \\
\text { Damping coefficient: } \quad \zeta & =D^{\prime \prime} /\left(2 M \omega_{n}\right) \\
\text { Resonant frequency: } \omega_{r} & =\omega_{n} \sqrt{1-2 \zeta^{2}} \\
f_{r} & =\omega_{r} / 2 \pi
\end{aligned}
$$

Wire-tethered buoy: Measured frequency response data for the wire-tethered buoy from five records of December 19, 1975 is shown in Figure $D-1$ in Appendix D. Averaged results are shown in Figure 30. There was insignificant wave action and buoy motion at frequencies less than 0.25 hertz or greater than 0.42 hertz. Phase decreased steadily from $70^{\circ}$ with increasing frequency as would be expected beyond the resonant frequency. I concluded that waves had been higher in frequency than the resonance of the wire-tethered buoy. Consequently, the resonant frequency--at which phase would have been $90^{\circ}-$-could not be inferred directly from the data except by extrapolation.

By his linear model, Seymour (1974) had been able to calculate $C_{M}$ from measured frequency response because his range of ocean wave frequencies had spanned the resonant frequency of his tethered float and because his calculations of $C_{M}$ could be done independent of damping coefficient $\zeta$. His system damping was low--about 0.10 , I estimated--due to the large mass of his steel buoy. Consequently, natural and resonant frequency for his system were effectively the same-- 
that is, $2 \zeta^{2}$ was effectively zero. In contrast, my buoy had negligible mass compared to that of water it displaced--damping exceeded 0.40, I estimated--and wave frequencies in the lake did not span the resonant frequency of my system. Consequently, I had to infer $C_{M}$ and $C_{D}$ by matching the results of modeling to frequency response measured in the field.

From data Record \#9 of December 19, the significant horizonta? buoy excursion was $X_{S}=4.5$ feet. For initial simulations, I assumed $C_{M}=0.35$ and $C_{D}=0.25$, values Seymour had reported. Substituted into the non-linear model, these values resulted in a significant buoy excursion $X_{s}=7.0$ feet. I concluded that they were incorrect: simulated buoy response was too great. Furthermore, it appeared that fully turbulent flow had not been achieved in the field.

For Record \#9, the estimated ms Reynolds number was $2.0 \times$ $10^{5}$, below the minimum usually sited for fully turbulent flow around spheres. Similarly, the estimated $r m s a_{r} / d$ value was 0.65 , below the minimum sited by Seymour (1974) for fully turbulent oscillatory flow. I suspected that $C_{M}$ and $C_{D}$ were greater than my initial estimates. A larger $C_{M}$ would bring the model's resonant frequency nearer to that measured in the field. The drag coefficient for spheres at $N_{R}$ just below the region of fully turbulent flow is 0.42 . Therefore, $C_{M}=0.50$ and $C_{D}=0.42$ were substituted into the non-linear model. Other drag and mass coefficients were investigated as well.

The best correspondence between buoy-response statistics of the field and the model data were for $C_{M}=0.50$ and $C_{D}=0.42$. Significant buoy excursion calculated from simulation was about 25\% greater 
than that calculated from field data. Some of the discrepency between model and test results may have to do with fiberglass shell which was on this buoy--e.g., some water was entrained between the buoy and the she11.

The flow coefficients $C_{D}=0.42, C_{M}=0.50$ were also substituted into the linear model. From the results, the characteristic parameters of a damped harmonic oscillator were calculated to be:

$$
\begin{array}{ll}
\text { Damping coefficient: } & \zeta=0.55 \\
\text { Resonant frequency: } & f_{r}=0.20 \text { hertz }
\end{array}
$$

I extrapolated the measured phase response data shown in Figure 30. Resonance appeared to be close to 0.20 hertz, near that calculated by the linear model.

In Figure 30 , the average measured response of the wiretethered system is compared to that calculated by both the linear and non-linear models. Significant buoy excursion calculated from the linear model was about $10 \%$ greater than that calculated from field data. Spectra of horizontal relative velocity determined from both models and the field data are shown in Figure 31 . The rms of horizontal buoy relative velocity calculated from the non-linear model was about $25 \%$ greater than that calculated from field data. That calculated from the linear model was about $10 \%$ greater. Statistical results are summarized in Table 5.

Elastic-tethered buoy: Measured frequency response data for the elastic-tethered buoy from three records on December 18 and 


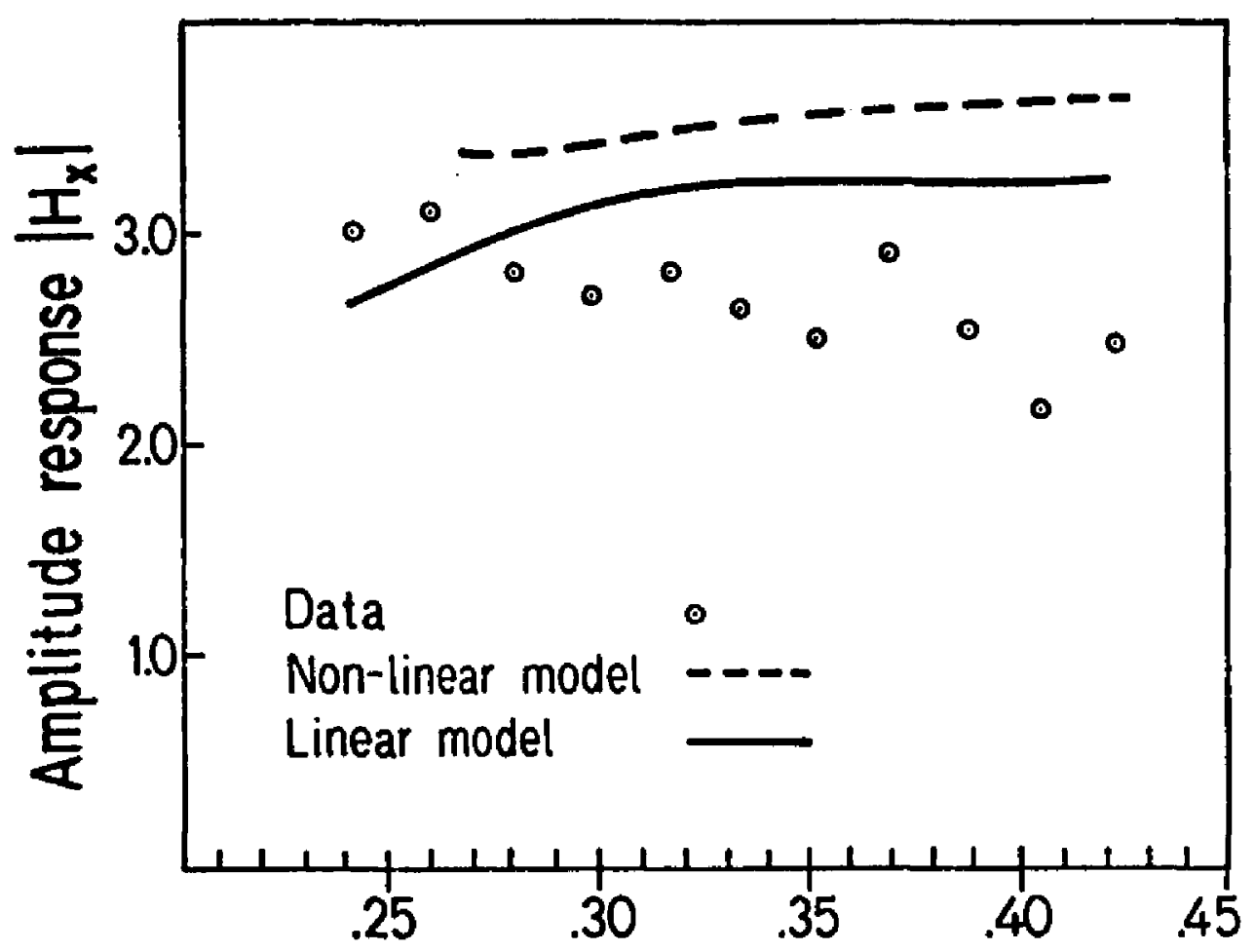

Dec. 19 Wire tether

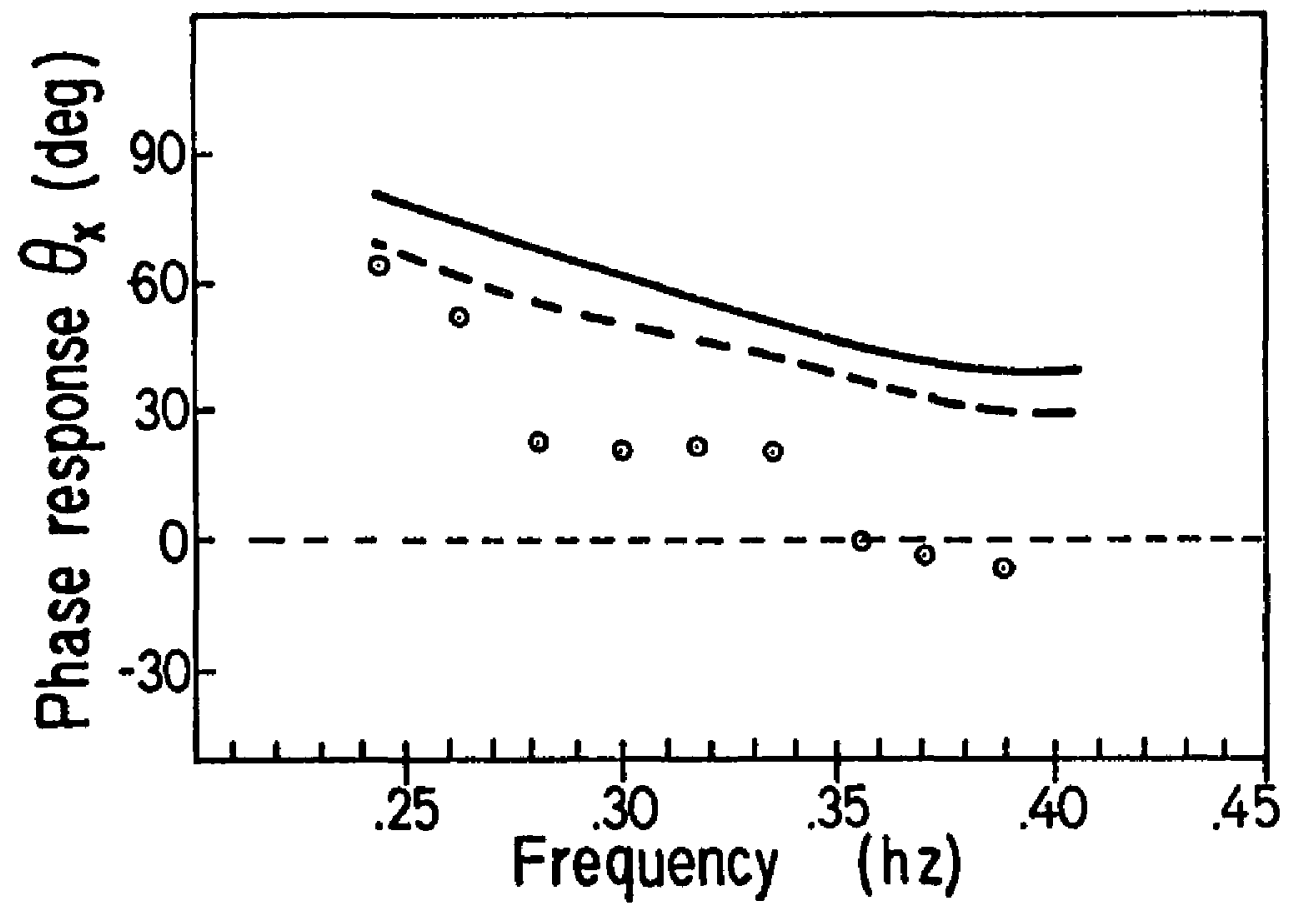

Figure 30. Horizontal frequency response. 


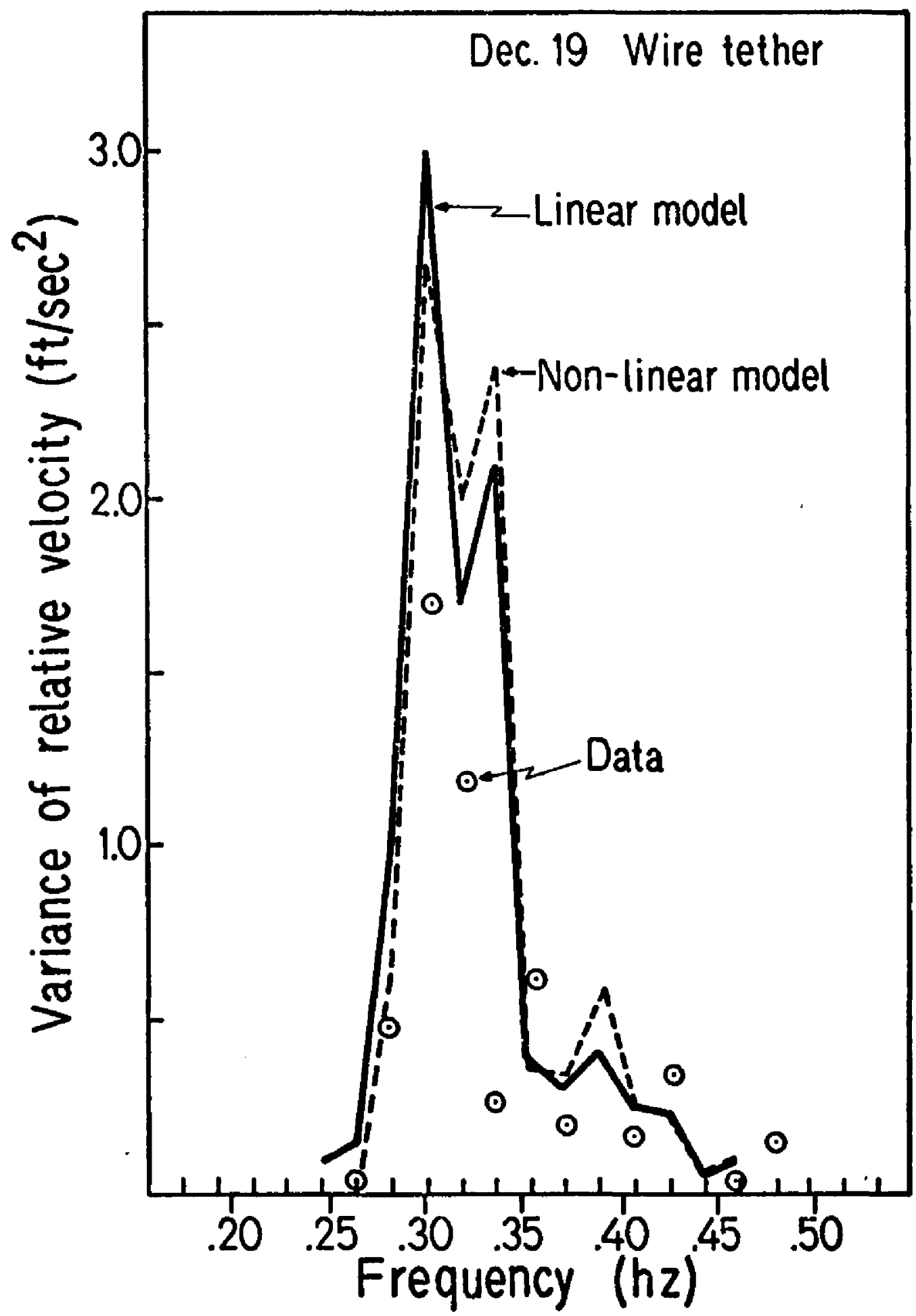

Figure 31. Spectrum of horizontal relative velocity. 
TABLE 5

Statistics for the Measured and Simulated Motions

of the Wire-tethered Buoy

Response estimated from

field experiment

non-1 inear model

Tinearized model $x_{s}$

$4.5^{\prime}$

$5.8^{\prime}$

$5.0^{\prime}$
${ }_{u}$ $1.91 / \mathrm{sec}$ $2.4^{\prime} / \mathrm{sec}$ $2.11 / \mathrm{sec}$ 
from five records on November 5 are provided in Appendix D. Scatter in the measured vertical response on November 5 , shown in Figure D-4, was considerable; however, the trend of the data was consistent with what analysis predicted. I estimated the vertical natural frequency to be 0.64 hertz based on a measured elastic tether spring constant of 65 pounds per foot. Assuming the damping coefficient in the vertical direction was 0.40 , I estimated the vertical resonant frequency would be 0.50 hertz, higher than the wave frequencies in the lake.

This mismatch in vertical resonance and wave frequency was reflected in the measured spectrum of buoy motion. Typically, the variance of horizontal buoy displacements was an order of magnitude greater than the variance of the vertical displacements. The vertical amplitude response, though low, increased with frequency as would be expected.

Initial assumptions for drag and mass coefficients for modeling the smooth, elastic-tethered buoy were 0.42 and 0.50 , respectively. A range of other values was investigated as well, but the best correspondence between models and data was for these initially assumed values. Figure 32 compares the average measured frequency response for the records of December 18 with predictions by the models. Significant buoy excursion calculated from the non-linear and linear models were within 5\% and $12 \%$ respectively of that calculated from the field data. Figure 33 compares the measured and predicted spectrum of horizontal relative velocity. The rms of buoy relative velocities calculated from both 


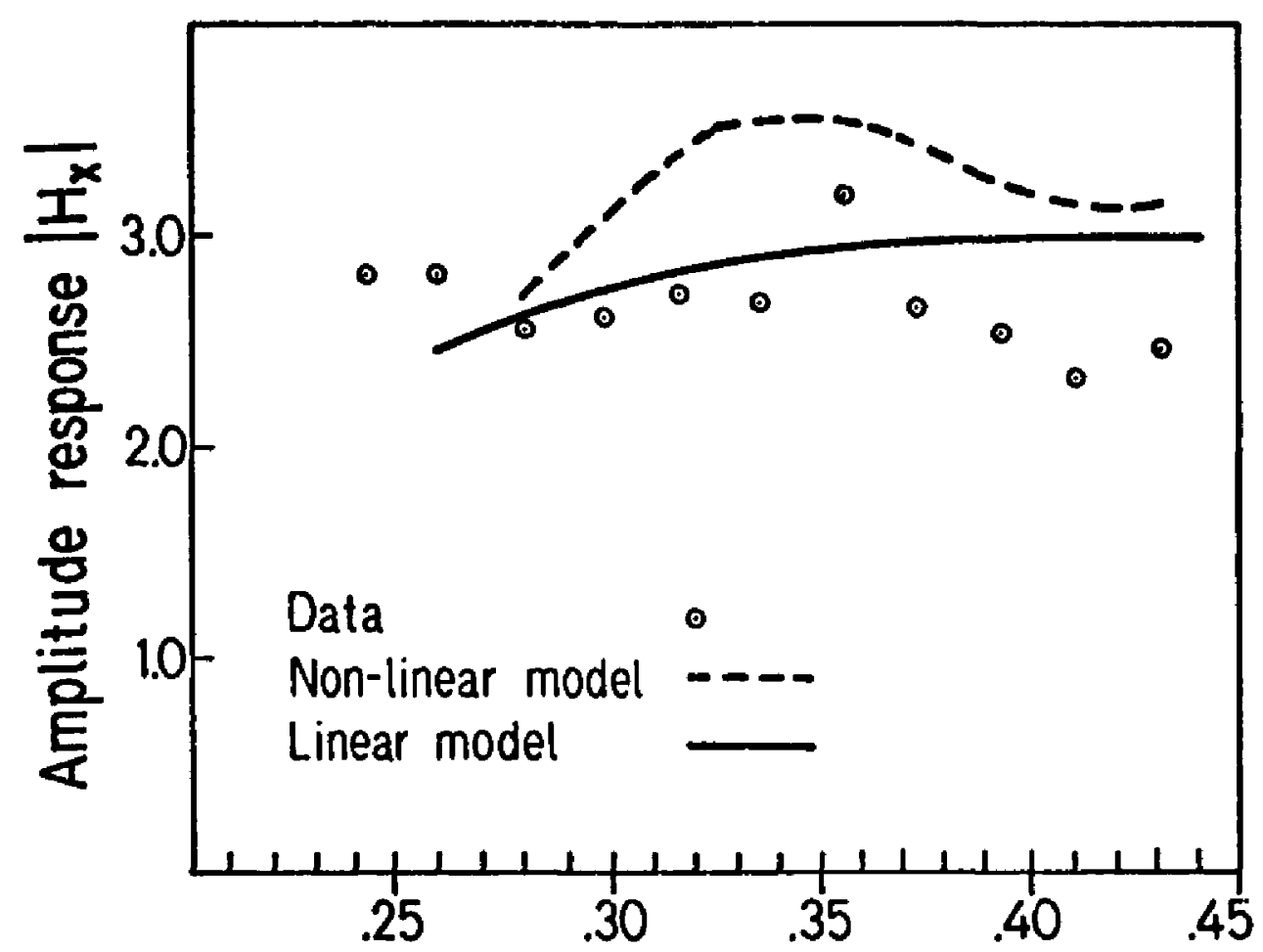

Dec. 18 Elastic tether

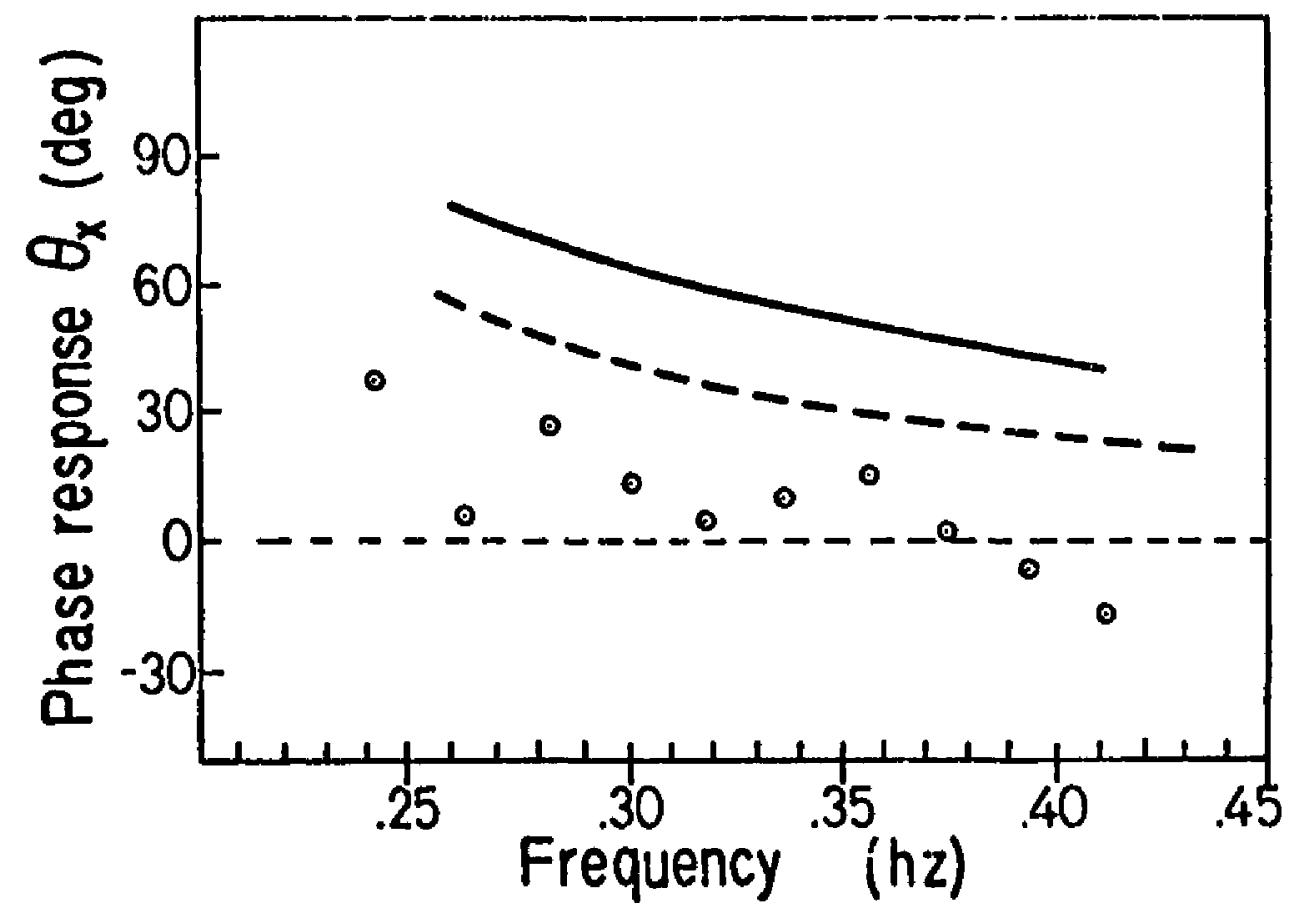

Figure 32. Horizontal frequency response. 


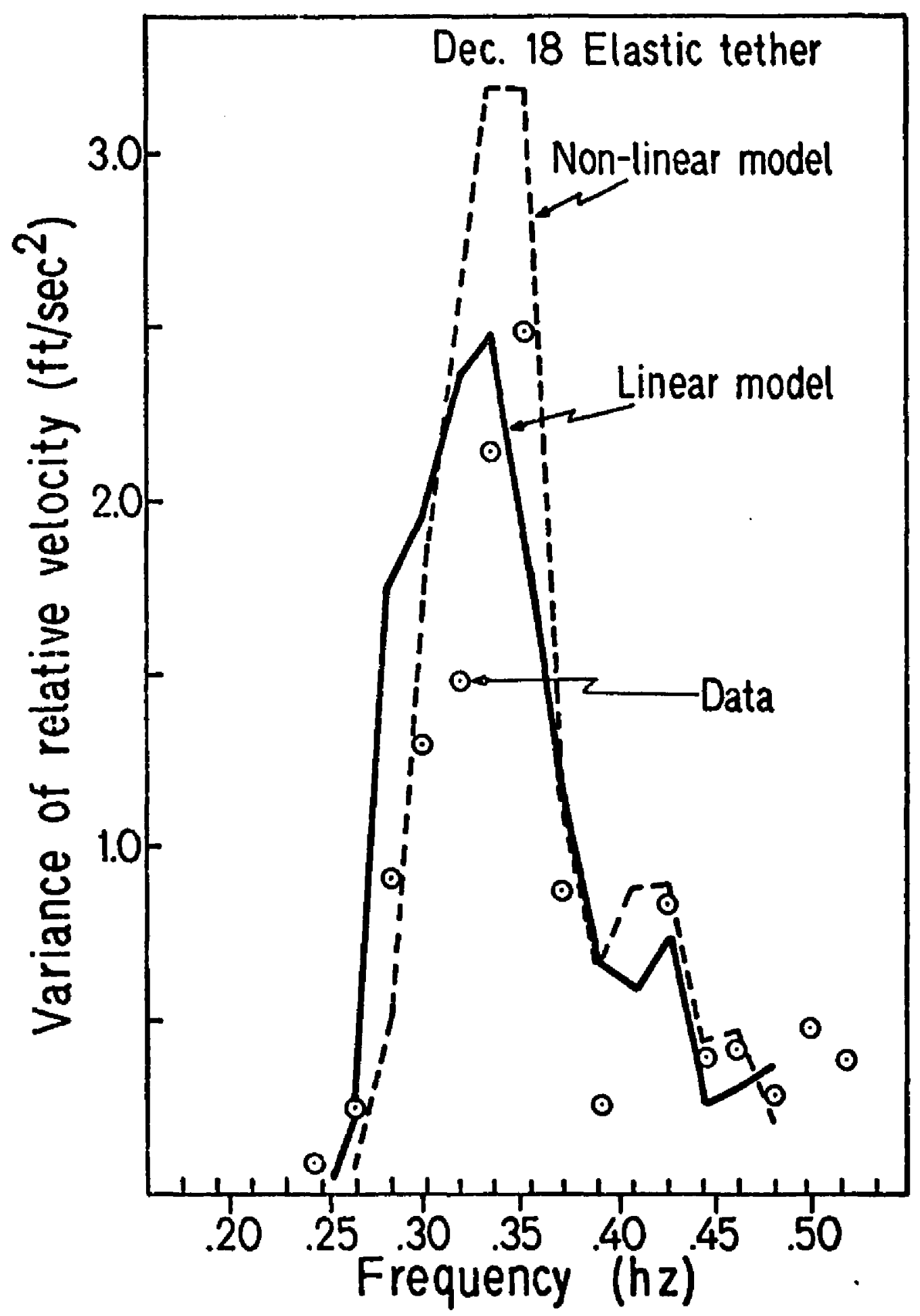

Figure 33. Spectrum of horizontal relative velocity. 
TABLE 6

Statistics for the Measured and Simulated Motions of an Elastically Tethered Element

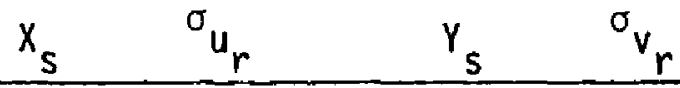

December 18

Record $\overline{9,10}$

\begin{tabular}{|c|c|c|c|}
\hline Measured & $4.6^{\prime}$ & $1.9^{\prime} / \mathrm{sec}$ & n.a. \\
\hline $\begin{array}{l}\text { non- } 1 \text { inear } \\
\text { model }\end{array}$ & $4.8^{\prime}$ & $2.0^{\prime} / \mathrm{sec}$ & $1.2^{\prime}$ \\
\hline $\begin{array}{l}\text { linear } \\
\text { mode } 1\end{array}$ & $4.2^{\prime}$ & $1.9^{\prime} / \mathrm{sec}$ & $1.4^{\prime}$ \\
\hline
\end{tabular}

November 5

$\begin{array}{cccccc}\text { Record } \overline{1,2,3} & \begin{array}{c}\text { Measured } \\ \text { non-linear } \\ \text { model }\end{array} & 3.7^{\prime} & 1.6^{\prime} / \mathrm{sec} & 1.0^{\prime} & 1.0^{\prime} / \mathrm{sec} \\ & 4.0^{\prime} & 1.8^{\prime} / \mathrm{sec} & 0.9^{\prime} & 1.0^{\prime} / \mathrm{sec}\end{array}$


models were within about $10 \%$ of that calculated from the field data. Statistical results are sumarized in Table 6.

\section{B. Modeling Energy Dissipation}

The simulated wave excitations and buoy excursions were sampled and spectrally analyzed. The resulting spectra of wave-induced water and buoy displacements were substituted into Equation 88 , yielding a spectrum of buoy relative velocity in each direction--horizontal and vertical. By Equation 84, the performance of a row of buoys was computed. Performance was also computed by the linear model. Figure 34 compares the results from both with performance measured in the field on Decmeber 18. I fit a straight line to the data by the method of least squares. The measured and predicted results were close to one another, particularly at frequencies of maximum energy.

Figure 35 shows a similar comparison for breakwater performance November 5. Statistical results are summarized in Table 7 . Although these statistical predictions were very close, they do not reveal from where in the spectrum the energy was dissipated, as is shown in Figures 34 and 35 . The low wave energy at either end of the spectrum-and therefore larger possible errors--may have contributed to the discrepencies between field and model results there. Also, contributions to energy dissipation by high-frequency vertical buoy response in the model may not have actually occurred in the field. Relative motions in this direction were small and whether energy was dissipated according to the model at these small oscillations is open to question. 


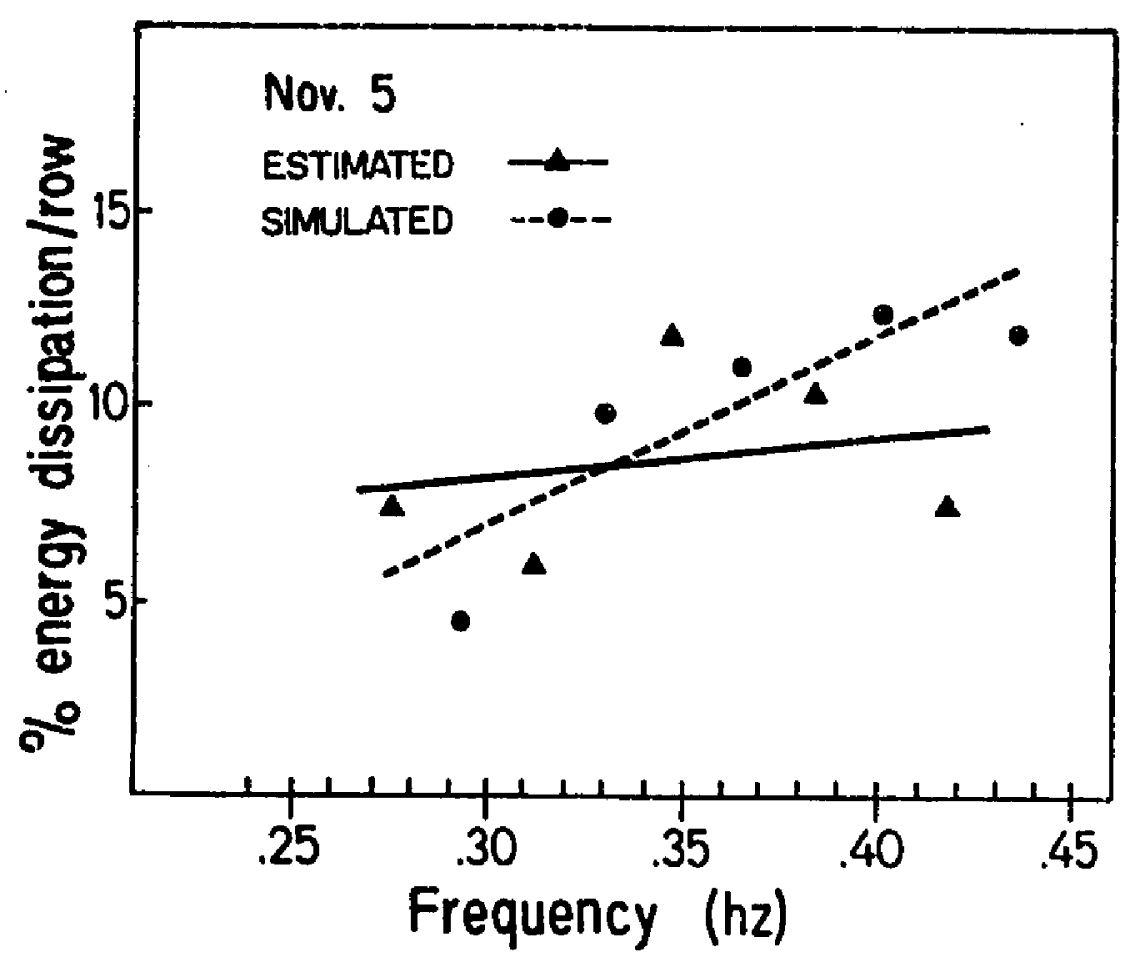

Figure 34. Measured and modeled breakwater performance.

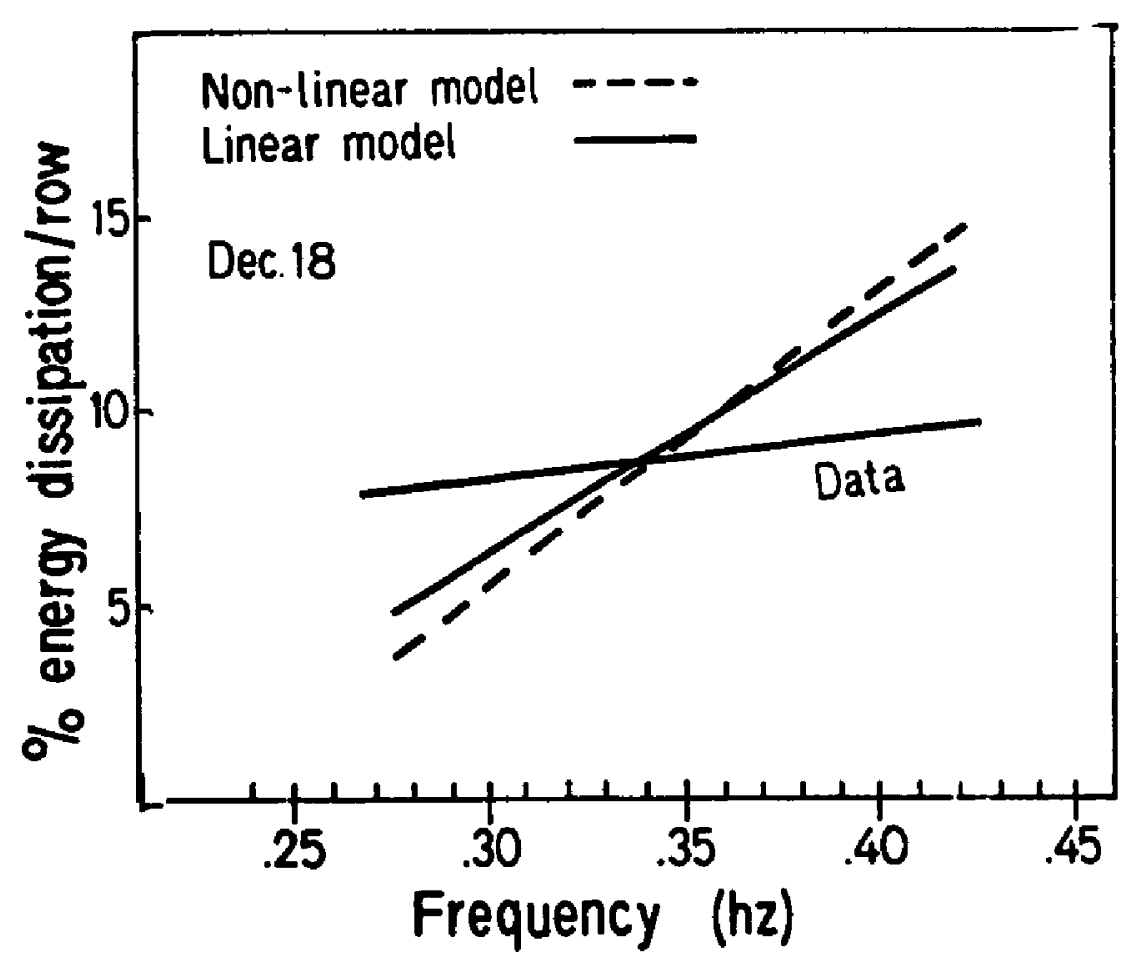

Figure 35. Measured and modeled breakwater performance. 
TABLE 7

Comparison of Performance Estimates from Field

Data and Models

$H_{S_{i}} \quad H_{S_{a}} \quad \bar{E}_{D} \quad \bar{\ell}_{D}$

$\begin{array}{llllll}\frac{\text { December }}{9,10} 18 & \text { Measured } & 2.1 & 1.4 & 55 \% & 8.5 \% \\ & \begin{array}{c}\text { non-1inear } \\ \text { model }\end{array} & 2.0 & 1.4 & 54 \% & 7.8 \%\end{array}$

November 5

$\overline{1,2,3}$

$\begin{array}{ccccc}\text { Measured } & 1.8 & 1.2 & 56 \% & 8.7 \% \\ \begin{array}{c}\text { non-linear } \\ \text { model }\end{array} & 1.7 & 1.1 & 57 \% & 8.9 \% \\ & & & & \end{array}$


C. Discussion of Results and Application of the Model to Design Problems

Elastic versus wire tethers: Initial mathematical analysis had indicated that properly tuned elastic-tethered buoys could dissipate more wave energy than identical wire-tethered ones when cable drag is small and the buoy is moored in the region of highest wave pressure. Wave tank tests using gum rubber bands for tetheres supported this finding. However, the compliance of tether material commercially available was too low for use in the field test. Consequently, vertical buoy response observed in the wave tank tests could not be duplicated in the field test.

What tether compliance would be required for an elastic-tethered system to be more effective than a wire-tethered one? To answer this question, I mathematically simulated energy dissipation by tethered buoys over a range of spring constants. Real tethers have a nonlinear loadelongation curve (see Figure 4). Nevertheless, I used the percentage of static elongation (elongation due to net buoy displacement) of an idealized linear elastic tether for a non-dimensional measure of spring constant. This measure provided a benchmark for future tether material assessment. For the simulations, I used the following values of model parameters:

$$
\begin{array}{ll}
\text { wave height, } H & =2.50 \mathrm{ft} . \\
\text { wave period, } \tau & =3.00 \mathrm{secs} . \\
\text { buoy diameter, } d & =1.67 \mathrm{ft} . \\
\text { elastic tether diameter, } d_{t} & =1.25 \mathrm{in} . \\
\text { wire tether diameter, } d_{t} & =0.1875 \mathrm{in} . \\
\text { tether length, } 1_{0} & =8.0 \text { to } 16.0 \mathrm{ft} .
\end{array}
$$




$$
\begin{aligned}
\text { tether drag coefficient, } C_{D} & =1.00 \\
\text { percent elongation } & =100\left(1_{0}-r_{0}\right) / r_{0} \\
\text { depth buoy submergence, } z_{0} & =d\left(10-r_{0}\right)
\end{aligned}
$$

The depth of buoy submergence was made to increase with static elongation in such a way that the buoy did not broach the surface during its dynamic response. In future investigations, this constraint should be relaxed because tethering the buoy near the surface, where the wave pressure is greatest, may dissipate the most energy. Surface effects and partial wave reflection by oscillating buoys have not been modeled either experimentaliy or mathematically.

Figure 36 shows the modeling results for three different static tether lengths, $1_{0}$. Energy dissipation by a buoy whose static linear tether elongation was $100 \%$ only slightly exceeded that of the same buoy tethered by a wire. The combination of increased tether drag due to the larger diameter rubber filaments and the decreased wave pressure due to deeper submergence offset the dissipation from increased vertical response, as shown in Figure 37. This conclusion will bear re-evaluation in light of experiments using surface-broaching buoys or thinner more compliant elastic tethers not presently available.

Effect of wake development on performance: From his ocean experiment, Seymour (1974) deduced $C_{M}$ to be 0.35 and $C_{D}$ to be 0.25 , values he thought represented fully developed wake conditions. From my wave tank and lake experiments, I deduced $C_{M}$ to be 0.50 and $C_{D}$ to be 0.42 , values representing 


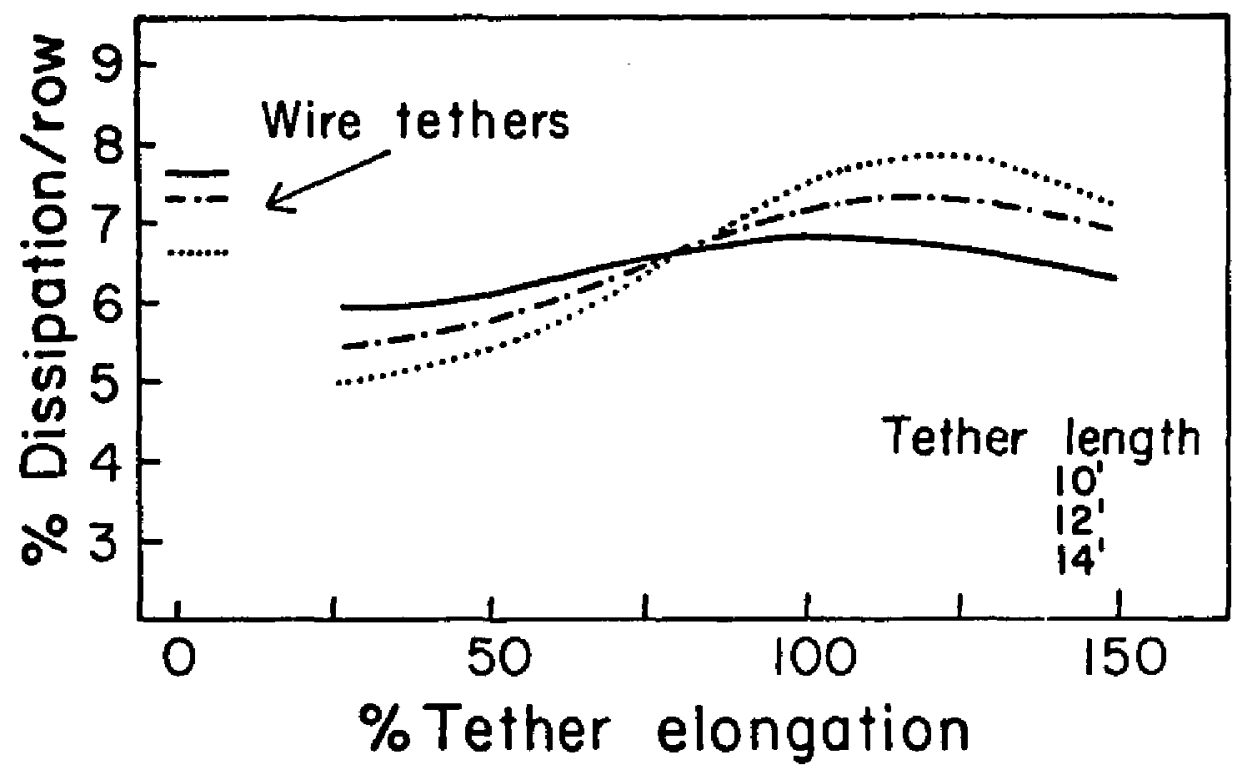

Figure 36. Breakwater performance versus tether compliance (\% elongation).

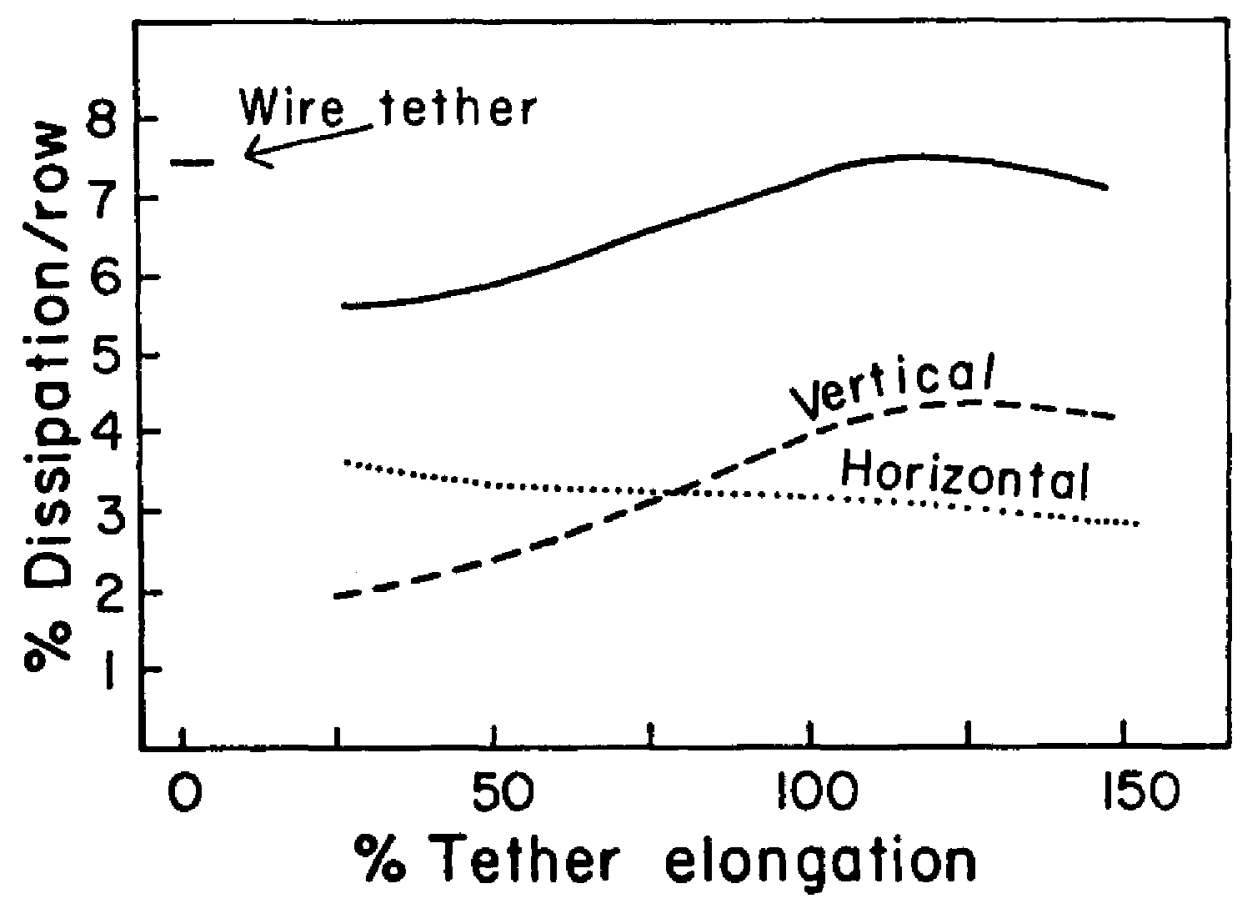

Figure 37. Horizontal and vertical components. of breakwater performance. 
turbulent, but not fully turbulent wake conditions. From the standpoint of breakwater performance, does it matter whether the wake is fully or partially developed? To answer this question, I substituted each pair of flow coefficients into the linear mathematical model of a wire-tethered system. Results, summarized in Table 8 , indicated that the maximum wave energy dissipation per row would be the same in both cases--about eight percent. Tethered sphere response is inversely related to hydrodynamic resistance. Consequentiy, energy dissipation--the product of response and resistance--has low sensitivity to drag coefficient. However, tether length to achieve maximum energy dissipation for a given pair of flow coefficient is unique, as pointed out in Table 8.

Flow Coefficients: Sarpkaya (1975) correlated flow coefficients with period parameter for spheres in one-directional oscillatory flow. He found "absolutely no correlation of flow coefficients with Reynolds number" $\left(N_{R}\right)$ over a range of $N_{R}$ from $10^{4}$ to $6 \times 10^{5}$. In contrast to Sarpkaya, Rance (1969) found that maximum wave force was related to both period parameter and Reynolds number, based on his experiments on fixed cylinders in a pulsating water tunnel where $N_{R}$ reached $3.5 \times 10^{5}$. He concluded that small scale model tests would give erroneous indications of wave forces on prototype ocean pile structures.

Sarpkaya's and Rance's data are shown in Figures 38 and 39 , respectively. It is difficult to make comparisons between their experiments because the tests were conducted under different conditions. In attempting to achieve Reynolds numbers higher than $2.5 \times 10^{5}$ in the laboratory, the investigators may have introduced effects not accounted for in the Morison 
TABLE 8

Optimum tether length and maximum performance

for different levels of wake development

\begin{tabular}{lllll} 
& $D$ & $1_{0}$ & $\bar{\ell}_{x}$ & $\sigma_{u_{r}}$ \\
\hline $\begin{array}{l}\text { Turbulent flow } \\
C_{M}=0.50\end{array}$ & $1.67^{\prime}$ & $7.5^{\prime}$ & $8 \%$ & $2.5^{\prime} / \mathrm{sec}$ \\
$C_{D}=0.42$ & & & & \\
$\begin{array}{l}\text { Fully turbulent flow } \\
C_{M}=0.35 \\
C_{D}=0.25\end{array}$ & $1.67^{\prime}$ & $11.0^{\prime}$ & $8 \%$ & $3.0^{\prime} / \mathrm{sec}$ \\
\hline
\end{tabular}



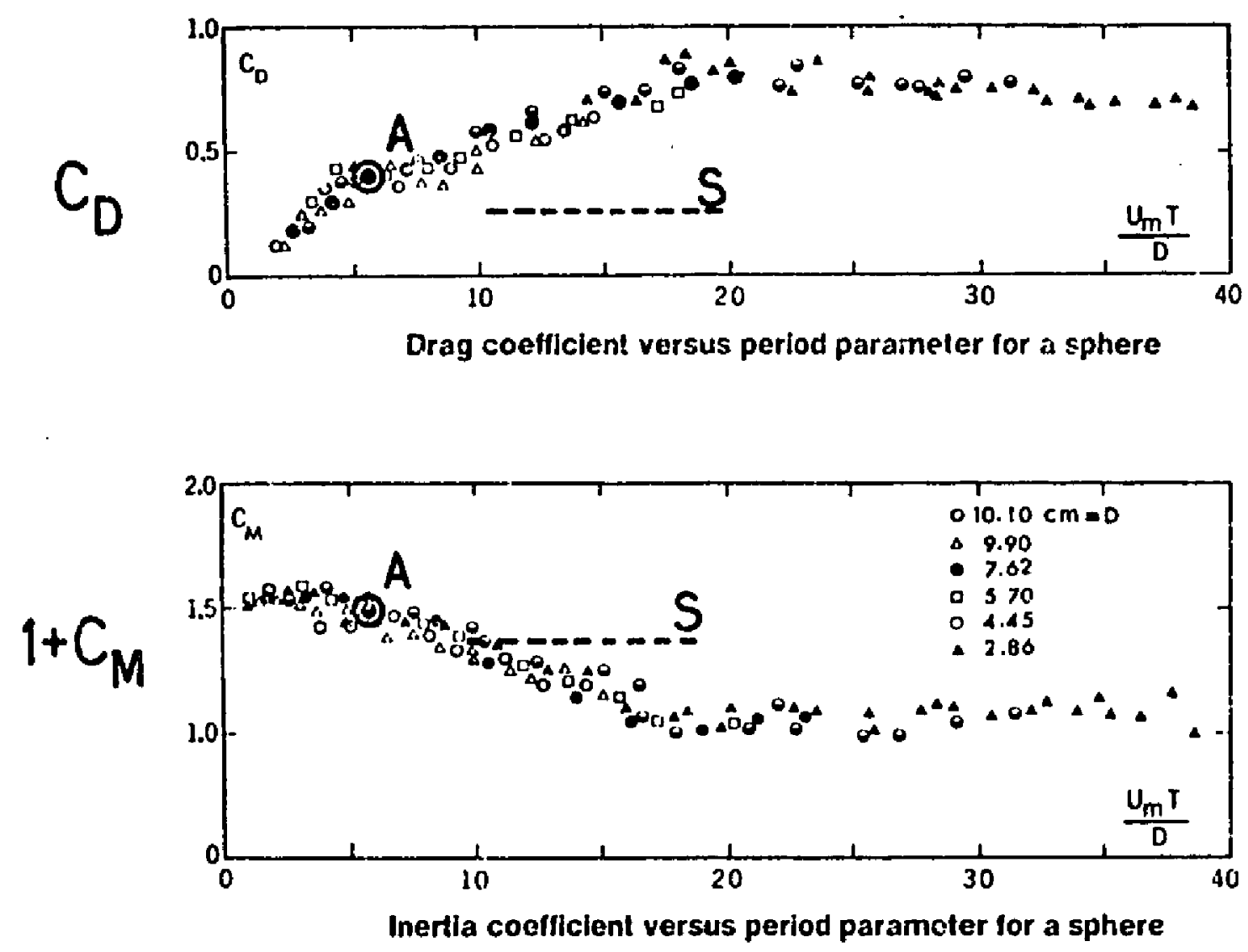

Flow coefficients vs period parameter

Figure 38. Drag and mass coefficients for spheres vs. period parameter (Sarp̣kaya, 1975). 


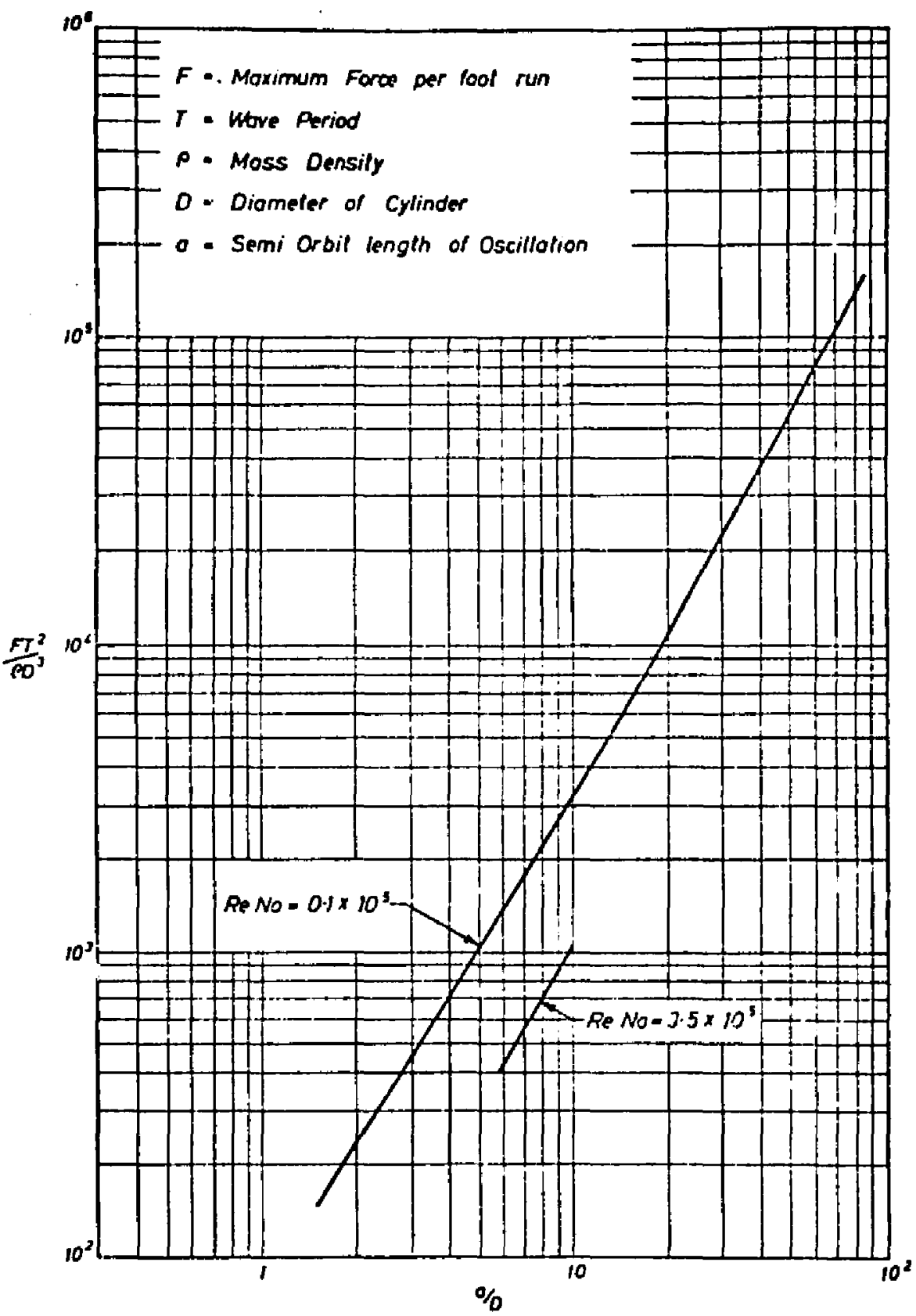

FORCES IN THE LINE OF MOTION

Figure 39. Maximum wave force parameter vs. a/d and $\|_{r}$ for cylinders (Rance, 1969). 
equation--such as wave scattering or reflection.

In my wave tank and lake experiments, the wave height to diameter ratio $\left(H_{S} / d\right)$ was equal to $1.0^{\star}$. Although average $N_{R}$ was an order of magnitude greater in the lake, the flow coefficients were the same on both scales. I do not know if these flow coefficients would remain the same for constant period parameter (ratio $\mathrm{H}_{\mathrm{S}} / \mathrm{d}$ ) but higher Reynolds number. There are no data or firmly established relationships on which to reach such a conclusion.

In addition to my work, only one two-dimensional laboratory wave force experiment has been reported for spheres: Harleman and Shapiro's in 1958. It would be speculation to say that results of experiments conducted in one-dimensional flow are applicable in all respects to the two-dimensional flow probiem of a tethered sphere. In this latter case, the flow separation points rotate around the object with the changing direction of flow. Also, the vertical accelerating flow may alter (or be altered by) the low pressure wake due to horizontal flow.

Despite such unknown effects I compared my estimates of flow coefficients with Sarpkaya's. The average $a_{r} / d$ for my field test buoy was 0.65 . Multiplying that number by $2 \pi \sqrt{2}$, the buoy had an equivalent period parameter of about 6.0. At this period parameter, Sarpkaya reported values of $C_{M}$ and $C_{D}$ of 0.50 and 0.40 , respectively--very close to those I deduced from my lake and wave tank experiments. In Figure 38, my data are plotted on top of Sarpkaya's and are symbolized by heavy circles, denoted "A".

The match between field test data and Sarpkaya's laboratory data

* Experiments at $H_{s} / d$ as high as 1.5 were also conducted. 
may not occur at higher period parameters, possibly because of a Reynolds number effect as occurs in steady flow at $N_{R}=2.5 \times 10^{5}$. Flow coefficients reported by Seymour (1974) at higher $N_{R}$ and period parameter than mine did not correspond to Sarpkaya's (1975) data. I estimated that Seymour's equivalent period parameter had been between 10 and 20 and that his $N_{R}$ was at least $5 \times 10^{5 *}$. For these period parameters, Sarpkaya reported $C_{D}$ values between 0.50 and 0.80 , two to three times higher than the value reported by Seymour. Seymour's data over the estimated period parameter range is shown by a dashed line in Figure 38 and is denoted by "S".

Scale Model Testing: If flow coefficients were solely functions of $\mathrm{H} / \mathrm{d}$ (period parameter), then model tests could provide scalable results for a broad range of Reynolds numbers. The question of this possibility is raised by Sarpkaya's (1975) and Keulegan and Carpenter's (1958) results. However, little data has been available at sufficiently high $N_{R}$ (greater than $2.5 \times 10^{5}$ ) test the hypothesis.

Based on my experiments and analysis, I reached three conclusions regarding physical scale model testing of tethered float breakwaters: 1) The wave tank experiments could have provided a scalable model of a wire-tethered breakwater for the lake experiments because the flow coefficients were the same in both. 2) Wave tank tests can yield accurate estimates of full-scale breakwater performance if the drag and mass co-efficients do change with scale to the values Seymour reported. 3) In

* I estimated $N_{R}$ for Seymour's field experiment as $2 \sigma_{u_{r}} d / 1.3 \times 10^{-5}$ for comparison with Sarpkaya's data in regular oscillatory flow. 
addition to dissipation effects, some wave tank model designs may scale to ocean prototype because at low period parameters (6 to 10) the wake is not fully developed and a Reynolds number effect--like that observed in steady flow at $N_{R}=2.5 \times 10^{5}$--may not occur.

Choice of Buoy Diameter: Choice of tether length and spring constant was based on maximizing energy dissipation. Choice of buoy diameter was approached differently. As long as flow coefficients don't change with increasing diameter, the buoy which dissipates the most energy will be the largest allowable within the model assumptions. However, by the criteria of cost and practicality, it is not obvious whether an array of many small buoys is to be preferred over an array of fewer large buoys.

To assess cost effectiveness, I computed the cost per foot of breakwater frontage required to dissipate 75 percent of the incident wave energy in a lake-scale installation. Modeling results indicated that 1) the most economic lake-scale installation would use the largest size buoy. 2) Achieving fully turbulent flow conditions--which requires high period parameters--appears undesirable from the standpoint of cost-effectiveness. 3) Cost variation over the diameter range examined was $300 \%$, indicating that the choice of buoy size is a critical economic decision.

Cost per foot of breakwater frontage was calculated as

$$
C / F F=n_{r} \beta \$
$$

where $n_{r}$ is the number of rows of buoys required to dissipate $75 \%$ of the incident energy; $\beta$ is the buoy packing density, 1/2d; and $\$$ is the 
unit cost of breakwater element. The number of rows $n_{r}$ was computed from Equation 35. The maximum percentage energy dissipation per row $\ell$ for a given buoy diameter was found by varying tether length over successive model runs. Optimum tether length varied with damping, so it had to be determined for each case. Dissipation per row was determined from the linear model for a range of buoy diameters from 0.5 to 2.0 feet. The excitation spectrum was that of December 18 in which $H_{S}=2.2$ feet. Thus, $H_{S} / d$ ratios ranged from 1.0 to 4.4 . Both pairs of flow coefficients were substituted into the model.

I estaimated unit costs of a tethered breakwater element based on currentiy available materials: inflatable Norwiegen fishing floats, wire-rope, and safety-pin shackles. Figure 40 shows the almost linear relationship of unit material costs to buoy diameter. I did not estimate labor, anchoring and installation costs because my field experiment was not typical of a production type installation. Also, I do not know how these cost figures would change for a larger scale installation. Consequently, my results do not necessarily represent the general case.

Figure 41 shows the number of rows of buoys required to dissipate $75 \%$ of the incident wave energy. Figure 42 shows the dollar cost of per foot of breakwater frontage. Buoys 0.5 feet in diameter $\left(H_{s} / d=4.4\right)$ were so small that drag forces dominated inertial forces. Consequently, there was hardly any buoy response or energy dissipation. The upper limit of $\mathrm{H}_{\mathrm{S}} / \mathrm{d}$ is about 3.0 if the array rows are to number less than one hundred. The lower limit of $\mathrm{H}_{\mathrm{s}} / \mathrm{d}$ was $1.0(\mathrm{~d}=2.0 \mathrm{ft}$.) for a system in waves as short as 20 feet in length. Larger diameters would have been beyond the limits of the Morison equation. 


$$
M
$$




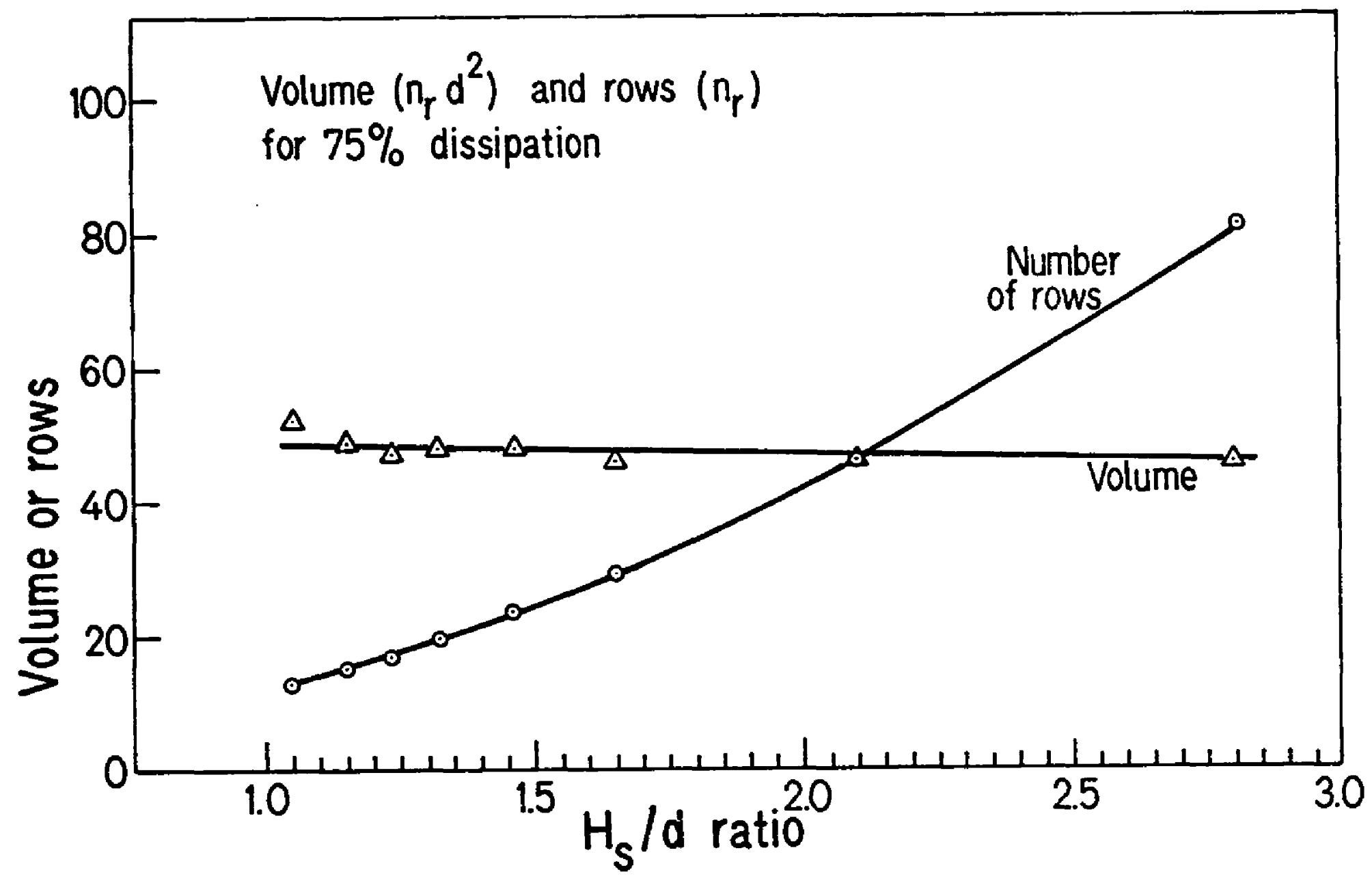

Figure 41. Total volume displacement per foot and number of rows of buovs required to dissipate $75 \%$ of incident vave energy vs. His /d ratio. 


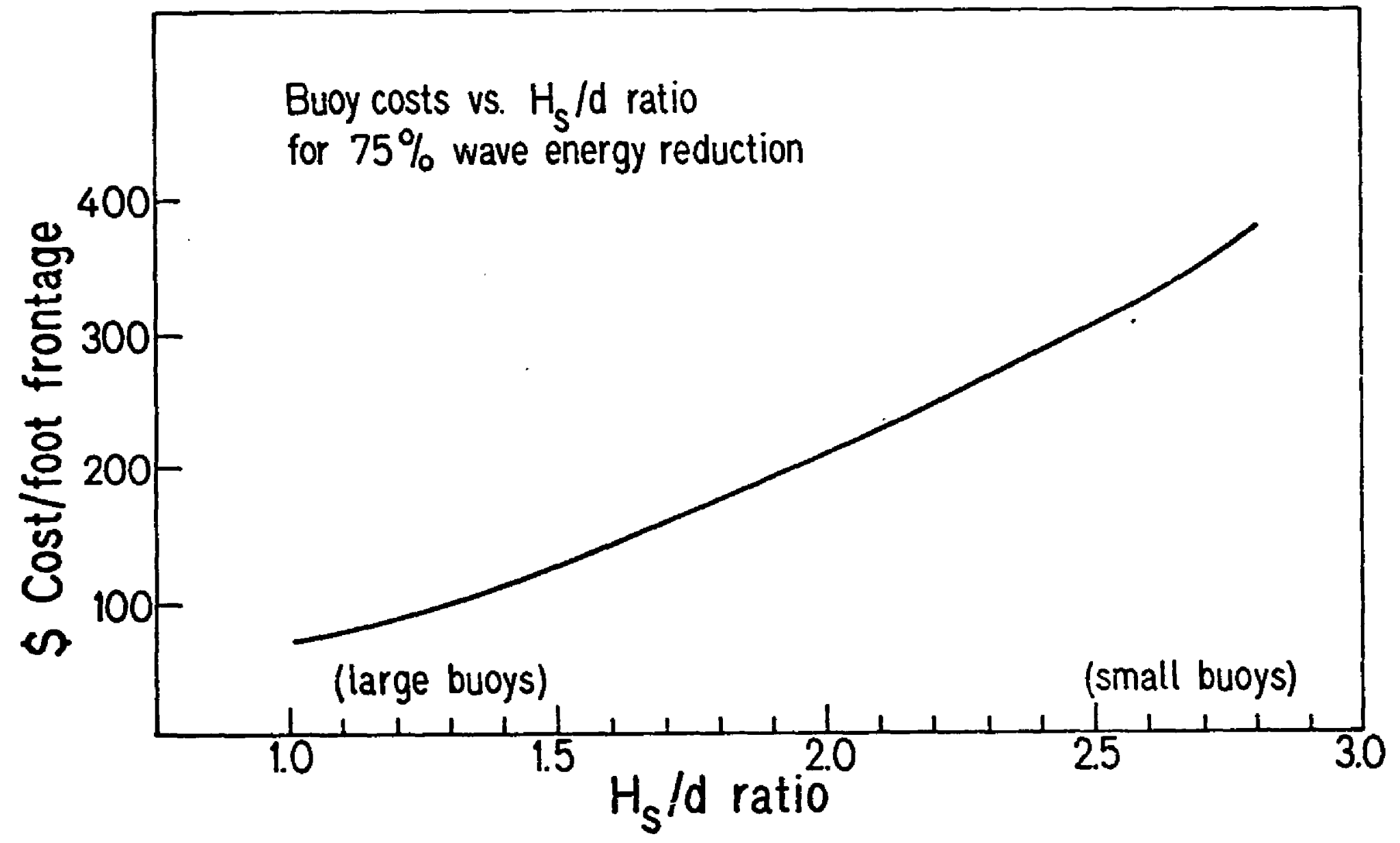

Figure 42. Cost per foot frontage to dissipate $75 \%$ of incident wave eneroy vs. $\mathrm{H}_{\mathrm{S}} / \mathrm{d}$ ratio. 
As diameter increases, the buoy will begin to act as a wall reflecting wave energy. Generation of turbulence will probably decrease. Mathematical models do not yet account for wave height attenuation from a mix of form drag and reflection. It may be that partial reflection can be used advantageously in an installation providing the mooring loads and anchoring requirements of large buoys can be accommodated technically and economically.

Results of my modeling also indicated that the total volume displaced by the buoy array to achieve $75 \%$ dissipation was independent of buoy diameter, as shown in Figure 41 . Therefore, total anchoring weight requirements are not sensitive to buoy diameter.

The array beam (width) is proportional to the number of required rows times the buoy diameter. It follows from results shown in Figure 41 that the narrowest array would be for the largest buoy diameter. Therefore, anchoring frame material costs are inversely related to diameter, adding further economic incentive to use large buoys. 


\section{CONCLUSIONS AND RECOMMENDATIONS}

\section{Conclusions:}

1. Mathematical Modeling: Dynamic response and energy dissipation by an array of tethered buoys can be predicted with reasonable accuracy providing the following conditions apply:

a) The wave forces can be described by the Morison equation.

b) Surface effects and wave reflection by the buoys are insignificant.

c) Incident wave fronts are parallel to the array rows.

d) Coefficients of buoy mass and drag are known.

e) Tethered buoys act independently of one another.

For the special case of low compliance tethers--such as were used in the field test--the linear and nonlinear mathematical models gave nearly identical results.

2. Use of Elastic Tethers: Field testing the use of elastic tethers to enhance wave energy dissipation was limited by the state of the art and quality control in the manufacturing of solid rubber filaments. However, mathematical modeling of idealized tethers indicated that at the anticipated tether thicknesses and depths of buoy submergence, energy dissipation by an elastic-tethered system will be only slightly greater than that by a wire-tethered system. A premise of this conclusion is there are no surface effects or wave reflection.

3. Tethered Float Design: The two major decisions facing the 
designer are choice of tether length and buoy diameter. Tether length to properly tune the system is found from an iterative solution to the linear model. Both damping and mass coefficient effect the system's resonant frequency, and therefore, the choice of tether length. Choice of buoy size is a decision based on cost and technical considerations. The most cost-effective buoy size is the largest allowable within the limits of model assumptions. However, technical problems in deploying, anchoring, and holding on the buoys may become dominant design considerations.

4. Scale Model Testing: Achieving a fully developed turbulent wake is not a prerequisite for maximum breakwater energy dissipation. Therefore, relatively low cost wave tank models can accurately predict full-scale breakwater energy dissipation. Moreover, at period parameters where the wake is not fully developed, there is evidence that flow coefficients for a full scale prototype may be unchanged from their values in the wave tank. In this case, wave tank model designs will scale to prototype.

\section{Recommendations:}

1. Flow Coefficients: The relationships between period parameter, Reynolds number, and flow coefficients for tethered spheres in waves are uncertain. It is important that they be determined, particularly for Reynolds numbers above $2.5 \times 10^{5}$. Field tests lack the flexibility, and they are dependent upon the weather. Some large wave basins (such as at Wageningen, Netherlands can generate waves more than an order of magnitude 
larger than those in the MIT wave tank and larger than I measured in Lake Winnipesaukee. Experiments in such a facility are therefore recommended as a next step in tethered float breakwater development.

2. Hydrodynamic Design Questions: Several engineering design questions deserve investigation. These include the following:

a) The effects of wave diffraction within and behind the array.

b) The effects of the breakwater on waves impinging from directions other than the perpendicutar.

c) The effect of surface-piercing buoys versus always-submerged buoys.

3. Practical Design Questions: During this investigation, I did not consider the practical problems which would be encountered in an offshore tethered float breakwater installation. These include the following:

a) Anchoring the array in deep water.

b) Supporting the array of buoys in a multiple-connected space frame.

c) Deploying the breakwater system.

d) Maintaining the breakwater over long time periods. These areas require attention before tethered float breakwaters can be depended upon as a wave-protection system. 


\section{REFERENCES}

Agerschou, H. A., and J. J. Edens, Fifth and first order wave-force coefficients for cylindrical piles, Coastal Engineering: Santa Barbara Specialty Conference, ASCE, October, 1975.

Bendat, J. S., and A. G. Piersol, Random data: analysis and measurement procedures, Wiley-Interscience, 1971.

Boonton, R. C. Jr., The analysis of nonlinear control systems with random inputs. Proc. of Symposium on nonlinear circuit analysis, Polytech. Inst. of Brooklyn, April 1953.

Borgman, L. E., The spectral density for ocean wave forces, Coastal Engineering: Santa Barbara ASCE. October, 1965.

Bretschneider, C. L., Revision in wave forcasting: deep and shallow water, Proc. Sixth Conf. Coastal Engr., ASCE, 1957.

Delano, J. R., Design and field test of transmission line wave staffs for breakwater performance measurement, Master of Science project report, University of New Hampshire, 1976.

Demos, S. E., G. A. Stewart, and R. W. Corell, A computer study of the hydrodynamic loading of a compliant taut-wire mooring, Engineering Design and Analys is Laboratory, University of New Hampshire, Technical Report No. 109, July 1970.

Faltinsen, 0. M., and F. C. Michelsen, Motions of large structures in waves, Proc. international symp. on dynamics of marine vehicles and structures in waves, Univ. of College London, 1974.

Grace, R. A., and F. M. Casciano, Ocean wave forces on a subsurface sphere, J. Waterways Harbors Div., ASCE, Vol. 95, WW3 (8/69).

Griffiths, W. F., Dynamics of a buoy and mid-water body system, with elastic links, Masters Thes is, Univ. of N.H., Durham, N.H., 1973.

Harleman, D. F., and W. Shapiro, Dynamics of moored sphere in oscillatory waves, Proc. Seventh Conf. Coastal Engr., ASCE, 1960.

Hjelmfelt, A. T., J. F. Carney, III, C. F. Mocros, and S. L. Lee, Dynamic response of a restrained sphere in a fluid, J. Eng. Mechanics Div., ASCE, Vo1. 93, EM1, February 1967.

Horner, S. F., Fluid-Dynamic Drag, Published by the author, 1965. 
Jacobsen, L. S., Steady forced vibration as influenced by damping, Irans. ASME, Vol. 52, no. APM 52-15, 1930.

Keulegan, G. H., and L. H. Carpenter, Forces on cylinders and plates in an oscillating fluid, J. Res. National Bur. Standards, $\underline{\underline{60}}, 5$, May 1958.

Kikkawa, H., and T. Kono, Interference of submerged spheres caused by surface waves, Coastal Eng. in Japan, Vol. 13, 1970.

Kim, Y. Y., and H. C. Hibbard, Analysis of simultaneous wave force and water particle velocity measurements, Proc. 1975 Offshore Tech. Conf., Paper No. 2192.

Kuo, S. S., Computer applications of numerical methods, Addison-Welsey Publishing Co., Inc., 1972.

Laird, A. D. K., Water forces on flexible oscillating cylinders, J. Waterways Harbors Div., Proc. ASCE, Vol. 88, WW3, August 1962.

Lamb, Sir Horace, Hydrodynamics, Sixth ed., Dover Publications, Inc., 1945.

Longuet-Higgins, M. S., On the statistical distribution of the heights of sea waves, J. Mar. Res., Vol. 11, 3, December 1952.

MacCamy, R. C., and R. A. Fuchs, Wave forces on piles: a diffraction theory, U. S. Army, Corps of Engineers, Beach Erosion Board, Tech. Memo, No. 69, December 1954.

McNown, J. S., and G. H. Keulegan, Vortex formation and resistance in periodic motion, J. Engr. Mechanics Div., Proc. ASCE, Vol. 85, No. EM7, January 1959.

Morison, J. R., J. W. Johnson, M. P. O'Brien, and S. A. Schaaf, The forces exerted by surface waves on piles, Petroleum Trans., Vol. 189, TP2846, 1950.

Nath, J. H., and T. Yamamoto, Forces from fluid flow around objects, Proc. Fourteenth Coastal Engr. Conf., ASCE, Copenhagen, 1974.

Noble, H. M., Use of wave-maze flexible floating breakwater to protect offshore structures, Proc. 1976 Offshore Tech. Conf., Paper No. 2542 .

O'Brien, M. P., and J. R. Morison, The forces exerted by waves on objects, Trans. Amer. Geophys. Union, Vol. 33, 1, February 1952.

Penny, W. G., and A. T. Price, Diffraction of sea waves by breakwater, and the shelter afforded by breakwater, Phil. Trans. Roy. Soc., London, ser. A, 244, March 1952. 
Petryk, S., Drag on cylinders in open channel flow, Ph.D. Dissertation, Colorado State Univ., December 1969.

Rance, P. J., The influence of Reynolds number on wave forces, Proceedings: Research on Wave Action Symposium, Delft Hydrautics Lab., 1969.

Sarpkaya, T., and C. J. Garrison, Vortex formation and resistance in uns teady flow, J. Applied Mechanics, Vol. 30, No. 1, March 1963.

Sarpkaya, T., Forces on cylinders and spheres in a sinusoidally oscillating fluid, Transactions ASME, J. Applied Mechanics, March 1975.

Savage, G. H., and H. B. Hersey, Project seaspider: the design, assembly construction and sea trials of a tri-moored buoyant structure with neutrally buoyant legs to provide a near-motionless instrument base for oceanographic research, Reference No. 6842, Woods Hole, Mass.: Woods Hole Oceanographtc Institution, June 1968.

Savage, G. H., Buoy mooring systems, Annual Report of Progress-1971, Engr. Design and Analysis Lab., Univ. of New Hampshire, Durham, ONR Contract No. N00014-67-A-0158-0004.

Savage, G. H., Testing rubber band filaments as buoy moorings for some test navigation buoys, Engineering Design and Analys is Laboratory Report, Univ. of New Hampshire, Durham. Letter Report to United States Coast Guard Research and Development Center, Contract No. 4-20050-000, November 9, 1973.

Schlichting, H., Boundry-layer theory, J. Kestin, Trans. Sixth ed., McGraw-HiT1 Book Co., 1968.

Seymour, R. J., Resistance of spheres in oscillatory flows, Ph.D. Dissertation, Univ. California, San Diego, 1974.

Seymour, R. J., and J. D. Issacs, Tethered float breakwaters, Proceedings of First Int'l Conf. on Floating Breakwaters, Newport, R. I., Sea Grant Office, Univ, of Rhode Island, April 1974.

Shi-igai, H., and T. Kono, Study of vibration of submerged spheres caused by surface waves, Coastal Engr. in Japan, Vol. 12, 1969.

Stotz, K. C., D. 0. Libby, and G. H. Savage, Computer mode1 and data interpretation for a rubber cable tethered wave measuring buoy, Proc. Ocean 75 Conf., IEEE and MTS, San Diego, 1975.

Vidal, D. A., Design, analysis, construction, and installation of a floating breakwater anchoring system and related structures, Master of Science Project Report, Untv. of New Hampshire, 1975.

Wiegel, R. L., Oceanographic engineering, Prentice-Ha11, Inc., 1964. 
Wiegel, R. L., K. E. Beebe, and J. Moon, Ocean wave forces on circular cylindrical piles, J. Hyd. Div., ASCE, Vol. 83, HY2, Paper 1199, April 1957.

Winn, A. L., G. H. Savage, and R. R. Hickman, Design and instrumentation of a shore-recording wave amplitude measuring buoy, Proc. Ocean 75 Conf., IEEE and MTS, San Diego, 1975.

Winn, A. L., and K. C. Stotz, Design of transmission line wave staffs and associated instrumentation for a floating breakwater field test. [In progress, 1976]. 


\section{APPENDICES}

A. Kinematics of a Small Amplitude Wave

B. Instrumentation Calibration Curves

C. Computer Programs

D. Frequency Response Data 


\section{APPENDIX A}

Water particle kinematics in a traveling deep-water Airy wave were modeled by the following equations from Wiegel (1964):

Water-particle position:

$$
\begin{array}{ll}
\text { Vertical } & \eta=a e^{-k z} \sin (\omega t-k x) \\
\text { Horizontal } p=a e^{-k z} \cos (\omega t-k x)
\end{array}
$$

Water-particle velocity:

$$
\begin{aligned}
& v=\omega a e^{-k z} \cos (\omega t-k x) \\
& u=\omega a e^{-k z} \sin (\omega t-k x)
\end{aligned}
$$

Water-particle acceleration:

$$
\begin{aligned}
& \dot{v}=\omega^{2} a e^{-k z} \sin (\omega t-k x) \\
& \dot{u}=\omega^{2} a e^{-k z} \cos (\omega t-k x)
\end{aligned}
$$

In deep water-where depth $h$ exceeds one-half the wave length $\lambda--$ hyperbilic sine/cosine terms simplify with negligible error. Each such term,

$$
\frac{\cosh (k z+k h)}{\cosh (k h)} \text { and } \frac{\sinh (k z+k h)}{\cosh (k h)}
$$

has been replaced by the term $e^{-k z}$ in above equations. 


\section{APPENDIX B: Instrumentation Calibration}

B-1 Wave staff $A$, Incident Waves

B-2 Wave staff $B$, Attenuated Waves

B-3 Inclinometers

B-4 Tensiometer 


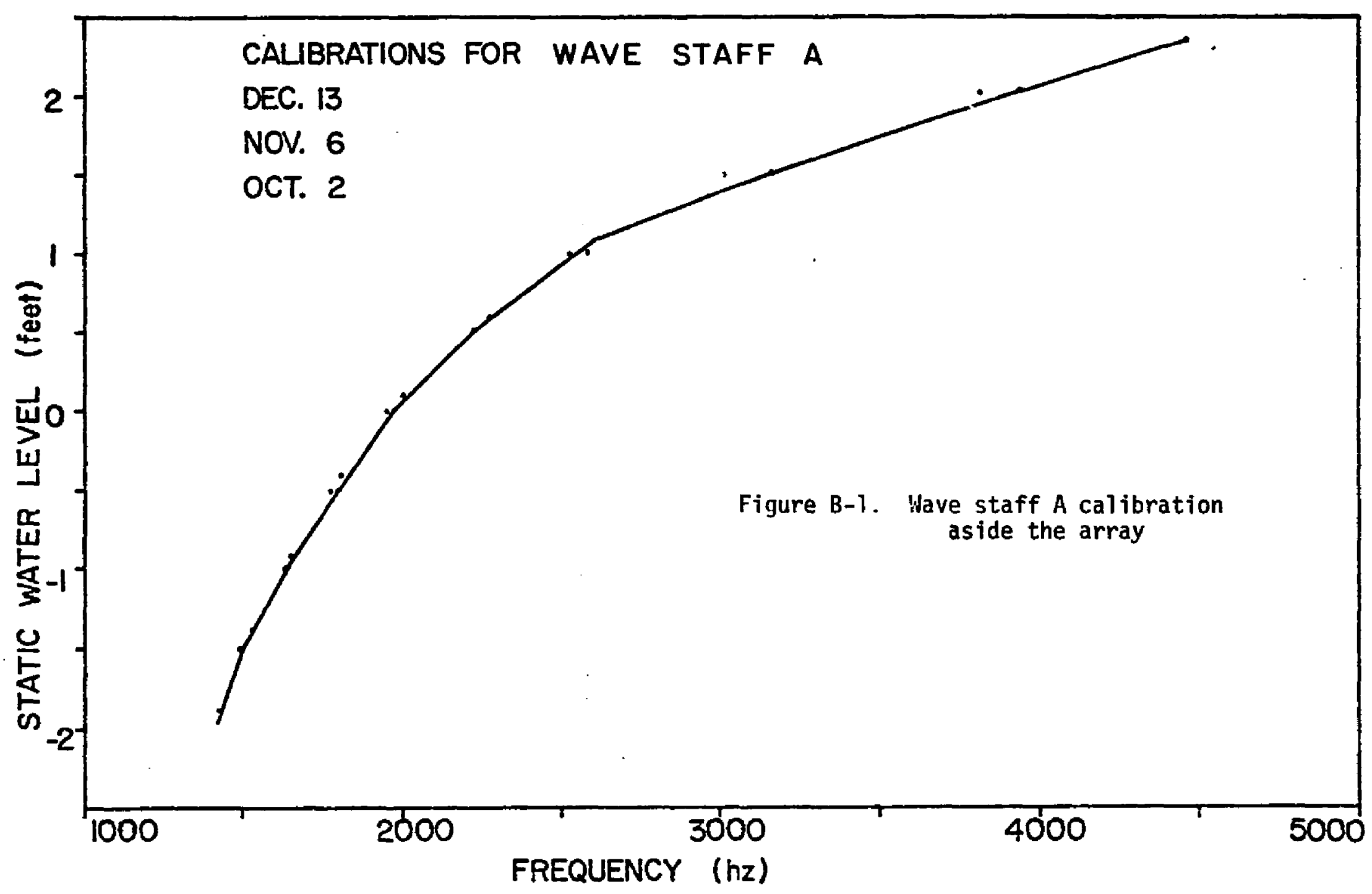




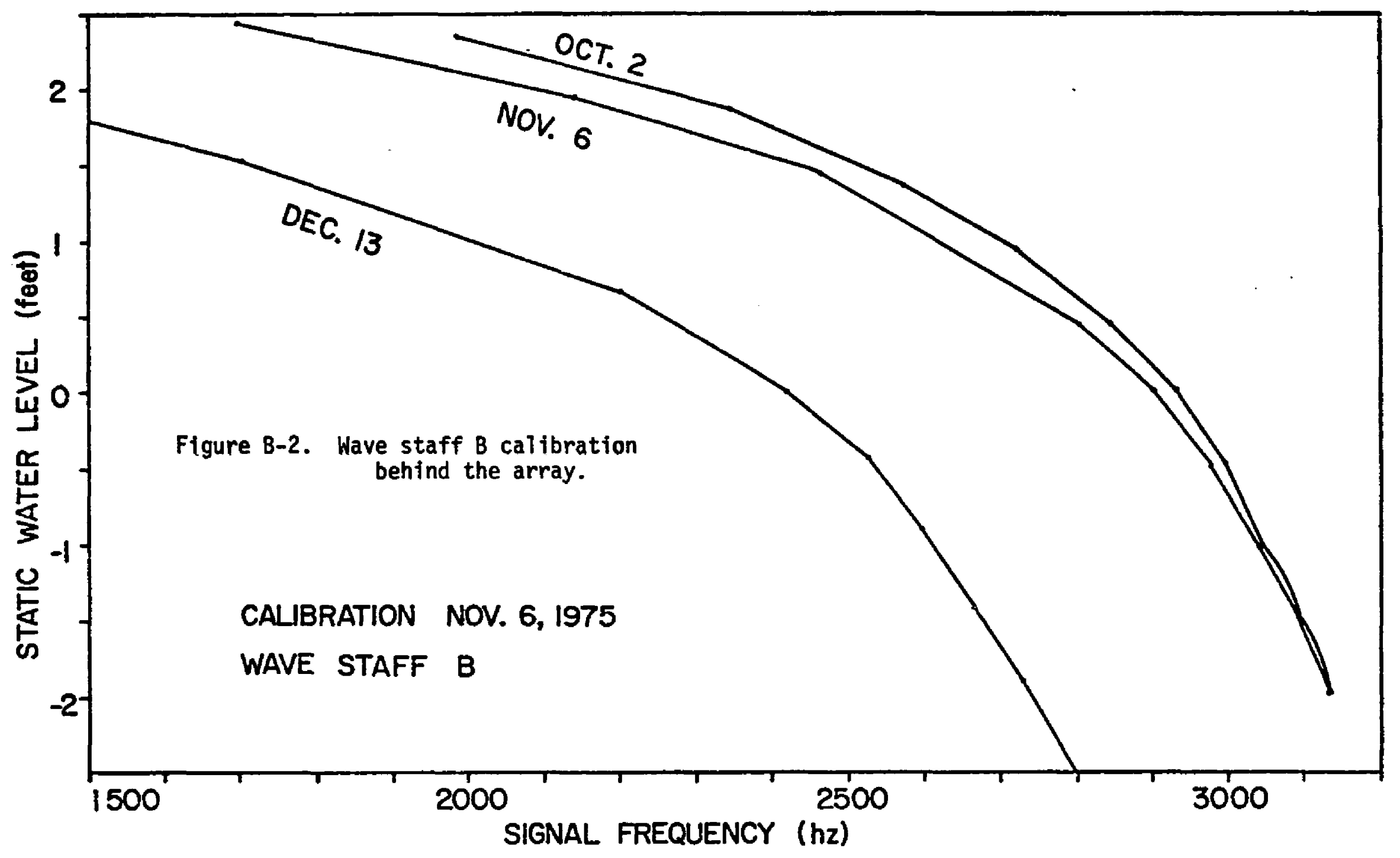




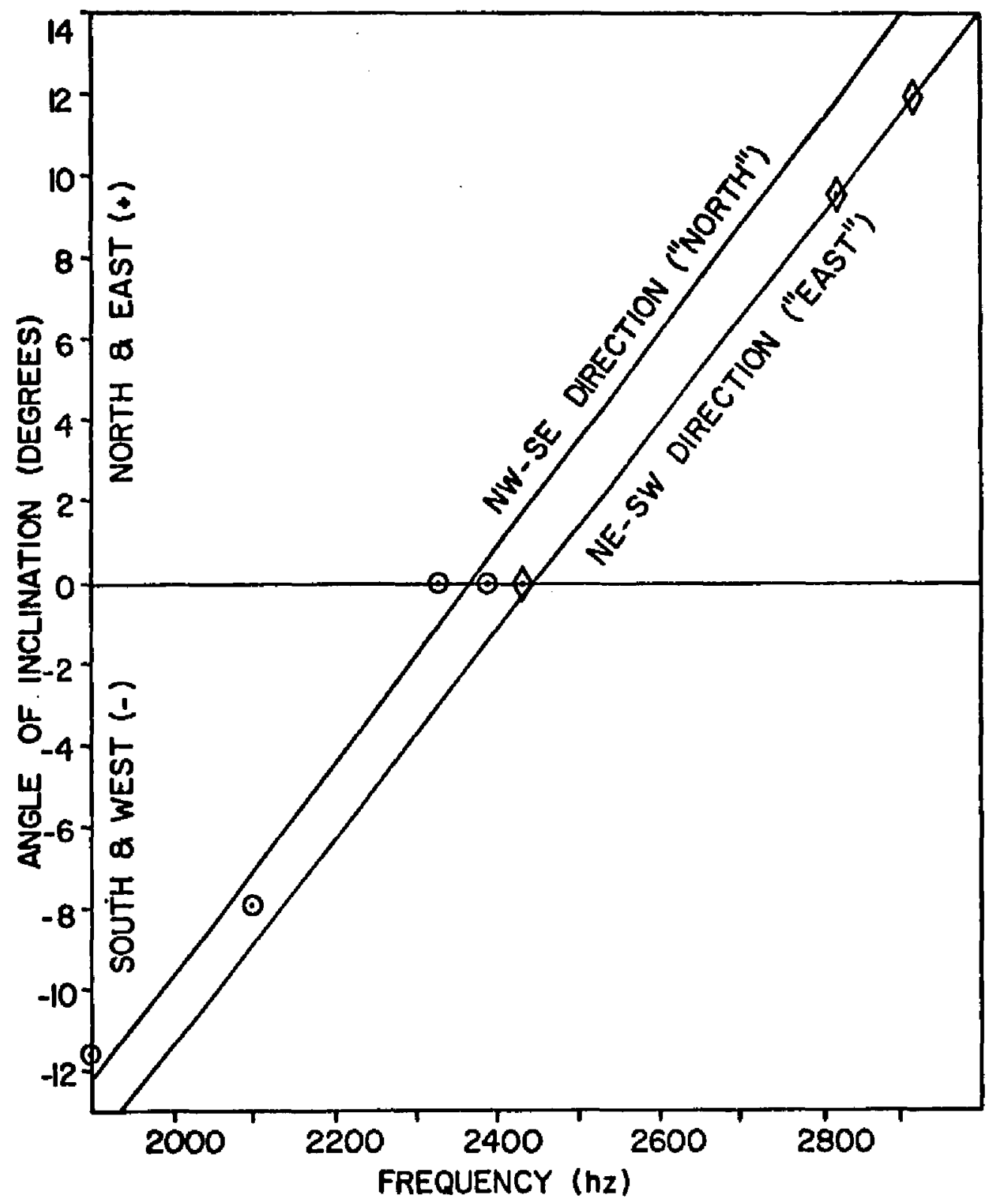

Figure B-3. Inclinometer calibrations 


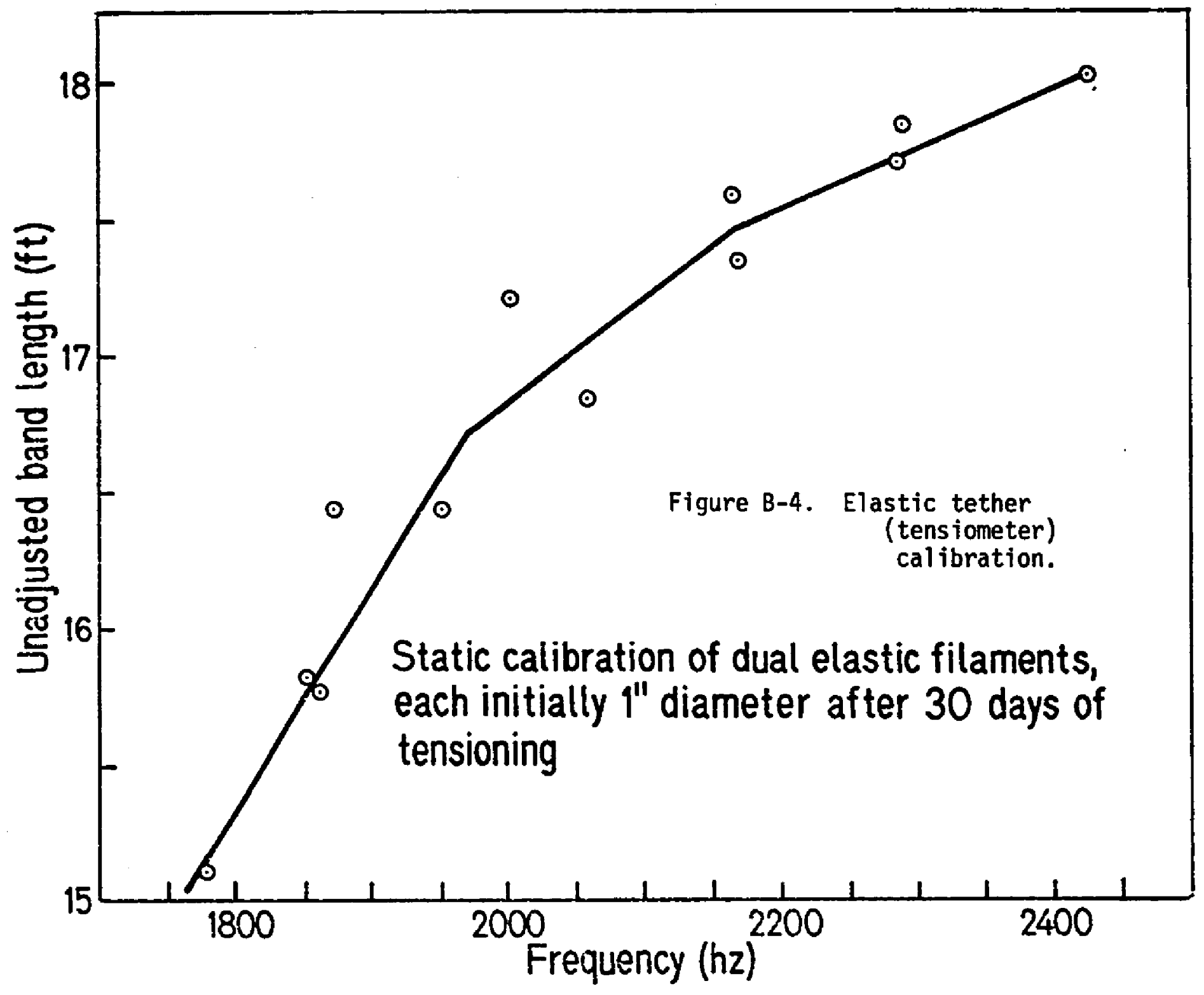


APPENDIX C: Computer Programs

C-1 BUOY:

a program to process and analyze wave staff, tensiometer and inclinometer data.

C-2 BSIM:

a program to simulate an elastic-tethered buoy in irregular waves.

C-3 SPANAL:

a program to analyze irregular wave and buoy data generated by simulation.

C-4 BLELAS:

a program to solve a linear model of an elastictethered buoy in irregular waves.

C-5 BRSIM:

a program to simulate an elastic-tethered buoy in regular waves. 
PLEASE NOTE:

Computer print-out on the following pages has small type. Best available copy. Filmed as received.

UNIVERSITY MICROFILMS. 
**** pROGFAN TC PPOLFSS OATA FROM ONE WAVE STAFF, **** ****

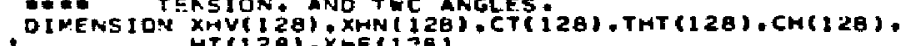

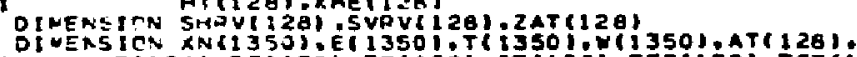

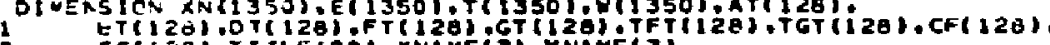

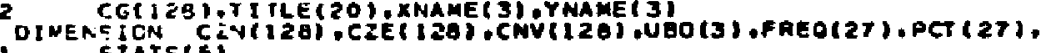

$L=13 \pm 0$ FEAC (SS.SCS) TITLE

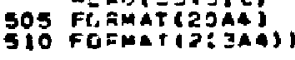

$c$

PATECE:FOS) TITLE

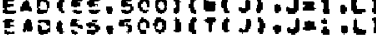

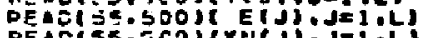

FCRMATIIJFE. II

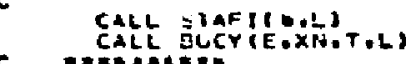

C E E CULL IO INSEETEO TF EAST ANGLE OATA IS BAD IS DASO

$c$

$0025 E \mathrm{~J}=1 \cdot 1$

se centrite

CALL ECSITIE,XN.T,L)

U9o(1) $=-5.25$

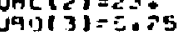

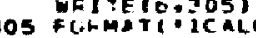

52 ERT

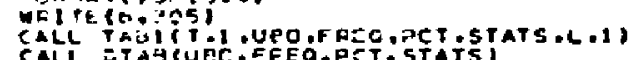

altritacel

306 FOGY T: FCALCULATED MOTIONS: NOPTH HOAIZE/

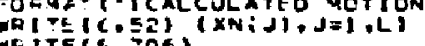

Nop th Hof CALC CFADCUEO OFAEQ.PCT.ETATSI

307

GRT HORI 2111

c

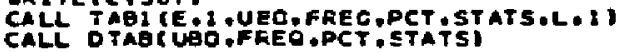

NEX $=$ i

The $=5$

$15=12$

YOUM=0.10

$\operatorname{Con}=4$

CMPUT NUMHES OF CEGREES OF FREEDOM

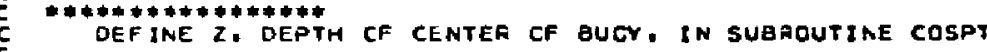

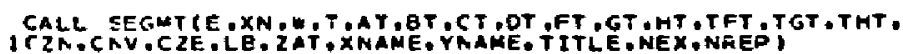

TrotA $=0.0$

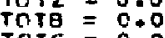

$\begin{aligned} \text { TOTC } & =0.0 \\ \text { TOTO } & =0.0\end{aligned}$

C WE* zEPO OUT ARRAYS TO START

DO $77, J=1 . L \mathrm{H}$

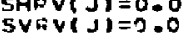

$x+4 V(\&)=0.0$

$x \rightarrow F(J)=0.0$ CG $\sin =0.0$

*... SL avezaged spectrun to compute m-1/3: Potho Jols. TE

InTz = TOTE + BAT(J)

TUTC = TOTC * CTMS

360

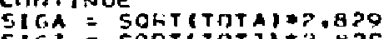

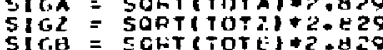

SIGC = SaHTYOTC

c

*** *** CCMfUTE FFEOUENCY DESPCNSES

xinisi $=0: 0$

IF IATTJi.LT.0.0035) GO TO 200

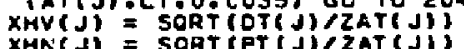

XHN(J) = SORT (ET

$c^{204}$

\section{C-1 PROGRAM BUOY}


C OHOHO CCMFUTE COMEAENCE FUHCTION FORM AVERAGEO VALUES:

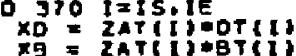

$\cot (1)=0.0$

IFIATEIT-LT 0.0035160 10 370

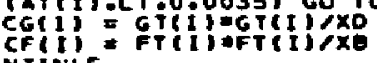

c 37

COUFLTE SPECTRUM OF RELATIVE VElocities

PF $=1,0.25 \%$

ToT $Y$ Y $=0.0$

Dn $70 \mathrm{C}$

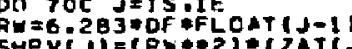

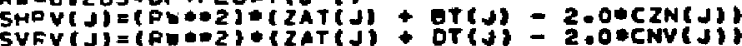

rog

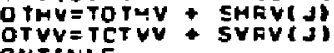

STEVV=.707*SORT (TOTVY SIGHV=STOHV*A-0

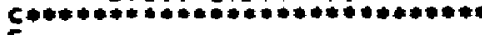

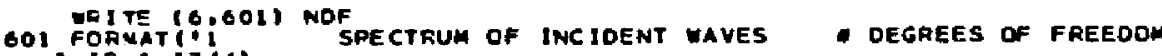
IISTEib.oín, SIGA

eds Fonmati: C

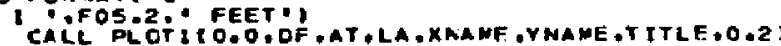

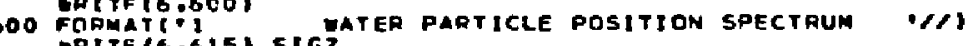
MITE fG. fi.15J 5 IGZ

670 FOITE $(6,670)$ SPECTRUM OF NORTH-MOA 12 EUOY POSITION $/ / 1$

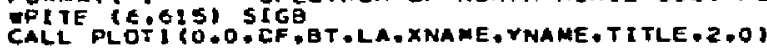

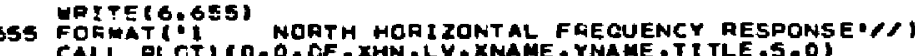

c

665 FOITE $(6,665)$ PHASE OF CROSS-SPECTRUM IN MORTH HORIZ.11)

c

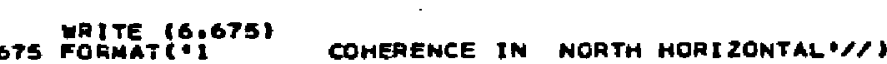
605 FOFIE $16: 605$ S

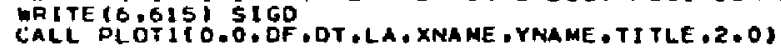
DRITE 5.0501

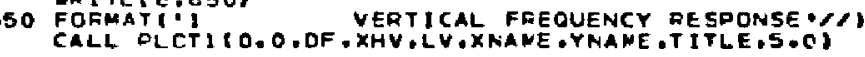

610 FRITE $16: 6101$ PHASE OF CROSS-SPECTRUM IN VERTICAL DS

C WRTTE $(6,630)$

SPECTFUM OF EAST MORTZONTAL BUOY PESITION $\%$

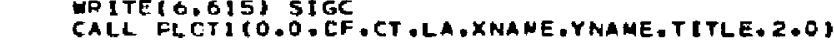

MRITEET00001

690 FORMAT1 1 SPECTRUH EF NCFTH-HCFIZ. RELATIVE VELOCITYM/1

090 FOFMAT:SO STEH

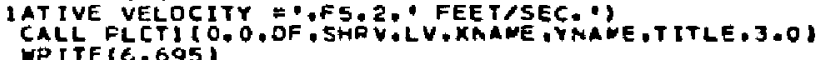

605 FOFMAT: 695$)$ SPECTFUM CF VERTICAL AELATIVE VELOCI

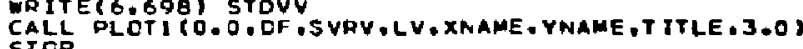
STRP

PEAL FUNCTION TAN (K)

c

SUTROUTINE FFTA(A:S,N,LG)

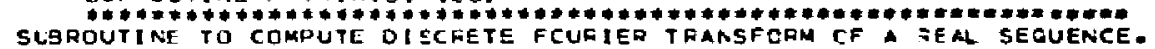

$X$ IS THE ATRAY OF N=2*TM KEAL AUMBERS.

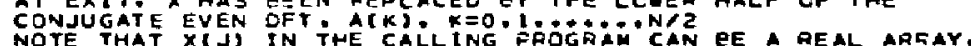

THE MAX VALUE OF THE SUESCFIPT CF THE ARRAY AIKI IN TMESE SUDADUTINES

$S=+0 R-100$ THIS THIS IS THE SIGN OF THE EXPENENT OF

IN THE FOURIER TRANSFORM.

PROPER SCALING GF RESULTS TO OETAIN THE CLASSIC FOUFIER SERIES 
c

$c$
$c$
$c$
$c$
$c$
$c$
$c$
$c$
$c$
$c$
$c$

50

CONDLEX A(LG), W.U,T+X1,X2,CMPLX,CONJG

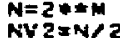

NVIINZIZ

NYAPI $=N / 4+1,14159 / N Y 2$

Y=CEPLX(CÓS (ANGLETISIN(ANGLE))

AR=REALCACH

Á $Y Y Z+1$ Ji=AR-AL,

$=N \times 2 F 2-J$

$T=$ Crnjg(ainjul

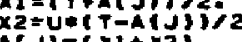

$A(N)=\left\{\left(C_{0 N}\right) G\left(x_{1}=\times 2\right)\right)$

END

SUGHOUTINE FFT(A,S,M.LG)

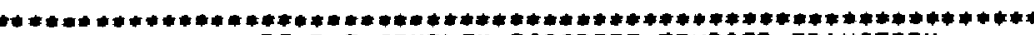

SUBROUT INE TC COMFUTE THE COMPLEX DISCRETE FOURIER TRANSFORM

A COMPLEX SEQUENCE $X(1), j=0.1 .2 \ldots \ldots \ldots, 1$

COMPUTING THE DFT LET X BE DATA ANO S=-1

COMPLEX A(LG), U.V.T.CMPLX

NVZ $2=N / 3$

C IIT-PEYEFSAL OF INPUT ARRAY OF EACH OTHER

Do $, 1=1, \mathrm{Nm}$

IF I I, GE:Ji, GC TO S

$T=A(j)=$

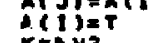

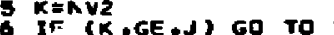

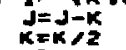

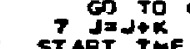

ART TME FFT ALGORITHM

SO 200.13 .150

LEIIELE⿱

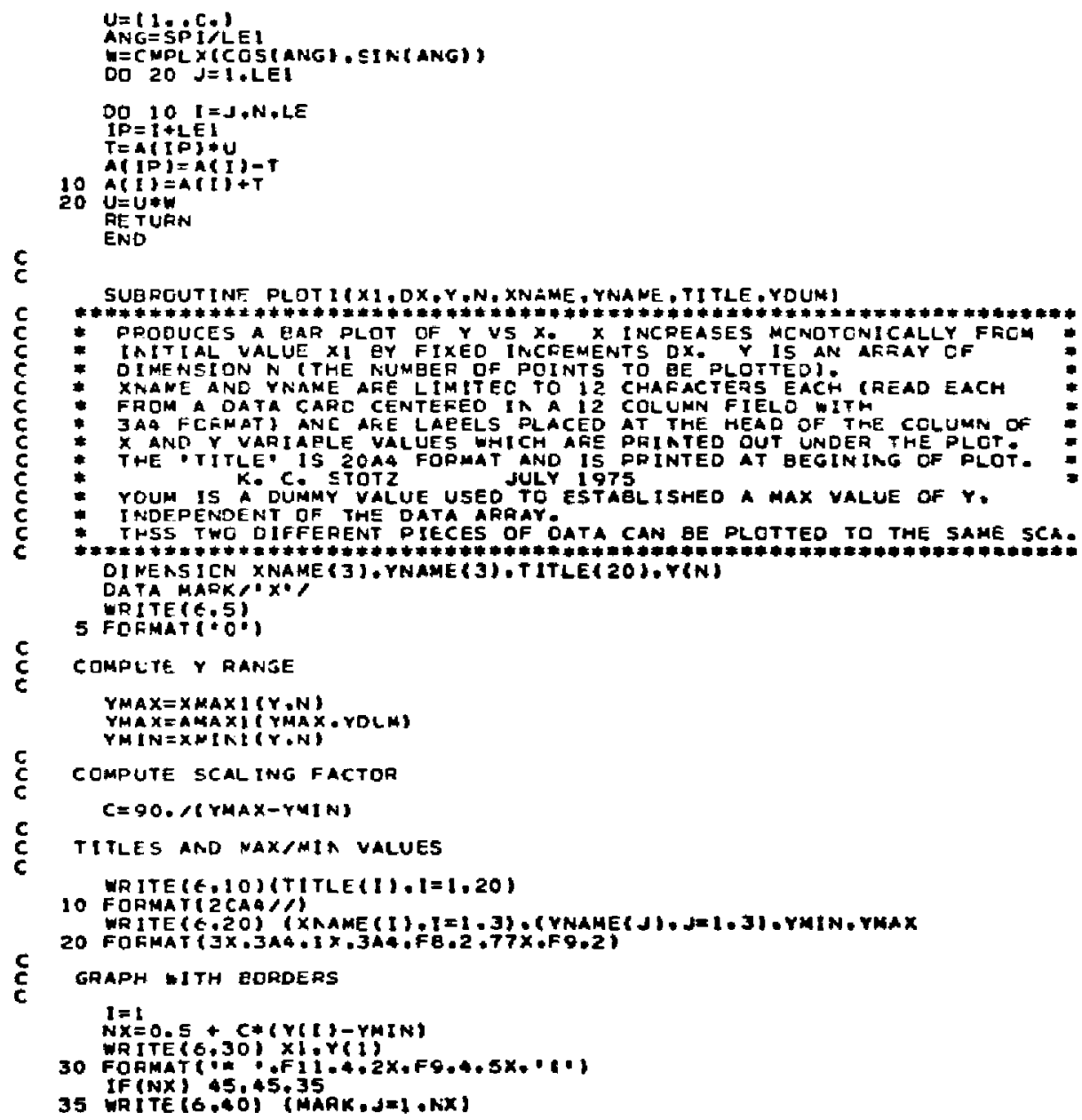


c

40 FOFWAT $1+2.20 x+50411$

50 FOFMAT: $+! .28 \times+911+=13)$

$0060 \quad 1=2, N$

NTITE(6.30) $x \times$.YII)

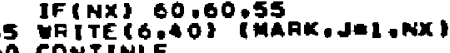

c

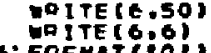

RE TUA

FUNCTION XMAXICY,N

$2=r(1)=2 . N$

$x \rightarrow a x 1=2$

EETU⿴囗十

FUACTICN XMINI $(Y, N)$

$z=r(1)$

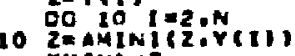

RETUIN

c

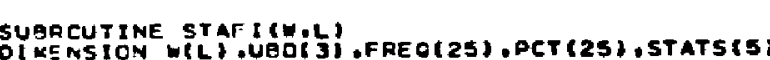

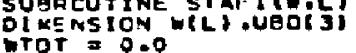

c

OD 120 JIJ

INPUT IAVE STAFF FOR SEPT 00 TO DEC 20

IFIUCMA.GT. 3.37 , GC TO 300

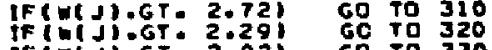

iF (w)i:GT: 1.02$)$ G0 TO 330

300

O 100 (0)

(1) $x=0.01 \operatorname{cov}(J)=0.56$

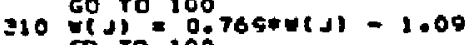

$320 \mathrm{~m} J)=1.163 * 4(\mathrm{~d})-2.16$

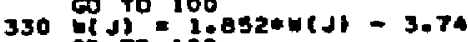

340 I 1 TO $=2.708 * 4(\lambda)-5.61$

200 vTOT $=$ -
120 CONTINUE

XLAT FLOAT $(L-2)$

int $(1)=0$

***** CHECK AND OUTPUT STATISTICS CF CATA ****

(1)

537 FOFMAT:

500 FOFMAT

600 FORMAT (6. ${ }^{600)}$ WAVE SURFACE STATISTICS ON INPUT STAFFI CALL TAEI CW:D,UEC,FREQ,PCT, STATS,L:11 DO 140 J J $)^{3 . L}$ WTOT

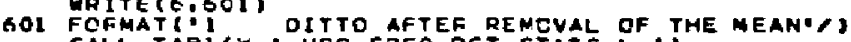

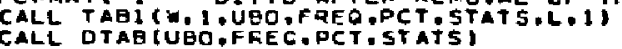
EETUAN

SUBROUTINE EUOY $(E, X N, T * L)$ CONYERTS COUNT DATA INTO ANGLES E ANE N AND LENGTH T. EE EASP ANCLE. COUNT ON INPUT: FACLANS ON DUTPUT

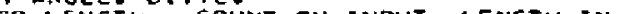
ONH IN FEET ON OUTPUT.

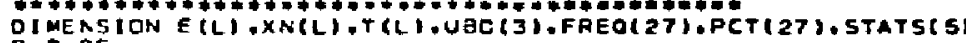

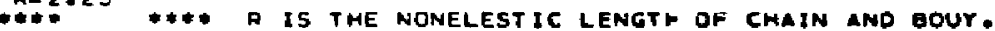

c

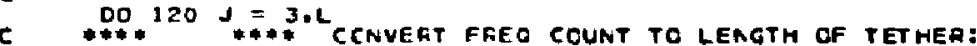

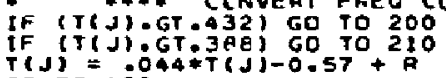

200 T(J) $=0.0110 * 1 / 7)+12.7+R$

210 T(S) $=0.0216 * T(J)+8.12+A$

******** CCNUEFT FREO COUNT TO ANGLES: EN(J)=0.00241EXN(J)

$\left.c^{120}+* * *\right)+* *$ 


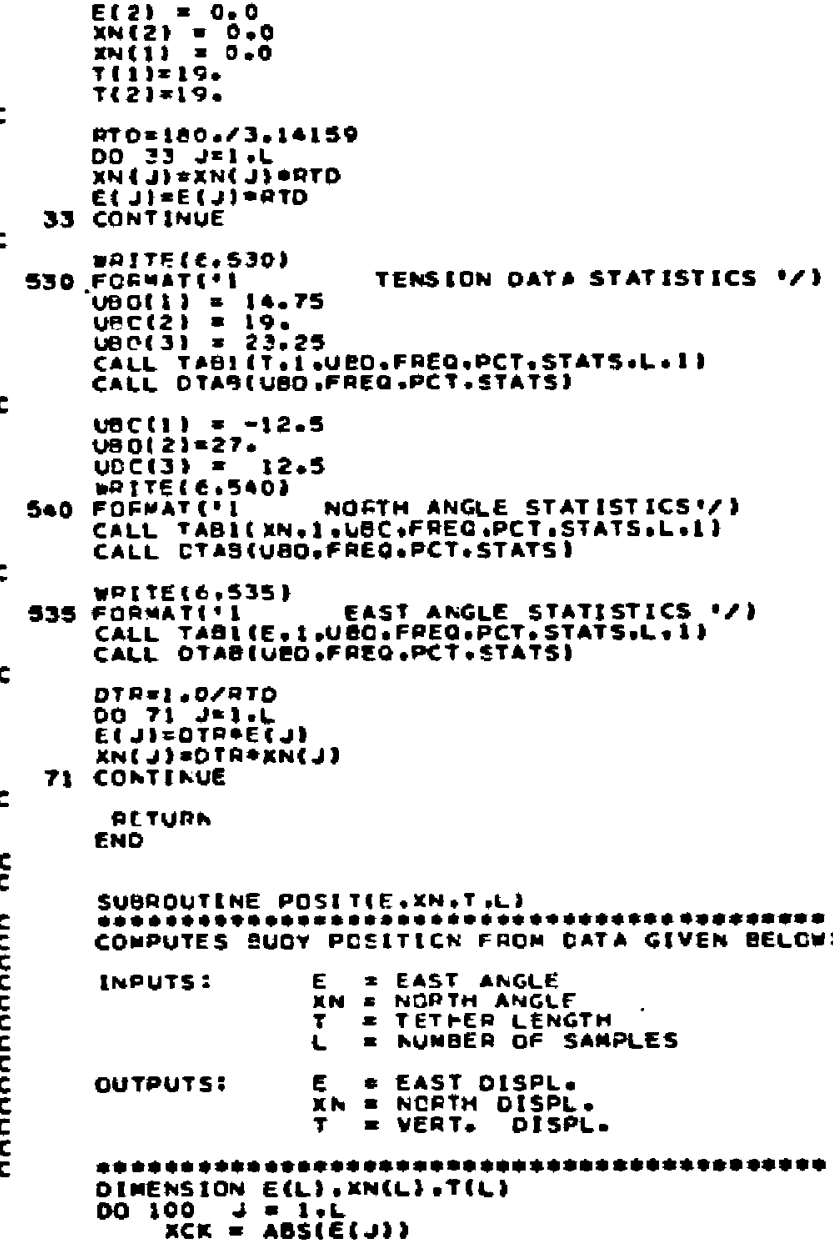

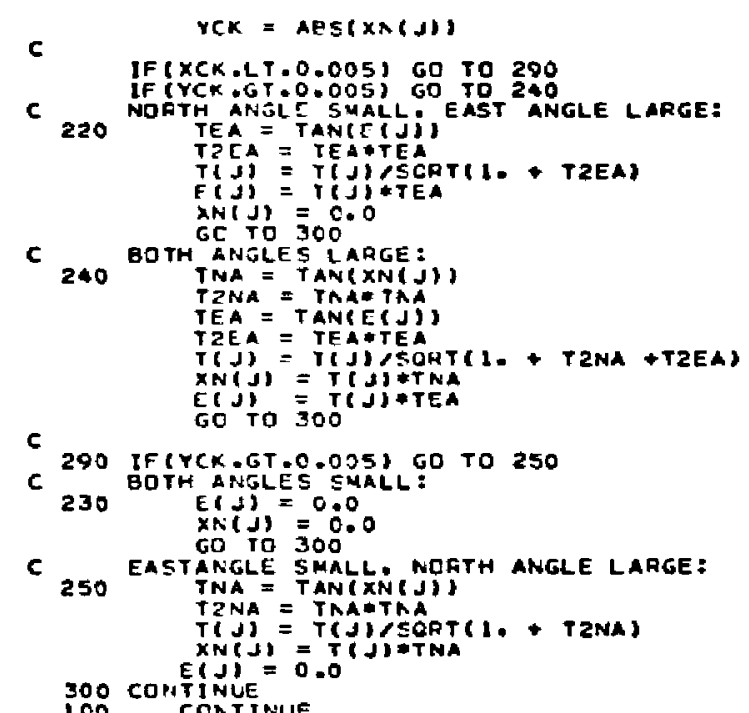

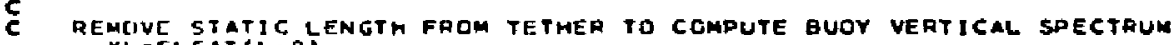
$X(1)=0.0$
$T\{\}\}=0.0$

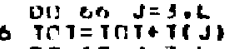

6) Ti

END

c

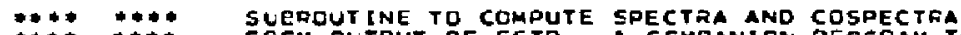
20.

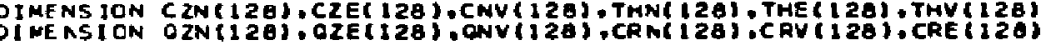
CZNII) $=0.0$

CZE $(1)=0: 0$

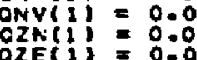



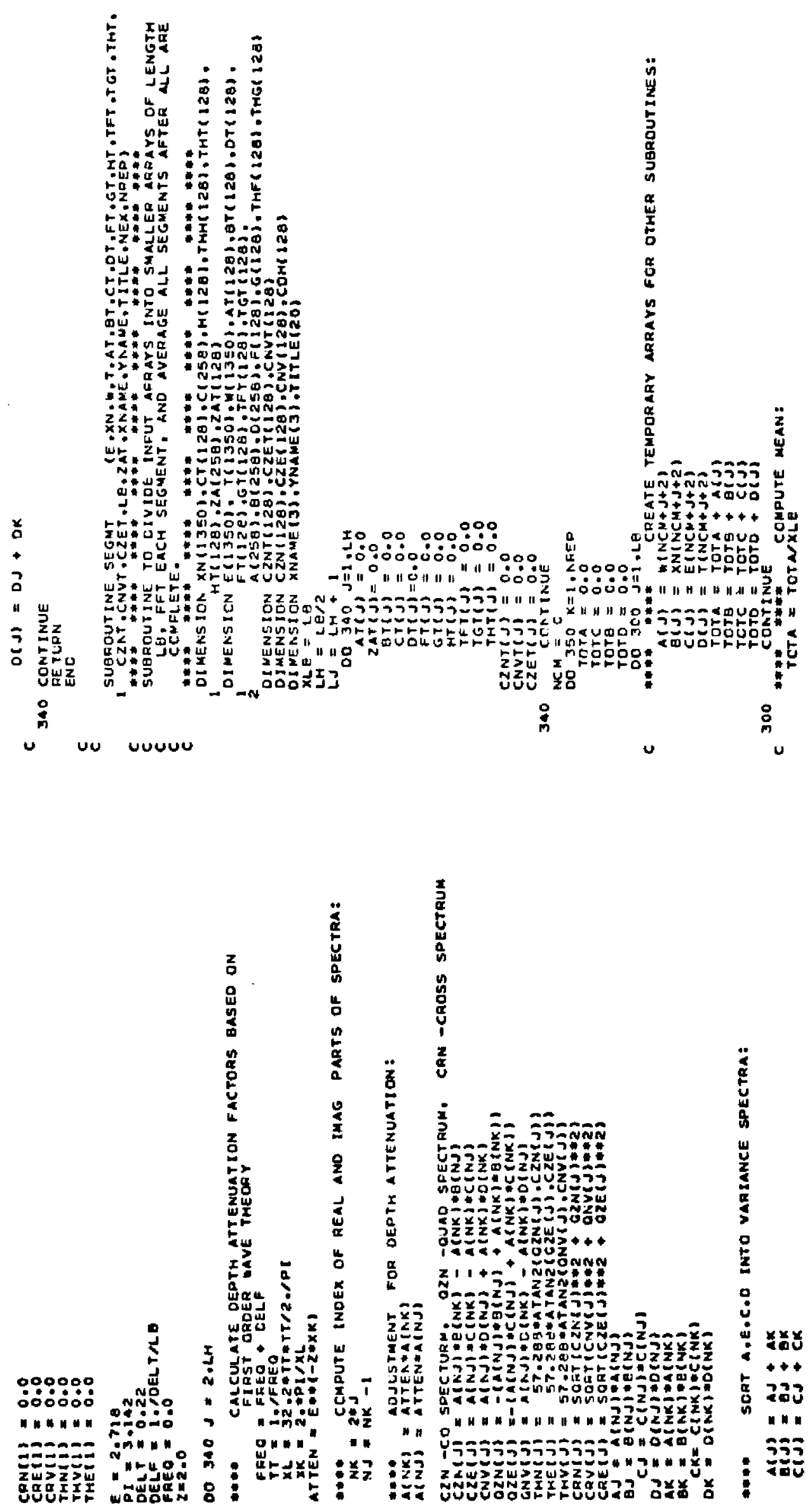

$\mathbf{v}$

y une vo us us

Uบบ 


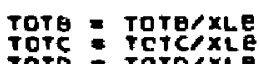

DC 3300 T:

$c$

$c$ A REMOVE MEAH:

a (u) = A(s)= $=$ Tota

c(J) = CIJ = Totc

CALL EFTR (A, - 1 . NEX.LJ)

CALL FFTRCA:-1: MNEX:LJ

C CREATE ZA. TO EE THE NATER PART ICLE OABIT AT THE BUOY CENTER Do 30 jel 20

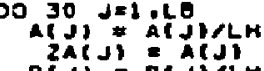

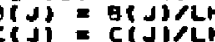

30 SIJ) = DQJiNLH

CALL CCSPT (ZA,E,C,C,CZN,CNY,CZE,THF,THG,THH,F, G.H,LE) YDum=0.1 if $=1 .-22 / 1 \mathrm{~B}$

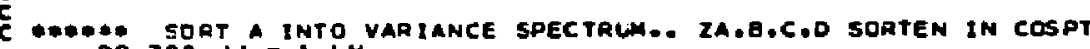
NK $=\sum^{2}+1$

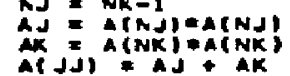

Go.t IHUE. STORE FCR LATER AVERAGting:

ZATY(J) $=z A T(J)+2 A(J)$

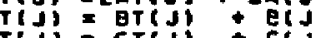

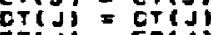

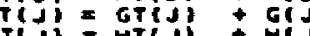

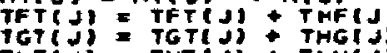

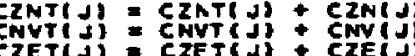

$e^{330}$

CONTINUE

sso CONTINUE - LB $c$

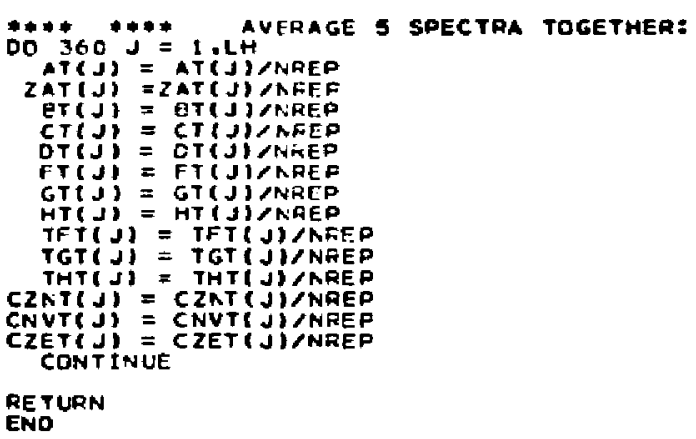

SLBRGUTINE TABI

Purpose

TABULATE FCA CNE VAFIAELE IN an OESERVATION uatrix COR GIVEN CLASS INTERVALS IN ACY AND PEFCENT FRE JUENCY ONEA ARD

USAGE CALL TABICA.NOVAR,UBC,FFEO,PCT, STATS NO.NV)

OESCRIPTION OF FAFANETERS

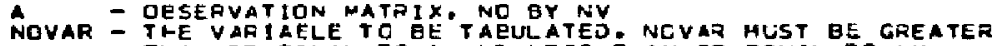
- THAN DF EQUAL TO

UBD - SPECIFICATION MATRIX FOR GAYDS INTO LIMIT. WHICH OF EANCS EET EETLATYITS +2. AND UPFER LIMIT CO VARIAELE TC EE TABULATED

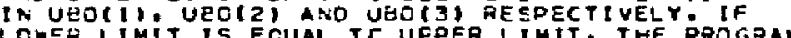
UEESTTEMINIMUM AND MAXIMUG VALUES OF TME VARIADLE.

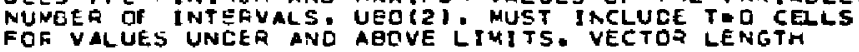

FREO - IETPUit VECTOR OF FRECUENCIES. VECTOR LENGTH IS

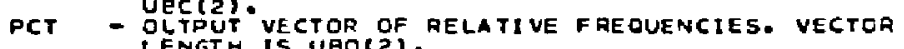

STATS - QLTPUT VECTOR OF SUMMART STATISTICS. I.E. TCTAL. AYEAAGE OSTANDAFO CEYIAT ICN. MINIMUM AND MAXIMUM:

- ANO STANOARC DEVIATION $=$ O. MINLI.ET5 AND MAXE-1.E

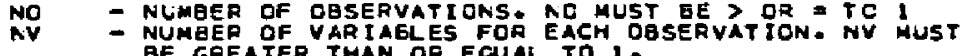



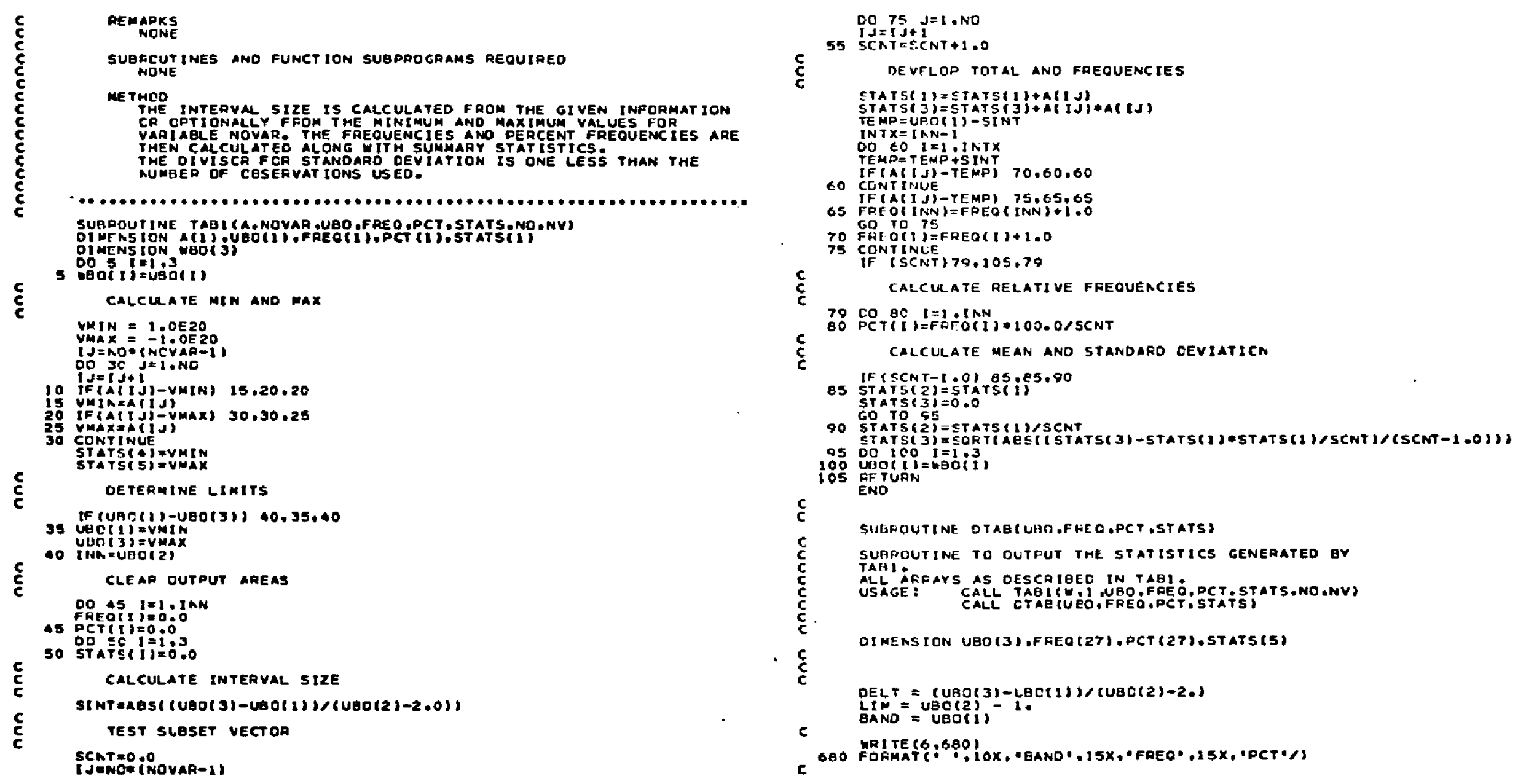
OD 300 J

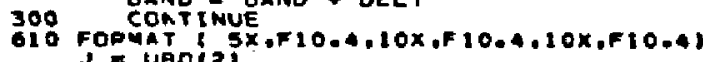

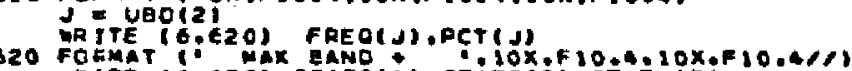

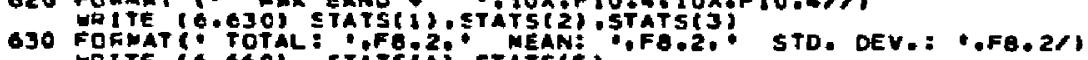

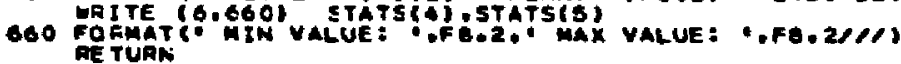
ENo 

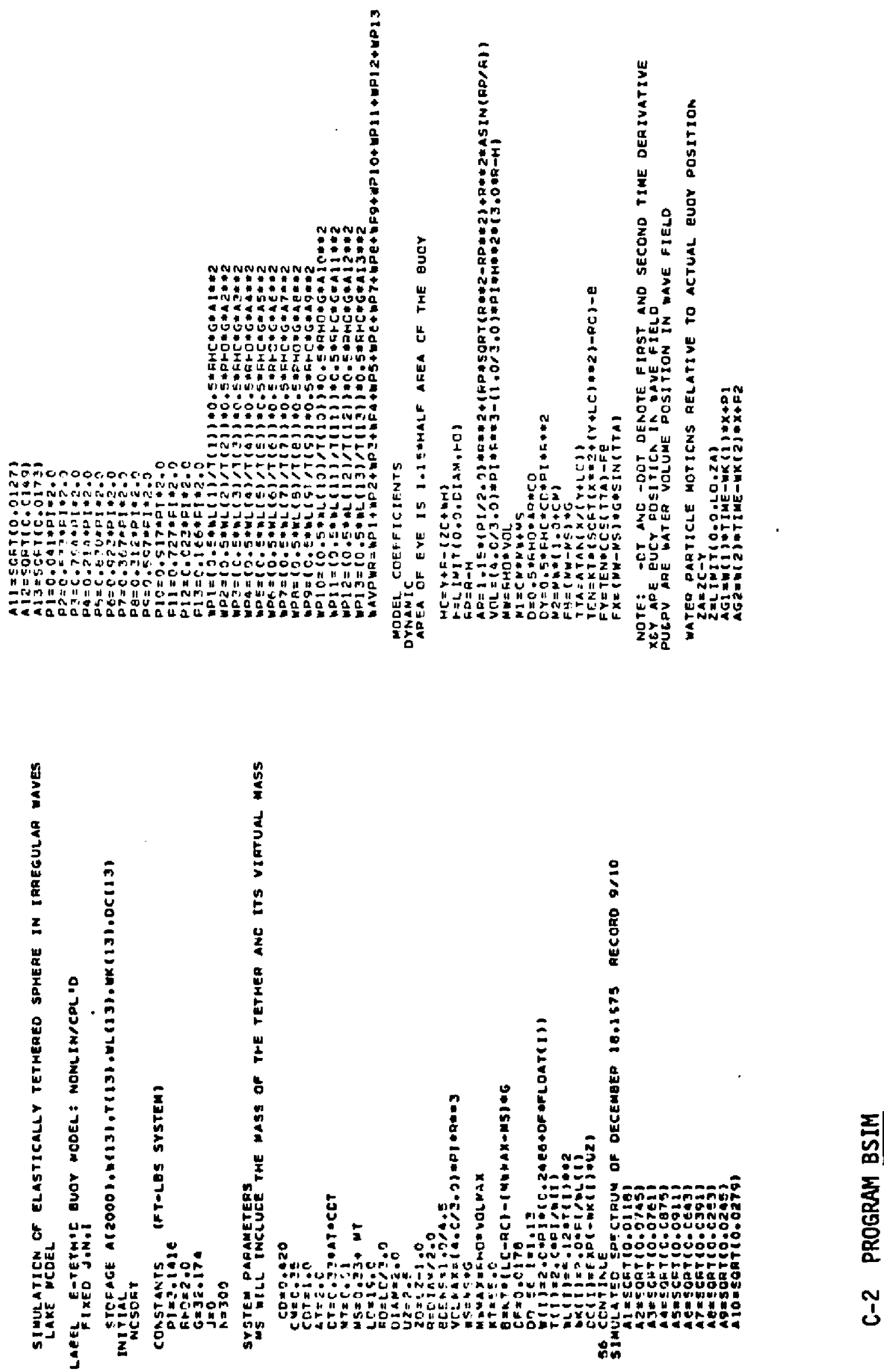

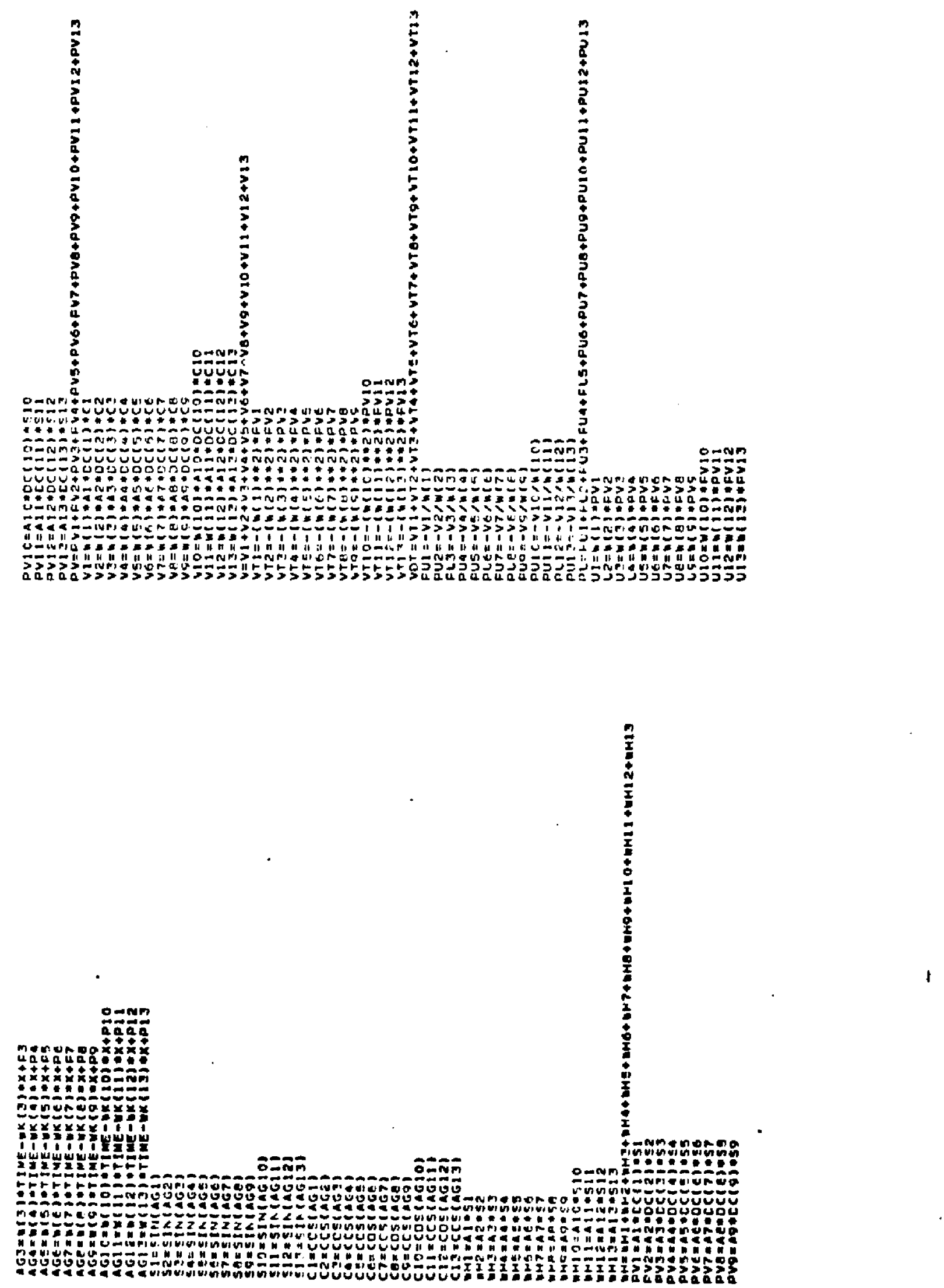
C13
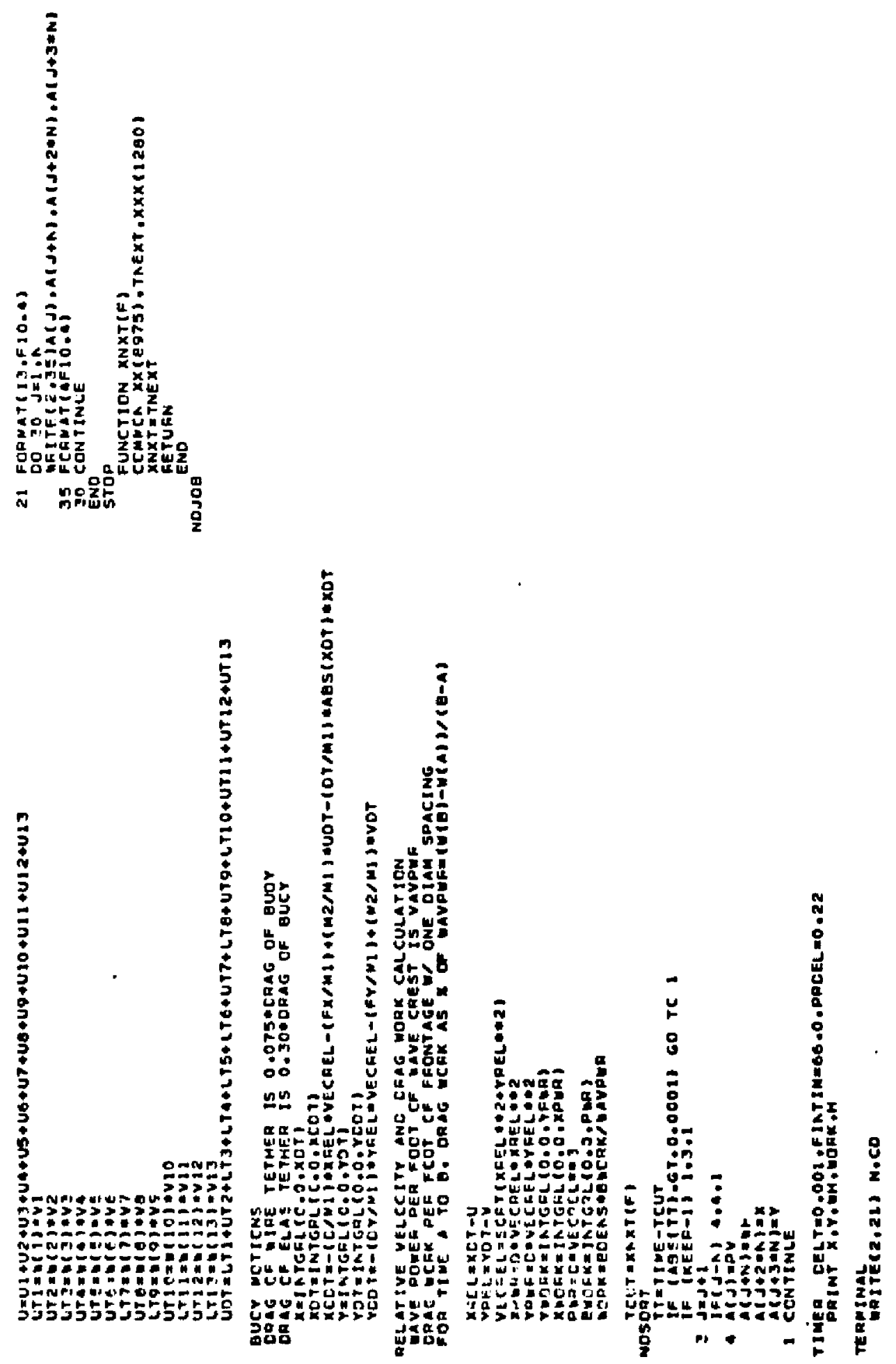

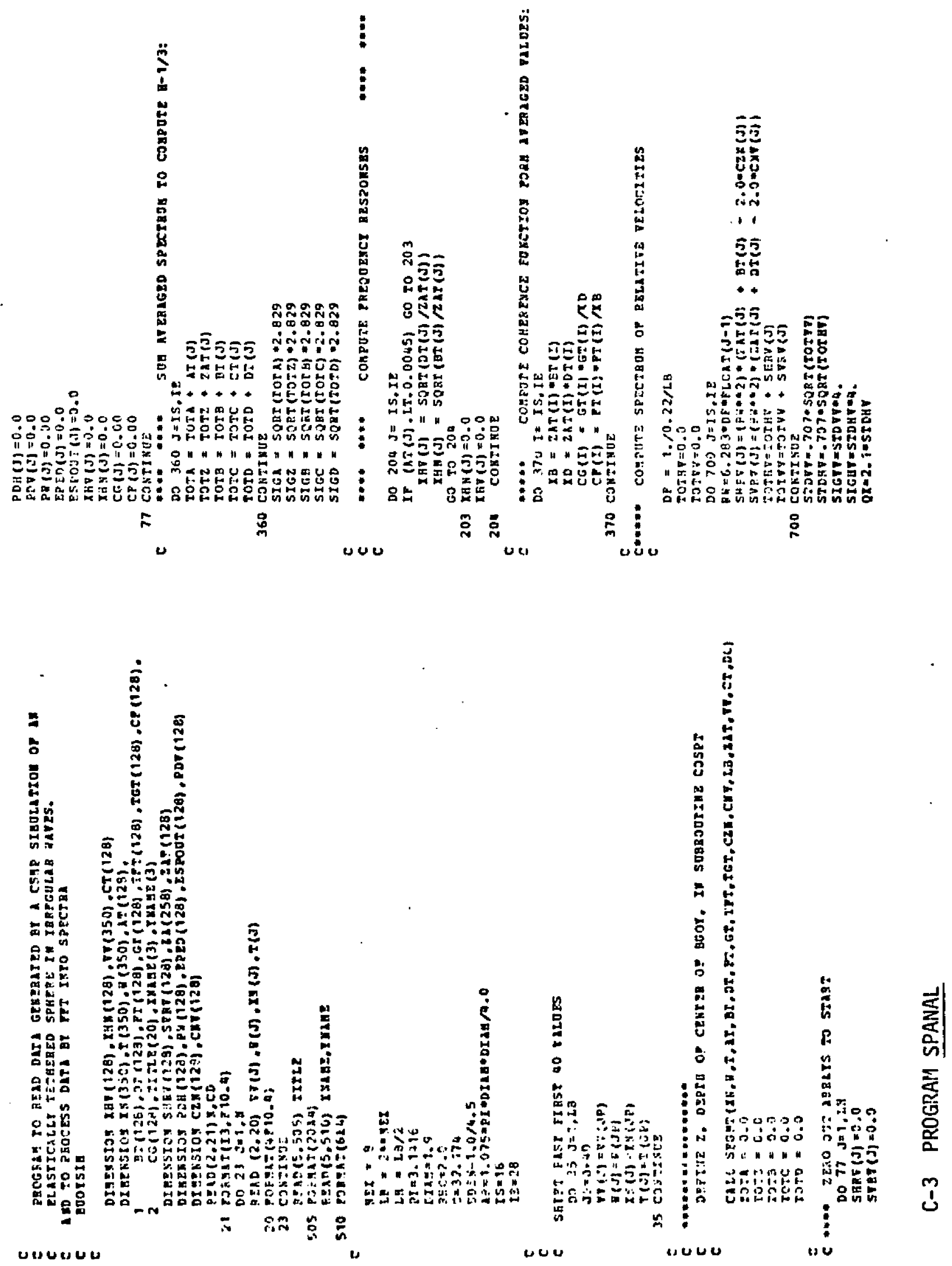


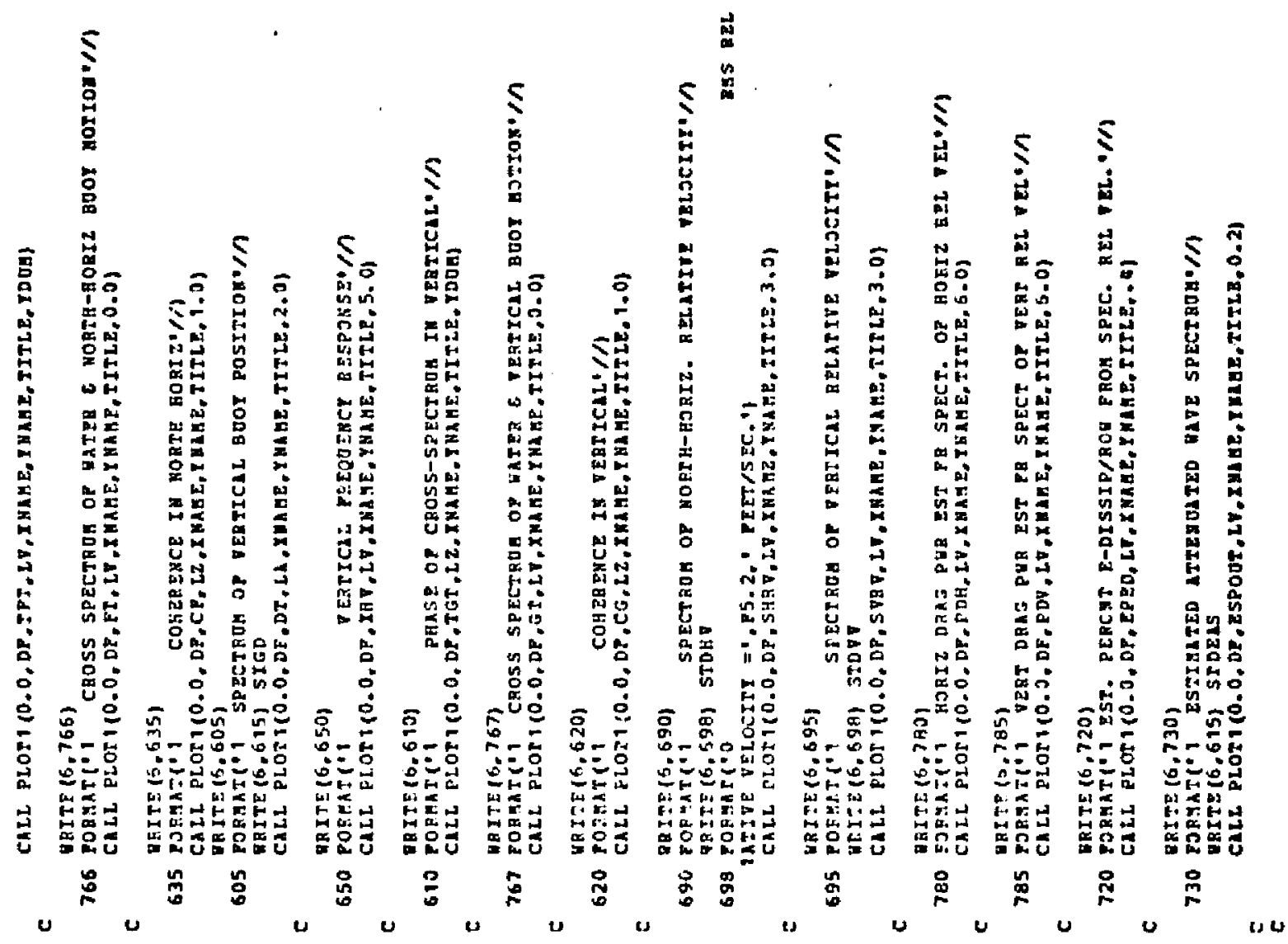

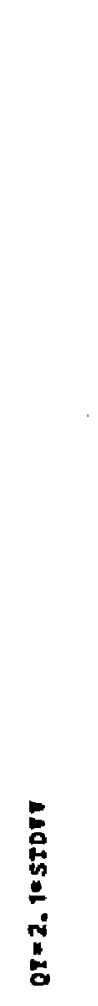



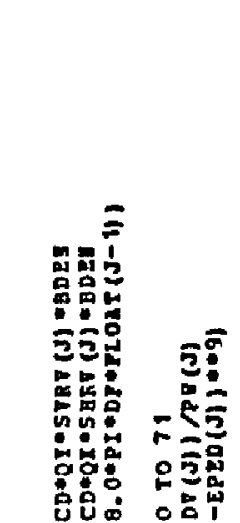

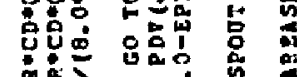

ำ

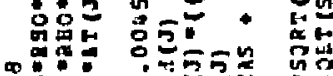

舟的

o do.

侘" "

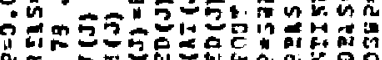

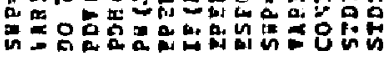

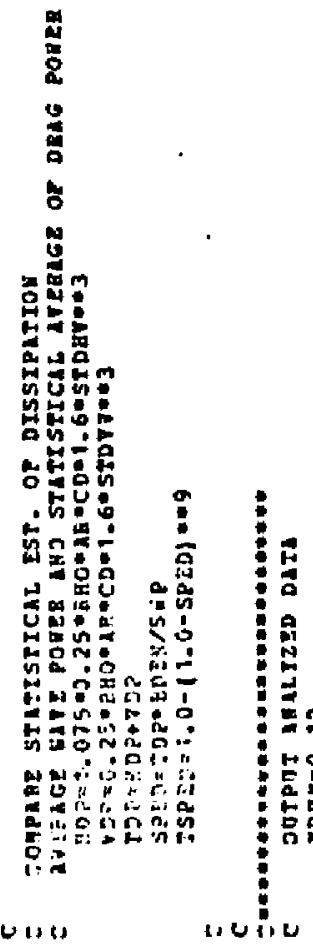

Uis)

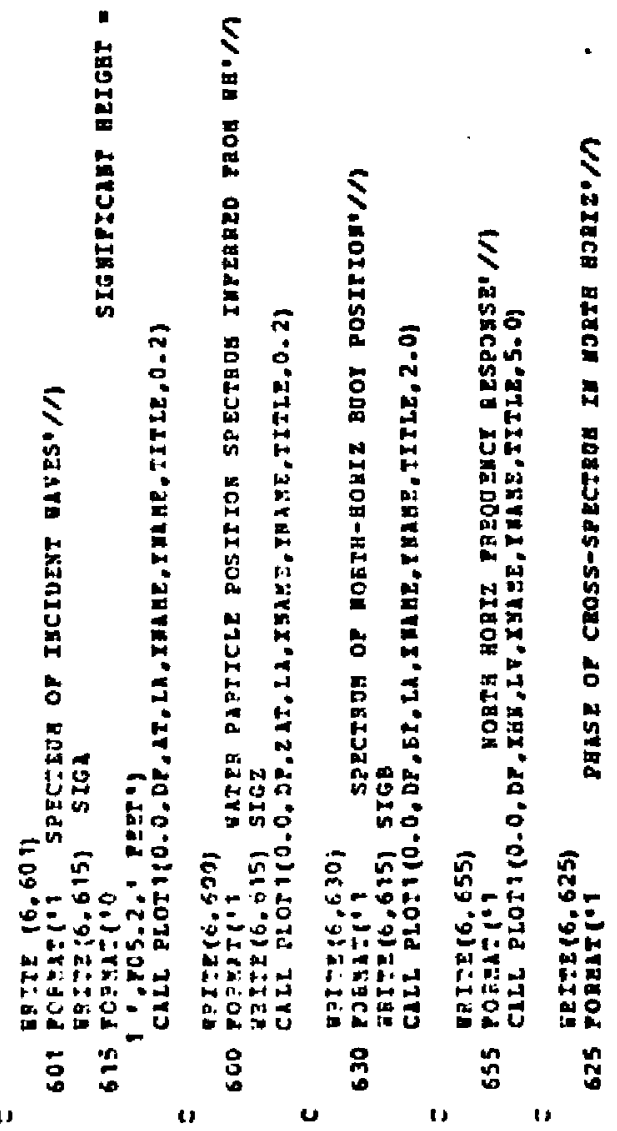



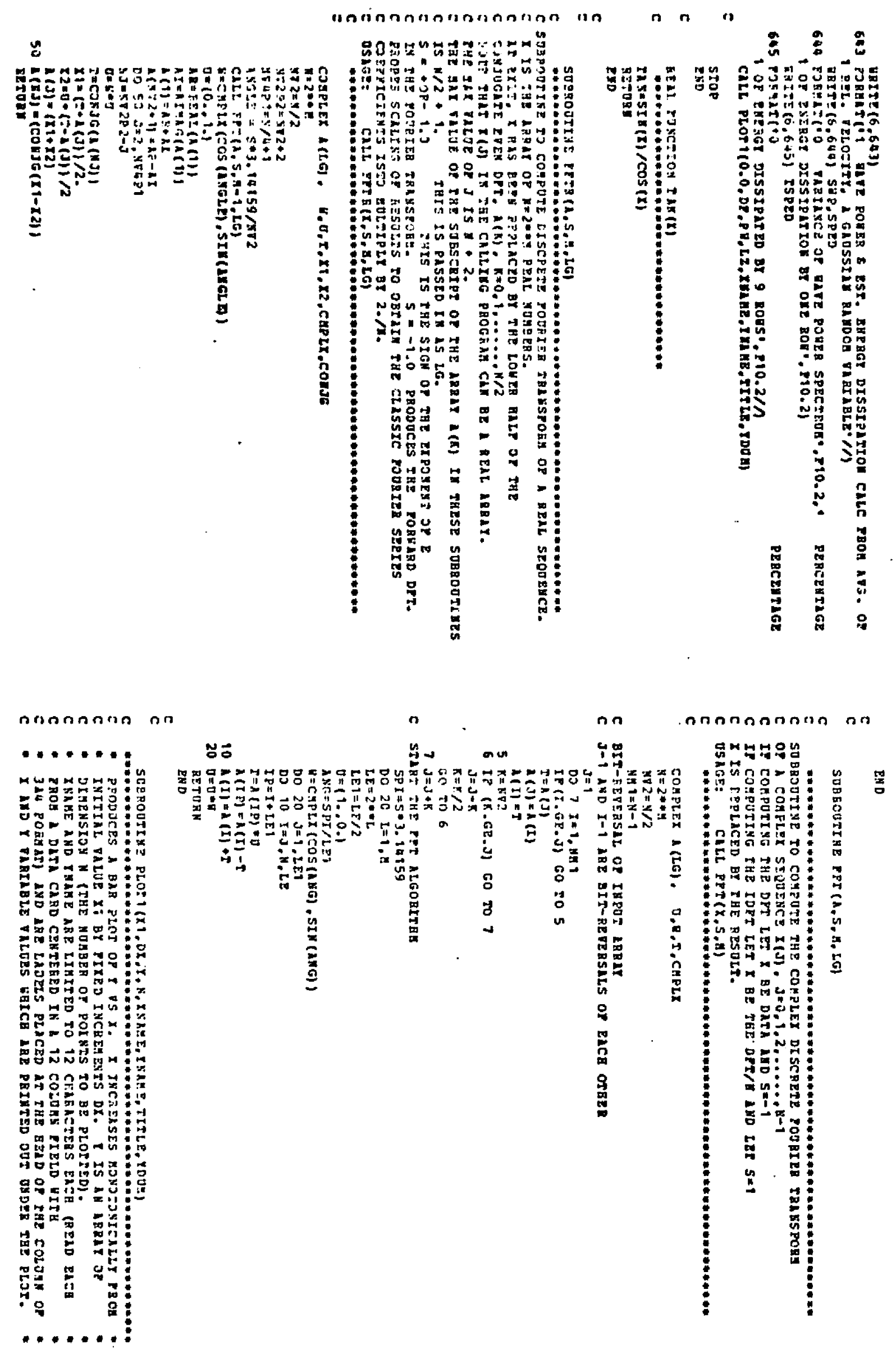


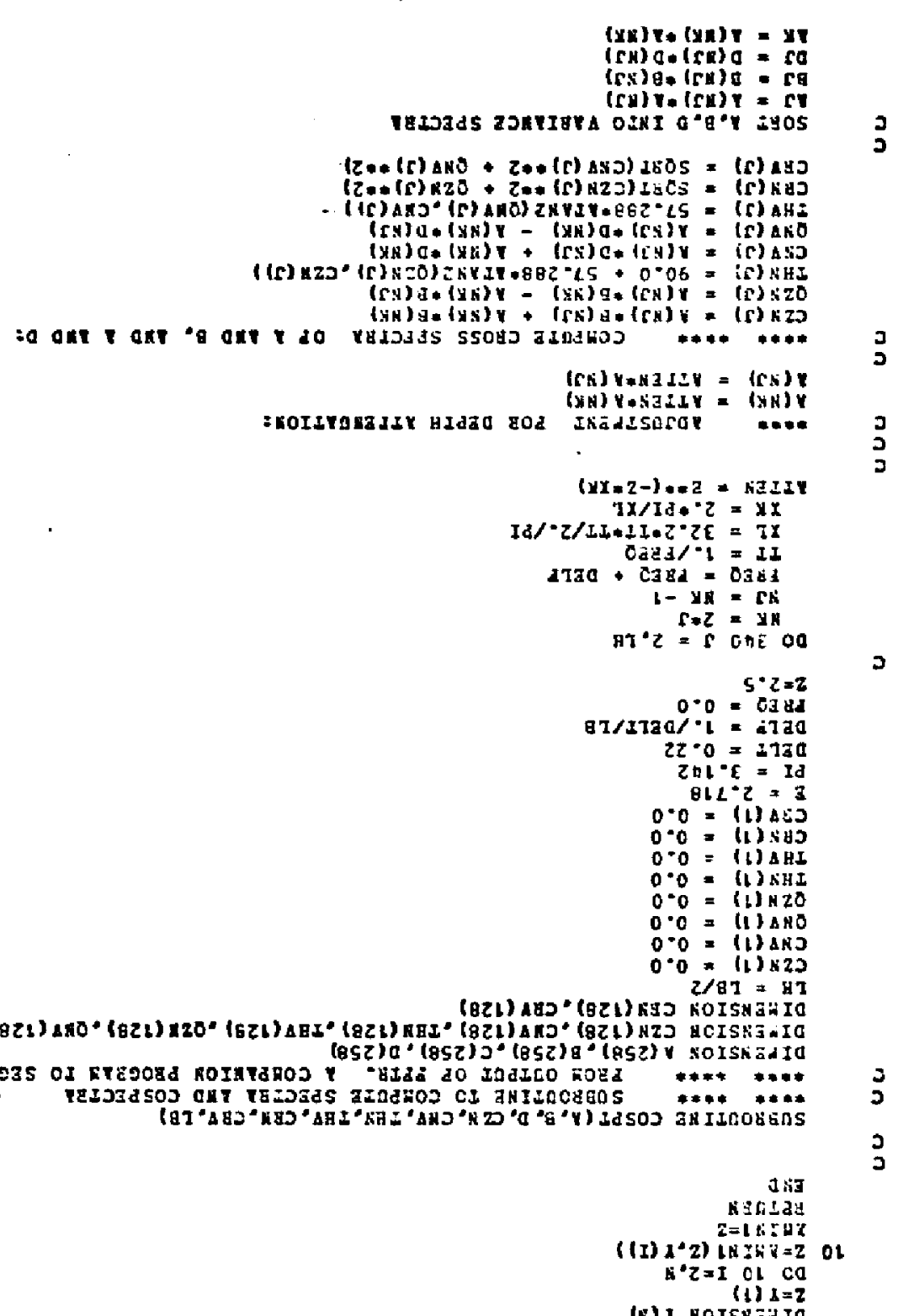

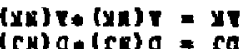

$(5) \cos (5)=0$

(c)i)

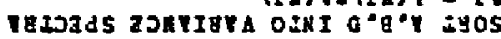

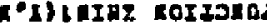

$\operatorname{cxa}$
$\operatorname{manaz}$ $x=1 \mathrm{xTHx}$ (I) $z^{\circ} z$ z) IXVtit=2 $\mathrm{al}$ n-2-I of of

(a) 1 morskeiso

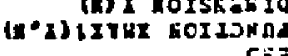
30133

(.0.7)rizod

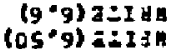

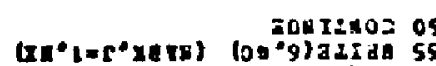

$55^{\circ} 09^{\circ} 09$ (Xs) 11

(1) $)^{2} 11$ (ce 9$)$ i=Ij

(IIDL-(I) 1 ) $* 3: 5=0=25$ $\left.(1,-1) 16^{\circ} 102 \cdot 90^{\circ}\right)$ Itiged os

(1706'162".tillibica of (IT) $1=[$ 'y

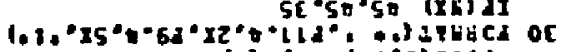

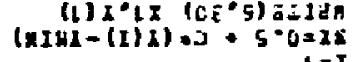

Sÿaxod HII yarag

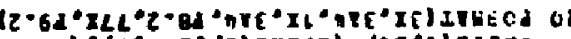

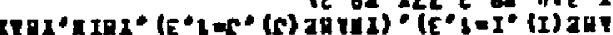

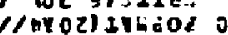

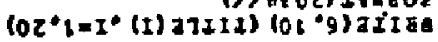

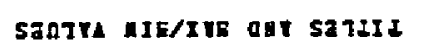

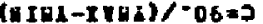

בa:sT 9EI7TOS 2203000

(h)

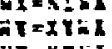
$(k \cdot 2)$ iI $x=x=x$ in

asuy 1 aEodios

$(, 0,1)$ veacas (s'g) ziIsh

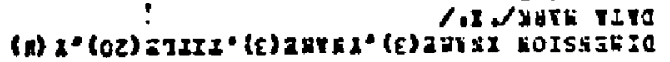

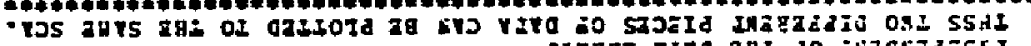
- 

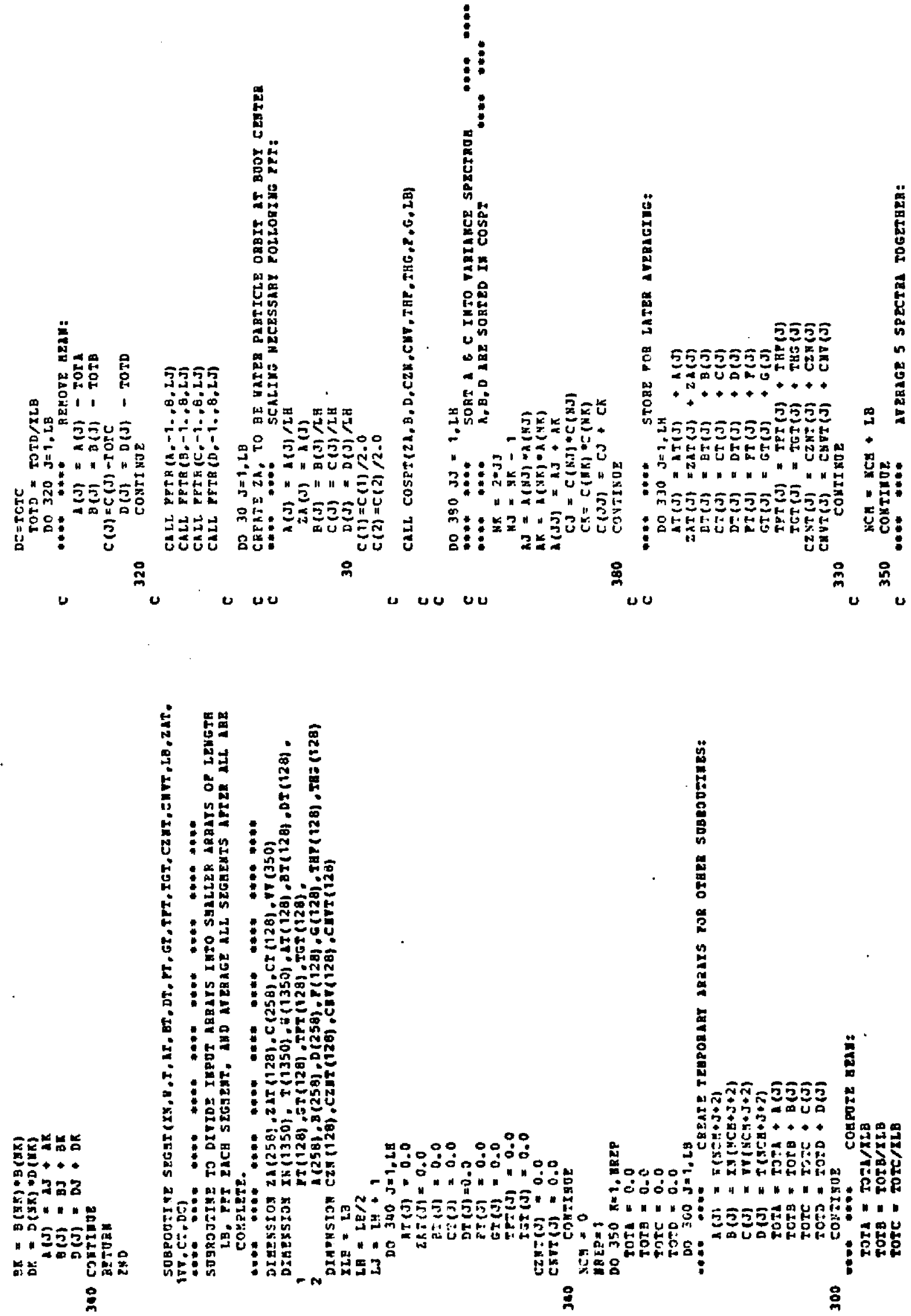

u

:




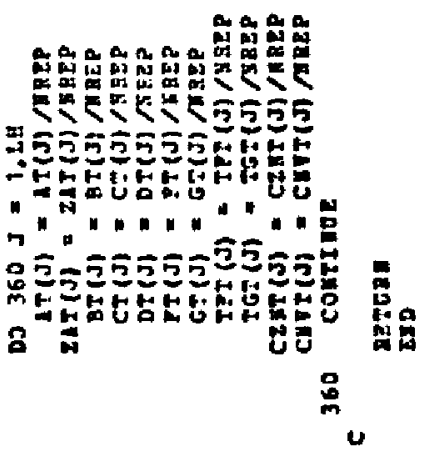



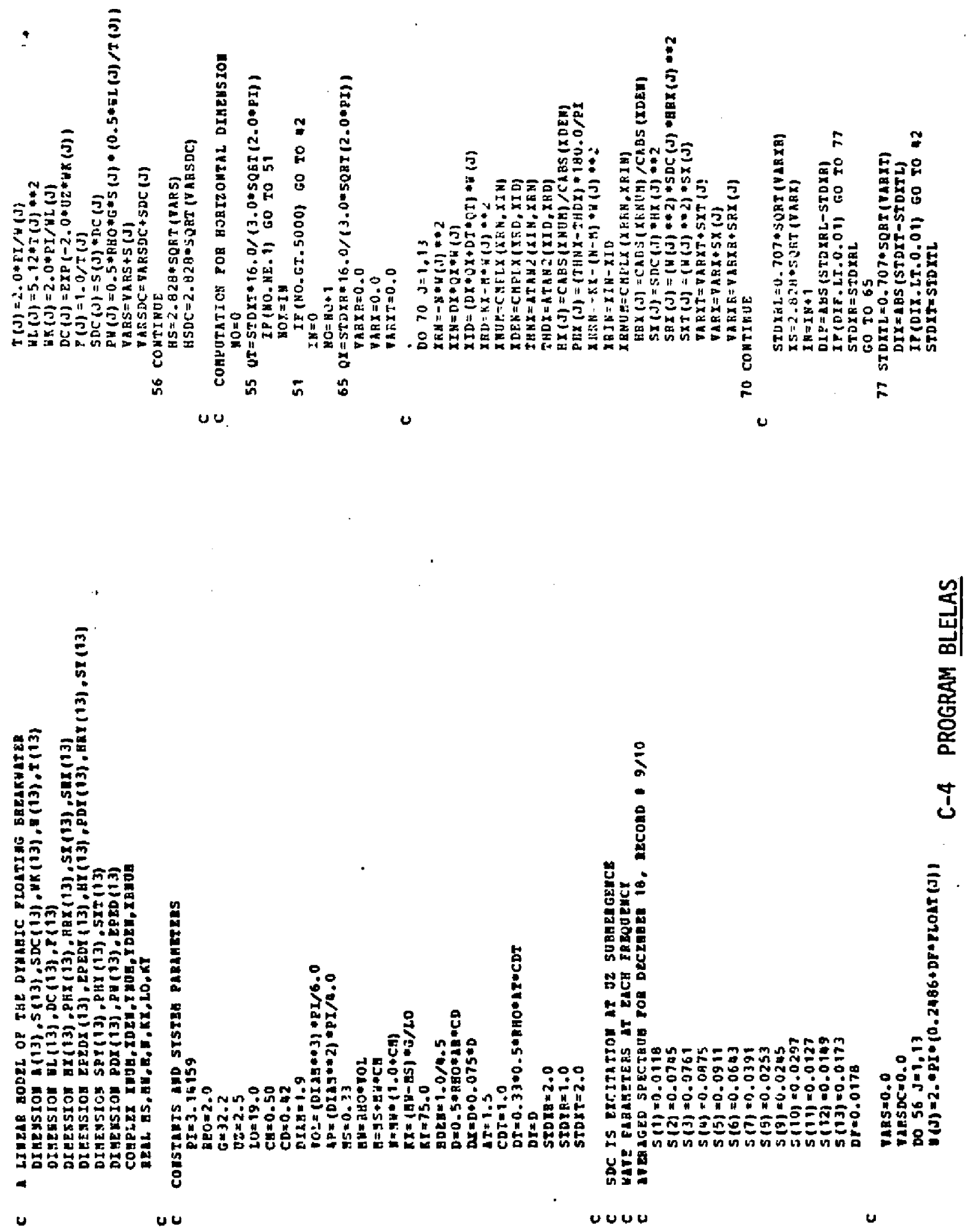

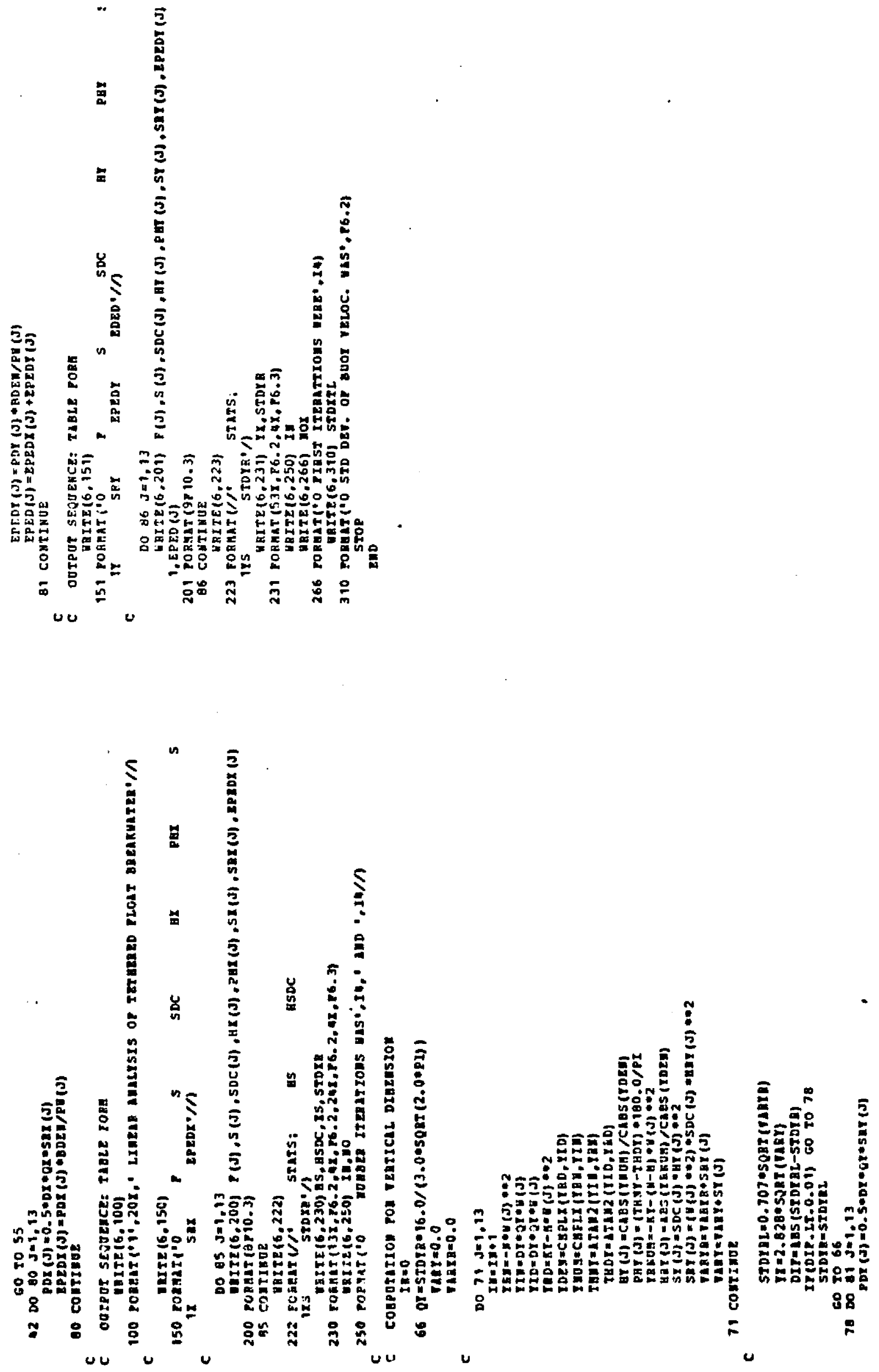


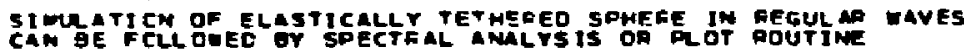
LAKF MODEL

LABEL E-TETH'D OUOY PCDEL: NGM IN/CPL·D

STOEDGE ATEOAST

INITIAal

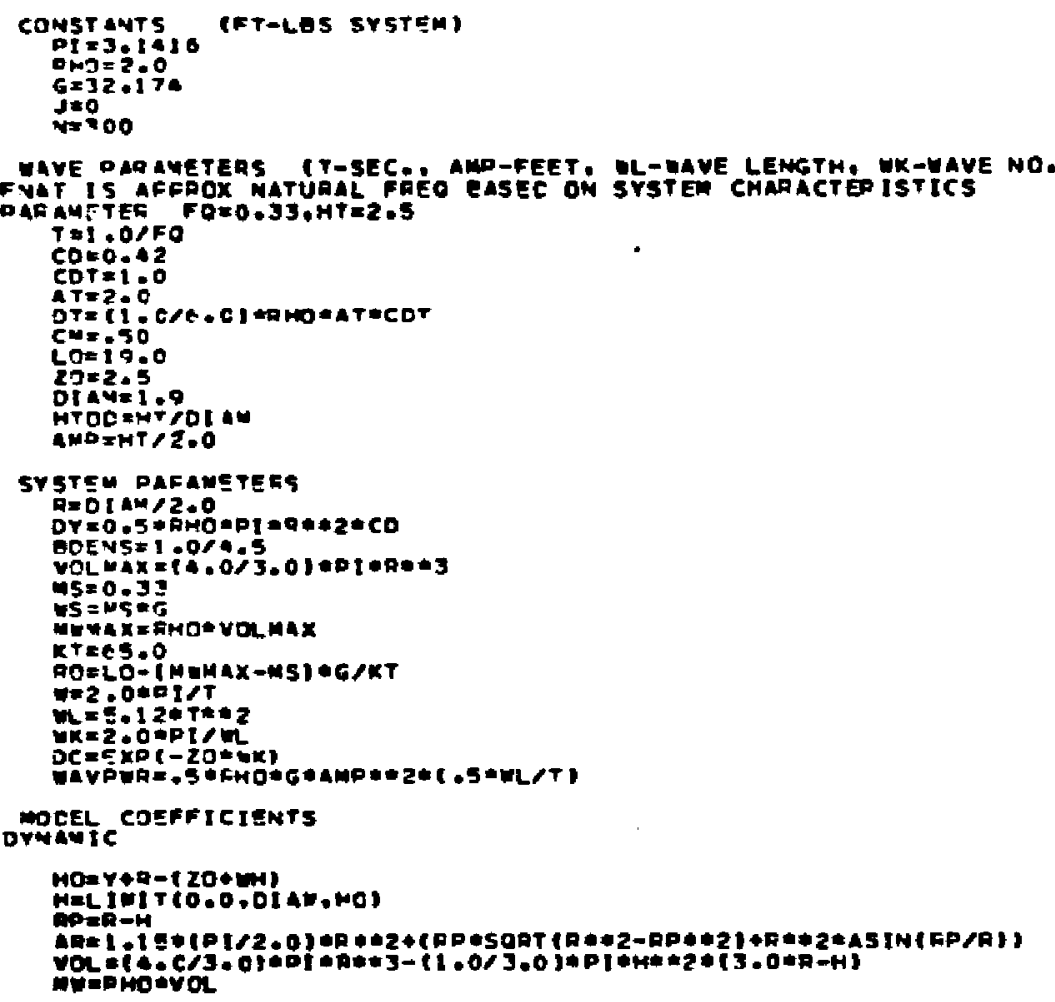

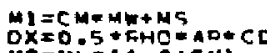

$m Z=N=\{1.0+C N\}$

The

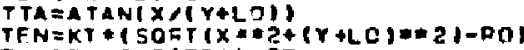

$F Y=T E M+C O S(T T A)-F$
$F X=T E N$ SIN(TTA)

NOTE: -DT ANO -ODT DENOTE FIRST AMD SECOND TIME OER IVATIVE XCY ARE PUCY FOSITIDN IN WAVE FIELD UAV FIELO

mated paEticle moticns pelative to actual eucr position

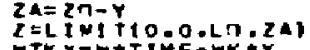

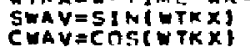

DECAY=FXP $(-W K=z)$

$V=$ *AYP TDECAY*TWAV

Dot =-rwe

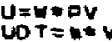

RuOY MOTIONS:

GOY POSTTION: APDECXIMATE, CRAG: OUADRADTC

$x=1 N T$ GELT: $0 . x D T$ T

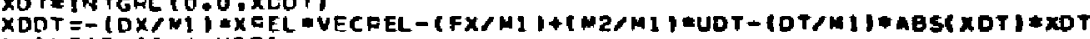
$Y=1 N T G F L 10.0 . Y 0 T 1$

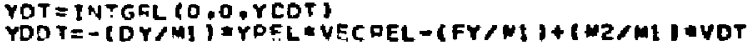

DELATIVE VFL OCITY ANC CPAG WODK CAL CULATION

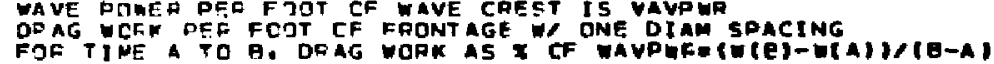

XFFL IXDT $-U$

VECEEL $x$ SORT (XPEL **2+YREL**2)

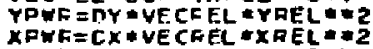

Ywo

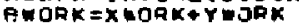

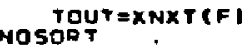

IF TIMESTTTIT

IF (KEE ITT):GT:0.0001) GO TO 1

3 j=J+1

- IFIJUN! $A 4,1$

\section{C-5 PROGRAM BRSIM}




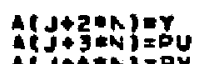

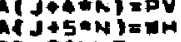

1 Continue

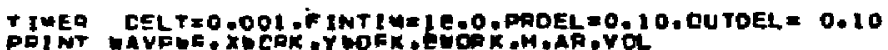

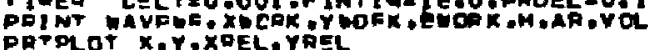

TIE HINAL

OD JO Jet

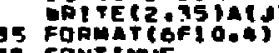

mo 30

Funct tow XnXT(F)

,THEXT.XXX11100

OETURN

nosoo 
APPENDIX D: Frequency response data

D-1 Wire-tethered buoy, Dec. 19, 1975

D-2 Elastic-tethered buoy, Dec. 18, 1975

D-3 Elastic-tethered buoy, Nov. 5, 1975

D-4 Elastic-tethered buoy, Nov. 5, 1975 

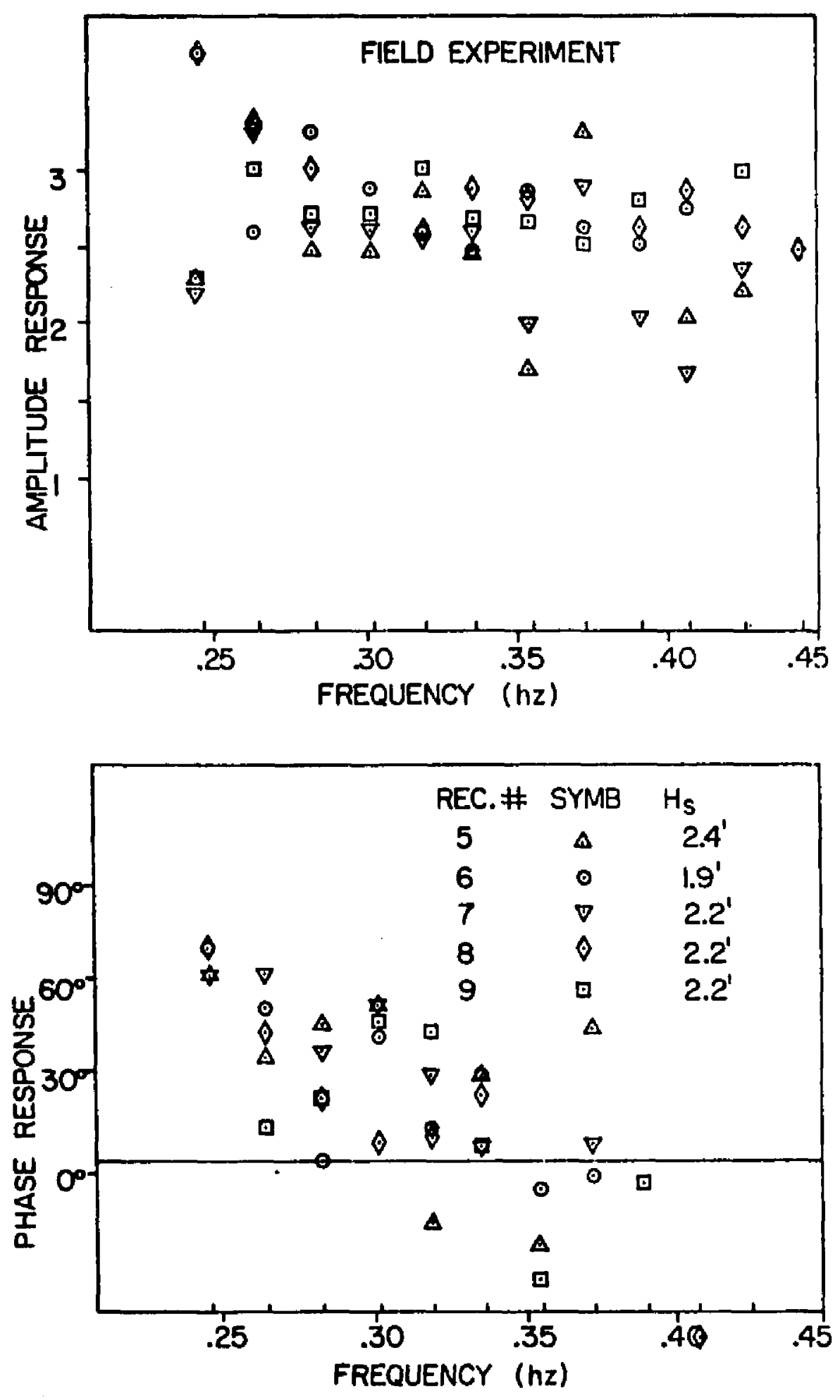

Figure $0-1$. Horizontal frequency response for a wire-tethered buoy from 5 records on Dec. 19, 1975 for points where coherence exceeded 0.80 . 

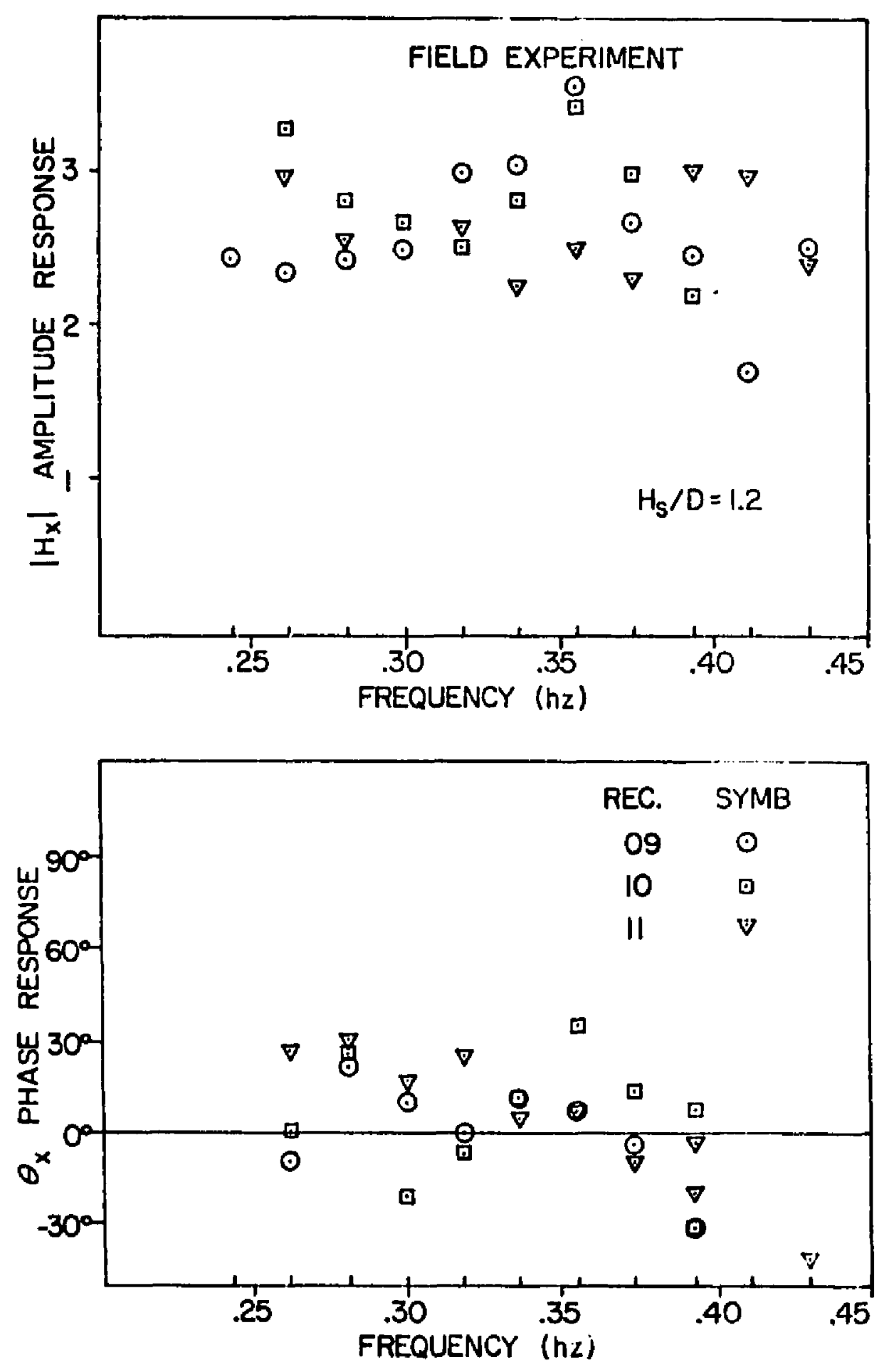

Figure D-2. Horizontal frequency response for an elastictethered buoy from 3 records on Dec. 18, 1975 for points where coherence exceeded 0.80 . 

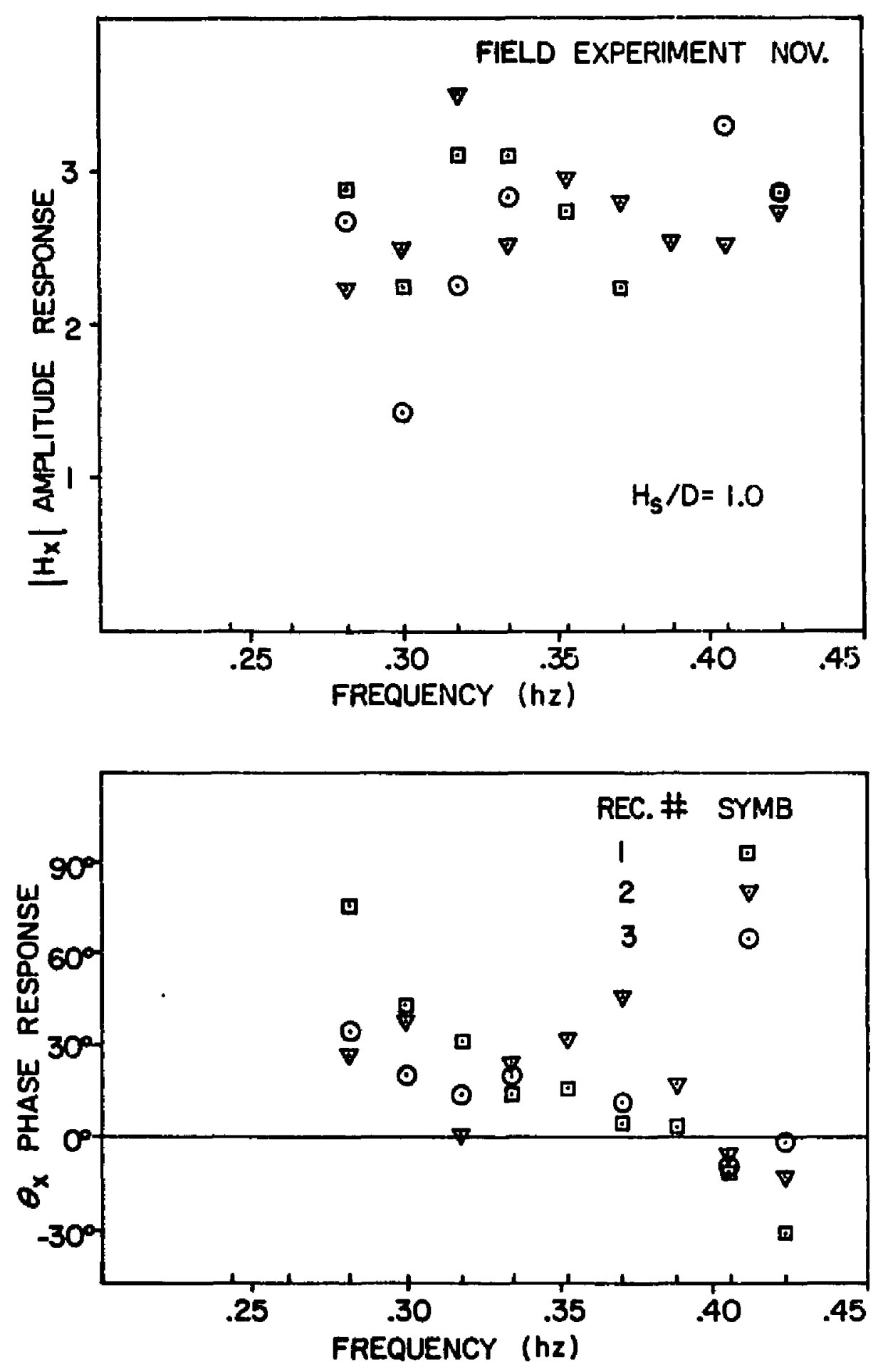

Figure D-3. Horlzontal frequency response for an elastictethered buoy from 3 records on Nov. 5, 1975 for points where coherence exceeded 0.80 . 

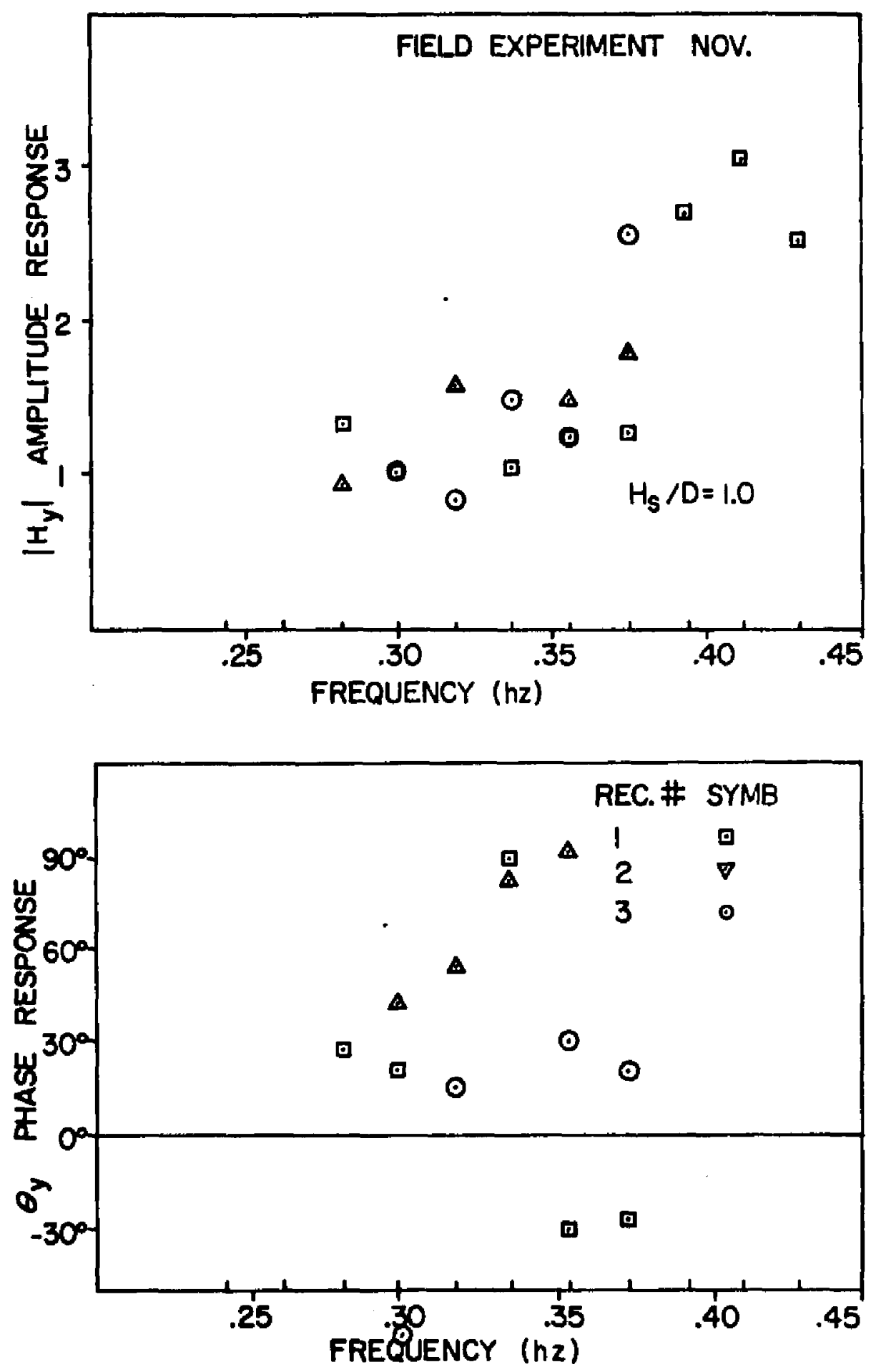

Figure D-4. Vertical frequency response for an elastictethered buoy from 3 records on Nov. 5, 1975 for points where coherence exceeded 0.80 . 